University of Nebraska - Lincoln

DigitalCommons@University of Nebraska - Lincoln

U.S. Environmental Protection Agency Papers

U.S. Environmental Protection Agency

2004

Mutagens in contaminated soil: a review

Paul A. White

Health Canada, paul_white@hc-sc.gc.ca

Larry D. Claxton

US Environmental Protection Agency

Follow this and additional works at: https://digitalcommons.unl.edu/usepapapers

White, Paul A. and Claxton, Larry D., "Mutagens in contaminated soil: a review" (2004). U.S. Environmental Protection Agency Papers. 111.

https://digitalcommons.unl.edu/usepapapers/111

This Article is brought to you for free and open access by the U.S. Environmental Protection Agency at DigitalCommons@University of Nebraska - Lincoln. It has been accepted for inclusion in U.S. Environmental Protection Agency Papers by an authorized administrator of DigitalCommons@University of Nebraska - Lincoln. 


\title{
Mutagens in contaminated soil: a review
}

\author{
Paul A. White ${ }^{\mathrm{a}, *}$, Larry D. Claxton ${ }^{\mathrm{b}}$ \\ ${ }^{a}$ Mutagenesis Section, Safe Environments Program, Health Canada, Tunney's Pasture 0803A, Ottawa, Ont., Canada K1A OL2 \\ ${ }^{\mathrm{b}}$ Environmental Carcinogenesis Division (MD-B143-06), US Environmental Protection Agency, \\ Research Triangle Park, NC 27711, USA
}

Available online 18 November 2004

\begin{abstract}
The intentional and accidental discharges of toxic pollutants into the lithosphere results in soil contamination. In some cases (e.g., wood preserving wastes, coal-tar, airborne combustion by-products), the contaminated soil constitutes a genotoxic hazard. This work is a comprehensive review of published information on soil mutagenicity. In total, 1312 assessments of genotoxic activity from 118 works were examined. The majority of the assessments (37.6\%) employed the Salmonella mutagenicity test with strains TA98 and/or TA100. An additional 37.6\% of the assessments employed a variety of plant species (e.g., Tradescantia clone 4430, Vicia faba, Zea mays, Allium cepa) to assess mutagenic activity. The compiled data on Salmonella mutagenicity indicates significant differences $(p<0.0001)$ in mean potency (revertents per gram dry weight) between industrial, urban, and rural/agricultural sites. Additional analyses showed significant empirical relationships between S9-activated TA98 mutagenicity and soil polycyclic aromatic hydrocarbon $(\mathrm{PAH})$ concentration $\left(r^{2}=0.19\right.$ to $\left.0.25, p<0.0001\right)$, and between direct-acting TA98 mutagenicity and soil dinitropyrene (DNP) concentration $\left(r^{2}=0.87, p<0.0001\right)$. The plant assay data revealed excellent response ranges and significant differences between heavily contaminated, industrial, rural/agricultural, and reference sites, for the anaphase aberration in Allium cepa (direct soil contact) and the waxy locus mutation assay in Zea mays (direct soil contact). The Tradescantia assays appeared to be less responsive, particularly for exposures to aqueous soil leachates. Additional data

Abbreviations: Ac, acetone; ACN, acetonitrile; $\mathrm{BaP}$, benzo(a)pyrene; Bq, Becquerel; CA, chromosomal aberration; ASTM, American Society for Testing and Materials; CERCLA, Comprehensive Environmental Response, Compensation, and Liability Act; CERCLIS, Comprehensive Environmental Response, Compensation, and Liability Information System; Cyclohex, cyclohexane; DCM, dichloromethane; DDE, 1,1-dichloro-2,2-bis(p-chlorophenyl)ethylene; DEK, diethylketone; DMSO, dimethylsulfoxide; DNP, dinitropyrene; EDC, ethylene dichloride; EPCRA, Emergency Planning and Community Right-To-Know Act; EtOH, ethanol; GAP, Genetic Activity Profile; HDPE, high density polyethylene; Hex, hexane; HMX, cyclotetramethylene-tetranitramine; HPRT, hypoxanthine phosphoribosyltransferase; IARC, International Agency for Research on Cancer; MetOH, methanol; MN, micronucleus; NFRAP, No Further Remedial Action Planned; NPL, National Priorities List; NPRI, National Pollutant Release Inventory; PAH, polycyclic aromatic hydrocarbon; PCB, polychlorinated biphenyl; PCDD, polychlorinated dibenzodioxin; PCDF, polychlorinated dibenzofuran; PCP, pentachlorophenol; Pfu, plaque forming unit; PPA, Pollution Prevention Act; Prop, 2-propanol; RCRA, Resource Conservation and Recovery Act; RDX, hexahydro-1,3,5-trinitro-1,3,5-triazine; Rev, Salmonella revertent; SCE, sister chromatid exchange; SDR, studentized deleted residual; SHM, stamen hair mutation; SIC, Standard Industrial Classification; S.E., standard error of the mean; Tol, toluene; TNT, trinitrotoluene; Trad, Tradescantia; TRI, Toxic Release Inventory; WPW, wood preserving waste

* Corresponding author. Tel.: +1 613941 7373; fax: +1 6139418530.

E-mail address: paul_white@hc-sc.gc.ca (P.A. White).
\end{abstract}

1383-5742/\$ - see front matter. Crown Copyright (C) 2004 Published by Elsevier B.V. All rights reserved. doi:10.1016/j.mrrev.2004.09.003

This article is a U.S. government work, and is not subject to copyright in the United States. 
analyses showed empirical relationships between anaphase aberrations in Allium, or mutations in Arabidopsis, and the ${ }^{137}$ Cs contamination of soils. Induction of micronuclei in Tradescantia is significantly related to the soil concentration of several metals (e.g., $\mathrm{Sb}, \mathrm{Cu}, \mathrm{Cr}, \mathrm{As}, \mathrm{Pb}, \mathrm{Cd}, \mathrm{Ni}, \mathrm{Zn}$ ). Review of published remediation exercises showed effective removal of genotoxic petrochemical wastes within one year. Remediation of more refractory genotoxic material (e.g., explosives, creosote) frequently showed increases in mutagenic hazard that remained for extended periods. Despite substantial contamination and mutagenic hazards, the risk of adverse effect (e.g., mutation, cancer) in humans or terrestrial biota is difficult to quantify.

Crown Copyright (C) 2004 Published by Elsevier B.V. All rights reserved.

Keywords: Salmonella; Tradescantia; Allium; Mutagen; Clastogen; Soil pollution

\section{Contents}

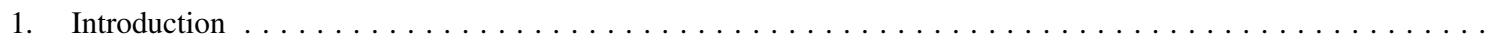

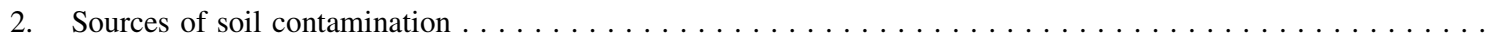

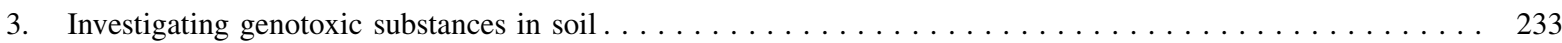

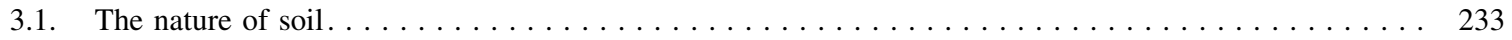

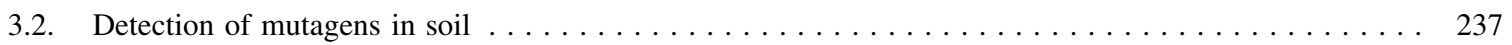

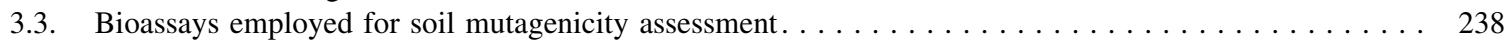

4. Collection and analysis of published soil mutagenicity/clastogenicity data . . . . . . . . . . . . 239

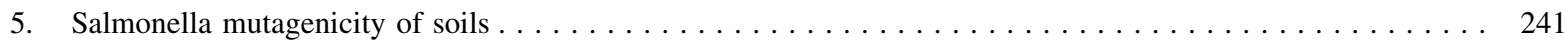

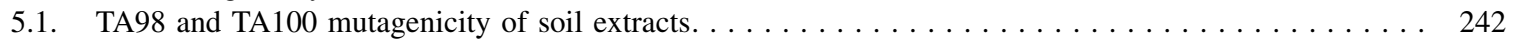

5.2. Relationships between Salmonella mutagenicity and extraction solvent. . . . . . . . . . . . . . . . 247

5.3. Relationships between Salmonella mutagenicity and soil contamination . . . . . . . . . . . . . . . . . . . . . . . . . . . . . .

5.4. Mutagenic activity detected using other Salmonella strains $\ldots \ldots \ldots \ldots \ldots$

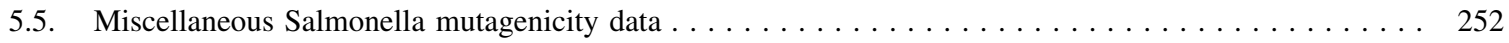

6. Other prokaryote or molecular in vitro assays used for soil genotoxicity assessment . . . . . . . . . . . 252

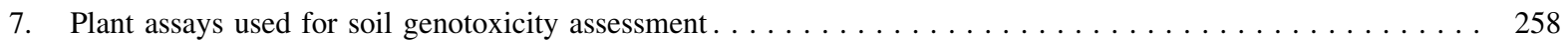

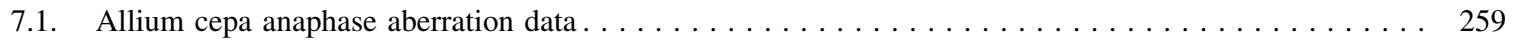

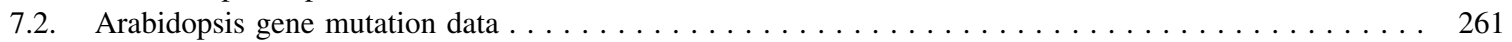

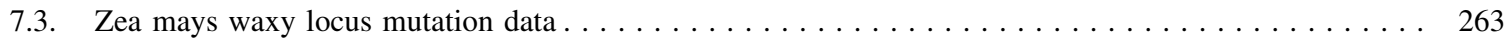

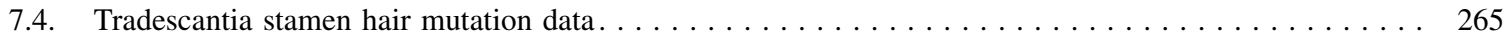

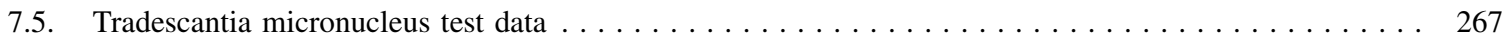

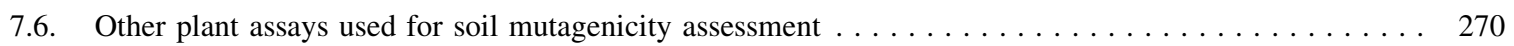

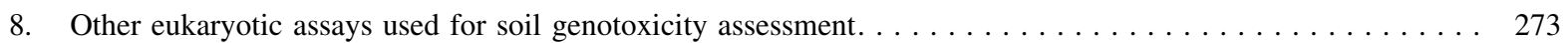

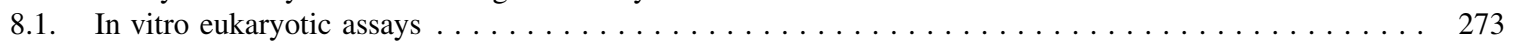

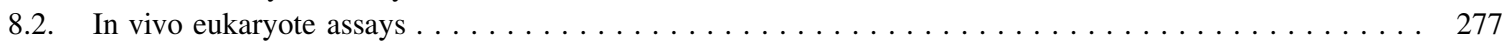

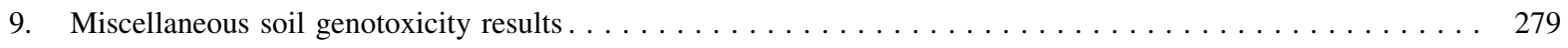

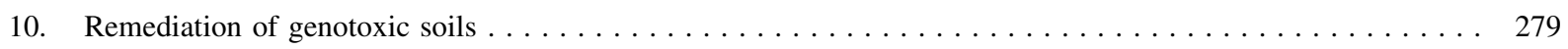

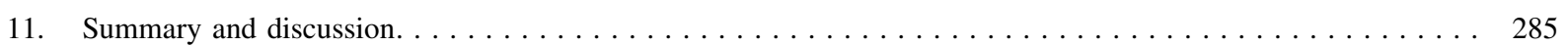

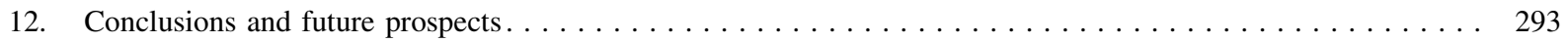




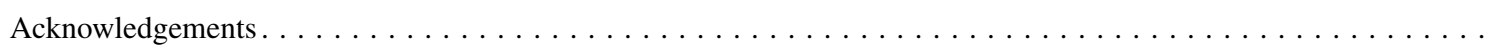

Appendix A: Salmonella mutagenicity data collected from the literature $\ldots \ldots \ldots \ldots$

Appendix B: Plant clastogenicity and mutagenicity data collected from the literature $\ldots \ldots \ldots \ldots$

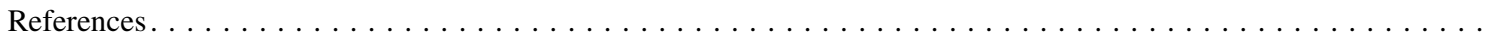

\section{Introduction}

An unfortunate consequence of industrialization and industrial production is the generation and release of toxic waste products. Although these wastes can be treated, reused and recycled, large quantities of toxic material is released into the atmosphere, hydrosphere and lithosphere. Although much of the waste is released directly into the atmosphere and hydrosphere (i.e., surface waters of lakes, rivers, and streams), land disposal activities, intentional or otherwise, contribute to direct contamination of surface soils and subterranean (groundwater) aquifers. Intentional land disposal activities such as landfills, lagoons, surface impoundments, ponds, septic systems, and land treatment are cost effective disposal strategies that take advantage of the enormous capacity of soil to retain and degrade toxic pollutants. However, inadequate information about waste toxicity and post-disposal behaviour, poor planning, improper disposal, and poor management of disposal sites has resulted in serious contamination problems at industrial and hazardous waste disposal sites. Moreover, accidental leaks/spills occurring during transport and storage of industrial materials (e.g., solvents, fuels, etc.) have resulted in contamination problems at sites not intended for waste disposal. Finally, widespread fossil fuel combustion, solid waste incineration, and pesticide application has also contributed to regional soil contamination.

Prior to the mid-1970s few countries had regulations restricting land disposal of hazardous waste materials. Consequently, it was difficult to estimate the numbers of contaminated industrial areas and hazardous waste disposal sites, the total area of contaminated land in a given country, or the approximate liability and remediation costs associated with these sites. However, a gradual increase in environmental awareness, and evidence of serious mismanagement of industrial and waste disposal sites, has prompted many countries to pass legislation aimed at proper management and rehabilitation of present and future hazardous waste disposal areas. For example, in 1976 the United States passed the Resource Conservation and Recovery Act (RCRA), followed in 1980 by the Comprehensive Environmental Response, Compensation, and Liability Act (CERCLA), otherwise known as the Superfund Act. These acts ensured proper management and permitting of waste disposal sites. Moreover, they require an inventory and assessment of older sites including orphaned sites resulting from facility closure and site abandonment. As of May 2004 the US Comprehensive Environmental Response, Compensation, and Liability Information System (CERCLIS) contained information on 45,516 contaminated sites, including 12,040 Superfund sites currently under investigation and 33,476 NFRAP (no further remedial action planned) sites that have been removed from the Superfund list. The Superfund list includes 1238 National Priorities List (NPL) sites that have been thoroughly evaluated and warrant further investigation to assess exposure pathways and the extent of human health or environmental hazards. This information, in addition to an inventory of contaminated sites in Canada and several European nations, is provided in Table 1. The data presented indicate that the United States and Canada collectively possess more than 60,000 contaminated sites. Moreover, several industrialized countries in Western Europe that are only a fraction of the size of the USA or Canada (e.g., Germany, Denmark, Switzerland, Austria) have equivalent or greater numbers of contaminated sites.

\section{Sources of soil contamination}

The quantities of toxic industrial wastes released to land vary according to industrial sector. Until recently, the exact annual land releases of toxic material were 
Table 1

Inventory of contaminated terrestrial sites in several industrialized countries

\begin{tabular}{|c|c|c|c|c|c|}
\hline Country & $\begin{array}{l}\text { Total } \\
\text { area }\left(\mathrm{km}^{2}\right)\end{array}$ & $\begin{array}{l}\text { Population } \\
\text { (millions) }\end{array}$ & $\begin{array}{l}\text { Number of } \\
\text { contaminated sites }^{\mathrm{a}}\end{array}$ & $\begin{array}{l}\text { Sites per } \\
1000 \mathrm{~km}^{2}\end{array}$ & $\begin{array}{l}\text { Sites per } 10^{6} \\
\text { people }\end{array}$ \\
\hline Canada & $9,976,140$ & 31.6 & $15,000-40,000$ & $1.5-4.0$ & $475-1266$ \\
\hline Federal sites & & & 3,843 & 0.4 & 121.6 \\
\hline United States & $9,656,345$ & 288.4 & 45,516 & 4.7 & 157.8 \\
\hline Total CERCLIS ${ }^{\mathrm{b}}$ sites & & & 12,040 & 1.2 & 41.8 \\
\hline Federal CERCLIS sites & & & 1,021 & 0.1 & 3.5 \\
\hline Total NFRAP ${ }^{c}$ sites & & & 33,476 & 3.5 & 116.1 \\
\hline Federal NFRAP sites & & & 1,032 & 0.1 & 3.6 \\
\hline Current $\mathrm{NPL}^{\mathrm{d}}$ sites & & & 1,238 & 0.1 & 4.3 \\
\hline Germany ${ }^{\mathrm{e}}$ & 356,910 & 82.8 & 202,880 & 568.4 & 2450.2 \\
\hline Denmark & 43,090 & 5.3 & 37,000 & 858.7 & 6981.1 \\
\hline Switzertland & 41,290 & 7.3 & 35,000 & 847.7 & 4794.5 \\
\hline Austria & 83,850 & 8.1 & 28,000 & 333.9 & 3456.8 \\
\hline Finland & 338,130 & 5.2 & 10,396 & 30.7 & 1999.2 \\
\hline Italy & 301,270 & 57.6 & 8,873 & 29.5 & 154.0 \\
\hline Belgium & 30,518 & 10.2 & 7,728 & 253.2 & 757.6 \\
\hline Sweden & 449,960 & 8.9 & 7,000 & 15.6 & 786.5 \\
\hline Spain & 504,780 & 40.0 & 4,902 & 9.7 & 122.6 \\
\hline Norway & 323,900 & 4.5 & 2,121 & 6.5 & 471.3 \\
\hline Lithuania & 65,300 & 3.6 & 4,430 & 67.8 & 1230.6 \\
\hline Romania & 238,381 & 22.4 & 1,634 & 6.9 & 72.9 \\
\hline Estonia & 45,227 & 1.4 & 1,565 & 34.6 & 1117.9 \\
\hline
\end{tabular}

${ }^{a}$ Values in bold are totals for each country. Values for Canada are estimates from the Ministry of Environment or from The Federal Contaminated Sites and Solid Waste Landfills Inventory (http://publiservice.tbs-sct.gc.ca/dfrp-rbif/cs-sc/home-accueil.asp?Language=EN). Values for the USA refer to identified contaminated sites as of May 2004 (see http://www.epa.gov/superfund/sites/phonefax/products.htm). Values for western European countries refer to identified sites of potential contamination [452]. Values for former Warsaw Pact countries refer to contaminated sites that have been registered with the relevant authorities [453].

$\mathrm{b}$ The Comprehensive Environmental Response, Compensation, and Liability Act (CERCLA) Information System, a database of current Superfund sites.

c Archived "No Further Remedial Action Planned" sites that have been removed from the Superfund list.

d National Priorities List. Prioritized Superfund sites slated for hazard ranking and remedial action.

${ }^{\mathrm{e}}$ Potentially contaminated current and former military sites not included.

difficult, if not impossible, to determine. However, in response to catastrophes such as the industrial accident in Bhopal, India in 1984 many countries began tracking the production, usage, and release of toxic substances. For example, in 1986 the US government passed the Emergency Planning and Community Right-To-Know Act (EPCRA). This legislation was enacted to promote emergency planning, and provide the public with information on the use, production, and release of toxic substances. To accomplish this monumental information distribution task the EPCRA, and the subsequent Pollution Prevention Act (PPA), required the creation of a publicly accessible database containing information on the release of toxic chemicals. This database is known as the Toxics Release Inventory (TRI). Several countries followed with similar databases, such as Canada's National Pollutant Release Inventory (NPRI) established in the early 1990s as part of the Canadian government's Green Plan.

The 2002 TRI data indicate that a total of 24,379 industrial facilities released 2.17 billion $\mathrm{kg}$ of toxic material (518 substances or substances groups). Approximately $53 \%$, or 1.15 billion $\mathrm{kg}$ of material, was disposed via on- and off-site land release. Therefore, in 2002 American industries disposed of 1.15 billion $\mathrm{kg}$ of toxic waste via on- and off-site landfill, land treatment, and surface impoundment. The 2002 Canadian NPRI data indicate that 4596 industries released a total of 402.5 million $\mathrm{kg}$ of toxic material (274 substances). Approximately $8.1 \%$ or 32.5 million $\mathrm{kg}$ was disposed via on-site land release. Therefore, in 2002 Canadian industries disposed of 32.5 million $\mathrm{kg}$ of toxic waste via on-site landfill, land treatment, and surface impoundment. The difference between the 
proportions of American and Canadian total releases disposed via land release is primarily due to differences in the industrial sectors monitored, and inclusion of offsite landfill and land farming activities in the US inventory. For example, the US release inventory includes all metal mining facilities, whereas only mining facilities involved in the secondary processing of mined material are included in the Canadian inventory. A summary of the 2002 land releases in the US and Canada by industrial sector is provided in Tables $2 \mathrm{a}$ and $2 \mathrm{~b}$. The data in Table 2a indicate that in the United States over $70 \%$ of the total annual on- and off-site land releases of 1149.1 million $\mathrm{kg}$ are accounted for by metal mining and processing facilities, with another $14 \%$ accounted for by electric, gas, and sanitary services, primary metal processing and smelting, and solvent recovery operations. In Canada (Table 2b), chemical and allied industries account for over $32 \%$ of the total annual on-site land releases of 32.5 million $\mathrm{kg}$, with a further $48 \%$ accounted for by primary metal processing and smelting, electric, gas, and sanitary services, and pulp and paper production.

Neither the Canadian NPRI, nor the American TRI provides a complete list of all land releases of toxic pollutants. For the most part, these lists contain an inventory of releases for substances that are manufactured, processed, or used in fairly large quantities (e.g., $>10,000 \mathrm{~kg}$ for NPRI Group I substances, $\sim 5000-10,000 \mathrm{~kg}$ for TRI) by fairly large industries ( $>10$ full-time employees). In addition, the inventories

Table $2 \mathrm{a}$

2002 TRI on- and off-site land releases in the United States (by industrial sector)

\begin{tabular}{|c|c|c|}
\hline Industry type & $\mathrm{SIC}^{\mathrm{a}}$ & Land releases $\left(\times 10^{6} \mathrm{~kg}\right)^{\mathrm{b}}$ \\
\hline Metal mining (e.g., $\mathrm{Fe}, \mathrm{Cu}, \mathrm{Pb}, \mathrm{Zn}, \mathrm{Au}, \mathrm{Ag}$ ) & 10 & 580.1 \\
\hline Primary metal smelting and processing & 33 & 245.2 \\
\hline Electric, gas, and sanitary services & 49 & 159.9 \\
\hline Solvent recovery operations (under $\mathrm{RCRA}^{\mathrm{c}}$ ) & $4953 / 7389$ & 69.5 \\
\hline Chemical and allied products & 28 & 31.2 \\
\hline Paper and allied products & 26 & 9.0 \\
\hline Food and related products & 20 & 8.6 \\
\hline Coal mining and coal mine services & 12 & 6.7 \\
\hline Fabricated metal products & 34 & 5.6 \\
\hline Transportation equipment manufacture & 37 & 4.0 \\
\hline Plastic and rubber products & 30 & 3.9 \\
\hline Stone, clay, glass, and concrete products & 32 & 3.8 \\
\hline Electronic and other electrical equipment & 36 & 1.8 \\
\hline Industrial and commercial machinery & 35 & 1.8 \\
\hline Petroleum refining and related industries & 29 & 1.0 \\
\hline Lumber and wood products & 24 & 1.0 \\
\hline Leather and leather products & 31 & 0.4 \\
\hline Textile mill products & 22 & 0.2 \\
\hline Tobacco manufacture & 21 & 0.2 \\
\hline Photographic, medical, and optical goods & 38 & 0.1 \\
\hline Petroleum bulk stations and terminals & 5171 & 0.1 \\
\hline Chemical wholesalers & 5169 & 0.1 \\
\hline Apparel manufacture & 23 & $<0.03$ \\
\hline Furniture and fixtures & 25 & $<0.02$ \\
\hline Printing, publishing, and related industries & 27 & $<0.01$ \\
\hline No reported SIC code & - & 5.1 \\
\hline Miscellaneous manufacturing & 39 & 0.3 \\
\hline Industries with multiple SIC codes & $20-39$ & 9.6 \\
\hline Total & & 1149.1 \\
\hline
\end{tabular}

\footnotetext{
${ }^{a}$ Standard Industrial Classification Codes (see http://www.osha.gov/pls/imis/sic_manual.html).

${ }^{\mathrm{b}}$ Includes on- and off-site disposal via landfill, land treatment, surface impoundment, and underground injection. Source: 2002 Toxic Release Inventory. Available online at http://www.epa.gov/triexplorer. Values rounded to the nearest $10^{5} \mathrm{~kg}$.

${ }^{\mathrm{c}}$ The US Resource Conservation and Recovery Act.
} 
Table $2 \mathrm{~b}$

2002 NPRI on-site land releases in Canada (by industrial sector)

\begin{tabular}{|c|c|c|}
\hline Industry type & $\mathrm{SIC}^{\mathrm{a}}$ & Land releases $\left(\times 10^{3} \mathrm{~kg}\right)^{\mathrm{b}}$ \\
\hline Chemical and allied products & 28 & 10422.6 \\
\hline Electric, gas, and sanitary services & 49 & 8511.4 \\
\hline Primary metal smelting and processing & 33 & 4868.2 \\
\hline Paper and allied products & 26 & 2204.6 \\
\hline Air transportation & 45 & 1936.4 \\
\hline Food and related products & 20 & 1334.0 \\
\hline Heavy construction & 1629 & 950.8 \\
\hline Miscellaneous services and consulting & 8999 & 651.1 \\
\hline National security & 9711 & 388.1 \\
\hline Crude petroleum and natural gas & 1311 & 324.3 \\
\hline Lumber and wood products & 24 & 231.1 \\
\hline Wholesale trade - durable goods/scrap & 50 & 187.4 \\
\hline Metal mining (e.g., $\mathrm{Fe}, \mathrm{Cu}, \mathrm{Pb}, \mathrm{Zn}, \mathrm{Au}, \mathrm{Ag}$ ) & 10 & 131.3 \\
\hline Air/water resource and solid waste Management & 9511 & 124.6 \\
\hline Plastic and rubber products & 30 & 65.5 \\
\hline Petroleum and coal products & 29 & 58.6 \\
\hline Miscellaneous manufacturing & 39 & 25.1 \\
\hline Commercial printing & 2752 & 21.4 \\
\hline Stone, clay, glass, and concrete products & 32 & 13.5 \\
\hline Chemical and allied products/petroleum bulk & 51 & 3.7 \\
\hline Health and allied services & 80 & 1.0 \\
\hline Electrical and electronic equipment & 36 & 0.5 \\
\hline Correctional institutions & 9223 & 0.4 \\
\hline Special trade contractors (e.g., paint removal) & 1799 & 0.3 \\
\hline Crude petroleum pipelines & 4612 & 0.1 \\
\hline Fabricated metal products & 34 & 0.1 \\
\hline Farm machinery and equipment & 3523 & 0.1 \\
\hline Aircraft parts and auxiliary equipment & 3728 & $<0.1$ \\
\hline Commercial research (physical and biological) & 8731 & $<0.1$ \\
\hline Automotive transmission repair & 7537 & $<0.1$ \\
\hline Total & & 32456.2 \\
\hline
\end{tabular}

${ }^{a}$ Standard Industrial Codes (see http://www.osha.gov/pls/imis/sic_manual.html).

${ }^{\mathrm{b}}$ Includes on-site landfill disposal, land treatment, surface impoundment, leaks, and spills. Source: 2002 National Pollutant Release Inventory of 266 substances. Available online at http://www.ec.gc.ca/pdb/npri/npri_dat_rep_e.cfm\#complete. Criteria air pollutants (e.g., $\mathrm{SO}_{2}, \mathrm{NO}_{\mathrm{x}}, \mathrm{CO}$, total particulates) were not included.

do not provide any indication of post-emission behaviour or the potential human hazard of the toxic emissions. However, both the TRI of 518 substances and the NPRI of 274 substances do provide a separate inventory of substances that are known or probable animal carcinogens. Of the 518 substances monitored by the TRI, 144 substances are described as known or suspected animal carcinogens (i.e., IARC categories 1 , $2 \mathrm{~A}$, and $2 \mathrm{~B}$ ). Of the 274 substances monitored by the NPRI, only 20 known or suspected animal carcinogens, or groups of compounds that include carcinogens (e.g., polycyclic aromatic hydrocarbons or PAHs), had measurable land releases. According to The International Agency for Research on Cancer (IARC), these substances are predominantly manufactured, processed and released by 15 industrial categories: rubber production, printing and print processing, pulp and paper production, dry cleaning, paint manufacture and painting, inorganic chemical production, carpentry and joinery, leather tanning and shoe manufacture, petroleum refining, iron founding and coke production, coal gasification, aluminum production, textile manufacture and finishing, organic chemical production, and glass manufacturing (see http://monographs.iarc.fr/ for additional details).

A survey of the 2002 TRI results indicates that total US on- and off-site land releases of suspected or known carcinogens was 513.8 million kg. The 2002 
NPRI results indicate that total Canadian on-site land releases of carcinogens during the same period were 3.8 million $\mathrm{kg}$. In both cases, inorganic chemicals such as asbestos, lead, chromium, nickel, and arsenic (and related compounds) account for almost all $(\geq 99 \%)$ of the annual carcinogenic releases. Several of the carcinogens included in these release values, including some substances with the highest on-site land releases, are also well known mutagens and/or clastogens. Examples include chromium and arsenic compounds, asbestos, creosote, styrene, benzene, urethane, formaldehyde, vinyl chloride, tetrachloroethylene, and a variety of PAHs. Table $3 \mathrm{a}$ summarizes the 2002 TRI on- and off-site land releases of noteworthy mutagens, clastogens, and carcinogens with annual releases of at least $10^{3} \mathrm{~kg}$. Table $3 \mathrm{~b}$ summarizes the 2002 NPRI on-site land releases of noteworthy mutagens, clastogens, and carcinogens with annual releases of at least $100 \mathrm{~kg}$. It should be noted that neither inventory would include atmospheric fallout of mutagenic aromatic hydrocarbons and their derivatives (e.g., PAHs, nitroarenes, quinolines, thiophenes, etc.) that are by-products of industrial and domestic fossil fuel combustion, and waste incineration [1-3]. In addition, the NPRI would not include off-site transfers for land disposal (e.g., land treatment).

\section{Investigating genotoxic substances in soil}

\subsection{The nature of soil}

Soil is a dynamic and complex medium that forms at the interface of the atmosphere, lithosphere, hydrosphere, and biosphere. It is essentially an aggregate of unconsolidated mineral and organic material produced by a complex combination of physical, chemical, and biological processes [4,5]. The properties of soil are spatially and temporally variable, and dependent on the combined effects climate, biological activity, topography, and the mineralogical composition of the parent rock. On a volumetric basis soil is about $45 \%$ mineral, $2-5 \%$ organic material, $20-30 \%$ air, and $20-30 \%$ water $[5,6]$. The bulk density of mineral soil ranges from 0.86 to $2.08 \mathrm{~g} / \mathrm{cm}^{3}$, with typical organic soils yielding values between 0.1 and $0.6 \mathrm{~g} / \mathrm{cm}^{3}$ [7]. On a dry weight basis, soils are approximately 93-99\% mineral with the remainder composed of organic material [6].

The mineral portion of soil is most often described in terms of its particle size distribution. Soil mineral particles can range from extremely fine clay particles to coarse sand. The primary soil particles, which resist further breakdown, are sand (0.5-2 mm diameter), silt $(0.002-0.5 \mathrm{~mm}$ diameter $)$, and clay $(<0.002 \mathrm{~mm}$ diameter). The relative proportions of each of these minerals determines the property known as soil texture [5]. The organic material portion of soil is derived from decomposed or partially decomposed plant and/ or animal tissues. Much of this material (85-90\%) consists of humic matter, complex high molecular weight polymers formed from the microbial decomposition of organic material [4]. Although most soils contain $2-5 \%$ organic matter by volume, the values can range from less than $1 \%$ to greater than $80 \%$. These highly organic soils are usually referred to as peat.

Variations in soil texture (i.e., particle size distribution), organic matter content, water content, and a variety of other variables (e.g., gradation, consistency, porosity, permeability, compressibility, oxidation state, particle shape, particle charge, and cation exchange capacity), results in an enormous range of soil types with vastly different physical and chemical properties [7]. Several soil classification systems have been devised to categorize soils with different properties. One of the more common textural classification systems, devised by the US Department of Agriculture, relies on the familiar triangular diagram with the three apexes representing sand, silt and clay content. Using the percent (by weight) of clay, silt and sand, any soil sample that passes through a $2 \mathrm{~mm}$ sieve can be positioned on the diagram and classified. Detailed descriptions of the various soil classification systems (e.g., Unified Soil Classification System, American Association of State Highway and Transportation Officials Classification System, US Comprehensive Soil Classification System) that categorize soils on the basis of texture, organic matter content, and oxidation state are beyond the scope of this work. For additional details on soil classification, as well as soil chemistry and soil physics, the reader should consult Weingardner [5] or Dragun [7].

Differences in soil type can have profound effects on the environmental fate and toxicity of soil 
Table $3 \mathrm{a}$

2002 TRI on- and off-site land releases of carcinogenic substances in the United States $(>1000 \mathrm{~kg} \text { only })^{\mathrm{a}}$

\begin{tabular}{|c|c|c|c|}
\hline Compound & Mutagenicity/clastogenicity ${ }^{\mathrm{b}, \mathrm{c}}$ & Carcinogenicity $^{\mathrm{d}}$ & Total land releases $\left(\times 10^{3} \mathrm{~kg}\right)$ \\
\hline Arsenic compounds ${ }^{\mathrm{e}}$ & $+/ \mathrm{CC}$ & 1 & 182033.2 \\
\hline Lead compounds ${ }^{\mathrm{f}}$ & $\mathrm{CC}$ & $2 \mathrm{~B}$ & 181618.0 \\
\hline Chromium compounds ${ }^{\mathrm{g}}$ & $+++/ \mathrm{CC}$ & 1 & 19089.8 \\
\hline Nickel compounds ${ }^{\mathrm{h}}$ & $++/ \mathrm{CC}$ & 1 & 15669.8 \\
\hline Asbestos (friable) & $\mathrm{C}$ & 1 & 3016.2 \\
\hline Cobalt compounds ${ }^{\mathrm{i}}$ & $++/ \mathrm{CC}$ & $2 \mathrm{~B}$ & 2697.0 \\
\hline Cadmium compounds ${ }^{\mathrm{j}}$ & $++/ \mathrm{CC}$ & 1 & 2396.9 \\
\hline Polychlorinated biphenyls & - & $2 \mathrm{~A}$ & 872.4 \\
\hline Styrene & $+++/ \mathrm{CC}$ & $2 \mathrm{~B}$ & 774.4 \\
\hline Creosote $^{\mathrm{k}}$ & ++ & $2 \mathrm{~A}$ & 765.1 \\
\hline 1,4-Dioxane & $+{ }^{1} / \mathrm{C}$ & $2 \mathrm{~B}$ & 438.2 \\
\hline Polycyclic aromatic compounds ${ }^{\mathrm{m}}$ & & & 427.2 \\
\hline $\operatorname{Benz}(a)$ anthracene & $+++/ \mathrm{CC}$ & $2 \mathrm{~A}$ & \\
\hline $\operatorname{Benzo}(a)$ pyrene & $+++/ \mathrm{CC}$ & $2 \mathrm{~A}$ & \\
\hline Benzo $(b)$ fluoranthene & $+/ \mathrm{C}$ & $2 \mathrm{~B}$ & \\
\hline Dibenzo $(a, h)$ anthracene & $++/ \mathrm{CC}$ & $2 \mathrm{~A}$ & \\
\hline Indeno $(1,2,3-c d)$ pyrene & + & $2 \mathrm{~B}$ & \\
\hline Dibenz $(a, h)$ acridine & + & $2 \mathrm{~B}$ & \\
\hline Beryllium compounds ${ }^{\mathrm{n}}$ & $++/ \mathrm{C}$ & 1 & 362.3 \\
\hline Bis(2-ethylhexyl)phthalate & $+{ }^{\circ} / \mathrm{C}$ & 3 & 335.1 \\
\hline Formaldehyde & $+++/ \mathrm{CC}$ & $2 \mathrm{~A}$ & 208.0 \\
\hline Chlorothalonil & $+{ }^{\mathrm{p}} / \mathrm{C}$ & $2 \mathrm{~B}$ & 115.4 \\
\hline Polychlorinated alkanes & $++^{\mathrm{p}} / \mathrm{C}$ & $2 \mathrm{~B}^{\mathrm{q}}$ & 91.2 \\
\hline Tetrachloroethylene & $+/ \mathrm{C}$ & $2 \mathrm{~B}$ & 86.2 \\
\hline Dichloromethane & $++/ \mathrm{CC}$ & $2 \mathrm{~B}$ & 65.2 \\
\hline Vinyl acetate & $\mathrm{CC}$ & $2 \mathrm{~B}$ & 49.3 \\
\hline Benzene & $+++/ \mathrm{CC}$ & 1 & 48.6 \\
\hline Propylene oxide & $+++/ \mathrm{CC}$ & $2 \mathrm{~B}$ & 42.0 \\
\hline Chloroform & $+/ \mathrm{CC}$ & $2 \mathrm{~B}$ & 40.6 \\
\hline Ethyl acrylate & $++/ \mathrm{CC}$ & $2 \mathrm{~B}$ & 39.8 \\
\hline Urethane (ethyl carbamate) & $+++/ \mathrm{CC}$ & $2 \mathrm{~B}$ & 20.0 \\
\hline Ethylbenzene & $+^{\mathrm{p}}$ & $2 \mathrm{~B}$ & 18.6 \\
\hline Toluene diioscyanate ${ }^{r}$ & $++\mathrm{s} / \mathrm{C}$ & $2 \mathrm{~B}$ & 15.4 \\
\hline Catechol & $++/ \mathrm{C}$ & $2 \mathrm{~B}$ & 14.2 \\
\hline 1,2-Dichloroethane & $+++/ \mathrm{C}$ & $2 \mathrm{~B}$ & 13.8 \\
\hline Trichloroethylene & $++/ \mathrm{C}$ & $2 \mathrm{~A}$ & 12.6 \\
\hline 2,4-Dichloro-1-(4-nitrophenoxy)-benzene & + & $2 \mathrm{~B}^{\mathrm{t}}$ & 11.5 \\
\hline Diaminotoluene & - & $2 \mathrm{~B}^{\mathrm{u}}$ & 8.9 \\
\hline Acetaldehyde & $+++/ \mathrm{CC}$ & $2 \mathrm{~B}$ & 8.4 \\
\hline Acrylonitrile & $+++/ \mathrm{CC}$ & $2 \mathrm{~B}$ & 7.6 \\
\hline Hexachlorobenzene & + & $2 \mathrm{~B}$ & 6.9 \\
\hline Nitrilotriacetic acid & $+^{\mathrm{o}}$ & $2 \mathrm{~B}$ & 6.4 \\
\hline 4,4'-Diaminodiphenyl ether & + & $2 \mathrm{~B}$ & 6.4 \\
\hline Pentachlorophenol & $+/ \mathrm{CC}$ & $2 \mathrm{~B}$ & 5.1 \\
\hline Nitrobenzene & - & $2 \mathrm{~B}$ & 5.1 \\
\hline 2,4-Dichlorophenoxyacetic acid & $+++/ \mathrm{C}$ & $2 \mathrm{~B}^{\mathrm{v}}$ & 3.9 \\
\hline Methoxone & $+++/ \mathrm{CCY}$ & $2 \mathrm{~B}^{\mathrm{v}}$ & 3.8 \\
\hline Toluene-2,4-diisocyanate & $++{ }^{\mathrm{s}} / \mathrm{C}$ & $2 \mathrm{~B}$ & 3.5 \\
\hline Ethylene oxide & $+++/ \mathrm{CC}$ & 1 & 3.4 \\
\hline Carbon tetrachloride & $+/ \mathrm{C}$ & $2 \mathrm{~B}$ & 3.0 \\
\hline Epichlorohydrin & $++/ \mathrm{CC}$ & $2 \mathrm{~A}$ & 2.8 \\
\hline $4,4^{\prime}$-Methylenedianiline & $++/ \mathrm{CC}$ & $2 \mathrm{~B}$ & 2.7 \\
\hline
\end{tabular}


Table 3a (Continued)

\begin{tabular}{lllc}
\hline Compound & Mutagenicity/clastogenicity ${ }^{\mathrm{b}, \mathrm{c}}$ & Carcinogenicity $^{\mathrm{d}}$ & ${\text { Total land releases }\left(\times 10^{3} \mathrm{~kg}\right)}$ \\
\hline Toxaphene & $+/ \mathrm{C}$ & $2 \mathrm{~B}$ & 2.6 \\
1,3 -Butadiene & $+++\mathrm{CC}$ & $2 \mathrm{~A}$ & 1.6 \\
Mecoprop & - & $2 \mathrm{~B}^{\mathrm{v}}$ & 1.5 \\
Acrylamide & $+++\mathrm{CC}$ & $2 \mathrm{~A}$ & 1.4 \\
Chlorophenols & + & $2 \mathrm{~B}$ & 1.2 \\
2,4-Dinitrotoluene & +++ & $2 \mathrm{~B}$ & 1.1 \\
Ethylene thiourea & + & $2 \mathrm{~B}$ & 1.0 \\
Total inorganic & & & 406883.1 \\
Total organic & & & 4593.2 \\
Grand total & & 411476.3 \\
\hline
\end{tabular}

${ }^{\mathrm{a}}$ Includes on- and off-site disposal via landfill, land treatment, surface impoundment, and underground injection. See Table 2a for additional details. Thirty-one other organic compounds with values $>100$ and $<1000 \mathrm{~kg}$ (i.e., chlordane, tolunene-2,6-diisocyanate, 1,2,3-trichloropropane, 1,4-dichlorobenzene, 2,6-dinitrotoluene, hexachloroethane, 1,3-dichloropropylene, $N$-nitrosodi- $N$-butylamine, $N$-nitrosodiethylamine, chlorendic acid, 2-nitropropane, heptachlor, vinyl chloride, thiourea, o-toluidine, dimethyl sulfate, dichlorovos, 2,4,6-trichlorophenol, 1,2dibromo-3-chloropropane, 1,2-dibromoethane, 2-acetlyaminofluorene, 4,4'-methylene-bis(2-chloroaniline), 4-dimethylaminoazobenzene, hydrazine, $N$-nitrosodi- $N$-proplyamine, $N$-nitrosopiperidine, $p$-chloroaniline, propane sultone, safrole, and 2,4-dichlorophenoxyacetic acid 2-ethylhexyl ester) account for an additional $7160.4 \mathrm{~kg}$.

b Based on data from the Genetic Activity Profile (GAP) database [454,455], the Monograph Series of the International Agency for Research on Cancer (IARC) (available online at http://monographs.iarc.fr/), and the published results of the US national Toxicology Program (available online at http://ntp-server.niehs.nih.gov/).

${ }^{c}(-)$ Compounds for which there is no evidence of mutagenicity or clastogenicity, $(+)$ mutagenic in bacterial and/or fungal/yeast cells in vitro, (++) also mutagenic in plants or animal cells in vitro, $(+++)$ also mutagenic in the Drosophila melanogaster somatic mutation and recombination test, and/or sex-linked recessive lethal test, and/or transgenic rodent assays, and/or rodent dominant lethal test. For cytogenetic endpoints $\mathrm{C}$ refers to substances that are clastogenic in in vitro assays, CC refers to substances that are clastogenic both in vitro and in vivo. Note: In some instances conflicting results have been reported in the literature.

d IARC classification system: (1) carcinogenic to humans, (2A) probably carcinogenic to humans, (2B) possibly carcinogenic to humans, (3) inadequate or limited evidence of carcinogenicity in experimental animals.

${ }^{\mathrm{e}}$ Both the +3 and +5 oxidation states are clastogenic in vitro.

${ }^{\mathrm{f}}$ Various compounds.

${ }^{\mathrm{g}}$ Hexavalent chromium compounds only (e.g., $\mathrm{K}_{2} \mathrm{Cr}_{2} \mathrm{O}_{7}, \mathrm{~K}_{2} \mathrm{CrO}_{4}$ ).

${ }^{\text {h }} \mathrm{Nickel}(\mathrm{II})$ salts (e.g., $\mathrm{NiCl}_{2}$ ) and insoluble crystalline nickel (e.g., $\mathrm{Ni}_{3} \mathrm{~S}_{2}$ ).

${ }^{\mathrm{i}}$ Cobalt(II) salts only (e.g., $\mathrm{CoCl}_{2}$ ).

j Cadmium(II) salts only (e.g., $\mathrm{CdCl}_{2}$ ).

${ }^{\mathrm{k}}$ A complex coal tar distillate that contains a variety of PAHs, PAH derivatives, and heterocyclic aromatic compounds [427].

${ }^{1}$ Rodent dominant lethal assay only.

${ }^{m}$ The TRI lists PACs (polycyclic aromatic compounds) as a category of 19 individual compounds. A list of compounds included is available at http://www.epa.gov/tri/chemical/chemlist2001.pdf.

${ }^{\mathrm{n}}$ Primarily beryllium(II) compounds (e.g., $\mathrm{BeSO}_{4}$ ).

${ }^{\circ}$ Drosophila SLRL (sex-linked recessive lethal) assay or aneuploidy assay only.

p Animal cells only.

${ }^{\mathrm{q}}$ Classification restricted to chlorinated paraffins (alkanes) of average chain length $\mathrm{C}_{12}$ and average chlorination of approximately $60 \%$. Chromosomal effects (SCEs in vitro) observed for $\mathrm{C}_{12}$ compounds only.

${ }^{\mathrm{r}}$ Mixed isomers.

${ }^{\mathrm{s}}$ Drosophila sex-linked recessive lethal and mouse lymphoma assays only.

${ }^{\mathrm{t}}$ Also known as nitrofen.

"Only 2,4-diaminotoluene evaluated.

v $2 \mathrm{~B}$ classification is for chlorophenoxy herbicides. 2,4-D, mecoprop (2-(4-chloro-2-methylphenoxy) propanoic acid), and methoxone ((4chloro-2-methyl-phenoxy) acetic acid) are classified as group 3 - inadequate evidence of animal carcinogenicity or inadequate evidence for a definitive evaluation. Methoxone tests positive for mutagenicity in yeast, bacteria (Mutatox ${ }^{\circledR}$ only), and Drosophila SLRL. Weak evidence of SCE induction in vitro and in vivo in Chinese Hamsters and chick embryos. 
Table $3 \mathrm{~b}$

2002 NPRI on-site land releases of carcinogenic substances in Canada ( $>100 \mathrm{~kg}$ only $)^{\mathrm{a}}$

\begin{tabular}{|c|c|c|c|}
\hline Compound & Mutagenicity/clastogenicity ${ }^{\mathrm{b}, \mathrm{c}}$ & Carcinogenicity $^{\mathrm{d}}$ & Total land releases $\left(\times 10^{3} \mathrm{~kg}\right)$ \\
\hline Lead compounds ${ }^{\mathrm{e}}$ & $\mathrm{CC}$ & $2 \mathrm{~B}$ & 1738.7 \\
\hline Asbestos (friable) & $\mathrm{C}$ & 1 & 521.2 \\
\hline Chromium compounds $^{\mathrm{f}}$ & $+++/ \mathrm{CC}$ & 1 & 917.4 \\
\hline Nickel compounds ${ }^{\mathrm{g}}$ & $++/ \mathrm{CC}$ & 1 & 265.6 \\
\hline Cadmium compounds ${ }^{\mathrm{h}}$ & $++/ \mathrm{CC}$ & 1 & 150.8 \\
\hline Arsenic compounds ${ }^{\mathrm{i}}$ & $+/ \mathrm{CC}$ & 1 & 134.4 \\
\hline Cobalt compounds $^{\mathrm{j}}$ & $++/ \mathrm{CC}$ & $2 \mathrm{~B}$ & 42.6 \\
\hline Polycyclic aromatic compounds ${ }^{\mathrm{k}}$ & $+++/ \mathrm{CC}$ & $2 \mathrm{~A} / 2 \mathrm{~B}$ & 9.1 \\
\hline 1,4-Dioxane & $+/ \mathrm{C}$ & 2B & 6.1 \\
\hline Ethylbenzene & $+{ }^{1}$ & $2 \mathrm{~B}$ & 1.0 \\
\hline Benzene & $+++/ \mathrm{CC}$ & 1 & 0.9 \\
\hline Chloroform & $+/ \mathrm{CC}$ & $2 \mathrm{~B}$ & 0.5 \\
\hline Total inorganic & & & 3770.7 \\
\hline Total organic & & & 17.6 \\
\hline Grand total & & & 3788.3 \\
\hline
\end{tabular}

${ }^{a}$ Includes on-site landfill disposal, land treatment, surface impoundment, leaks, and spills. See Table $2 \mathrm{~b}$ for additional details. Five other organic compounds with values $>10$ and $<100 \mathrm{~kg}$ (i.e., 1,2-dichloroethane, formaldehyde, acetaldehyde and vinyl acetate) account for an additional $102 \mathrm{~kg}$.

b Based on data from the Genetic Activity Profile (GAP) database [454,455], the Monograph Series of the International Agency for Research on Cancer (IARC) (available online at http://monographs.iarc.fr/), and the published results of the US national Toxicology Program (available online at http://ntp-server.niehs.nih.gov/).

c $(-)$ Compounds for which there is no evidence of mutagenicity or clastogenicity, $(+)$ mutagenic in bacterial and/or fungal cells in vitro, $(++)$ also mutagenic in plants or animal cells in vitro, $(+++)$ also mutagenic in the Drosophila melanogaster somatic mutation and recombination test, and/or sex-linked recessive lethal test, and/or transgenic rodent assays, and/or rodent dominant lethal assay. For cytogenetic endpoints $\mathrm{C}$ refers to substances are clastogenic in in vitro assays, CC refers to substances that are clastogenic both in vitro and in vivo. Note: In some instances conflicting results have been reported in the literature.

d IARC classification system: (1) carcinogenic to humans, (2A) probably carcinogenic to humans, (2B) possibly carcinogenic to humans, (3) inadequate or limited evidence of carcinogenicity in experimental animals.

e Various compounds.

${ }^{\mathrm{f}}$ Hexavalent chromium compounds only (e.g., $\mathrm{K}_{2} \mathrm{Cr}_{2} \mathrm{O}_{7}, \mathrm{~K}_{2} \mathrm{CrO}_{4}$ ).

g Nickel(II) salts (e.g., $\mathrm{NiCl}_{2}$ ) and insoluble crystalline nickel (e.g., $\mathrm{Ni}_{3} \mathrm{~S}_{2}$ ).

${ }^{\mathrm{h}}$ Cadmium(II) salts only (e.g., $\mathrm{CdCl}_{2}$ ).

${ }^{\mathrm{i}}$ Both the +3 and +5 oxidation states are clastogenic in vitro.

${ }^{\mathrm{j}}$ Cobalt(II) salts only (e.g., $\mathrm{CoCl}_{2}$ ).

${ }^{\mathrm{k}}$ Facilities had the option of reporting quantities for each of 17 individual PAHs, or, under a separate listing, the total for the 17 PAHs categorized as toxic under section 11 of the Canadian Environmental Protection Act (1999, http://laws.justice.gc.ca/en/C-15.31/). Value is the sum of IARC 2A carcinogens, IARC 2B carcinogens, and total PAH listings.

${ }^{1}$ Animal cells only.

pollutants. For example, fine clay particles possess a net negative charge and are capable of retaining positively charged ions of toxic metals such as zinc, copper, aluminum, chromium, arsenic, nickel, and cadmium. Moreover, the oxidation state of a given soil can dramatically modify the toxicity of metals such as aluminum and arsenic.

Organic pollutants with limited water solubility (e.g., aromatic hydrocarbons, chlorinated pesticides, etc.) are usually sorbed to soil organic matter and clay particles. The degree of sorption is primarily a function of the solute's water solubility and the soil organic matter content, with solute vapour pressure and soil clay content playing lesser roles. Sorption potential of a given compound to a selected soil is usually expressed as $K_{\mathrm{d}}$, the slope of a linear sorption isotherm [8]. $K_{\mathrm{d}}$ values that are corrected for organic matter content are generally referred to as $K_{\mathrm{om}}$ or $K_{\mathrm{oc}}$, with the subscripts referring to organic matter and organic carbon, respectively [5].

The sorption of organic pollutants, a phenomenon that is highly dependant on $K_{\text {ow }}$ (octanol-water 
partition coefficient), is an important mechanism for removal of pollutants from soil water, and consequent inhibition of leaching to groundwater [4]. For example, the mobility potential of most substances with $K_{\text {ow }}$ values above 1000 are generally low to nil [5]. Moreover, sorption of organic pollutants can alter toxicity by reducing bioavailability and exposure. Detailed discussions on the partitioning dynamics of toxic organic pollutants in contaminated soils can be found in Donnelly et al. [4], Winegardner [5], Young et al. [9], Dragun [7], and Yaron et al. [10].

\subsection{Detection of mutagens in soil}

The spatial heterogeneity of the soil environment complicates the selection of sampling locations, as well as the selection of an appropriate sampling method. Since budgetary considerations do not permit the collection of an unlimited numbers of samples, a variety of strategies and instruments have been created to assist efficient sample collection and site assessment. Three sample collection strategies are commonly employed to effectively characterize a site: biased or likely location sampling, grid or pattern sampling, and stratified random sampling [5,11]. Each of these strategies offers a variety of advantages and disadvantages. Biased sampling is simple and quick, but generally reserved for situations of obvious contamination. Prior site investigation or simple visual surveys reveal obvious or likely areas of contamination and these are selectively sampled (e.g., storage facilities, area containing damaged storage drums). As such, this strategy is effective for confirming site contamination, but not effective for comprehensive risk assessment. Grid sampling, collection of samples at regular intervals in a gridded pattern that divides the site into an equal number of uniform shapes, is easy to design and implement, and provides excellent site coverage for identifying spills and hot-spots. However, it is not practical for large areas and may require an unacceptably large number of samples. Stratified random sampling, a method that is more cost effective than grid sampling, involves collection of samples from a series of non-overlapping strata that are defined on the basis of topological or geophysical features. Random samples are collected from each stratum, and because the variance within a stratum is smaller than that between strata, the combined results from numerous strata can provide more accurate averages for selected parameters than either grid or non-stratified random sampling [12-14]. However, this method requires competent topographical and/or geophysical surveys of the site prior to sample collection. A detailed discussion of the various soil collection strategies and the statistical considerations of effective site monitoring are clearly beyond the scope of this work. Interested readers should consult Gilbert [12], Mason [13] and Cochran [14].

Appropriate collection, handling, and storage of soil samples depend on the depth required and the type of analyses to be conducted. Soil samples are usually collected with a surface sampler such as a spade or scoop, a soil boring devise such as a manual or power auger, or a soil coring devise that can provide an undisturbed profile of soil condition and contamination. Scoop or spade sampling is the simplest and most direct collection method that can readily provide small quantities of surface cover to a specified depth. This method is effective where disturbed shallow samples are acceptable. Soil boring devises are commonly used for subsurface sampling of disturbed soils from depths below $20 \mathrm{ft}$. These devises (e.g., barrel auger, continuous flight auger, etc.) permit continuous removal of soil that can be sampled as it arrives on the surface. Undisturbed soil samples are generally collected using coring devises that push tube samplers below the bottom of a borehole, or, in the case of the hollow stem auger, the auger remains in place to support the borehole walls while the core sampler is inserted. More recent improvements on the hollowstem auger permit continuous coring as the auger advances to the desired depth. Detailed descriptions of soil collection techniques can be found in Winegardner [5] and Boulding [15]. The latter publication, an expanded version of the US EPA's guide to the description and sampling of contaminated soil [16], also recommends a standard protocol for site and sample description. Site descriptions should include climate and weather (e.g., air temperature, humidity, wind speed and direction), slope, vegetation, surface erosion, and surface runoff. Sample descriptions should include soil texture (i.e., sand, clay, silt content), soil porosity, water content, and soil colour. Detailed standardized methodologies can be found in several ASTM publications $[17,18]$. 
Assessing the toxic contamination of a solid medium like soil is not a simple task. Some of the difficulties are not unique to soils and are common in investigations of complex environmental samples such as surface waters, groundwater, industrial effluents, sediments, and airborne particulate matter. First, the large number of toxic chemicals that may potentially be present at a contaminated site can hinder successful chemical analyses. Second, detailed chemical analysis is limited in its ability to predict the toxicity of complex chemical mixtures $[19,20]$. To overcome these problems many researchers advocate a complex mixture approach that employs bioassays to measure the mutagenic potential of a complex environmental sample or the extract/concentrate of an environmental sample (e.g., for details see [19,21-29]). This approach alleviates the need for chemical-specific analyses, and integrates the effects of all mixture components, whether or not they are known and identified. Moreover, bioassay-directed chemical analyses can subsequently be employed in an effort to identify the putative mutagens (e.g., $[22,23,30$ 32]).

Soil texture, spatial heterogeneity, and microbial content can further complicate assessment of mutagenic potential. The most popular mutagenicity assays, such as the Salmonella mutagenicity test [33-36], require sterile samples and do not readily accept solids. In addition, the low concentration of mutagens in many environmental samples necessitates extraction and concentration of substances prior to mutagenicity assessment. Since a variety of known environmental mutagens are organic compounds (e.g., PAHs, heterocyclic compounds, aromatic amines, etc.) [37], many researchers employ organic solvents to extract and concentrate organic constituents prior to mutagenicity testing.

Dichloromethane (DCM) and methanol (MetOH), as well as solvent mixtures such as acetone/hexane, are the most popular extraction solvents, and many recent publications investigating the mutagenic hazards of contaminated soils examined the mutagenicity of DCM, MetOH or acetone/hexane extracts of dried soils (e.g., [38-57]). Other extraction solvents or solvent mixtures include acetonitrile (ACN) [5860], acetone [60,61], ethyl ether [62], acetone/ cyclohexane [63], DCM/MetOH [64], and ethanol/ dimethyl sulfoxide [65]. Some researchers employing plant assays for soil mutagenicity assessment do not expose plant tissues (e.g., cuttings, root tips, etc.) to organic soil extracts [66-69]. Rather, plant tissues are exposed directly to unaltered soil [70-80], either in situ or ex situ, or tissues are exposed to aqueous extracts, leachates, or elutriates [63,67-69,76,81-85].

Although many researchers have employed bioassays to investigate the sources and identity of mutagens and carcinogens in complex samples from aquatic systems (e.g., $[19,86,87])$, there is a paucity of information about the sources and potential hazards of mutagens in soil. Moreover, few researchers have investigated the efficacy of short-term mutagenicity assays such as the Salmonella mutagenicity test in the assessment of soil mutagenic hazard. Thus, there is a need to investigate the mutagenic hazards of contaminated soils, and moreover, incorporate the use of well-established assays in assessments of potential hazard. This work provides a comprehensive review of published research that employed bioassays to investigate the mutagenic properties of soil.

\subsection{Bioassays employed for soil mutagenicity assessment}

Published accounts of soil genotoxicity assessment have employed more than 30 assays to assess DNA damaging ability, mutagenicity, or clastogenicity. These include popular bacterial and plant assays such as the Salmonella mutagenicity test, the anaphase aberration test in Allium cepa and the Tradescantia micronucleus test, as well less common tests such as micronucleus (MN) induction test in Xenopus laevis $[88,89]$ and rifampicin resistance forward mutation test in Pseudomonas putida [90]. Fig. 1 provides a breakdown of the genotoxicity assessments techniques employed in published examinations of contaminated soils. The figure shows that $37.6 \%$ of the published assessments employed the Salmonella mutagenicity test; with a further $13.4 \%$ employing other prokaryote mutagenicity and DNA damage tests (e.g., SOS Chromotest, Mutatox ${ }^{\circledR}, \lambda$ prophage induction assay, Salmonella uти test, rec $^{-}$differential survival assay). The popularity of the Salmonella mutagenicity test for the assessment of soil mutagenicity is similar, but notably lower, than that described by Houk [19] for assessments of industrial wastes and effluents. Houk [19] indicated that almost $60 \%$ of works that 

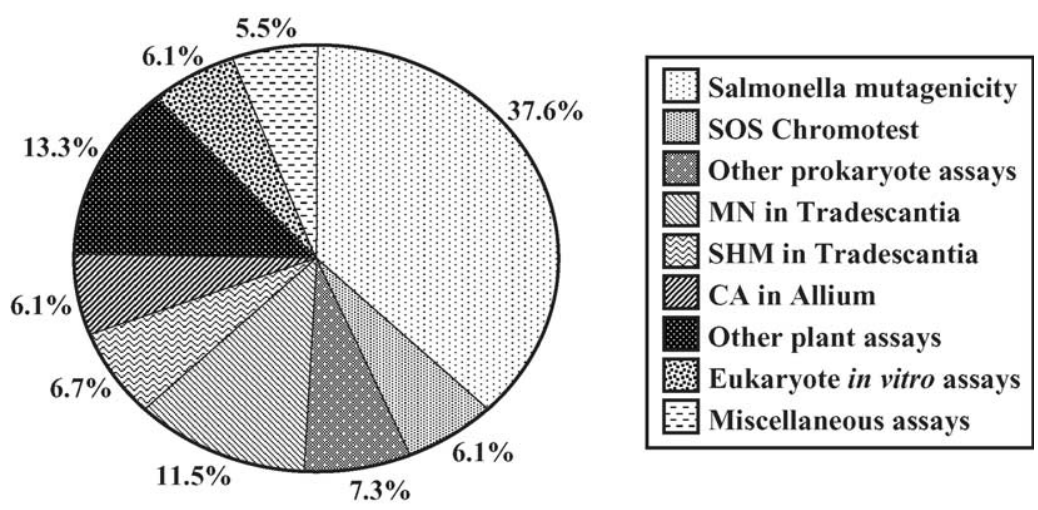

Fig. 1. Breakdown of the assays employed in published assessments of soil genotoxicity.

investigated the mutagenicity of industrial effluents and wastes employed the Salmonella mutagenicity test. Most of the remaining assessments (i.e., $37.6 \%$ of the total) employed one of several plant mutagenicity or clastogenicity assays (e.g., anaphase aberrations test in Allium sp., stamen hair mutation test in Tradescantia sp.). The remaining $11.6 \%$ of the assessments employed a variety of assays examining cytogenetic effects (e.g., sister chromatid exchanges or SCEs) in cultured human lymphocytes, somatic mutations in Drosophila, forward mutations in Aspergillus nidulans, and hprt mutations in Chinese Hamster V79 cells.

Fig. 2 provides a breakdown of the genotoxicity endpoints employed in published examinations of contaminated soils. The majority (i.e., 60\%) of the assessments measured induction of gene mutations. Loci examined include the his loci in Salmonella $[33,34,36]$, the stamen hair colour loci in Tradescantia [91], the waxy locus in Zea mays [72], the $m w h$ and flr wing morphology loci in Drosophila melanogaster [92], the hprt locus in Chinese Hamster V79 cells [93], the methionine suppressor loci in Aspergillus nidulans [94,95], and the ade loci of Saccharomyces cerevisiae [96]. Twenty-seven percent of published soil genotoxicity assessments employed a variety of clastogenicity endpoints such as chromosomal aberrations (CAs), MN induction, and the induction of SCEs. Although enhanced risk of gene mutation is associated with a variety of adverse health effects including cancer (e.g., [97-100]), only two of the clastogenicity endpoints (e.g., MNs and CAs) are known to be useful biomarkers of adverse health effects such as cancer [101-103]. SCEs are useful markers of cytogenetic effects in vitro and in vivo [104,105]; however, their utility as biomarkers of adverse health effect is disputed [102,106]. Much of the remaining $12.7 \%$ of genotoxicity assessments measured induction of DNA damage using assays such as the rec ${ }^{-}$differential survival assay in Bacillus subtilus [107,108], the SOS Chromotest [109,110], the Salmonella ити test [111], and the Microscreen prophage induction assay [112].

\section{Collection and analysis of published soil mutagenicity/clastogenicity data}

In total, 165 published assessments (i.e., endpoint/ sample combinations) of soil genotoxicity were obtained from 118 publications, including thirteen foreign language publications (e.g., Spanish, Russian, Italian and Japanese). These included journal articles, book chapters, government reports, and conference abstracts.

For the purposes of empirical analyses, the reviewed soil genotoxicity assessments were divided into two main groups. Those that used popular assays for which large amounts of published data are available (i.e., $>30$ observations), and those that employed assays rarely used for soil genotoxicity assessment. Five assay systems have been frequently used for soil genotoxicity assessment, the Salmonella mutagenicity test and four plant assay systems: the stamen hair mutation assay in Tradescantia, the Tradescantia $\mathrm{MN}$ assay, the anaphase aberration assay 

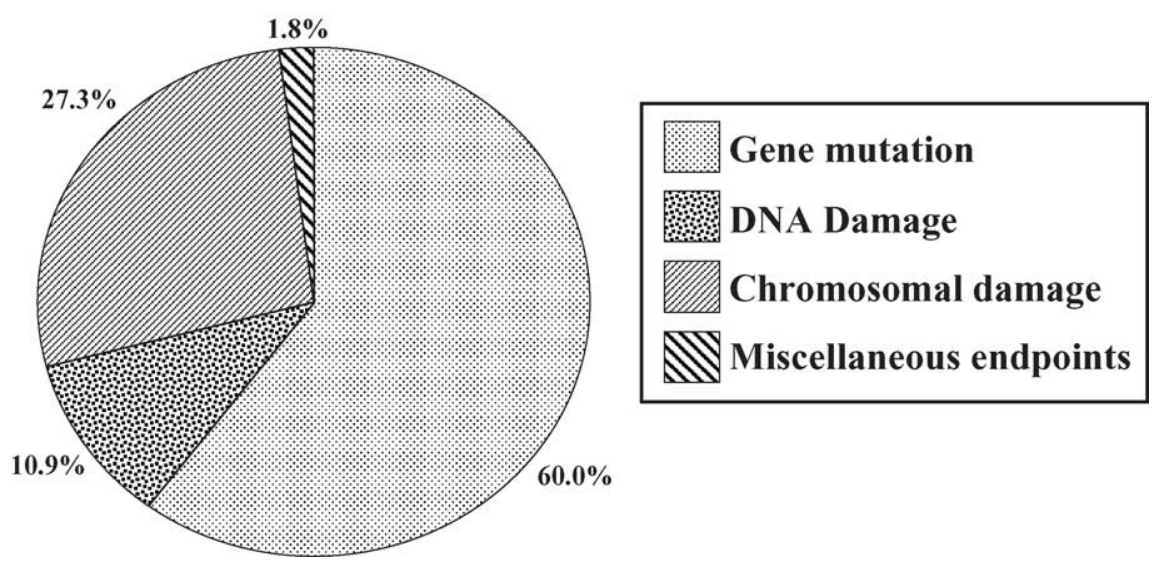

Fig. 2. Breakdown of endpoints employed in published genotoxicity assessments of soils and soil extracts. Gene mutation endpoints include his loci in Salmonella, the Wx locus in Zea mays, the hprt locus in mammalian cells, stamen hair colour loci in Tradescantia, and methionine suppressor loci in Aspergillus. Chromosome damage endpoints include chromosome aberrations, micronucleus formation, sister chromatid exchanges, mitotic recombination, gene conversion, and aneuploidy. DNA damage endpoints include SOS response induction (e.g., rec dependant DNA repair, prophage induction, sulA induction, ити induction), formation of DNA adducts, and induction of alkali-labile DNA damage sites. Miscellaneous endpoints include the formation of nuclear anomalies in maize and white clover (Trifolium repens) assessed via flow cytometry.

in Allium cepa root tip, and the waxy locus mutation assay in Zea mays.

Soil contamination data (e.g., PAHs, dinitropyrenes, ${ }^{137} \mathrm{Cs}$, etc.) were also collected where available. All values were converted to a common unit such as ppm dry weight (i.e., $\mu \mathrm{g} / \mathrm{g}$ dry soil) or Bq per dry $\mathrm{kg}$. $\mathrm{PAH}$ contamination values were collected from 13 studies that employed the Salmonella mutagenicity assay, four studies that employed the Tradescantia $\mathrm{MN}$ assay, and one study that assessed induction of rifampicin resistance mutations in Pseudomonas putida. Soil PAH data for one Salmonella study [39] were obtained from a separate, but related publication [113]. Unfortunately, there was little consistency across the studies with respect to the identity of the PAHs examined. Three studies provided total PAH values, but failed to provide a list of measured PAHs [57,114,115]. Seven studies provided data for 10 to 14 PAHs, including several noteworthy mutagenic carcinogens such as benzo $[a]$ pyrene, benz $[a]$ anthracene, dibenz $[a h]$ anthracene, and benzo[b]fluoranthene $[39,59,63,113,116-118]$. Six studies provided data for 3-8 PAHs selected to indicate anthropogenic contamination by pyrolytic emissions (e.g., fluoranthene, chrysene, pyrene, benzo[a]pyrene) [56,83,119-122]. Despite these variations in the identity of the PAHs selected for analysis, all the selected PAHs are members of the list of 16 PAHs commonly referred to as priority PAHs [123].

For studies that employed the Salmonella mutagenicity test, total PAH was operationally defined as the total PAH value provided by the author(s), or the sum of the most frequently measured PAHs: fluoranthene, pyrene, benz $[a]$ anthracene, chrysene, benzo $[a]$ pyrene, benzo $[b]$ fluoranthene, benzo[ $k]$ fluoranthene, and benzo[ghi]perylene. A matrix of Pearson correlations between eight measured PAHs showed high correlations between individual PAH concentrations across the studies examined, with an average coefficient of $0.92(0.81-0.99)$. Thus, where the concentration of one or more of the required PAHs was not available, predictive regression models based on all available data were used to predict missing values. With respect to the Tradescantia studies, Total PAH simply refers to the sum of individual values available from the relevant publications.

Four studies provided detailed information on a series of dinitropyrenes (DNPs) [50,51,53,124]. For the purposes of data analyses, Total DNPs was operationally defined as the sum of 1,3-dinitropyrene, 1,6-dinitropyrene, and 1,8-dintropyrene.

Several studies that employed the Tradescantia $\mathrm{MN}$ assay also measured soil concentrations of several metals (e.g., As, Cd, Sb, Cr, Cu, Ni, Pb, Zn) 
Table 4

Overview of the collected soil contamination data ${ }^{\mathrm{a}}$

\begin{tabular}{|c|c|c|c|c|c|}
\hline Assay system & Analyte & Minimum & Maximum & Geometric mean & $N$ \\
\hline Salmonella TA98 with S9 & PAHs & 0.07 & 12266 & $11.0 \pm 4.7$ & 80 \\
\hline Salmonella TA98 without S9 & DNPs & 0.03 & 15.7 & $0.62 \pm 0.15$ & 37 \\
\hline \multirow[t]{9}{*}{ Tradescantia $\mathrm{MN}$ assay } & PAHs & 0.02 & 5749 & $2.6 \pm 2.4$ & 17 \\
\hline & $\mathrm{Cr}$ & 0.05 & 214 & $7.7 \pm 1.6$ & 34 \\
\hline & $\mathrm{Pb}$ & 0.08 & 28144 & $101.0 \pm 48.8$ & 34 \\
\hline & As & 0.02 & 2940 & $7.2 \pm 3.7$ & 34 \\
\hline & $\mathrm{Cd}$ & 0.01 & 89.9 & $0.7 \pm 0.3$ & 34 \\
\hline & $\mathrm{Sb}$ & 0.2 & 6720 & $2.9 \pm 2.6$ & 34 \\
\hline & $\mathrm{Cu}$ & 0.03 & 3203 & $13.5 \pm 7.0$ & 34 \\
\hline & $\mathrm{Ni}$ & 0.08 & 366 & $10.5 \pm 2.84$ & 34 \\
\hline & $\mathrm{Zn}$ & 0.02 & 23727 & $66.1 \pm 26.9$ & 34 \\
\hline Allium cepa CA assay & ${ }^{137} \mathrm{Cs}$ & 22.0 & 6880 & $2084.1 \pm 354.2$ & 17 \\
\hline Arabidopsis mutation & ${ }^{137} \mathrm{Cs}$ & 22.0 & 2529 & $333.5 \pm 200.4$ & 4 \\
\hline
\end{tabular}

${ }^{a}$ Values expressed as ppm dry wt. (i.e., $\mathrm{mg} / \mathrm{kg}$ ), except DNPs, which are ppb dry wt. (i.e., $\mu \mathrm{g} / \mathrm{kg}$ ), and ${ }^{137} \mathrm{Cs}$, which are Bq/kg. All metal concentrations are total extractable metals.

$[63,76,77,81,83]$. However, total concentrations of $\mathrm{Cr}$, $\mathrm{Pb}, \mathrm{As}, \mathrm{Cd}, \mathrm{Sb}, \mathrm{Cu}, \mathrm{Ni}$, and $\mathrm{Zn}$ were only collected from two studies that conducted direct soil exposures of intact Tradescantia plants [76,77]. Table 4 provides an overview of the soil contamination data that was used to investigate empirical relationships between bioassay response and soil contamination.

All data analyses were performed using the SAS system version 8.02 for Windows [125]. Analysis of variance (ANOVA) was employed to investigate relationships between bioassay response (e.g., Salmonella revertents/mg dry weight) and site classification (e.g., urban/industrial, remote). Ordinary leastsquares linear regression analysis was used to investigate relationships between genotoxic potency and measures of environmental contamination (e.g., PAH concentration). In some cases, analysis of covariance (ANCOVA) was employed to simultaneously investigate the effects of site classification and site contamination. Following the notation of Gujarati [126]], the general model $Y_{i}=\alpha_{1}+\alpha_{2}\left(D_{2}\right)+\alpha_{3}\left(D_{3}\right)$ $+\alpha_{n}\left(D_{n}\right)+\beta_{1}\left(X_{i}\right)+\left(\left(\beta_{2} \times D_{2}\right) \times\left(X_{i}\right)\right)+\left(\left(\beta_{3} \times D_{3}\right)\right.$ $\left.\times\left(X_{i}\right)\right)+\left(\left(\beta_{n} \times D_{n}\right) \times\left(X_{i}\right)\right)+\mu_{i}$ was fit to the data. $Y_{i}$ is the observed mutagenic potency value, $X_{i}$ is the value for a continuous environmental contamination variable at observation $i$ (e.g., PAH concentration, where available), and $D_{2}$ through $D_{n}$ are dichotomous variables that indicate membership of observation $i$ in a given group (e.g., remote sites, urban/industrial sites, etc.). $D_{2}$ through $D_{n}$ are set to 1 when the condition of group membership is satisfied and 0 when the condition is not satisfied. This model permits an assessment of the relationships between genotoxic potency and a multitude of continuous or dichotomous variables taken individually or in various combinations. The scalars $D_{2}$ through $D_{n}$ permit adjustments in slope and intercept values where appropriate. The residual error term $\mu_{i}$ was assumed to be independent and normally distributed and normality was assessed using the Shapiro-Wilk test and visual examination of a normal probability plot [127]. Where necessary the data were log transformed to meet the assumptions of least squares regression, ANOVA and ANCOVA. The absolute value of the residual error values was used to detect outliers and identify data entry errors. To identify significant outliers, externally studentized residuals $\left(\mathrm{d} i^{*}\right)$ were calculated for each residual [128]. Comparison of $\mathrm{d} i{ }^{*}$ values to the appropriate $t$ distribution permitted the identification of significant residuals, which lie beyond the 0.05 limits of the distribution.

\section{Salmonella mutagenicity of soils}

The Salmonella mutagenicity test is undoubtedly the most popular bioassay in environmental mutagenesis research, particularly for the analysis of complex mixtures such as organic extracts of soil, air, and water [26-29,31,129-133]. The standard version of the 
assay, known as the plate incorporation assay, is a reverse mutation test that quantifies the frequency of reversion from histidine auxotroph to wild-type following a 48- to 72-h incubation with the test substances [33-36]. Several tester strains of Salmonella are available, carrying a variety of his mutations. The most popular tester strains, TA98 and TA100, carry the hisD3052 and hisG46 alleles, respectively. The former is a -1 frameshift mutation reverted to wild type by frameshift mutagens (e.g., ICR-191, nitrosamines). The latter carries a base-substitution mutation that is reverted by base-pair substitutions at a GC pair in a proline codon [33]. These strains have been extensively employed for the detection of environmental mutagens including PAHs [134-136], nitroarenes [137,138], aromatic amines (e.g., Ncontaining heterocyclics) [139-141], S-containing heterocyclics [142,143], and phenylbenzotriazoles $[144,145]$. Although some of these compounds have noteworthy mutagenic activity on both TA100 and TA98 (e.g., PAHs) [134], several are known to have more potent frameshift activity (e.g., aromatic amines, phenybenzotriazoles, nitroarenes) [137,139,141,144].

Sixty-two published works contained Salmonella mutagenicity data on soil extracts. The majority of these studies employed the standard plate incorporation version of the assay with Salmonella strains TA98 and/or TA100. Where mutagenic potency values were not provided and the published data showed at least a two-fold increase in response over the control, ordinary least squares regression was employed to calculate potency from the initial (linear) portion of the concentration-response relationship. In all cases, reported mutagenic potency values were converted to net Salmonella revertents per equivalent dry $\mathrm{mg}$ of soil. Some researchers examining soil extracts have referred to potency expressed as net revertents per $\mathrm{g}$ dry soil as weighted activity [56,114,115,117,118].

In several cases, missing information (e.g., yield of extractable material per gram of soil) or additional details about sites and/or extraction procedures were obtained directly from the corresponding author $[53,56,146,147]$. If mutagenic potency was reported for individual chemical fractions (e.g., base/neutral compounds), total mutagenic potency was defined as the sum of the individual fractions. In cases where the number of spontaneous revertents was not reported, the following values were used: 25 for TA98 without
S9, 35 for TA98 with S9, 100 for TA100 without S9, and 120 for TA100 with S9. Salmonella mutagenicity data were not collected from studies that only provided a qualitative response index (e.g., positive/ negative) [147,148], studies that did not provide sufficient information about concentration [149,150], or sufficient information to calculate mutagenic potency in revertents/mg dry soil $[38,44,62,151-$ 155]. The majority of the studies in the latter category expressed mutagenic potency as net revertents per unit of extractable organic material (e.g., mg extractable residue or $\mu \mathrm{L}$ of solvent extract), and did not provide the information required (i.e., mg extractable material per mg dry wt. of soil) to convert the potency to revertents per gram of soil.

A total of 1633 observations of Salmonella mutagenic potency were collected from the literature. Over $50 \%$ of these values were generated from tests of $\mathrm{MetOH}$ extracts. Roughly $24 \%$ of the values were generated from examinations of hexane/acetone extracts, and $14 \%$ were generated from DCM extracts. The remaining $11 \%$ of the mutagenic potency values were generated from examinations of extracts that employed a variety of solvents including ACN, cyclohexane, or solvent mixtures (e.g., hexane/ isopropanol, $\mathrm{DCM} / \mathrm{MetOH}$, benzene/EtOH, etc.). Appendix A contains the Salmonella mutagenicity data obtained from the literature.

Site descriptions in the publications, or information obtained from the corresponding author, were used to divide the Salmonella data into three separate site categories: rural/agricultural, urban/suburban, and industrial. Rural/agricultural sites are all located outside urban or suburban communities and include remote park-like settings or agricultural areas. Urban/ suburban sites include sites located in cities or towns but not directly on the grounds of an industrial facility that receives industrial wastes and discharges. Category assignments were based on site descriptions only, without prior examination of the mutagenicity data. Table 5 shows the distribution of the data between the three site categories.

\subsection{TA98 and TA100 mutagenicity of soil extracts}

Much of the soil mutagenicity literature is concerned with the identification of hazardous sites that may pose a mutagenic hazard to humans and 
Table 5

Breakdown of the Salmonella mutagenicity data collected from the literature

\begin{tabular}{|c|c|c|c|c|c|}
\hline \multirow[t]{4}{*}{ Site/sample category } & \multicolumn{5}{|c|}{ Number of observations } \\
\hline & \multicolumn{4}{|c|}{ Salmonella strain } & \multirow[t]{3}{*}{ Total } \\
\hline & \multicolumn{2}{|l|}{ TA98 } & \multicolumn{2}{|l|}{ TA100 } & \\
\hline & No S9 & $+\mathrm{S} 9$ & No S9 & $+\mathrm{S} 9$ & \\
\hline Rural/agricultural & 125 & 144 & 92 & 109 & 470 \\
\hline Urban/residential & 219 & 241 & 157 & 199 & 816 \\
\hline Industrial & 105 & 202 & 15 & 25 & 347 \\
\hline Total & 449 & 587 & 264 & 333 & 1633 \\
\hline
\end{tabular}

indigenous fauna (e.g., $[44,45,47,117,118])$, and the predominance of particular Salmonella strain-activation combinations in the literature reflects their utility in this regard. Much of the published Salmonella mutagenicity data on soil extracts are TA98 results, often obtained in the presence of an S9 metabolic activation mixture (see Table 5). This suggests that much of the mutagenic activity in contaminated soils is S9-activated frameshift activity. This assertion is supported by numerous studies of organic extracts from soils contaminated with a wide range of pollutants (e.g., wood preserving wastes, petrochemical wastes, sewage sludge) that yielded little or no response on the base-substitution strain TA100 (e.g., $[38,41,47,48,54,64,115,116,156])$. Moreover, many of these studies have noted the presence of known frameshift mutagens such as nitroarenes and $\mathrm{N}$ containing heterocyclics in soil extracts that show potent TA98 activity [64,116,121,157]. However, it should be noted that some studies, such as those that examined extracts of soils contaminated with munitions wastes (e.g., di- and trinitrotoluenes) and dintropyrenes (e.g., 1,3-, 1,6-, and 1,8-dinitropyrene), also showed strong responses in Salmonella TA100 (e.g., $[51,158])$.

Table 6 provides a descriptive summary of the Salmonella mutagenic potency values for each combination of site category and Salmonella strain. The data presented illustrate that mutagenic potency values range from a low of less than 0.001 revertents per dry mg at rural sites, to a high of almost 1000 revertents/mg at highly contaminated industrial sites. Fig. 3 contains a box plot that illustrates the distribution of the log transformed Salmonella TA98 results obtained in the presence of S9 metabolic activation $(N=587)$. Analysis of variance (ANOVA), employed to investigate the relationship between mutagenic potency and site category, revealed a significant relationship between site category and mutagenic potency $(p<0.0001)$, and a significant difference between rural, urban, and industrial sites (geometric mean values $=0.06,0.47$, and 0.95 revertents/mg, respectively).

The box plot for industrial soils shown in Fig. 3 (top left) suggests that several observations would likely be considered to be outliers. Studentized deleted residuals $\left(\mathrm{d} i^{*}\right)$ for each observation were calculated to identify significant outliers from the ANOVA model. Based on $\mathrm{d} i$ values, 40 of the mutagenic potency values shown in Fig. 3 (top left) were identified as significant outliers. Thirty-nine of these outliers are industrial sites, with almost half of them (43\%) being negative outliers with potency values below 0.02 revertents/mg. These results are not surprising in light of the fact that some low potency values were assigned to the industrial category based solely on the published site descriptions, and many of the negative outliers reflect results obtained for samples collected on transects extending a considerable distance from the source(s) of the industrial contamination (e.g., coal gasification site sample 201 from Donnelly et al. [118] and munitions site soil 006 from Donnelly et al. [54]). The other negative outlier is a sample from an urban site in Azerbaijan. The authors described the sample collection area as a location "near apartments in a highly populated urban area" [56].

The remaining significant industrial outliers (i.e., $57 \%$ ) are positive outliers with potency values above 55 revertents/mg. All of these positive outliers, with extremely high mutagenic potency values (i.e., 56.9376 revertents/mg), are from heavily contaminated sites such as the Superfund site studied by McDaniels et al. [46], the tar pit perimeter studied by Donnelly et al. [118], the explosive contaminated soils studied by Donnelly et al. [54], Griest et al. [158], and BertheCorti et al. [65], and the petrochemical and wood preserving wastes studied by Brown et al. [49].

Fig. 3 (top right) contains a box plot that illustrates the distribution of the log transformed Salmonella TA98 results obtained in the absence of S9 metabolic activation $(N=449)$. The ANOVA results reveal a significant relationship between site category and mutagenic potency $(p<0.0001)$, and a significant 
Table 6

Descriptive summary of the Salmonella mutagenicity data ${ }^{\mathrm{a}}$

\begin{tabular}{|c|c|c|c|}
\hline & \multicolumn{3}{|l|}{ Category } \\
\hline & Rural & Urban/suburban & Industrial \\
\hline \multicolumn{4}{|c|}{ TA98 with metabolic activation $(N=587)$} \\
\hline$N$ & 144 & 241 & 202 \\
\hline Minimum & 0.0020 & 0.0083 & 0.00070 \\
\hline Maximum & 0.77 & 10.90 & 376.00 \\
\hline Mean & 0.10 & 1.04 & 21.67 \\
\hline S.E. ${ }^{b}$ & 0.0091 & 0.11 & 3.81 \\
\hline Geometric mean ${ }^{\mathrm{c}}$ & 0.060 & 0.47 & 0.95 \\
\hline Distribution $^{\mathrm{d}}$ & No & No & No \\
\hline \multicolumn{4}{|c|}{ TA98 without metabolic activation $(N=449)$} \\
\hline$N$ & 125 & 219 & 105 \\
\hline Minimum & 0.00029 & 0.032 & 0.0020 \\
\hline Maximum & 0.50 & 46.8 & 288.35 \\
\hline Mean & 0.095 & 1.35 & 24.69 \\
\hline S.E. & 0.0092 & 0.30 & 5.91 \\
\hline Geometric mean & 0.057 & 0.43 & 0.77 \\
\hline Distribution & No & No & No \\
\hline \multicolumn{4}{|c|}{ TA100 with metabolic activation $(N=333)$} \\
\hline$N$ & 109 & 199 & 25 \\
\hline Minimum & 0.00078 & 0.047 & 0.016 \\
\hline Maximum & 1.04 & 6.72 & 925.11 \\
\hline Mean & 0.15 & 0.75 & 93.72 \\
\hline S.E. & 0.016 & 0.067 & 43.18 \\
\hline Geometric mean & 0.096 & 0.45 & 3.18 \\
\hline Distribution & No & Yes & Yes \\
\hline \multicolumn{4}{|c|}{ TA100 without metabolic activation $(N=262)$} \\
\hline$N$ & 92 & 157 & 15 \\
\hline Minimum & 0.0019 & 0.029 & 0.0075 \\
\hline Maximum & 0.64 & 4.89 & 259.00 \\
\hline Mean & 0.17 & 0.39 & 17.77 \\
\hline S.E. & 0.014 & 0.044 & 17.24 \\
\hline Geometric mean & 0.12 & 0.26 & 0.13 \\
\hline Distribution & No & Yes & $\mathrm{NA}^{\mathrm{e}}$ \\
\hline
\end{tabular}

${ }^{a}$ Data obtained using standard plate incorporation version of the Salmonella mutagenicity test on organic soil extracts. All values are mutagenic potency values expressed as Salmonella revertents per equivalent mg dry soil.

b Standard error of the mean.

${ }^{\mathrm{c}}$ Geometric mean.

${ }^{\mathrm{d}}$ Result of Shapiro-Wilk test for normality on log-transformed values. No indicates that the null hypothesis of normal distribution was rejected at $p<0.05$.

e Insufficient data for normality test.

difference between rural, urban, and industrial sites (geometric mean $=0.06,0.43$, and 0.77 revertents $/ \mathrm{mg}$, respectively). The $\mathrm{d} i *$ values revealed 37 significant outliers, 31 of which are industrial sites. More than a third $(39 \%)$ of these industrial sites yielded organic extracts with unexpectedly low potency values (i.e., below 0.03 revertents $/ \mathrm{mg}$ ). The remaining industrial outliers (i.e., 61\%) are those that yielded extremely potent extracts (e.g., above 30 revertents/mg). Eighteen of the 19 positive outliers are soils contaminated with munitions and explosive wastes studied by Donnelly et al. [54], Berthe-Corti et al. [65], and Griest et al. [158]. This may not be surprising since diand trinitrotoluenes and related compounds found in munitions contaminated soils (e.g., HMX and RDX) are known to be potent direct-acting frameshift 

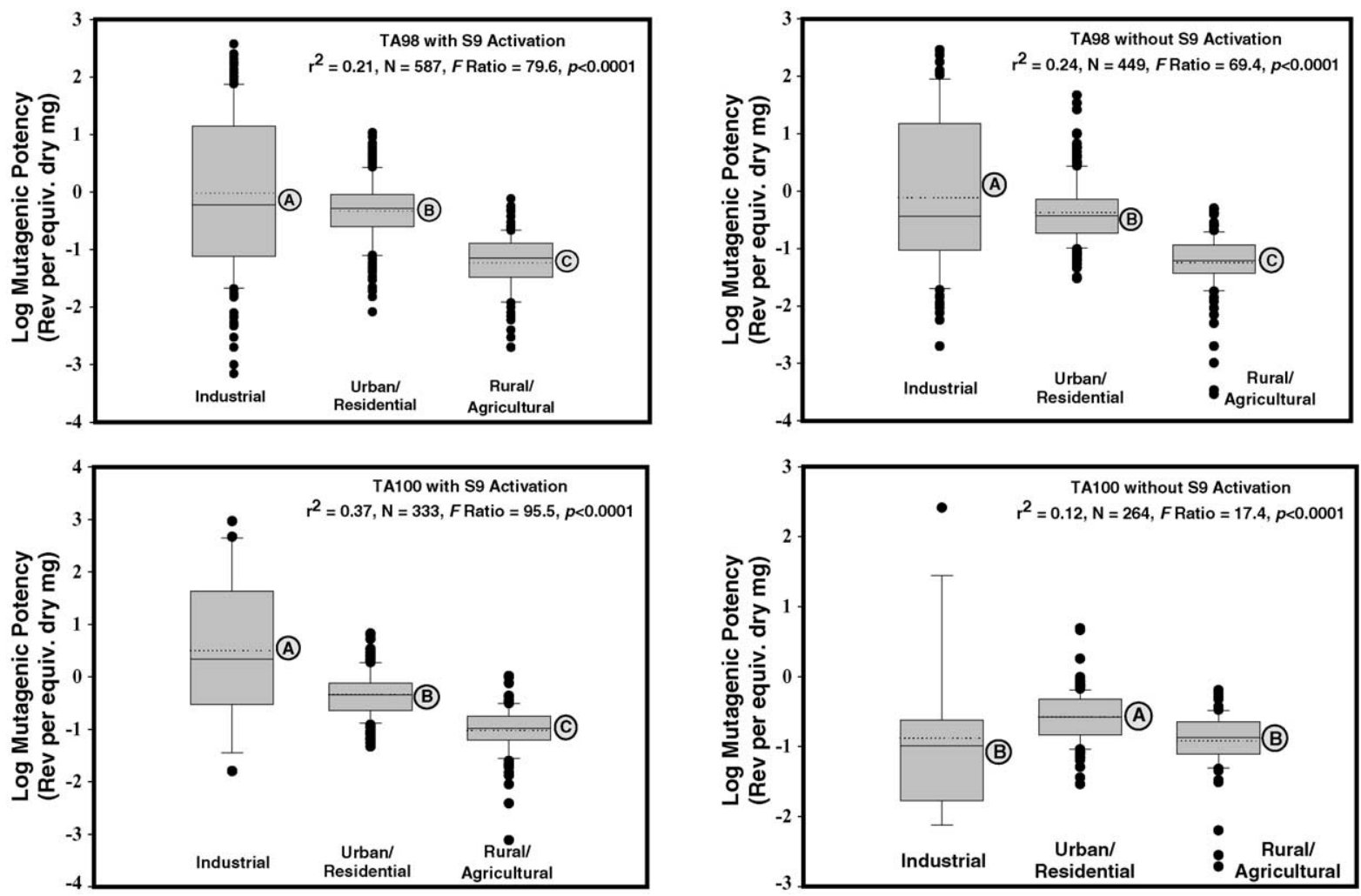

Fig. 3. Box plots of published Salmonella (TA98 and TA100) mutagenic potency values for organic extracts of soils collected from heavily contaminated, urban/industrial, and remote sites. From bottom to top, the horizontal solid lines in each box represent the 10th, 25th, 50th, 75th, and 90th percentiles of the distributions. The dotted horizontal line is the mean value. Suspected outliers are shown as dots. The overlayed text shows the results of the ANOVA analysis for site category effect. Boxes labeled with different letters are significantly different at $p<0.05$ (Duncan multiple range test [127]). Potency values were log transformed to meet the assumptions of least squares ANOVA. The number of observations in each site category is available in Table 5. The sources of all data are shown in Appendix A.

mutagens $[159,160]$. The remaining positive outlier is an extract of a soil sample experimentally treated with diesel oil [157]. Diesel fuel, a petroleum middle distillate composed of a complex mixture of alkanes, cycloalkanes and aromatic compounds in the $\mathrm{C}_{9}$ to $\mathrm{C}_{28}$ range, can contain high concentrations (5-10 wt.\%) of 3- to 7-ring aromatic compounds [161]. However, it should be noted that several separate studies noted that the Salmonella mutagenicity of diesel oil was found to be weak or equivocal [161-164], and it is not immediately obvious what components in a diesel oil treated soil could be responsible for a potent directacting response on TA98.

Three rural sites yielded extremely low potency values (e.g., $\geq 0.001$ revertents $/ \mathrm{mg}$ ) that were significant negative outliers. These are reference soils used in numerous studies of contaminated soils, amended soils, and remediated soils conducted by researchers at Texas A\&M University [40,42,48, $49,165,166]$. The three remaining outliers are urban sites in Japan that yielded highly potent samples and large positive residuals (e.g., Hekinan). These sites are known to be contaminated with combustion related dinitropyrenes (e.g. 1,3-1,6- and 1,8-dinitropyrenes) that account for $18-51 \%$ of the observed direct acting TA98 mutagenicity [52,53].

Fig. 3 (bottom left) contains a box plot that illustrates the distribution of the log transformed Salmonella TA100 results obtained in the presence of S9 metabolic activation $(N=333)$. The ANOVA revealed a significant relationship between site category and mutagenic potency $(p<0.0001)$, and 
a significant difference between rural, urban, and industrial sites (geometric mean $=0.096,0.46$, and 3.2 revertents/mg, respectively). The $\mathrm{d} i *$ values revealed 15 significant outliers including eleven industrial, two urban, and two rural/agricultural sites. Five of the industrial outliers as well as the two rural outliers yielded low potency values and were significant negative outliers. The two rural outliers are the aforementioned reference soils used by researchers at Texas A\&M University. Four of the five negative outliers from industrial sites are samples collected in the vicinity of a carbon electrode production facility. The authors of the study [63] describe the area as "a contaminated area in Lombardy, near a factory for carbon electrode production" and the sampling site as "highly contaminated" with PAHs. Nevertheless, cyclohexane/acetone extracts from the collected samples yielded low mutagenic potency values. The fifth outlier is a weak extract of an agricultural soil treated with industrial and domestic wastewaters [60].

The remaining eight outliers were all significant positive outliers, six industrial and two urban. The two urban samples were collected from highly urban sites located in the Aishi and Hokkaido prefectures of Japan (e.g., Hekinan, Muroran) [53]. More specifically, regions previously recognized for contamination by atmospheric mutagens (e.g., PAHs, DNPs) from gasoline and diesel powered vehicles [50-52]. The six industrial outliers yielded potency values between 87 and 925 revertents/mg associated with extracts of six soils contaminated by petrochemical or wood preserving wastes [49], and one extract of an explosive contaminated soil [158].

Fig. 3 (bottom right) contains a box plot that illustrates the distribution of the $\log$ transformed Salmonella TA100 results obtained in the absence of S9 metabolic activation $(N=264)$. The ANOVA reveals a significant relationship between site category and mutagenic potency $(p<0.0001)$, and a significant difference between rural and urban sites, and urban and industrial sites (geometric mean $=0.12,0.26$, and 0.13 revertents/mg for rural, urban, and industrial sites). However, despite industrial potency values greater than 200 revertents/mg for an explosive contaminated soil [158], the results did not reveal a significant difference between rural and industrial sites. This is most likely caused by the paucity of industrial data, combined with the large range and skewed nature of the industrial data (e.g., 8 of the industrial potency values are $<0.01$ revertents $/ \mathrm{mg}$ ). The $\mathrm{d} i^{*}$ values revealed 12 significant outliers, including 6 of the 13 industrial sites, 3 urban sites, and 3 rural sites. All three rural sites yielded low potency values (e.g., $<0.01$ revertents $/ \mathrm{mg}$ ) that were significant negative outliers. All four of the industrial sites that yielded negative outliers, were samples collected in the vicinity of the aforementioned carbon electrode production facility [63]. Both of the industrial soils that yielded significant positive outliers are soils contaminated with explosive residues or munitions wastes that elicited potency values between 6 and 259 revertents/mg [65,158]. Again, these elevated potency values are presumably related to the potent direct-acting activity of munitions compounds (e.g., TNT and related compounds) on both TA98 and TA100 [159,160].

The three urban outliers include one negative outlier from a public park in Japan [53], and the two positive outliers are heavily urbanized sites in Japan and Germany $[51,53,116]$. One of the latter sites is the same positive outlier identified in the analyses of TA100 S9-activated results (i.e., Hekinan, Aishi Prefecture).

The geometric mean Salmonella mutagenicity results for each site category (Table 7) indicate that sites unimpacted by urban or industrial emissions may be expected to yield positive Salmonella mutagenicity responses with mean TA98 potency values of roughly 0.06 revertents $/ \mathrm{mg}$ and mean TA100 potency values of roughly 0.1 revertents $/ \mathrm{mg}$. These values are in agreement with several "background" soil mutagenicity values noted in the literature. Jones and Peace [39] stated that the natural background level of Salmonella mutagenicity in soil can be expected to be less than 0.1 revertents/mg. In their study of DCM extracts of

Table 7

Geometric mean Salmonella mutagenicity values ${ }^{\mathrm{a}}$

\begin{tabular}{lcll}
\hline & \multicolumn{3}{l}{ Category } \\
\cline { 2 - 4 } & Rural & Urban/suburban & Industrial \\
\hline TA98 with S9 & $0.06 \pm 0.005$ & $0.47 \pm 0.05$ & $0.95 \pm 0.17$ \\
TA98 without S9 & $0.057 \pm 0.006$ & $0.43 \pm 0.10$ & $0.77 \pm 0.18$ \\
TA100 with S9 & $0.096 \pm 0.01$ & $0.46 \pm 0.04$ & $3.18 \pm 1.46$ \\
TA100 without S9 & $0.12 \pm 0.01$ & $0.26 \pm 0.03$ & $0.13 \pm 0.13$ \\
\hline \multicolumn{2}{c}{${ }^{2}$ Salmonella revertents per equivalent mg dry soil \pm standard } \\
error.
\end{tabular}


Welsh soils they observed $0.006-0.019$ revertents/mg for TA98 and 0.024-0.038 revertents $/ \mathrm{mg}$ for TA100. A study by Donnelly et al. [114] of an abandoned solvent recovery site indicated that TA98 mutagenicity values for "background" soils are less than 0.02 revertents/ $\mathrm{mg}$ (without S9). Jones and Page [167] further assert that values in the 1.0 to 1.5 revertents $/ \mathrm{mg}$ could be a "trigger" for identifying contaminated, potentially hazardous soils that are worthy of concern. This value is in agreement with the more rigorously determined geometric mean values for urban/suburban and industrial soils summarized in Table 7 (i.e., 0.290.43 revertents $/ \mathrm{mg}$ for urban sites and $0.81-4.0$ revertents/mg for industrial sites).

\subsection{Relationships between Salmonella mutagenicity and extraction solvent}

The abundance of TA98 mutagenicity data permitted an examination of the effect of extraction solvent on the mutagenic potency of soil extracts. Two-way ANOVA was conducted on the direct-acting data $(N=392)$ to investigate a site category effect, an extraction solvent effect (DCM, MetOH, acetone/ hexane only), and a solvent-site interaction (i.e., an extraction solvent effect that differs with respect to site category). The results revealed a significant solvent effect $(p<0.005)$ and a significant solvent-site interaction $(p<0.005)$. Post-hoc examination of the mean values for each ANOVA cell indicated that for industrial soils DCM extracts are almost twice as potent as MetOH extracts. Conversely, for rural/ agricultural soils, the results suggest that $\mathrm{MetOH}$ and acetone/hexane extracts are an order of magnitude more potent than DCM extracts. Two-way ANOVA of the S9-activated values $(N=511)$ failed to reveal a significant solvent (DCM, MetOH, acetone/hexane only) effect, but revealed a significant $(p<0.0001)$ solvent-site interaction. Post-hoc analyses of the mean values indicated that DCM extracts of industrial and urban soils are more than seven-fold more potent than their respective MetOH extracts, but the differences between mean values for rural/agricultural soils are negligible.

Despite the fact that the TA100 data set is considerably smaller than the TA98 data set, twoway ANOVA was also used to investigate extraction solvent effects (DCM, acetone/hexane, MetOH) and solvent-site interactions (S9-activated only). The results obtained $(N=306)$ revealed a marginal solvent effect $(p<0.02)$, and a significant site-solvent interaction $(p<0.0001)$. Again, post-hoc analyses of mean values suggest that the S9-activated mutagens extracted from industrial soils are considerably more soluble in DCM. Comparison of mean values showed that the average potency of DCM extracts from industrial soils are more than 20-fold greater than acetone/hexane extracts. Conversely, post-hoc analyses of the rural/agricultural data suggest that mutagens in these soils are soluble in more polar solvents such as MetOH. Examination of these mean values showed that $\mathrm{MetOH}$ extracts are, on average, more than two-fold more potent than DCM extracts. Unfortunately, limitations in the data did not permit more detailed analyses (i.e., study-specific) of the S9activated TA 100 potency values or similar analyses for the direct-acting TA100 data.

Although these results are interesting, and suggest that organic mutagens in contaminated industrial soils are lipophilic, the results are clearly biased by unbalanced ANOVA cell sizes, and variability in solvent choice across different studies examining very different sites. For example, DeMarini et al. [41] examined DCM extracts of PCB contaminated soil and recorded TA98 (with S9) mutagenic potency values of $0.1-0.2$ reverants $/ \mathrm{mg}$ dry soil. In contrast, McDaniels et al. [46] examined cyclohexane extracts of Superfund soils and recorded mutagenic potency values that are two orders of magnitude greater than those of DeMarini et al. Inference that cyclohexane extracts are generally more potent than DCM extracts would be misleading. A robust investigation of an extraction solvent effect requires matched mutagenic potency values (i.e., two or more extracts of subsamples of a single soil). Several studies (e.g., [46,47]) contain the data required for a balanced ANOVA investigating an extraction solvent effect. The results obtained, summarized in Table 8, indicate that only four of the twelve studies examined reveal a significant extraction solvent effect. These studyspecific results indicate that the less polar extraction solvents (e.g., cyclohexane, DCM) tended to provide more potent samples than the more polar solvents (e.g., MetOH). This assertion is in agreement with the aforementioned results based on the S9-activated TA98 data. Additional analysis of industrial values 
Table 8

Effect of soil extraction solvent on Salmonella TA98 mutagenicity

\begin{tabular}{|c|c|c|c|c|}
\hline Data & Extraction solvents & $N$ & $F$-ratio & Significance \\
\hline \multicolumn{5}{|l|}{ TA98 without S9 } \\
\hline All industrial sites & DCM, MetOH & 79 & 0.61 & No \\
\hline Abandoned solvent recovery site [114] & DCM, MetOH & 10 & 0.54 & No \\
\hline Munitions contaminated soils [54] & DCM, MetOH & 28 & 1.48 & No \\
\hline Abandoned chemical manufacturing site [47] & DCM, MetOH & 12 & 0.53 & No \\
\hline Soils amended with sewage sludge [156] & DCM, $\mathrm{MetOH}^{\mathrm{a}}$ & 12 & 5.54 & Yes $^{*}$ \\
\hline All rural/agricultural sites & $\mathrm{DCM}, \mathrm{MetOH}, \mathrm{Ac} / \mathrm{Hex}^{\mathrm{b}}$ & 118 & 21.27 & Yes $^{* * * *}$ \\
\hline \multicolumn{5}{|l|}{ TA98 with S9 } \\
\hline All industrial sites & DCM, MetOH, Cyclohex, Ac/Hex ${ }^{\mathrm{c}}$ & 167 & 5.20 & Yes $^{* *}$ \\
\hline Industrial sites (DCM, MetOH only) & DCM, MetOH ${ }^{\mathrm{d}}$ & 163 & 10.09 & Yes $^{* *}$ \\
\hline Abandoned wood preserving facility [115] & $\mathrm{DCM}, \mathrm{MetOH}^{\mathrm{e}}$ & 24 & 4.49 & Yes $^{*}$ \\
\hline Superfund sites (unspecified) [46] & DCM, Cyclohex ${ }^{\mathrm{f}}$ & 14 & 12.64 & Yes $^{* *}$ \\
\hline Munitions contaminated soils [54] & DCM, MetOH & 28 & 0.14 & No \\
\hline Hazardous waste dump site [117] & $\mathrm{DCM}, \mathrm{MetOH}$ & 12 & 0.23 & No \\
\hline Abandoned coal gasification site [118] & DCM, $\mathrm{MetOH}^{\mathrm{g}}$ & 28 & 8.45 & Yes $^{* *}$ \\
\hline Abandoned chemical manufacturing site [47] & $\mathrm{DCM}, \mathrm{MetOH}$ & 12 & 0.49 & No \\
\hline Soils amended with sewage sludge [156] & DCM, MetOH & 12 & 0.08 & No \\
\hline Hazardous waste landfill [423] & DCM, Ac/Hex & 6 & 0.21 & No \\
\hline All urban/residential sites & DCM, Ac/Hex, $\mathrm{MetOH}^{\mathrm{h}}$ & 214 & 47.18 & Yes $^{* * * *}$ \\
\hline All rural/agricultural sites & DCM, MetOH, Ac/Hex ${ }^{\mathrm{i}}$ & 130 & 12.46 & $\mathrm{Yes}^{* * * *}$ \\
\hline
\end{tabular}

${ }^{\mathrm{a}} \mathrm{DCM}>\mathrm{MetOH}$.

${ }^{\mathrm{b}} \mathrm{Ac} / \mathrm{Hex}>\mathrm{MetOH}>\mathrm{DCM}$.

${ }^{\mathrm{c}} \mathrm{DCM}>\mathrm{Ac} / \mathrm{Hex}>\mathrm{MetOH}$.

${ }^{\mathrm{d}} \mathrm{DCM}>\mathrm{MetOH}$.

e $\mathrm{DCM}>\mathrm{MetOH}$.

${ }^{\mathrm{f}}$ Cyclohex $>$ DCM.

g $\mathrm{DCM}>\mathrm{MetOH}$.

${ }^{\mathrm{h}} \mathrm{MetOH}>\mathrm{DCM}>\mathrm{Ac} / \mathrm{Hex}$.

${ }^{i} \mathrm{Ac} / \mathrm{Hex} />\mathrm{MetOH}>\mathrm{DCM}$.

${ }^{*} p<0.05$.

*** $p<0.01$.

**** $p<0.001$.

alone failed to reveal a significant solvent effect without S9, but revealed a significant effect with S9. The latter analysis indicated that less polar solvent such as DCM are more effective at extracting TA98 mutagens that require $\mathrm{S} 9$ activation from soils collected at industrial sites.

Although based on limited data, the results presented in Table 8 also suggest that the more polar solvents such as MetOH preferentially extract mutagens (TA98 with and without S9) from rural/ agricultural (i.e., non-industrial) soils. Again, this is in agreement with the aforementioned analyses conducted on the entire set of TA98 data. Although the results also suggest that MetOH may be more effective at extracting mutagens (TA98 with S9) from urban soils, these results are biased by fact that most of the urban data $(>80 \%)$ was obtained from Japanese assessments of MetOH extracts from contaminated urban soils.

\subsection{Relationships between Salmonella mutagenicity and soil contamination}

Several studies that employed the Salmonella mutagenicity assay also examined levels of selected contaminants previously shown to possess genotoxic activity. Studies that examined soils collected from industrial or urban areas frequently measured levels of homocyclic PAHs, the products of high-temperature combustion, including several known mutagens and 
animal carcinogens (e.g., benzo $[a]$ pyrene, $\operatorname{dibenz}[a-$ $h$ ]anthracene). Sources of these PAHs include industrial emissions (e.g., steel founding, coking), mobile source emissions (e.g., automobile), and natural emissions (e.g., forest fires, volcanoes). Three studies measured levels of dinitropyrenes, a group of compounds that include some of the most potent bacterial mutagens ever examined, which are emitted from heavy- and light-duty diesel vehicles including automobiles, trucks and rail locomotives.

Empirical analyses showed a weak but significant relationship between TA98 potency with $\mathrm{S} 9$ activation and soil PAH concentration $\left(r^{2}=0.17, p<0.0001\right)$. Since PAHs are hydrophobic compounds that are usually extracted from dry soil samples using a nonpolar solvent or solvent mixture such as hexane or hexane/acetone [168-170], it is not surprising that the strength of this relationship was significantly improved when $\mathrm{MetOH}$ extract values were excluded $\left(\mathrm{r}^{2}=0.25, p<0.0001\right)$. Despite the statistical significance of these relationships, illustrated in Fig. 4, it appears that the measured PAHs can only account for $17-25 \%$ of the variability in the S9-activated frameshift activity of soil extracts. Additional multiple regression analyses investigated the relationship between S9-activated TA98 mutagenic potency and the concentrations of individual PAHs. Despite a high degree of multicollinearity in the PAH data (e.g., average Pearson $r=0.91$ ) that can complicate multiple regression analysis [126], stepwise regression analyses (e.g., Mallow's $C_{\mathrm{p}}$ or Max $R$ selection. [127]) revealed a number of significant models. Using all TA98 data the highest $\mathrm{R}^{2}$ was associated with a model of mutagenic potency against soil concentrations of fluoranthene and benzo[ $a]$ pyrene $\left(R^{2}=0.23\right.$, $F$-ratio $=8.46, p<0.0007)$. When MetOH extract values were excluded, the results revealed a strong empirical relationship between TA98 mutagenic potency and soil concentrations of pyrene, benz $[a]$ anthracene, and benzo[ $k]$ fluoranthene $\left(R^{2}=0.52, F\right.$ ratio $=14.6, p<0.0001)$. Examination of the standardized (i.e., unit-independent) regression coefficients, also referred to as beta coefficients, from the aforementioned models suggest that the concentration of individual PAHs would tend to over predict mutagenic potency values relative to predictions based on the concentration of the PAH mixture (i.e., total PAH). This seems reasonable since competition
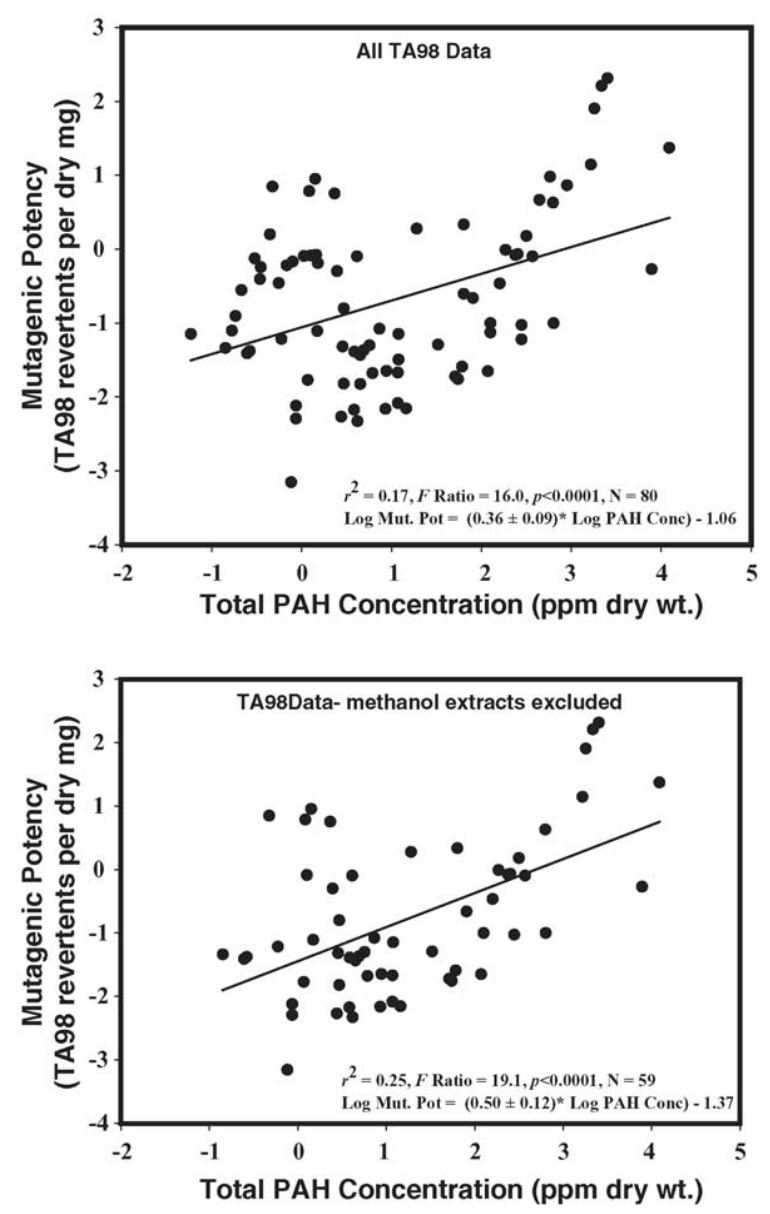

Fig. 4. Empirical relationship between the S9-activated Salmonella TA98 mutagenic potency of soil extracts and soil PAH contamination (ppm dry weight). All values were log transformed to meet the assumptions of least-squares regression. The overlaid information shows the results of the linear regression analyses. All values are from published soil mutagenicity assessments (see Appendix A). Four observations represent mutation induction in Pseudomonas putida by extracts of coal tar amended soil [90] (see Table 11). The upper panel includes all available data. The lower panel does not include the results of methanol extracts. Minimum, maximum, and mean PAH contamination values are summarized in Table 4.

for microsomal enzymes is thought to contribute to a decrease in the mutagenic potency of PAH mixtures such that they are below what would be expected if the total mixture mutagenicity was simply the sum of that expected from the mixture components [87]. Although it is tempting to draw additional conclusions from the beta coefficients, the high degree of multicollinearity suggests cautious interpretation [126]. 


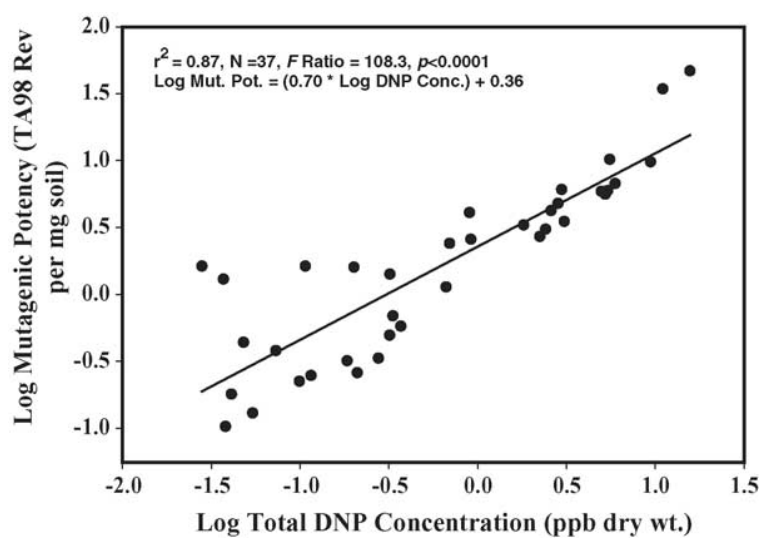

Fig. 5. Empirical relationship between the direct-acting Salmonella TA98 mutagenic potency of soil extracts and DNP (dinitropyerene) contamination (ppb dry weight). The DNP contamination value represents the sum of 1,3-, 1,6- and 1,8-dinitropyrene. All values were $\log$ transformed to meet the assumptions of least-squares regression. The overlaid information shows the results of the linear regression analyses. All data were collected from Watanabe et al. [50,51,124] and Goto et al. [53] (see Appendix A). Minimum, maximum, and mean values for DNP contamination are summarized in Table 4.

Similar analyses revealed a strong empirical relationship between TA 98 direct-acting mutagenic potency and the soil concentration of dinitropyrenes $\left(r^{2}=0.87, p<0.0001\right)$. In contrast to the relationship between PAH concentration and S9-activated frameshift activity, this relationship (Fig. 5) reveals that the direct-acting frameshift activity of urban soil extracts is largely determined by dinitropyrene contamination. However, it should be noted that all of the observations included in this analysis were obtained from Japanese publications and the relationship may not be generally applicable. One might expect the strength of this relationship to be dependant on traffic density, the proportion of diesel vehicles, and emission control strategies employed in the soil collection area.

\subsection{Mutagenic activity detected using other Salmonella strains}

Several recent studies employed metabolically enhanced strains of Salmonella (e.g., YG1021, YG1024, YG1026, YG1029) to examine the mutagenicity of soil extracts. These strains possess enhanced or reduced levels of enzymes required to metabolize specific classes of chemical mutagens such as aromatic amines and nitroarenes. The studies summarized in Table 9 employed a variety of metabolically enhanced strains that can assist in the identification of putative mutagens in complex environmental extracts. For example, strains YG1021 and YG1026 are TA98 and TA100 derived strains, respectively, which possess elevated classical nitroreductase (Cnr) activity that dramatically increases their ability to detect some nitroarenes including 1-nitropyrene, 2,6-dinitrotoluene, and 2,4,6-trinitrotoluene [171,172]. Strains YG1024 an YG1029 are TA98 and TA100 derived strains that possess elevated $O$-acetyltransferase (OAT) activity that dramatically enhances their ability to detect samples containing direct-acting dinitroarenes such as 1,8-dinitropyrene and S9-activated aromatic amines such as 2-aminofluorene and 2-aminoanthracene [173]. In addition, several mutant strains of TA98 have been constructed that lack nitroreductase (i.e., TA98NR) or $O$-acetyltransferase activity (i.e., TA98/ $1,8-\mathrm{DNP}_{6}$ ). When used in conjunction with the parent strains, these strains also permit the identification of complex samples containing aromatic amines and/or nitroarenes.

The results summarized in Table 9 indicate that nitroarenes make a major contribution to the mutagenic activity detected in extracts of urban soils collected in Japan and Germany [116,124]. Wesp et al. [116] and Watanabe et al. [124] used metabolically enhanced strains of TA98 and TA100 to determine that polar aromatics such as nitroarenes make a major contribution to the mutagenicity of soils collected from highly urbanized sites (e.g., Mainz-Finthen motorway, Kinki and Kanto megalopolises) that receive heavy automobile traffic. The results obtained using TA989NR and TA98/1,8-DNP 6 to investigate the direct acting activity of extracts from nonagricultural soils collected in and around Livermore, California (population $~ 73,000$ ) suggest that these soils are also contaminated by nitroarenes [58]. Moreover, the mean TA98 potency value for these soils of $0.17 \pm 0.03$ reverants $/ \mathrm{mg}$ is significantly greater than the geometric mean TA98 potency for all rural sites examined (i.e., $0.057 \pm 0.002$ ). This may not be surprising since some researchers have cited airborne anthropogenic emissions as a major source of soil mutagens [116], and the city of Livermore is located predominantly downwind of the San Francisco-Oakland area (population $\sim 1,068,000$ ). 
Table 9

Soil mutagenicity results obtained using metabolically enhanced strains of Salmonella

\begin{tabular}{lll}
\hline Sample(s) examined & Salmonella strains employed & Results obtained \\
\hline $\begin{array}{c}\text { MetOH extracts of soils from } \\
\text { urban locations in Japan }\end{array}$ & TA98 derived strains YG1021 ${ }^{\mathrm{a}}$, & Marked reduction in direct-acting \\
mutagenicity on TA98/1,8-DNP & Reference \\
Moderate increase on YG1021. \\
Marked increase on YG1024
\end{tabular}

DCM extract of creosote contaminated soil

DCM extract of creosote contaminated soi

Thirteen soils collected from a variety of contaminated sites

Soils exposed to traffic exhaust (German Autobahnen) for up to 26 weeks

Roadside soils collected at 13 locations in Kurume City (Japan)

ACN extract of non-agricultural soils
TA98 derived YG1041 $1^{\mathrm{e}}$ and TA98NR, and TA100 derived YG1042 ${ }^{\mathrm{f}}$

TA98 derived $\mathrm{YG} 1041^{\mathrm{e}}$ and TA98NR,

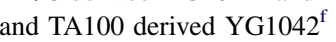

uти test in Salmonella typhimurium NM2009

TA98 derived strains YG1021, YG1024, TA98NR, and TA100 derived strains YG1026 $^{\mathrm{h}}$ and YG1029 ${ }^{\mathrm{i}}$

TA98 derived strain YG1041, TA100 derived strains YG1042, TA1535 derived strain YG7108, and TA102 derived strain $\mathrm{YG}_{3003^{\mathrm{k}}}$

TA98 derived strains TA98NR and TA98-1,8- DNP $_{6}$, and TA100 derived TA100NR

Marked reduction in direct-acting

mutagenicity on TA98NR. Some sample show elevated mutagenicity on YG1041 and YG1042 without S9

Detailed fractionation indicated that putative mutagens include azaarenes

Enhanced direct-acting activity in extracts of TNT contaminated soils and coking plant soils

Response pattern in Salmonella strains to the polar aromatic fraction indicates a major contribution by nitroarenes

No responses in repair deficient YG3003 and YG7108. Substantial increases on

YG1041 and YG1042 indicative of nitroarenes and/or aromatic amines

Marked reduction in activity mutagenicity on TA98NR, TA100NR, and TA98-1,8-DNP6

without activation

a TA98 (hisD3052 TA1538 + pKM101) with classical nitroreductase on plasmid pYG216 [456]

b TA98 with $O$-acetyl transferase on plasmid pYG219 [457].

c TA98 lacking classical nitroreductase activity [458]

d TA98 lacking $O$-acetyl transferase activity [459].

e TA98 with classical nitroreductase and $O$-acetyl transferase on plasmid pYG233 [460].

f TA100 (hisG46 TA1535 + pKM101) with classical nitroreductase and $O$-acetyl transferase on plasmid pYG233 [460].

TA1535/pSK1002 with pNM12 (enhanced $O$-acetyl transferase activity) [461].

h TA100 (hisG46 TA1535 + pKM101) with classical nitroreductase on plasmid pYG216 [456].

i TA100 (hisG46 TA1535 + pKM101) with $O$-acetyl transferase on plasmid pYG219 [457].

${ }^{3}$ TA1535 (hisG46) lacking $\mathrm{O}^{6}$-methylguanine DNA methyltransferases [462].

${ }^{\mathrm{k}}$ Repair deficient version of TA102 (hisG428) [463].

${ }^{1}$ TA100 lacking classical nitroreductase activity [458]. 
Tsukatani et al. [122] also employed a variety of specially designed TA98 and TA100 derivatives to investigate the mutagenicity of $\mathrm{MetOH}$ extracts from urban soils in Japan. Strains YG3003 and YG7108, which have enhanced sensitivity to oxidative mutagens and alkylating agents, respectively, showed no mutagenic responses. However, extracts of samples collected on roadway medians or adjacent to intersections showed enhanced responses, both with and without S9, on the OAT and Cnr enhanced TA98 and TA100 derivatives YG1041 and YG1042. The 4to 90-fold increase on YG1041 relative to TA98, and the 6- to 77-fold increase on YG1042 relative to TA100, confirm the involvement of both nitroarenes and aromatic amines in the observed mutagenic responses.

Additional studies employing metabolically enhanced strains of Salmonella include the analyses of extracts of creosote-contaminated soils by Hughes et al. [44] and Brooks et al. [22], as well as analyses of extracts of explosive-contaminated soils by Ehrlichmann et al. [174]. All three studies indicate that the putative mutagens in these samples include nitrogen heterocyclics, aromatic amines, and nitroarenes.

\subsection{Miscellaneous Salmonella mutagenicity data}

Table 10 summarizes the results of 14 studies that were not used in the data analyses described in Section 6 [38,44,60,62,147-149,151,153,154,175-178]. Thirteen of the listed studies did not contain the information required to calculate mutagenic potency and/or express potency in revertents per equivalent dry weight of soil. Most of these studies expressed the results as Salmonella revertents per unit of extractable organic matter (EOM in $\mu \mathrm{g}$ or mg per plate). Although this is perfectly reasonable for studies that are employing bioassay-directed fractionation to isolate and identify the putative mutagens, it does not permit cross-study comparisons of soils from different areas. Conversion from revertents per unit EOM to revertents per weight of soil requires the yield of EOM per unit weight of soil. Only a sub-set of published studies actually include this value (e.g., residue $\mathrm{mg} / \mathrm{mg}$ soil $[42,48,54,115,165,166,179])$. Readers should be aware that some researchers employing the Salmonella assay for examinations of soil extracts use the term specific activity to refer to mutagenic potency in revertents/mg EOM, and weighted activity to refer to mutagenic potency in revertents per unit weight of soil (e.g., $[42,48,56,64,114,115,117,118,165,166,179])$.

Although potency values in revertents/mg dry weight were not available in these studies, and could not be calculated using the published information, the results described are consistent with the aforementioned data analyses. Those studies that examined extracts of heavily contaminated (e.g., Superfund) soil detected potent mutagenic activity $[38,44,147,148$, $151,153,177]$. In addition, strong activity on TA98 with S9 generally corresponds to extracts of soils known to be contaminated with PAHs or waste materials that are likely to contain PAHs $[38,147$, $151,153,177]$. It is interesting to note that the study by Meloni et al. of an area described as a highly contaminated waste disposal site in the province of Padua did not detect any mutagenic activity (TA100 and TA98 without S9) in acetone and cyclohexane extracts [178]. Rather, they detected significant directacting frameshift mutagenicity in the acetone extract of the uncontaminated control soil.

One study contained TA98 and TA100 results that were included in the data analyses. However, the study also employed additional Salmonella strains that are not commonly used for the assessment of soils and soil extracts (i.e., TA97a, TA102, TA104) [60]. The results obtained revealed a significant response on TA97a, a frameshift strain that carries a +1 frameshift at a run of cytosines (i.e., hisD6610) [33]. This strain, known to be more effective for the detection of metals and some quinones, is sometimes used to supplement TA98 $[134,180]$. No significant responses were obtained on strains TA102 and TA104, strains with an AT-rich mutation target (i.e., hisG428) that are effective at detecting cross-linking agents such as mitomycin C [33].

\section{Other prokaryote or molecular in vitro assays used for soil genotoxicity assessment}

A number of studies have employed less popular prokaryotic assays for soil extract genotoxicity assessment. These include the SOS Chromotest, the $\mathrm{rec}^{-}$differential survival assay in Bacillus subtilus, the Microscreen phage induction assay, and the Mutatox ${ }^{\circledR}$ assay. Table 11 summarizes published soil 
Table 10

Published Salmonella mutagenicity results not used for detailed data analyses ${ }^{\mathrm{a}}$

\begin{tabular}{lll}
\hline Site(s) examined & Strains employed & Results obtained \\
\hline $\begin{array}{l}\text { Soils amended with motor oil } \\
\text { Soils (2) from coke production area }\end{array}$ & TA1535 and TA1537 on aqueous extracts & Detectable frameshift mutagenicity (-S9) in all samples \\
$\quad$ (600-800 ppm PAHs). & TA98 on DCM extracts & Significant frameshift activity with S9 \\
$\begin{array}{l}\text { Soils (3) contaminated by engine oils or } \\
\text { pesticides (2-20 ppm PAHs) }\end{array}$ & $\begin{array}{l}\text { TA98 and TA100 on DCM or } \\
\text { acetone extracts }\end{array}$ & $\begin{array}{l}\text { Significant frameshift activity (-S9 and +S9). } \\
\text { Significant base-pair activity without S9 }\end{array}$
\end{tabular}

Creosote contaminated soil (Superfund) TA98 and TA100 on DCM extracts

Petroleum contaminated soils (Tatarstan Republic, Russia)

Soils contaminated with petroleum refinery effluent (Tatarstan Republic, Russia)

Soils (2) contaminated with petrochemical wastes

Creosote (1) and petroleum contaminated (4) soils

Soils from industrial (22) and non-industrial (30) sites

Surface impoundment contaminated with wood-preserving wastes

Soil (waveland fine sand) column $(25 \mathrm{~cm})$ treated with a mutagenic $(\mathrm{TA} 98+$ S9) sludge extract

Salmonella TA98 and TA100

mutagenicity on aqueous extracts

Salmonella TA98 and TA100

mutagenicity on aqueous extracts

Salmonella TA98 and TA100

mutagenicity on ethyl ether/MetOH extracts

TA98 and TA100 on silica/alumina fractionated DCM extracts

Significant base-pair activity without $\mathrm{S} 9$

Extracts of untreated waste positive on TA100 without S9 [44]

Positive responses (both strains) enhanced by S9 activation [150]

No significant positive response

No significant positive response

Significant frameshift activity from polycyclic aromatic fractions (+S9) and polar fractions $(-\mathrm{S} 9)$

Salmonella TA98 and TA100 mutagenicity

on DCM/acetone extracts

$91 \%$ of the industrial sites, $33 \%$ of the non-industrial sites yield positive response (predominantly TA98 + S9)

Salmonella TA98 and TA100 on a crude extract (hexane/acetone, and DCM) and several fractions

Salmonella TA98 mutagenicity on aqueous leachates and acetone/hexane extracts

Basic extract elicited significant positive responses

in TA98 and TA100 + S9. Alumina fraction A2

elicited a strong response on TA98 + S9

Acidic leachates showed mutagenic activity (+S9).

Weak activity $(+\mathrm{S} 9)$ in organic extracts of

column soil (top $7 \mathrm{~cm}$ )

Salmonella TA97a, TA102 and TA104 on

Composite soil from agricultural fields irrigated with industrial and domestic wastewaters (Aligarh City, India)

Soil samples from oil fields in Kuwait $\mathrm{MetOH}$, acetone, and ACN extracts

Significant positive responses for all extracts on TA97a (with and without S9). Slight dose-related increases (not significant) for TA102 and TA104

Salmonella TA98 and TA100 on DCM extracts

No significant positive response despite detection of aromatics including benzo $[a]$ pyrene

Salmonella TA98 and TA100 (without S9) on cyclohexane and acetone extracts

Salmonella TA98 on DCM/MetOH extracts

Significant positive response only for acetone extract of control (uncontaminated) soil

Significant positive response with S9 (30\%, v/v in S9 mixture)

Greater direct-acting activity (per unit volume of extract) associated with solid fraction 
Table 11

Miscellaneous soil mutagenicity results - bacterial and molecular in vitro assay systems

\begin{tabular}{|c|c|c|c|}
\hline Site(s) examined & Bioassay employed & Results obtained & Reference \\
\hline $\begin{array}{l}\text { Storm-water runoff impoundment } \\
\text { (SWRI) waste }\end{array}$ & $\begin{array}{l}\text { Differential survival assay in } \mathrm{rec}^{-} \text {Bacillus } \\
\text { subtilus on DCM extracts }\end{array}$ & $\begin{array}{l}\text { Marginal genotoxicity with } \mathrm{S} 9 \\
\text { activation }(<2 \text { times background })\end{array}$ & {$[49,166]$} \\
\hline $\begin{array}{l}\text { Combined } \mathrm{API}^{\mathrm{b}} \text { separator sludge } \\
\text { and slop-oil emulsion solids }\end{array}$ & $\begin{array}{l}\text { Differential survival assay in } \text { rec }^{-} \text {Bacillus } \\
\text { subtilus on DCM extracts }\end{array}$ & $\begin{array}{l}\text { Moderate genotoxicity in acid fraction } \\
\text { with S9 activation }(<5 \text { times background })\end{array}$ & {$[49,166]$} \\
\hline $\begin{array}{l}\text { Wood-preserving bottom sediment } \\
\quad{\text { (surface impoundment })^{c}}^{c}\end{array}$ & $\begin{array}{l}\text { Differential survival assay in } \mathrm{rec}^{-} \text {Bacillus } \\
\text { subtilus on DCM extracts }\end{array}$ & $\begin{array}{l}\text { Positive response on acid fraction with } \\
\text { S9 activation. Approximately } 10 \text {-fold lower } \\
\text { survival in } r e c \text { deficient strains }\end{array}$ & {$[49,146]$} \\
\hline $\begin{array}{l}\text { Soils ( } 2 \text { ) contaminated with } \\
\text { petrochemical wastes }\end{array}$ & $\begin{array}{l}\text { Differential survival assay in } \mathrm{rec}^{-} \text {Bacillus } \\
\text { subtilus exposed to ethyl ether/MetOH extracts }\end{array}$ & $\begin{array}{l}\text { Positive (direct-acting) response } \\
\text { for one extract }\end{array}$ & {$[62]$} \\
\hline $\begin{array}{l}\text { Composite soil from agricultural } \\
\text { fields irrigated with industrial and } \\
\text { domestic wastewaters (Aligarh City, India) }\end{array}$ & $\begin{array}{l}\text { Differential survival in } r e c \mathrm{~A}, \operatorname{lex} \mathrm{A}, \text { polA } \\
\text { mutants of } E \text {. coli } \mathrm{K}-12 \text { exposed to } \mathrm{MetOH} \text {, } \\
\text { acetone, or ACN extracts }\end{array}$ & $\begin{array}{l}\text { Marked differential survival for all } \\
\text { extracts (MetOH }>\mathrm{ACN}>\text { acetone). } \\
\text { polA mutants show largest difference, } \\
\text { followed by lexA and } \operatorname{rec} \mathrm{A}\end{array}$ & {$[60]$} \\
\hline Soils treated with coal tar extract & $\begin{array}{l}\text { Rifampicin resistance in Pseudomonas } \\
\text { putida (direct contact) }\end{array}$ & $\begin{array}{l}\text { Changes in soil PAH contamination } \\
\text { unrelated to changes in genotoxicity }\end{array}$ & {$[90]$} \\
\hline Soils from hazardous waste sites & $\begin{array}{l}\text { SOS Chromotest (SOS response induction in } \\
\text { E. coli) on DCM and cyclohexane extracts }\end{array}$ & $\begin{array}{l}\text { S9-activated mutagenicity (at least } 2 \text {-fold } \\
\text { increase over control) in most samples }\end{array}$ & [46] \\
\hline $\begin{array}{l}\text { Soils from a former manufactured } \\
\text { gas plant (MGP) site }\end{array}$ & $\begin{array}{l}\text { SOS Chromotest (SOS response induction in } \\
\text { E. coli) on aqueous leachates }\end{array}$ & No positive response with or without S9 & [189] \\
\hline $\begin{array}{l}\text { Soils collected near a coking facility } \\
\quad(600-800 \text { ppm PAHs })\end{array}$ & SOS Chromotest on DCM extracts & Positive response with S9 & [153] \\
\hline $\begin{array}{l}\text { Soils contaminated by engine oils or } \\
\text { pesticides }(2-20 \mathrm{ppm} \text { PAHs })\end{array}$ & SOS Chromotest on DCM extracts & Marginal positive response without S9 & [147] \\
\hline $\begin{array}{l}\text { Soils spiked with petroleum products } \\
\text { (e.g., kerosene) }\end{array}$ & $\begin{array}{l}\text { SOS-Chromotest Pad (colourimetric SOS } \\
\text { Chromotest for solid samples) }\end{array}$ & $\begin{array}{l}\text { Positive response for crude petroleum } \\
\text { and used motor oil only }\end{array}$ & [465] \\
\hline Composted gasworks soil (Czech Republic) & SOS Chromotest on DCM extracts & Genotoxic activity with S9 only & {$[188]$} \\
\hline $\begin{array}{l}\text { Eight soils collected from a military } \\
\text { (antitank) training area }\end{array}$ & SOS Chromotest on aqueous elutriates ( $\mathrm{pH} 4.5)$ & $\begin{array}{l}\text { Several positive responses with and } \\
\text { without } S 9 . \text { S9 increased response in } \\
3 \text { samples. Three samples elicited } \\
\text { maximum IF }>1.5\end{array}$ & [193] \\
\hline
\end{tabular}

Thirteen soils collected from a variety of contaminated sites

SOS Chromotest and umu test in Salmonella typhimurium $^{\mathrm{d}}$ on aqueous extracts and concentrates of aqueous extracts

Wood preserving bottom sediment waste (surface impoundment)

E. coli prophage induction assay on several organic fractions

PCB contaminated soil

E. coli prophage induction assay on DCM extracts

Wood preserving bottom sediment (EPA K001)

E. coli prophage induction assay

on DCM/MetOH extracts

Potent direct acting samples from

TNT contaminated sites, moderate responses on concentrates of extracts from soils collected at coking plants Genotoxic activity with S9 in the acid and base fractions only

Genotoxic activity with and without S9 ( $\sim 500 \mathrm{pfu} / \mathrm{g}$ soil with $\mathrm{S} 9^{\mathrm{e}}, \sim 1700$ pfu/g soil without $S 9$ )

Samples highly toxic. Some indication of strong positive response (erratic) 

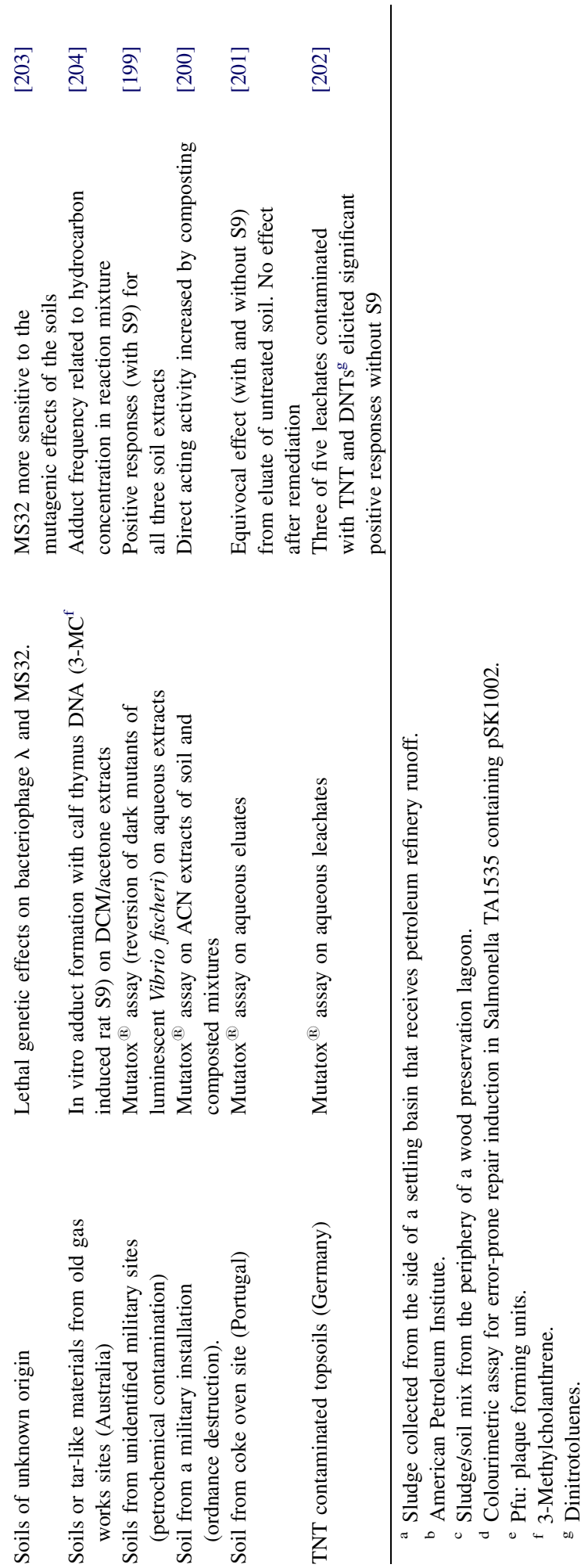

genotoxicity assessments that employed other prokaryotic or molecular in vitro systems.

The first three aforementioned tests all rely on the SOS response to DNA damaging agents $[181,182]$. The SOS Chromotest employs a variant of Escherichia coli (strain PQ37) in which the production of $\beta$ galactosidase is under the express control of the SOS response to DNA damage, and SOS induction is monitored colourimetrically $[109,110,183]$. Test results are expressed as SOS induction factor (IF), the ratio of toxicity-corrected SOS induction in the samples relative to the solvent control, with sample potency usually expressed as the SOS inducing potency (SOSIP), the initial slope of the concentration response relationship. A similar test, that has also been used for soil genotoxicity assessment, is the Salmonella $и т и$ test [111]. The test employs a plasmid (i.e., pSK1002) introduced into S. typhimuriumTA1535 to place the production of $\beta$-galactosidase under SOS control. The DNA repair or differential survival assay in Bacillus subtilus investigates the differential survival of SOS response deficient cells (e.g., $\mathrm{rec}^{-}$) in comparison to wild-type, repair proficient cells [108,184,185]. The results are generally expressed as a ratio of fractional survival between the deficient and proficient cells after a selected incubation period (e.g., $24 \mathrm{~h}$ at $37^{\circ} \mathrm{C}$ ). A variation on this assay, recently employed for analysis of extracts of agricultural soils, involved the use of various repairdeficient mutants of E. coli strain K-12 [60]. The Microscreen phage induction test assesses SOS response induction by quantifying the frequency of $\lambda$ prophage induction in $E$. coli $\mathrm{WP}_{2 \mathrm{~S}}[112,186]$. The results are generally expressed as plaque forming units at a given concentration following overnight incubation of the $\mathrm{WP}_{2 \mathrm{~S}}$ reaction mixtures (i.e., test agent$\mathrm{WP}_{2 \mathrm{~S}}$ mixtures) with wild-type E. coli.

Each of these assays has been shown to respond to a variety of base-pair and frame-shift mutagens, crosslinking agents, intercalating agents, and DNA synthesis inhibitors [112,183-187], and they have been successfully used to assess the genotoxic potential of soil extracts. Eight published studies used the SOS Chromotest to examine the genotoxic activity of soils or soil extracts. Several studies noted positive S9activated genotoxicity in organic extracts (e.g., DCM or cyclohexane) of soils contaminated by nearby hazardous waste disposal facilities (i.e., Superfund 
site), gasworks, or coking operations, [46,153,188]. These soils might be expected to contain S9-activated PAHs [189], and analyses conducted in two of the studies showed approximately 100-500 ppm PAHs at the Superfund site and 600-800 ppm PAHs near the coking operation [46,153]. A similar study that investigated the genotoxicity of aqueous leachates of soils collected near a former manufactured gas plant (MGP) did not detect any genotoxic activity [189]. Although MGP are known to produce coal tars via the pyrolytic destruction of coal $[190,191]$, the negative result is not surprising in light of the low water solubility and high $K_{\mathrm{ow}}$ of mutagenic PAHs [192]. Two studies examined the genotoxic activity of soils contaminated with a variety of petroleum products (e.g., engine oils, kerosene). Malachova et al. detected only marginal direct-acting genotoxicity in DCM extracts of soils contaminated by engine oils or pesticides (e.g., lenasil, trifluralin) [147]. Rojièková et al. used the SOS Chromotest solid phase test (i.e., SOS Chromotest pad) to analyze soils amended with a variety of petroleum products including kerosene, used motor oil, and crude petroleum. The results revealed direct-acting activity only for the crude petroleum amended soils.

Robidoux et al. investigated the genotoxicity of aqueous acid leachates from soils collected from an antitank firing range [193]. The aqueous leachates, suspected of being contaminated with polynitroorganic (PNO) compounds associated with munitions production and detonation, elicited positive directacting responses. Most positive responses were obtained in the absence of S9, and S9 addition enhanced the responses to only three of eight leachates. This is not surprising since a variety of PNO compounds employed in munitions (e.g., TNT or 2,4,6-trinitrotoluene), and their metabolites (e.g., 2-amino-4,6dinitrotoluene, 2,4-diamino-6-nitrotoluene, etc.), are known to be direct-acting bacterial genotoxins $[159,194]$. The highest response was obtained for a soil shown to contain tetryl ( $N$-methyl- $N-2,4,6-$ tetranitroaniline), an explosive compound that is known to be a direct-acting Salmonella mutagen (TA98 and TA100) [194]. Ehrlichmann et al. employed the SOS Chromotest and the Salmonella ити test to examine aqueous extracts of a variety of soils contaminated by munitions and abandoned armaments, coking plant wastes, and wood impreg- nation wastes [174]. Munitions contaminated sites known to contain TNT and other PNOs elicited potent direct-acting responses on the umu and SOS assays, and the response was increased when tested in an $O$ acetyltranferase enhanced version of the uти assay in Salmonella NM2009. Similar to the aforementioned results obtained for aqueous extracts of soils from an MGP site [189], aqueous extracts of soils collected near coal mining or coking operations were not genotoxic. However, the aqueous extracts from these soils did elicit a moderate response in the uти assay after 30-fold concentration on an ethylstyrene resin [174].

Six studies employed a differential survival assay in repair-deficient bacteria (e.g., the $\mathrm{rec}^{-}$assay in $B$. subtilus) or the Microscreen phage induction assay in $E$. coli $\mathrm{WP}_{2 \mathrm{~S}}(\lambda)$ to investigate the genotoxicity of soil extracts. Several studies used the $\mathrm{rec}^{-}$differential survival assay in $B$. subtilus to investigate the genotoxic activity of organic extracts (e.g., DCM, ethyl ether/ $\mathrm{MetOH}$, acetone, $\mathrm{ACN}$ ) from petroleum refinery stormwater runoff impoundment waste (SWRI), combined petroleum separator sludge and slop-oil emulsion solids, wood preserving surface impoundment sludge, soils contaminated with petrochemical wastes (Argentina), and agricultural soil irrigated with industrial and municipal wastewaters $[49,60,62,146,166]$. Analysis of DCM extracts from the SWRI waste, combined petroleum separator sludge and slop-oil emulsion solids, and wood preserving surface impoundment sludge showed marginal ( $<2$-fold control), moderate ( $<5$-fold control), and potent ( $\sim 10$-fold control) S9activated genotoxic activity, respectively. The acid fractions of both the combined petroleum separator sludge and slop-oil emulsion solids and wood preserving surface impoundment sludge elicited the strongest responses $[49,146,166]$. One extract of the petrochemical contaminated samples from Argentina yielded a positive direct-acting response [62]. Aleem and Malik [60] employed a host of repair deficient strains of E. coli $\mathrm{K}-12$ (i.e., polA, $\operatorname{lex} A, \operatorname{rec} A$ ) to assess the genotoxic activity of extracts from soils irrigated with industrial and municipal wastewaters. The results showed marked differential responses to $\mathrm{MetOH}$, acetone, and $\mathrm{ACN}$ extracts. MetOH extracts yielded the strongest responses followed by ACN and acetone. polA mutants were found to be more sensitive, followed by the lexA and $r e c A$ mutants. 
Three studies employed the E. coli Microscreen prophage induction assay to investigate the mutagenicity of organic extracts from soils contaminated with chlorinated contaminants. Although the Salmonella mutagenicity test is the most common test for the examination of complex environmental samples, several researchers have noted the increased sensitivity of the prophage induction assay for activity associated with chlorinated compounds $[41,195,196]$. Two studies examined organic extracts of bottom sediment from an impoundment at a wood preservation site $[151,177]$. The study by Cizmas et al. noted that extracts of the wood preserving waste (WPW), contaminated with numerous mutagenic PAHs (e.g., benz $[a]$ anthracene, dibenzo $[a, h]$ anthracene) and PCP, induced a potent $S 9$-activated response [151]. Subsequent fractionation demonstrated that the acid and base fractions were the most genotoxic. The study by Hong et al. detected a strong S9-activated response in an extract from a WPW-contaminated site. However, the extracts were highly toxic and the responses were erratic [177]. The third study examined DCM extracts of PCB contaminated soils collected at a US Navy site in Guam [41]. The results revealed that the soil extracts elicited positive responses both with and without S9, and the response was not reduced by remediation.

The Mutatox ${ }^{\circledR}$ assay, commercially available in kit form from Azur Environmental, employs reversion of a dark mutant (M169) of the luminescent bacteria Vibrio fisheri to detect mutagenicity. Reversion of dark mutants to luminescent wild type is detected using a luminometer and the intensity of the luminescent signal at a given concentration is directly related to the reversion frequency and the mutagenic activity of the tested sample $[197,198]$. The test, shown to respond to a variety of base-pair and frame-shift mutagens, crosslinking agents, intercalating agents, and DNA synthesis inhibitors [198], was employed in four studies that examined the mutagenicity of soil extracts or aqueous leachates [199-202]. Cook et al. and Picado et al. examined aqueous extracts of soils from a military site contaminated with petrochemicals, and soils from a coke oven site in Portugal, respectively $[199,201]$. The Cook et al. study detected a positive S9-activated response for extracts of three soils contaminated with middle distillate (e.g., diesel oil). Despite PAH contamination above $1000 \mathrm{ppm}$, the latter study only yielded an equivocal response with and without S9. As mentioned earlier, the lack of response is likely due to the inability of the aqueous solvent to extract and concentrate the mutagenic PAHs in the tested samples (e.g., benz $[a]$ anthracene, benzo $[a]$ pyrene, etc.). The remaining two studies employed the Mutatox ${ }^{\circledR}$ system to analyze extracts of soils contaminated with munitions and related compounds [200,202]. The study by Jarvis et al. noted that ACN extracts of soils from a site used for ordnance destruction elicited positive responses without $\mathrm{S} 9$, and these responses were increased following composting treatment [200]. Examination of aqueous extracts from soils collected at a former TNT production facility in Germany showed that three soils elicited positive responses without S9 [202]. Additional analyses revealed high concentrations of both TNT (>100 ppm) and two dinitrotoluenes ( $>35 \mathrm{ppm}$ ) in two of the three positive aqueous leachates.

Three additional studies employed other prokaryote or molecular in vitro assays to examine the genotoxic activity of soils or soil extracts. Alexander et al. employed a forward mutation assay for rifampicin resistance in Pseudomonas putida to examine soil mutagenicity [90]. The assay used a direct-contact approach to examine the induction of rifampicin resistance following a 16- to 18 -h incubation with a sterile soil treated with coal tar extract. The results showed an initial increase in genotoxic activity during bioremediation. Pererva et al. examined the ability of soils to induce lethal mutations in two bacteriophage (i.e., lambda and MS32) [203]. The results showed that MS32 is more sensitive to the effects of the soils examined. Shaw et al. employed an in vitro reaction system containing calf thymus DNA and an S9 activation mixture from 3-methylcholanthrene induced rats to examine the ability of extracts from coal-tar contaminated soils to induce the formation of bulky DNA adducts [204]. The results showed that adduct frequency is related to the hydrocarbon concentration in the reaction mixture.

Collectively, the studies summarized in Table 11 demonstrate that several other bacterial assays can be employed to assess the genotoxic hazards of soils. The studies employed a range of assays to analyse aqueous and organic extracts of soils contaminated with a range of compounds such as PAHs, munitions and explosive residues, petroleum distillates, and wood 
preservatives. Although some of the assays are reliable and extensively validated [183,187,205-207], and have some advantages over the more popular plate incorporation version of the Salmonella mutagenicity test, there are also some noteworthy disadvantages. For example, the SOS Chromotest offers the convenience of miniaturization and the test can be performed in only 2-3 h [208]. In addition, sample sterility and the survival of the tester strain are not required $[109,110]$. However, these advantages are offset by a lack of strains for diagnosis of mutational mechanism and compound metabolism, noted sensitivity to toxic (i.e., bacteriostatic) effects, and difficulties in handling coloured samples $[208,209]$. Moreover, some researchers have highlighted the fact that divalent metals in aqueous extracts (e.g., $\mathrm{Ni}^{2+}$, $\mathrm{Zn}^{2+}, \mathrm{Cd}^{2+}, \mathrm{Cu}^{2+}, \mathrm{Pb}^{2+}$, and $\left.\mathrm{Hg}^{2+}\right)$ may seriously disrupt the performance of the enzyme assays that form the cornerstone of the assay [208,210,211]. With respect to the Mutatox ${ }^{\circledR}$ assay, the system is hampered by a lack of mechanistic understanding of the event(s) required to revert dark mutants of $V$. fisheri [212]. The manufacturer claims that the dark mutation is in the luminescence "regulatory system" rather than one of the lux genes (i.e., luxA, lux $\mathrm{B})$ that code for the luminescent substance (i.e., luciferase) and its subunits [197]. The lux regulatory system has been shown to be quite complex and it is not clear whether induction of luminescence in the V. fisheri dark mutant used in the Mutatox ${ }^{\circledR}$ test actually requires a mutational event. Ambiguity surrounding the significance of a positive Mutatox ${ }^{\circledR}$ result has led some researchers to recommend confirmation with the Salmonella plate incorporation assay [213].

\section{Plant assays used for soil genotoxicity assessment}

Plant assays for the detection of mutagenic and clastogenic effects have been in existence for many years. For example, representatives of Allium (onion), Tradescantia (Spiderwort), Crepis (Hawksbeard), and Vicia were used as far back as the 1930s to assess the clastogenic effect of ionizing radiation [214-218]. In the 1960s and 1970s, representatives of several plant genera such as Vicia, Allium, Hordeum (barley), Zea (maize), Tradescantia, and Arabidopsis were adopted for routine use in the detection of chemical mutagens [219-226]. Several of the selected plants are readily amenable to mutagenicity research (e.g., easy to handle, sensitive, large chromosomes), and a small number of assays have been validated and standardized to stimulate routine use in the detection of environmental mutagens [227-237]. These include the Vica faba MN, chromosome aberration, and sister chromatid exchange assays [229,234], the anaphase aberration assay in Allium cepa root tips [231], the Tradescantia MN and stamen hair mutation assays [228,233,238], the gene mutation assay in Arabidopsis thaliana [230,236], and the specific locus mutation assays in Zea mays [232].

Several assays, such as the Tradescantia stamen hair mutation assay, the Tradescantia MN assay, and the Allium anaphase aberration assay have been effectively employed to monitor environmental mutagens in aqueous media (e.g., surface water, effluent) as well as contaminated air [239-247]. Since soil is the growth medium for most plants, it seems logical that these assays should be amenable to the assessment of soil genotoxicity.

Forty publications contained soil mutagenicity or clastogenicity assessments based on a variety of plant assays. With few exceptions, these publications employed one of five plant assays: the Tradescantia MN test, the Tradescantia stamen hair mutation test, the anaphase aberration assay in Allium cepa, the Arabidopsis gene mutation assay, and the waxy locus mutation assay is Zea mays. Detailed descriptions of these assays can be found in Ma et al. [91,228,229,238,245], Gichner et al. [236], Grant et al. [231,248,249], Kanaya et al. [234], Sandhu et al. [235,250], Van't Hof and Schairer [227], Underbrink et al. [223], and Plewa [72,251].

In total, 462 observations were collected from 29 of the 40 publications that contained sufficient data to investigate patterns in the results for a given endpoint. The most common endpoint encountered in the literature, MN induction in Tradescantia, accounted for $27.7 \%$ of the collected data. This was followed by stamen hair mutation induction in Tradescantia, which accounted for $24.4 \%$ of the data, and induction of CAs in Allium root tips, which accounted for a further $22.5 \%$. Over half of the remaining 117 observations ( $\sim 14 \%$ of the total) are Zea mays waxy 
locus mutation data (forward and reverse), with the remaining 52 observations including data from the following assays: Arabidopsis gametic mutation assay, Allium MN assay, Vicia MN assay, and the Vicia sister chromatid exchange assay.

Soil mutagenicity or clastogenicity assessment employing the aforementioned assays was conducted using a variety of exposure methods including direct soil exposure, soil slurry exposures, and exposures to aqueous extracts/leachates or organic extracts (e.g., $\mathrm{EtOH}, \mathrm{DCM}$, or dimethyl sulfoxide). The majority of the collected data $(62.1 \%)$ were generated from exposures to unaltered soils transported to the laboratory or in situ plantings. Twenty-five percent of the data represent exposures to aqueous extracts or leachates, with a further $10.6 \%$ of the data generated from dimethyl sulfoxide (DMSO) extracts. The remaining $2.4 \%$ (11 observations) were generated from $\mathrm{EtOH}$ or DCM soil extracts.

Since much of the published plant mutagenicity or clastogenicity assessments only provide a single value for each individual soil sample or soil extract/leachate, it was not possible to calculate potency values from concentration-response relationships. For the purposes of this review, only maximum responses and the responses to the negative control (e.g., tap water, nutrient solution, uncontaminated soil) were recorded. In addition, simultaneous observations of contamination by metals, PAHs and radionuclides were also recorded. Appendix B contains the published plant genotoxicity data discussed in the subsequent sections.

The collected data were divided into five categories based on site descriptions: reference/control, agricultural, industrial vicinity, heavily contaminated, and geogenic. The first category represents reference sites chosen for their distance from any known contamination source. Reference soils include greenhouse soils [70,71], undescribed control plots [78], potting soil [76], and garden soil [69]. Although these reference samples were usually described as unimpacted by vehicular and industrial emissions, such statements were rarely verified. Alternatively, researchers working with aqueous leachates routinely employed a reference solution (e.g., tap water, nutrient solution) as a negative control $[67,83,252]$. Agricultural sites refer to those used for cultivation or grazing. Examples include agricultural soils from the Transcarpathian region of the Ukraine [74], pest management research plots [253], and pesticide contaminated farms [252]. This category includes sites that were treated with selected pesticides in order to investigate their genotoxic hazards. Sites labelled as industrial vicinity are those that were chosen for their proximity to an industrial setting; however, the site is not a known for severe contamination due to direct industrial waste disposal. These include sites near metal smelting operations $[70,76,82]$, as well as sites near petrochemical refineries and organic chemical production facilities $[68,71,83]$. Sites specifically described as hazardous waste dumping areas or areas amended with hazardous materials received the designation heavily contaminated $[67,78,254]$. Geogenic sites are those that contain mutagenic substances thought to be of geologic origin (e.g., the As-rich Carinthian sample of Knassmüller et al. [76]).

Table 12 provides a breakdown, by site and assay, of the plant mutagenicity and clastogenicity data collected from the literature. The table indicates that for some assays (e.g., Vicia faba SCE assay) the data are very limited.

\subsection{Allium cepa anaphase aberration data}

The data summarized in Appendix B includes 104 observations of anaphase CAs in Allium cepa. Allium species have large chromosomes $(2 n=16)$ that are well-suited to scoring of chromosome aberrations, and tests for studying the genetic effect of chemicals on Allium chromosomes date back as far as 1938 [249,255].

A detailed description of the suggested protocol can be found in Grant [248,256]. Briefly, onion bulbs or seeds are germinated and 1-2 cm long roots are then exposed to soils, soil extracts, soil slurries, or soil leachates for 2-24 h (usually one mitotic cycle). Roots are then fixed, stained and 100 anaphase or telophase cells scored for aberrations including chromosome fragments and bridges. Some researchers also score the frequency of vagrant chromosomes and multipolar cells that are presumed to be the result of c-mitotic events [257].

Almost $80 \%$ of these Allium aberration data represent the results of direct soil exposures. The remainder of the data represents the results of exposures to aqueous or organic soil extracts. Table 13 summarizes the Allium chromosome 


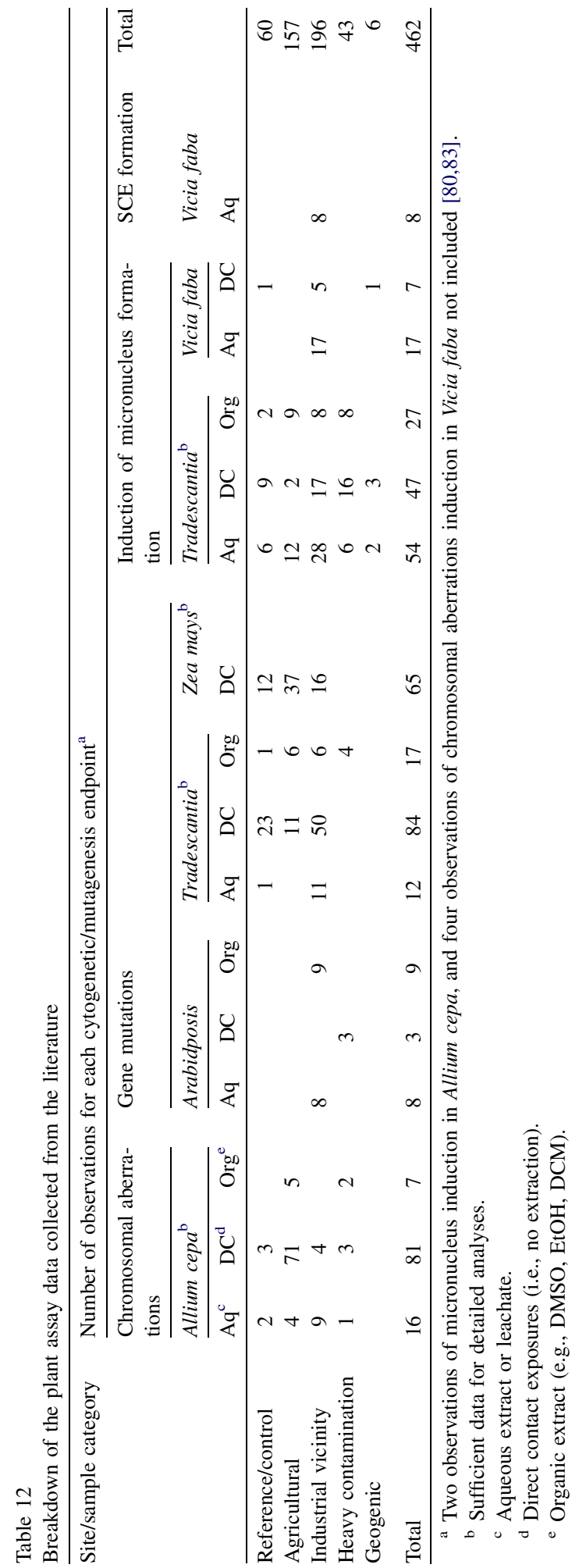

aberration data for different sites categories and each exposure type (i.e., extract or whole soil). The geometric mean values for direct soil exposures clearly indicate a trend showing increasing aberration frequency with increasing contamination. This relationship is illustrated in Fig. 6 (upper panel). The accompanying ANOVA results indicate a significant empirical relationship $(p<0.0001)$ between maximum aberration frequency and site category. Moreover, the post-hoc mean comparisons revealed a significant difference between each site category. Although the geometric mean values in Table 13 show some evidence of a similar relationship for the aqueous/DMSO extract results, separate analyses (not shown) revealed a borderline result with an $F$ ratio of less than 3.1 and an accompanying $p$-value of 0.053. Nevertheless, The lower panel of Fig. 6 indicates that the relationship between aberration frequency and site category is maintained when all the data are analyzed $(p<0.001)$. These results suggest that the Allium root tip anaphase aberration test is well suited to the detection of clastogens in soils, and to a lesser extent soil extracts or leachates. It appears to respond to a range of soil contaminants including radionuclides [257], pesticides [75], and industrial contaminants [67]. Moreover, the control values for direct contact exposures are very stable (e.g., reference soil geometric mean $=1.65 \pm 0.11$ ) and the endpoint shows a 10 -fold increase in response across a range of soils. Kovalchuk et al. [257] highlighted the sensitivity of the assays and noted that the assay is more sensitive to ionizing radiation than the Vicia faba MN test. Ma et al. [245] suggested that the increased sensitivity of Allium might be due to the greater total length of the diploid chromosomes and/or the higher number of metacentric chromosomes. In light of this sensitivity and the assays ability to identify hazardous samples, it is somewhat surprising that this rapid test has not been widely applied to studies of environmental contamination.

Analyses of ANOVA outliers revealed eight significant negative outliers from the relationship between maximum aberration frequency and site category for direct soil exposures (Fig. 6, upper panel). All eight of the outliers are agricultural soils from the Ukraine or Uzbekistan [74,75]. Unfortunately, the authors of these studies do not provide detailed descriptions of the relevant sites. 
Table 13

Descriptive summary of the collected Allium cepa chromosome aberration data ${ }^{a}$

\begin{tabular}{lllll}
\hline & Category & & \\
\cline { 2 - 5 } & Reference/control & Agricultural & Industrial vicinity & Heavy contamination \\
\hline Exposure to aqueous or DMSO extracts & & & & 3 \\
$N$ & 2 & 9 & 0.67 & 1.62 \\
Minimum & 0.62 & 2.98 & 6.33 & 3.20 \\
Maximum & 0.81 & 1.70 & 3.11 & 2.34 \\
Mean & 0.72 & 0.24 & 0.65 & 0.46 \\
S.E. & 0.095 & 1.54 & 2.53 & 2.25 \\
Geometric mean & 0.71 & Yes & Yes & NA \\
Distribution & NA & & & \\
Direct contact with contaminated soil & & 71 & 4 & 3 \\
$N$ & 3 & 0.60 & 3.10 & 13.70 \\
Minimum & 1.59 & 6.90 & 6.70 & 23.80 \\
Maximum & 1.77 & 3.38 & 4.80 & 17.47 \\
Mean & 1.65 & 0.19 & 0.91 & 3.19 \\
S.E. & 0.058 & 2.93 & 4.54 & NA \\
Geometric mean & 1.65 & No & NA \\
Distribution & NA & & \\
\hline
\end{tabular}

${ }^{\text {a }}$ Values are maximum aberrations per 100 cells for a given exposure/experiment.

b Insufficient data for normality test.

Additional analyses of the results shown in the lower panel of Fig. 6 revealed a total of ten outliers, nine negative outliers and one positive outlier. Most of the negative outliers are aqueous or DMSO extracts, including extracts of heavily contaminated municipal waste compost samples examined by Cabrera et al. [67]. This pattern confirms that direct soil exposure is a more effective means of assessing clastogenic hazard. The remaining negative outliers are the aforementioned Ukrainian and Uzbekistani agricultural sites. It is interesting to note that the sole positive outlier is a heavily contaminated soil from Chernobyl that was found to contain over $6000 \mathrm{~Bq} / \mathrm{kg}$ of ${ }^{137} \mathrm{Cs}$ [257]. The effect of ${ }^{137} \mathrm{Cs}$ contamination on Allium aberration frequency is illustrated in Fig. 7. The Figure shows a striking relationship $\left(r^{2}=0.98, p<0.0001\right)$ between ${ }^{137} \mathrm{Cs}$ contamination and the frequency of CA in Allium exposed via direct soil contact for two mitotic cycles.

\subsection{Arabidopsis gene mutation data}

Relatively few researchers have employed Arabidopsis for studies of contaminated soils; however, one interesting study used the Arabidopsis gene mutation system to examine the effects of radionuclidecontaminated soils $[68,258]$. Arabidopsis is a small, diploid $(2 n=10)$ species with a conveniently short life cycle. Large numbers of plants can be grown in a small area and a single plant can produce in excess of 50,000 seeds $[230,236,259]$. The test, originally developed by Müller [260], and described in detail by Redei [230,259], involves scoring lethal, chlorophyll defective embryos (i.e., seeds) in the siliquae (i.e., the dry, elongated fruit) of plants grown from seeds exposed to the test substance [236,249]. Embryonic mutations one generation removed from the initial exposure are usually scored as chlorophyll (e.g., white, yellow, or pale green seeds) and/or structural aberrations (e.g., abnormally small and shrunken).

Kruikov et al. [258] used the Arabidopsis gametic mutation system to examine the frequency of dominant lethal mutations in embryos from plants grown in soils contaminated with ${ }^{137} \mathrm{Cs}$. The results showed an enhanced frequency of mutations in soils with greater levels of ${ }^{137} \mathrm{Cs}$ contamination. When these data are combined with the spontaneous Arabidopsis mutation frequency [68] and background levels of ${ }^{137} \mathrm{Cs}$ [257], the combined data $(N=4)$ shows a strong empirical relationship between mutation frequency and radionuclide contamination. Fig. 8 illustrates the relationship between the frequency of siliquae segregating for dominant lethal mutations and soil concentration of ${ }^{137} \mathrm{Cs}$. Although only four 

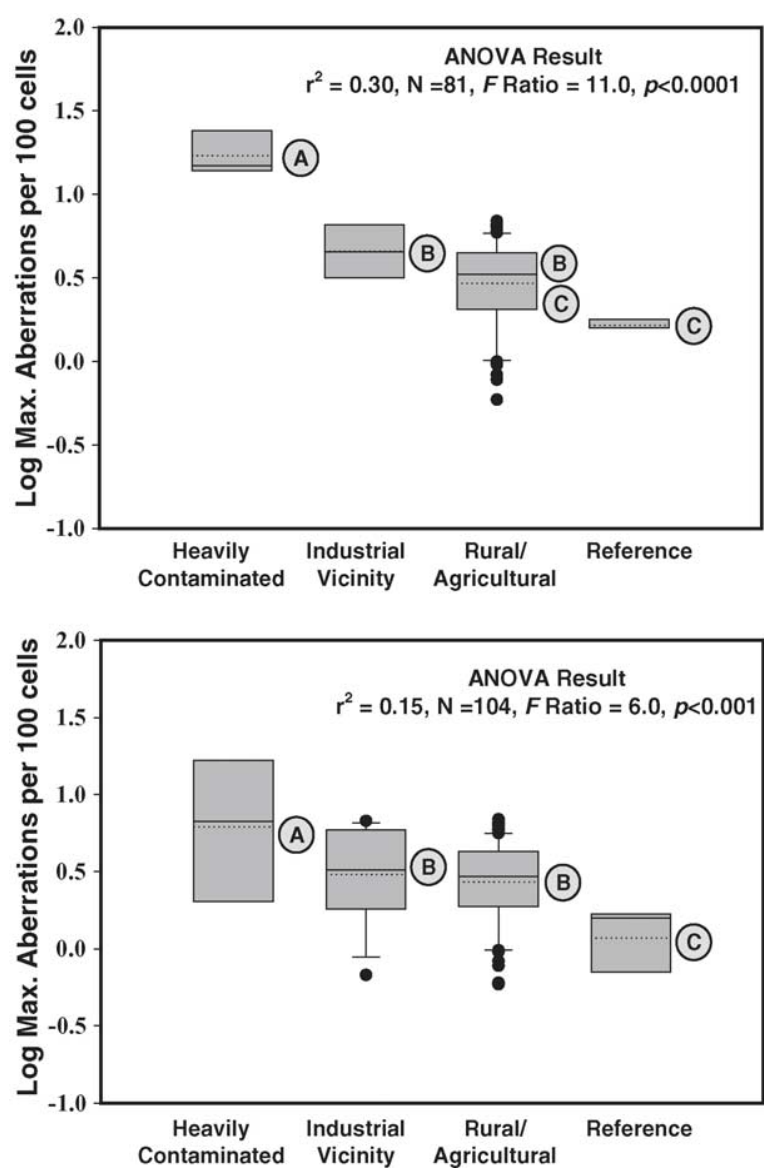

Fig. 6. Box plots of published Allium cepa anaphase aberration data for soils and soil extracts from heavily contaminated locations, industrial sites, rural/agricultural sites, and remote sites. The overlayed text shows the results of the ANOVA analysis for a site category effect. Potency values were log transformed to meet the assumptions of least squares ANOVA. The upper panel includes the results of direct-contact assays only. The lower panel includes all available published data (e.g., direct contact, aqueous extracts, organic extracts). Refer to the Fig. 3 legend for a detailed description of the box. Boxes labeled with different letters are significantly different at $p<0.05$ (Duncan multiple range test). All values and data sources are available in Appendix B. The number of observations in each site category is available in Table 13.

observations were available, the figure illustrates an extremely strong empirical relationship between mutation frequency and ${ }^{137} \mathrm{Cs}$ contamination. This relationship, as well as the aforementioned relationship for Allium, is not surprising since ionizing radiation such as $\mathrm{X}$-rays are known to induce mutations at a variety of plant loci [73,225,261-264].

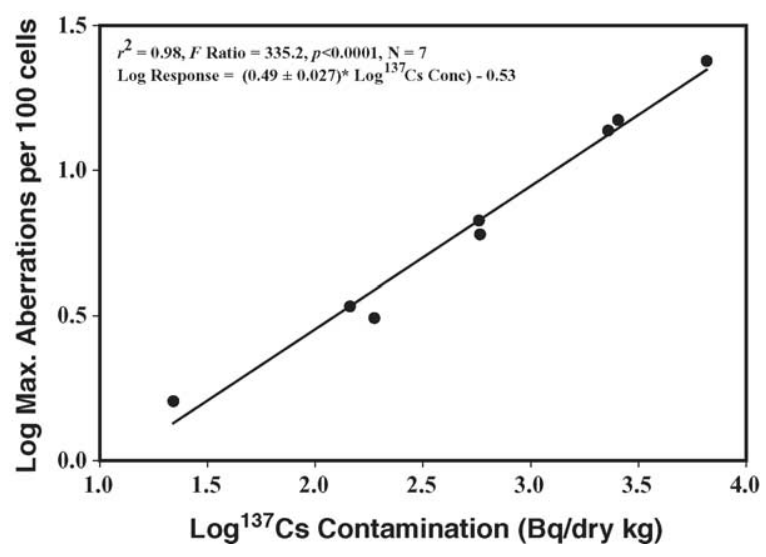

Fig. 7. The empirical relationship between the frequency of anaphase aberrations in Allium exposed to radionuclide-contaminated soils (direct contact assessments) and the level of ${ }^{137}$ Cs contamination $(\mathrm{Bq} / \mathrm{kg})$. All values were log transformed to meet the assumptions of least-squares regression. The overlaid information shows the results of the linear regression analysis. All values were obtained from Kovalchuk et al. [257] and are shown in Appendix B. Minimum, maximum, and mean ${ }^{137} \mathrm{Cs}$ contamination values are summarized in Table 4.

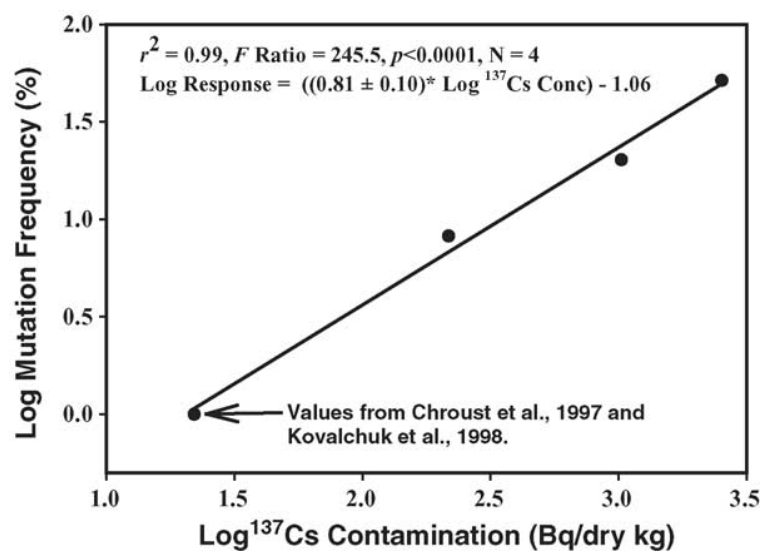

Fig. 8. Empirical relationship between mutation frequency in Arabidopsis thaliana exposed to radionuclide-contaminated soils (direct contact) and the level of ${ }^{137} \mathrm{Cs}$ soil contamination (Bq/kg). Background values for Arabidopsis mutation frequency and ${ }^{137} \mathrm{Cs}$ contamination are from Chroust et al. [68] and Kovalchuk et al. [257], respectively. All other values were obtained from Kriukov et al. [258]. All values were log transformed to meet the assumptions of least-squares regression. The overlaid information shows the results of the linear regression analysis. Minimum, maximum, and mean ${ }^{137} \mathrm{Cs}$ contamination values are summarized in Table 4 . All values are available in Appendix B. 
The study by Chroust et al. employed the Arabidopsis mutation assay to examine the effects of PAH contaminated soils collected from two industrial areas [68]. The results revealed that plants grown in PAH contaminated soils $(0.2-1.1 \mathrm{ppm})$ displayed a higher frequency of dominant lethals in the collected embryos. However, analysis of the published data failed to reveal a significant correlation between mutation frequency and PAH contamination (Spearman rank order $r=0.9, p=0.083$ ).

\subsection{Zea mays waxy locus mutation data}

The plant data summarized in Appendix B include 65 observations of single gene germinal mutations at the waxy locus in haploid Zea mays microgametophytes (pollen grains) following direct contact with contaminated soils. The plant, also known as maize, has been called the pillar of classical genetics and it was extensively used in early studies of spontaneous and induced mutations [251,265-267]. Maize is diploid $(2 n=20)$, has conveniently large chromosomes, its growth requirements are well-known, and hundreds of varieties with defined genotypes are available for research [251,268,269].

A complete description of the assay can be found in Plewa [72,251]. Briefly, the reverse mutation test (i.e., mutant $w x$ to $\mathrm{W} x$ ) employs iodine staining to reveal revertent $\mathrm{W} x$ pollen grains that stain blue-black, in contrast to $w x$ pollen that stain tan-brown [70-72]. In the forward mutation test $w x$ mutants are detected as tan-brown in contrast to the blue-black $\mathrm{W} x$ pollen [253]. The assay can be conducted by treating kernels or plants, and both acute and chronic treatments can be employed [251]. The reviewed studies employed chronic, direct contact exposures until anthesis (i.e., flowering), usually 12-14 weeks [70-72,270,271], and most studies employed the W22 or M14 inbred lines to score reverse mutation frequency at the $w x-\mathrm{C}$ or $w x$-90 alleles [251].

Although mutagenicity assessment with the W22 line has been shown to be effective for the detection of soil mutagens (e.g., [72,270,271]), the overall size of the plant can place practical limits on the utility of the assay for routine analyses. Moreover, although the long maturation period of 12-14 weeks ensures a lengthy chronic exposure, the interval between experiment initiation and data collection can be problematic. Consequently, Plewa and Wagner [272] developed an alternative waxy locus mutation assay employing Early-Early Synthetic corn, a plant that matures in four weeks and is only $50 \mathrm{~cm}$ in height. The system has been shown to be sensitive and responsive to potent mutagens such as ethyl methanesulphonate (EMS) and maleic hydrazide (MH), as well as soil amended with sewage sludge $[72,272]$. One of the reviewed studies employed the Early-Early system to examine the mutagenic hazards of soils treated with varying amounts of pesticides [84].

Despite the limited quantity of published data, the collected values summarized in Table 14 shows an interesting trend of increasing mean mutation frequency with site category. Reference sites showed the lowest mutation frequency, followed by agricultural sites exposed to a variety of pesticides [253,270,271], and finally contaminated industrial sites that received contamination from petrochemical and metal refining facilities [70,71]. The relationship between mutation

Table 14

Descriptive summary of the collected Zea mays waxy locus mutation data ${ }^{a}$

\begin{tabular}{lccc}
\hline & Category & & \\
\cline { 2 - 4 } & Reference/control & Agricultural & Industrial vicinity \\
\hline Direct contact with contaminated soil & & & \\
$N$ & 12 & 37 & 16 \\
Minimum & 1.74 & 2.45 & 3.72 \\
Maximum & 12.88 & 27.54 & 72.44 \\
Mean & 5.02 & 7.97 & 22.68 \\
S.E. & 0.89 & 0.81 & 4.38 \\
Geometric mean & 4.34 & 6.92 & 16.93 \\
Distribution & Yes & No & Yes \\
\hline
\end{tabular}

${ }^{\mathrm{a}}$ All values are maximum mutation frequency $\left(\times 10^{-5}\right)$ for a given exposure/experiment. 


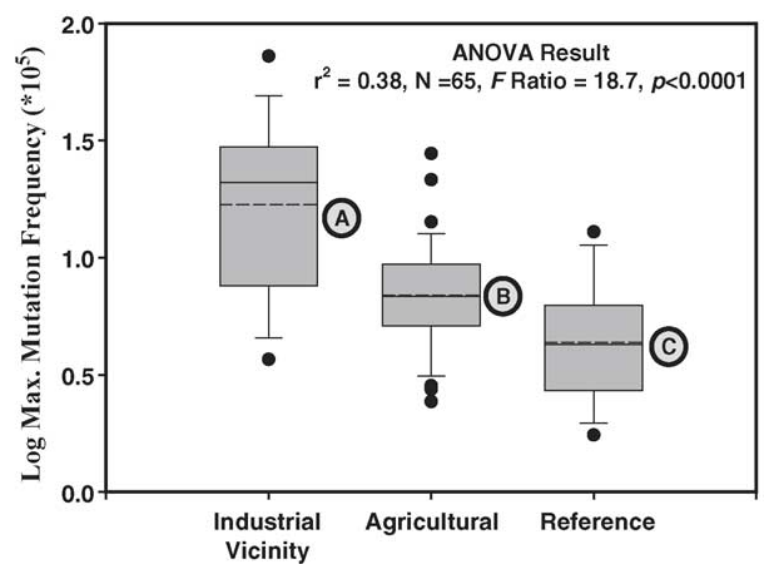

Fig. 9. Box plots of the published Zea mays waxy locus mutation data for soils from industrial sites, rural/agricultural sites, and remote sites (direct contact only). The overlayed text shows the results of the ANOVA analysis for a site category effect. Potency values were $\log$ transformed to meet the assumptions of least squares ANOVA. Refer to the Fig. 3 legend for a detailed description of the box. Boxes labeled with different letters are significantly different at $p<0.05$ (Duncan multiple range test). The data shown were obtained from six published studies [70-72,84,270,271]. Most assessments examined reverse mutation at the $w x-C$ allele in homozygous inbred strain W22. Exceptions are the sewage sludge amended soils examined via reverse mutation at the $w x-90$ allele in inbred M14 [72,272], and the pesticide treated soils examined via forward mutation at the $\mathrm{W} x$ allele in Early-Early Synthetic Zea mays [84]. All values are available in Appendix B. The number of observations in each site category is available in Table 14.

frequency and site category is illustrated in Fig. 9. ANOVA results revealed a significant relationship $(p<0.0001)$ between the maximum mutation frequency and site category. Moreover, post-hoc analyses of mean values revealed significant differences $(p<0.05)$ between each of the site categories. Analysis of the ANOVA residuals showed two positive outliers, one agricultural site treated with 4.48 to $4.80 \mathrm{~kg} / \mathrm{ha}$ of the herbicide mixture SD50093 (atrazine + cyanazine) [270], and one site $100 \mathrm{~m}$ from a oil refinery complex in Illinois [71]. These sites yielded waxy locus mutation frequencies of 27.8 and $72.5 \times 10^{-5}$ respectively; values that are 5- to 15 fold greater than their respective controls. It is not immediately obvious why either of these locations induced responses that were deemed to be significant positive outliers, particularly in light of the fact that an observation from the same industrial site in a previous year showed a markedly low response that was deemed to be a negative outlier [71,270]. A second negative outlier corresponded to a control site from Lower et al. [70] located in Granite City, Illinois $3.2 \mathrm{~km}$ from a lead smelter in Boss, Missouri.

It is interesting to emphasize that three studies examining soils treated with a variety of herbicides, insecticides, and fungicides frequently noted marked increases in gametophyte mutation rate, despite the fact that some of these pesticides were not found to be mutagenic in either Salmonella or Saccharomyces cerevisiae (reverse mutation at ade or trp loci). Exceptions include the herbicides dicamba, metolachlor, alachlor, and procyazine, as well as the insecticides fonofos, chlordane, heptachlor, and terbufos [270,271], and the fungicide captan. The latter compound, often used for seed treatment prior to storage, is known to be mutagenic in a variety of assay systems [195,273-275].

Rodrigues et al. [253] showed that heavy applications of pesticides for seed treatment and weed control (e.g., cyanazine, metolachlor, diazinon, chlorpyrifos, carboxin, and captan) resulted in a two-fold increase in mutation frequency $\left(\sim 8 \times 10^{-5}\right)$ in comparison to reference samples that did not receive any pesticides $\left(\sim 4.5 \times 10^{-5}\right)$ and/or laboratory controls $\left(\sim 3 \times 10^{-5}\right)$ grown in a commercial soil mixture. Plewa et al. [270] showed substantial increases in mutation frequency (i.e., 2- to 5-fold) in plants exposed to soils where certain herbicides had been applied. Application of the triazine herbicides such as cyanazine or simazine, compounds that are not mutagenic in Salmonella or Saccharomyces [276279], induced mutation frequencies of approximately $11-28 \times 10^{-5}$ in comparison to control values of approximately $3-5 \times 10^{-5}$. Combinations of metolachlor and triazine herbicides also induced substantial increases over the control. In addition, Gentile et al. [271] noted significant ( 2 -fold) increases in mutation frequency in plants exposed to soils where the insecticides chlordane, ethoprop or heptachlor had been applied. Although some of the pesticides studied by Plewa et al. and Gentile et al. are clearly nonmutagenic in Salmonella, it is interesting to note that Plewa et al. [270] also demonstrated that Salmonella incubation with a metabolic activation mixture derived from Zea mays kernels results in strong positive responses on TA100, TA98 and TA1537. 


\subsection{Tradescantia stamen hair mutation data}

Mutagenicity assay systems employing representatives of Tradescantia for chemical screening, as well as in situ assessment of airborne mutagens, have been available since the late 1960s and 1970s [223,225, 239,280-282]. The most popular assay systems, the stamen hair mutation system and the MN assay in meiotic pollen mother cells, are generally carried out using sterile hybrid clones such as Tradescantia clone 4430, an interspecific hybrid of T. hirsutiflora and $T$. subcaulis. The sterility of the clones is a convenient feature that ensures genetic homogeneity in the absence of mutagenic effects. A complete description of both assays can be found in Ma et al. [91,228, $238,245,247]$, as well as important earlier works by Underbrink et al. [223] and Sparrow et al. [225].

The collected plant data includes 113 observations of stamen hair mutation frequency assessment in Tradescantia. With three exceptions, all the reviewed studies employed the aforementioned sterile hybrid denoted clone 4430 [66,67,69-71,81,283]. One study employed clone 02, also referred to as clone BNL02 (Brookhaven National Laboratory clone 02), a putative diploid hybrid of $T$. occidentalis and $T$. ohiensis [73], and two Russian studies employed an unspecified isolate of $T$. poludosa $[74,75]$. The stamen hair mutation assay or Trad-SHM is based on the fact that stamen hair cells in clone 4430, and other clones such as BNL02, are heterozygous for phenotypically visible flower colour markers (i.e., blue-dominant and pink-recessive) [91]. Briefly, cuttings of Tradescantia clones heterozygous for the alleles controlling stamen hair colour are exposed to aqueous extracts, organic extracts diluted in an aqueous medium, whole soils, or soil slurries for up to several days. Following a lag period of up to 14 days (depending on treatment time) stamen filaments are microscopically examined and scored for pink mutations. The results are usually expressed as mutation events per 1000 stamen hairs. Although the most commonly employed protocols for treatment in aqueous media use relatively short exposure times between 6 and $30 \mathrm{~h}[66,67,69,81$, $91,252,283]$, assessments of soils by direct contact, and assessments of airborne mutagens often employ a chronic exposure lasting for several days [227] or even several weeks [70,71]. For example, in their studies of sites in the vicinity of a lead smelter and a petrochemical complex, Lower et al. conducted lengthy 6-12-week direct contact soil exposures [70,71].

A summary of the collected stamen hair mutation data is provided in Table 15. Almost $75 \%$ of the collected values were generated from direct soil exposures. The remaining data includes exposures to aqueous or organic (DMSO or EtOH) soil extracts [67,284]. Variations in extraction and exposure method, and background mutation frequency across the various studies complicated comparisons across site categories. For example, the direct soil exposure data indicate that the mean mutation frequency in plants exposed to agricultural soils is less than that for the reference (i.e., control) soils (Table 15, middle). However, closer examination of the agricultural data (see Appendix B) indicates that the geometric mean mutation frequency for the 11 Uzbekistani and Ukrainian sites examined by Kurrinyi et al. $\left(1.7 \times 10^{-3}\right)$, although unusually low in comparison with other published values, is significantly greater than its matching reference values (i.e., 0.85 and $\left.0.4 \times 10^{-3}\right)[74,75]$. Both of the Kurrinyi et al. studies employed an unspecified isolate of T. poludosa and it seems clear that this isolate yields spontaneous and induced mutation frequency values that are low in comparison to those recorded by other researchers. For example, the reference data from the studies of Ichikawa and Ishii and Lower et al. [70,71] provided mean mutation frequency values in the (1.8$2.5 \times 10^{-3}$ range, 2- to 6-fold higher than the Kurrinyi et al. values. This required separation of the Kurinnyi et al. $[74,75]$ data from the other published data prior to detailed data analysis.

The relationship between mean mutation frequency and site category for the remaining direct contact data is illustrated in Fig. 10 (upper panel). The figure and accompanying ANOVA results indicate a significant relationship $(p<0.0001)$ between mean mutation frequency and site category (industrial and reference only). Therefore, the direct-contact version of the SHM assay with Tradescantia clones 4430 or BNL02 appears to be effective at discriminating between background mutagenicity and levels associated with sites near industries associated with the production and emission of mutagenic substances (e.g., PAHs). However, it should be noted that the data from Ichikawa and Iishi [73], which were generated using 
Table 15

Descriptive summary of the collected Tradescantia stamen hair mutation (SHM) data ${ }^{a}$

\begin{tabular}{|c|c|c|c|c|}
\hline & \multicolumn{4}{|l|}{ Category } \\
\hline & Reference/control & Agricultural & Industrial vicinity & Heavy contamination \\
\hline \multicolumn{5}{|c|}{ Exposure to aqueous or organic extract } \\
\hline$N$ & 2 & 6 & 17 & 4 \\
\hline Minimum & 1.19 & 3.41 & 0.89 & 1.72 \\
\hline Maximum & 1.29 & 7.20 & 5.82 & 2.36 \\
\hline Mean & 1.24 & 4.68 & 2.80 & 1.94 \\
\hline S.E. & 0.05 & 0.60 & 0.31 & 0.14 \\
\hline Geometric mean & 1.24 & 4.50 & 2.50 & 1.92 \\
\hline Distribution & $\mathrm{NA}^{\mathrm{b}}$ & Yes & Yes & NA \\
\hline \multicolumn{5}{|c|}{ Direct contact with contaminated soil ${ }^{\mathrm{c}}$} \\
\hline$N$ & 23 & 11 & 50 & No data \\
\hline Minimum & 0.40 & 0.27 & 1.65 & \\
\hline Maximum & 3.87 & 3.00 & 7.17 & \\
\hline Mean & 2.12 & 1.59 & 3.38 & \\
\hline S.E. & 0.17 & 0.22 & 0.18 & \\
\hline Geometric mean & 1.95 & 1.39 & 3.16 & \\
\hline Distribution & No & No & No & \\
\hline \multicolumn{5}{|c|}{ Direct contact: clones 4430 and BNL02 only ${ }^{\mathrm{d}}$} \\
\hline$N$ & 22 & No data & 50 & No data \\
\hline Minimum & 1.34 & & 1.65 & \\
\hline Maximum & 3.87 & & 7.17 & \\
\hline Mean & 2.20 & & 3.38 & \\
\hline S.E. & 0.16 & & 0.18 & \\
\hline Geometric mean & 2.09 & & 3.16 & \\
\hline Distribution & No & & No & \\
\hline
\end{tabular}

clone BNL02, do suggest that this clone may be less sensitive than clone 4430. Clone BNL02 yielded lower reference and industrial mean values and a subsequent t-test comparing BNL02 and 4430 values showed a significant difference $(p<0.02)$ between the mean reference values, $1.78 \times 10^{-3} \pm 0.07$ and $2.49 \times$ $10^{-3} \pm 0.23$ (direct contact only), respectively. In a much earlier work comparing these two clones, Sparrow et al. also noted that the mutation rate in 4430 following a chemical exposure was appreciably higher than that of clone 02 [225].

The remaining 25\% of the Tradescantia SHM data $(N=29)$ are the results of assessments that employed aqueous or organic soil extracts (Table 15). These results, presented in Fig. 10 (lower panel), based on data collected from five studies [66,67,69,81,283], indicate that there is very little difference between the mean mutation frequency across the different site categories. Although the ANOVA analysis permitted rejection of the null hypothesis at $p<0.004$, the posthoc comparison of mean values indicates that the results from heavily contaminated soils are not significantly different from the results obtained for reference soils. In addition, the mean of the rural/ agricultural soils is significantly greater than the mean for the heavily contaminated soils (e.g., composted municipal waste). This may be due to the fact that all the agricultural/rural values reflect the mutagenicity of DMSO extracts from soils irrigated with water from the Queretaro River, a source that receives wastewater inputs from a variety of industrial and domestic sources. In addition, mine-dump sites with extremely high levels of metals that have been shown to be genotoxic in Tradescantia assays were categorized as industrial [76,77]; however, the actual samples examined contained low concentrations of metals 

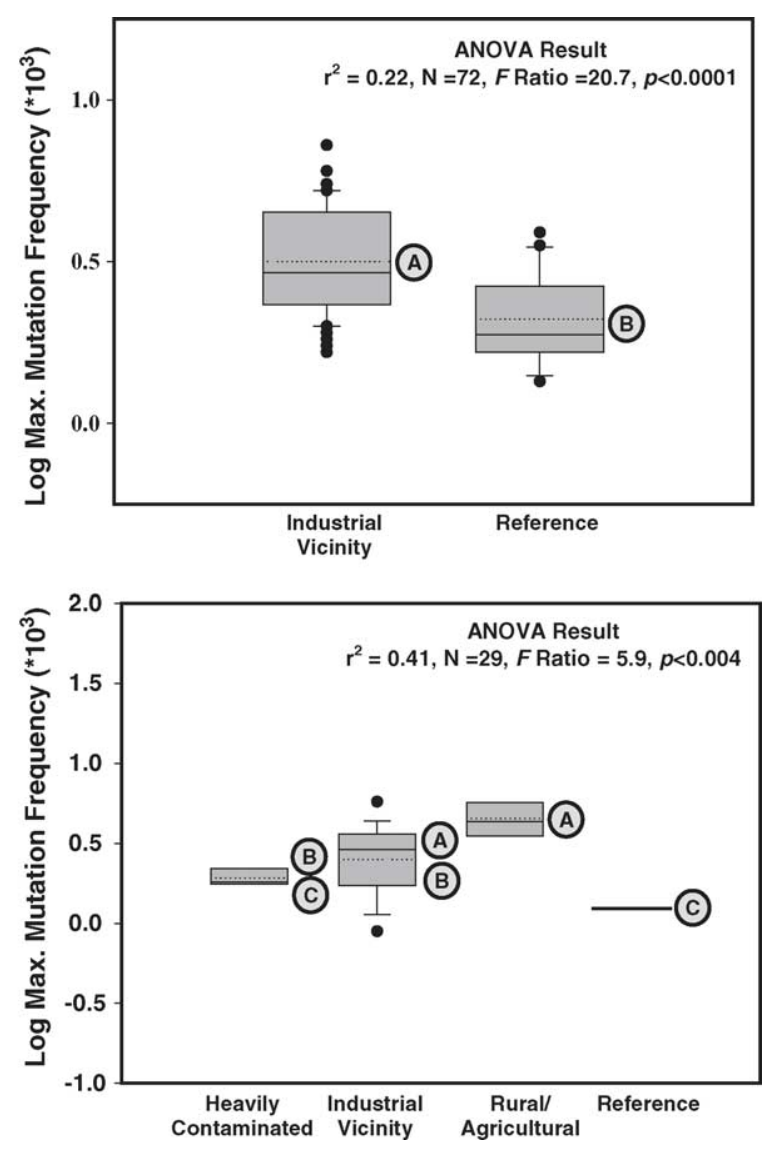

Fig. 10. Box plots of the published Tradescantia stamen hair mutation data for soils and soil extracts from heavily contaminated sites, industrial sites, rural/agricultural sites, and remote sites. The overlayed text shows the results of the ANOVA analysis for a site category effect. Potency values were log transformed to meet the assumptions of least squares ANOVA. The upper panel includes the results of assays with direct soil contact only. The bottom panel includes the results of exposures to soil extracts or aqueous leachates only. Refer to the Fig. 3 legend for a detailed description of the box. Boxes labeled with different letters are significantly different at $p<0.05$ (Duncan multiple range test). The values presented were collected from 8 published studies $[66,67,69-71,73,81,283]$. All values, shown in Appendix B, were generated using Tradescantia clones 4430 or BNL02 [91,225]. Exclusion of clone BNL02 from the upper panel yields a slightly stronger ANOVA result $\left(r^{2}=0.34, N=45, F\right.$ ratio $=22.3, p<0.0001$ ). Two studies that used an unspecified stock of Tradescantia poludosa were not included in the figure or accompanying data analyses (see text and Table 15) [74,75]. The number of observations in each site category is available in Table 15.

(e.g., $\mathrm{Cr}, \mathrm{Cd}, \mathrm{Ni}, \mathrm{Zn}, \mathrm{Pb}$ ) and induced weak responses [81]. Finally, variability in the Trad-SHM soil extract/ leachate data may also be due to variations in the exposure duration employed in the reviewed studies.
Although continuous treatment for $30 \mathrm{~h}$ is generally recommended for liquid samples $[66,67,252,283]$, the cited studies used a variety of exposure times between 6 and $30 \mathrm{~h}[69,81,252]$.

In general, the paucity of aqueous/organic extract data, and difficulty in objectively classifying the study sites complicated the interpretation of the data presented in the lower panel of Fig. 10, and it is not possible to draw any firm conclusions. However, the small range in the maximum mutagenic response to aqueous or DMSO extracts from a range of sites is troubling. The assay does not appear to have a great deal of dynamic range, and, moreover, there is a fair degree of variation in spontaneous mutation frequency across studies. The five studies discussed here show negative control values that range from 1.9 to 3.49 mutations per 1000 stamen hairs [66,67,69,81,283], and the positive controls maleic hydrazide and $O$ phenylenediamine often yielded responses that are less than 4-fold above the control.

\subsection{Tradescantia micronucleus test data}

The Tradescantia MN assay or Trad-MN, an assay originally developed for the assessments of gaseous and airborne mutagens $[227,239,256]$, is often used for investigations of contaminated aqueous media such as surface waters or wastewaters [241,242,246, $247,285,286]$. It is very popular, and its utility for analyses of complex environmental samples has been the subject of several review papers and international evaluation exercises [78,228,235,238,246,250,287, 288]. The assay involves exposure of 15-30 cuttings per treatment to the test material, and inflorescences are subsequently fixed and early stage tetrads (i.e., meiotic products of spore mother cells) are stained and scored for MN. Generally, 300 tetrads are scored from each experimental group and the results are expressed as MN per 100 tetrads [238]. Exposures times vary widely depending on the nature of the study and the media being examined. Typical values employed for complex mixture analyses include 3-12 h [69,83,238] for acute aqueous exposures, 24-30 h for chronic aqueous exposures [81,120], 3-24 h for in situ water monitoring [238], up to 10 days for monitoring of contaminated air [227], and $72 \mathrm{~h}$ for direct contact monitoring of contaminated soils [76]. 
Table 16 summarizes the data from 17 published soil genotoxicity assessments that employed the Tradescantia MN test. Of the 128 observations collected from the literature, approximately $63 \%$ used the assay to assess the mutagenic activity of aqueous soil leachates/extracts or DMSO extracts. These data are almost equal amount aqueous extract/leachate values and DMSO extract values. The remaining 37\% of the data was obtained from studies that used the assay to examine the effects of direct soil exposures.

Analysis of the direct contact results, illustrated in Fig. 11, show that although the null hypothesis of equal mean values for the various sites categories was rejected at $p<0.05$, post-hoc comparisons of mean values indicated that examinations of reference, rural/ agricultural, industrial vicinity, and heavily contaminated sites yielded similar levels of MN induction. Even heavily contaminated Superfund samples such as those investigated by Gill et al., which yielded clear positive responses (e.g., $p<0.05$ ) for direct soil and soil slurry exposures, only induced a maximum response 3.1-fold above the control [78]. This site is known to be contaminated with a variety of hazardous materials including pesticides (e.g., heptachlor, dieldrin) that have been shown to induce $\mathrm{MN}$ in Tradescantia [289]. The study by Majer et al. of soils contaminated with varying amounts of toxic and genotoxic metals (e.g., As, $\mathrm{Cd}, \mathrm{Sb}, \mathrm{Cr}, \mathrm{Cu}, \mathrm{Mn}, \mathrm{Ni}, \mathrm{Pb}$, and $\mathrm{Zn}$ ) showed numerous significant positive responses $(p<0.05)$; however, even the most dramatic responses only reached 3-fold above the mean control value ( $\sim 5 \mathrm{MN}$ per 100 tetrads) [77]. Thus, despite the ability to discriminate between test samples and reference samples within one study, the dynamic range appears to be too narrow to show cross-study differences between reference and test soils. The one exception are the soils with geogenic As contamination examined by Knasmüller et al. and

Table 16

Descriptive summary of the collected Tradescantia micronucleus induction (MN) data ${ }^{a}$

\begin{tabular}{|c|c|c|c|c|c|}
\hline & \multicolumn{5}{|l|}{ Category } \\
\hline & $\begin{array}{l}\text { Reference/ } \\
\text { control }\end{array}$ & Agricultural & $\begin{array}{l}\text { Industrial } \\
\text { vicinity }\end{array}$ & $\begin{array}{l}\text { Heavy } \\
\text { contamination }\end{array}$ & Geogenic \\
\hline \multicolumn{6}{|c|}{ Direct contact with contaminated soil } \\
\hline$N$ & 9 & 2 & 17 & 16 & 3 \\
\hline Minimum & 2.84 & 5.97 & 4.38 & 3.50 & 11.0 \\
\hline Maximum & 8.70 & 6.34 & 100.0 & 23.80 & 77.0 \\
\hline Mean & 6.10 & 6.16 & 18.36 & 10.51 & 34.8 \\
\hline S.E. & 0.62 & 0.18 & 6.44 & 1.43 & 21.2 \\
\hline Geometric mean & 5.80 & 6.16 & 10.75 & 9.21 & 24.0 \\
\hline Distribution & Yes & $\mathrm{NA}^{\mathrm{b}}$ & No & Yes & NA \\
\hline \multicolumn{6}{|c|}{ Exposure to aqueous extracts, DMSO extracts, or aqueous leachates } \\
\hline$N$ & 8 & 21 & 36 & 14 & 2 \\
\hline Minimum & 1.50 & 2.70 & 1.06 & 2.50 & 3.07 \\
\hline Maximum & 6.57 & 15.19 & 15.30 & 43.0 & 5.57 \\
\hline Mean & 4.07 & 7.07 & 5.95 & 8.28 & 4.32 \\
\hline S.E. & 0.52 & 0.65 & 0.52 & 2.70 & 1.25 \\
\hline Geometric mean & 3.78 & 6.52 & 5.18 & 6.28 & 4.14 \\
\hline Distribution & Yes & Yes & Yes & No & NA \\
\hline \multicolumn{6}{|c|}{ Exposure to aqueous extracts and leachates only } \\
\hline$N$ & 4 & 10 & 18 & 6 & No data \\
\hline Minimum & 1.50 & 4.40 & 1.90 & 2.50 & \\
\hline Maximum & 4.87 & 9.64 & 15.30 & 43.00 & \\
\hline Mean & 3.28 & 7.46 & 6.74 & 11.56 & \\
\hline S.E. & 0.74 & 0.54 & 0.78 & 6.32 & \\
\hline Geometric mean & 3.77 & 7.26 & 6.01 & 11.77 & \\
\hline Distribution & NA & Yes & Yes & NA & \\
\hline
\end{tabular}

\footnotetext{
${ }^{a}$ All values are maximum frequency of micronuclei in numbers per 100 tetrads for a given exposure/experiment.

b Insufficient data for normality test.
} 


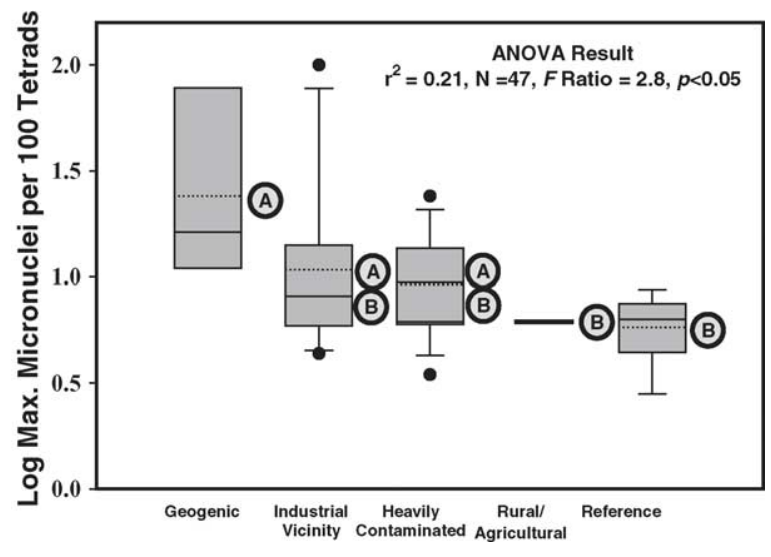

Fig. 11. Box plots of the published Tradescantia micronucleus induction data for soils from heavily contaminated sites, industrial sites, rural/agricultural sites, remote sites, and sites contaminated with geogenic metals (direct contact only). The overlayed text shows the results of the ANOVA analysis for a site category effect. Potency values were log transformed to meet the assumptions of least squares ANOVA. Refer to the Fig. 3 legend for a detailed description of the box. Boxes labeled with different letters are significantly different at $p<0.05$ (Duncan multiple range test). The values shown were obtained from 15 published studies [63,66,67,69,76$78,81,83,85,120,252,283,286,474]$. All values are available in Appendix B. The number of observations in each site category is available in Table 16.

Majer et al. [76,77]. These soils (i.e., Feistritz, Saualpe) contained natural levels of As between 150 and $1500 \mathrm{ppm}$, and additional experimentation showed an 11-fold induction of MN could be elicited by exposure to soils artificially spiked with $990 \mathrm{ppm}$ As $\left(\right.$ as $\left.\mathrm{As}_{2} \mathrm{O}_{3}\right)$ [77].

Separate analysis of the Tradescantia MN results for aqueous or DMSO extracts only showed no significant differences between the mean values across the four site categories (not shown). Therefore, although some studies have stated that the MN assay in Tradescantia is a sensitive endpoint for the detection of mutagenic activity in environmental samples (e.g., water, effluents, air) [85,252,283,289], the data collected and analysed in this review do not support its utility for analysis of soil extracts and aqueous leachates. This assertion is supported by the Knasmüller et al. study that observed significant positive MN responses for direct soil exposures, but not for aqueous leachates [76]. The authors of that study concluded that the Tradescantia MN assay is "less appropriate" for the detection of mutagenic activity in aqueous soil extracts. However, it should be noted that is not clear whether the lack of sensitivity observed with aqueous soil extracts is related to the exposure medium or the exposure duration. As already noted, exposure times for examinations of aqueous samples are usually $3-12 \mathrm{~h}[69,83,238]$, whereas the exposure duration for the direct-contact assessments described by Knasmüller et al. was $72 \mathrm{~h}$.

The assertion that exposure duration contributes to a lack of sensitivity in the Trad-MN assay on aqueous soil extracts is supported by the results of BaudGrasset et al. [120]. The study, which employed a $30 \mathrm{~h}$ exposure to an aqueous extract of a creosote contaminated soil with over $5000 \mathrm{ppm}$ PAH, showed a large increase in $\mathrm{MN}$ frequency [120]. In addition, empirical analysis of the Tradescantia MN data showed a significant positive relationship between MN induction frequency for aqueous extracts and PAH contamination. However, it should be noted that the relationship $\left(r^{2}=0.27, p<0.04\right)$, illustrated in Fig. 12, is heavily dependent on the single extreme value from the Baud-Grasset study. If this point is removed, the relationship is no longer significant $\left(r^{2}=0.005, F=0.07\right)$.

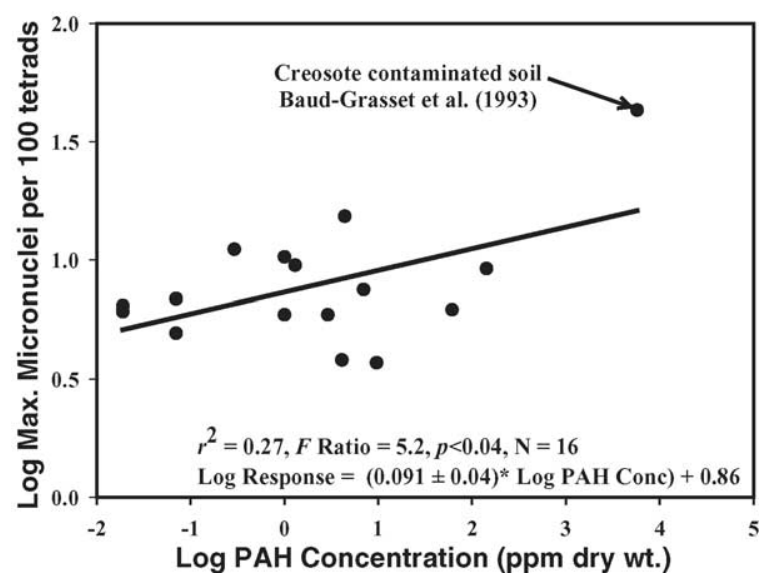

Fig. 12. Empirical relationship between the MN frequency in Tradescantia exposed to aqueous soil leachates and the level of PAH contamination (ppm dry weight). All values were log transformed to meet the assumptions of least-squares regression. The overlaid information shows the results of the linear regression analysis. All values shown were obtained from four published studies $[63,83,120,475]$ (see Appendix B). The relationship is not significant if the extreme value from Baud-Grasset et al. [120] is removed. Minimum, maximum, and mean PAH contamination values are summarized in Table 4. 
Data from the 33 samples examined by Knassmüller et al. and Majer et al. were used to explore empirical relationships between $\mathrm{MN}$ induction in the direct-contact assay and soil metal contamination (e.g., As, $\mathrm{Zn}, \mathrm{Pb}, \mathrm{Cr}, \mathrm{Cd}, \mathrm{Ni}, \mathrm{Sb}, \mathrm{Ni}$ ) [76,77]. The results, illustrated in Fig. 13, show significant relationships between Tradescantia MN frequency and the concentrations of eight metals: $\mathrm{Cr}, \mathrm{Pb}, \mathrm{Cd}$. As, $\mathrm{Cu}, \mathrm{Sb}, \mathrm{Ni}$, and $\mathrm{Zn}$. All relationships are significant at $p<0.03$ and $r^{2}$ values range from a low of 0.16 for cadmium and zinc, to a high of 0.42 for antimony. It is interesting to note that the Majer et al. study from which 18 observations were obtained, failed to detect a significant relationship between MN induction and metal concentration. An earlier study by Steinkellner et al. confirmed that the metals $\mathrm{As}^{3+}, \mathrm{Cd}^{2+}, \mathrm{Zn}^{2+}$, and $\mathrm{Pb}^{2+}$ all induce positive responses in the Tradescantia $\mathrm{MN}$ assay. In addition, Knasmüller et al. [76] showed a significant positive response to $\mathrm{Ni}^{2+}$ and $\mathrm{Cr}^{6+}$; however, neither study was able to show a significant positive response for $\mathrm{Cu}^{2+}$ or $\mathrm{Sb}^{3+}$.

The genotoxicity of many metals, including $\mathrm{Sb}$ and $\mathrm{Cr}$, is a complex and controversial topic. For example, $\mathrm{Cu}^{2+}$ elicits a positive response in the Mutatox ${ }^{\circledR}$ assay and the SOS Chromotest [290], but a negative response in the Salmonella mutagenicity test (TA98 and TA100) [290]. However, although this same study failed to detect a significant Salmonella response for $\mathrm{Cd}^{2+}$ and $\mathrm{Zn}^{2+}$, Pagano et al. detected a significant positive response in Salmonella TA97 [180]. $\mathrm{Cu}^{2+}$ has also been shown to induce chromosome damage in some in vivo assays such as the chick embryo $\mathrm{MN}$ and CA test [291]. The genotoxicity of antimony is also controversial. Antimony $\left(\mathrm{Sb}^{3+}\right)$ elicits negative results in the Salmonella mutagenicity test, the $t k$ mutation assay in L5178Y cells, and the MN assay in mouse peripheral blood (in vivo), but a positive clastogenic response in human peripheral lymphocytes, and positive responses in the $\mathrm{rec}^{-}$differential survival assay, an SCE induction assay in V79 cells, and an in vivo $\mathrm{CA}$ assay in mouse bone marrow (chronic 21-day exposure only) [292-294].

\subsection{Other plant assays used for soil mutagenicity assessment}

Table 17 includes assessments of soil mutagenic activity that examined induction of $\mathrm{MN}, \mathrm{CAs}$ and
SCEs in Vicia faba, and induction of MN in Allium сера. These endpoints are not as popular for soil genotoxicity assessments as the aforementioned assays in Tradescantia, Allium, Zea and Arabidopsis, and the amount of published data was insufficient for detailed analyses. Nevertheless, it is useful to include a descriptive summary of the results obtained with these less popular assay systems. Five studies, three of which also used one of the more popular tests, employed the MN assay in Vicia to examine contaminated soils $[68,76,79,82,83]$. The study by Knasmüller et al. examined MN induction in both Tradescantia and Vicia following direct contact exposures to metal contaminated soils (72-h) [76]. Although the results revealed a strong positive response for Tradescantia (up to 15-fold above control), the soils did not induce a significant positive response in the Vicia assay. Three other studies of metal contaminated soils revealed significant increases in MN or CA frequency in Vicia exposed to aqueous extracts of waste heap soil collected adjacent to a chromium processing facility $(\mathrm{Cr} \sim 3 \mathrm{ppm})$, tannery waste leachate $(\mathrm{Cr} \sim 86 \mathrm{ppm})$, or flyash-amended soil (direct-contact) examined before and after composting (Cr $\sim 30$ to $130 \mathrm{ppm})[68,80,82]$. The latter study also observed a significant increase in the frequency of chromosomal and mitotic aberrations [79]. It is interesting to note that although all of these studies detected high concentrations of chromium, and the authors of the flyash and tannery waste studies highlighted chromium as the probable source of the genotoxic activity [82], Knasmüller et al. could not induce $\mathrm{MN}$ in Vicia using exposures to $\mathrm{Cr}(\mathrm{III}) \mathrm{Cl}_{3}$ or $\mathrm{Cr}(\mathrm{VI}) \mathrm{O}_{3}$ [76]. The mutagenicity of chromium VI has been well studied and it is known to induce significant positive responses in numerous assay systems (e.g., Salmonella mutagenicity, prophage induction, murine peripheral blood MN) [112,180,290,295,296].

In an examination of soils contaminated with organic contaminants, Cotelle et al. noted that the Vicia $\mathrm{MN}$ assay was more sensitive than $\mathrm{MN}$ induction assays in Allium or Tradescantia for the detection of mutagenicity in a leachate sample from a soil contaminated with PCBs and solvents (e.g., toluene, benzene, chloroform) [83]. However, analysis of a leachate of a PAH contaminated soil revealed similar sensitivity for the three endpoints. A similar analysis of an aqueous leachate from an industrial soil contaminated with PAHs revealed a significant 

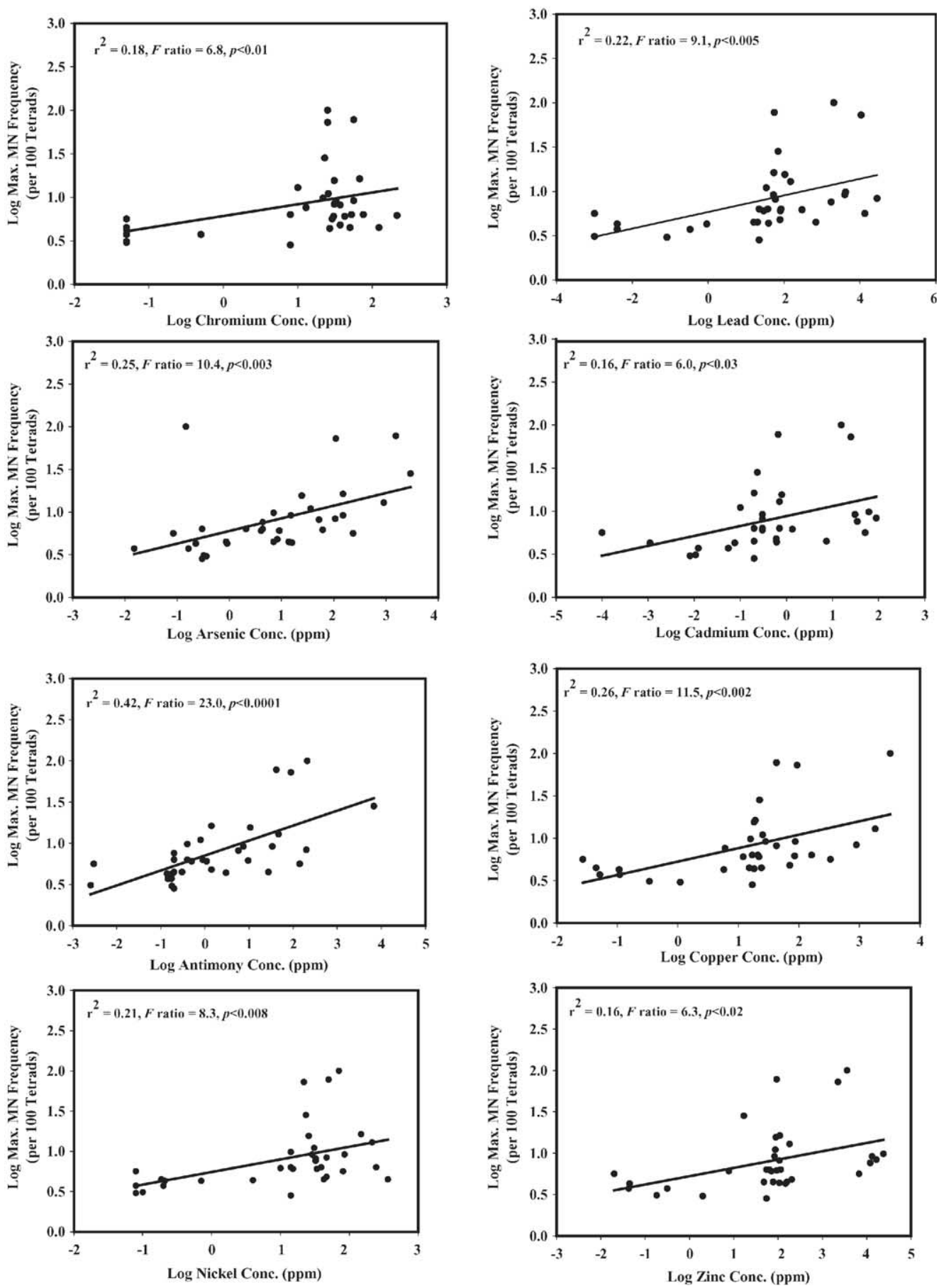

Fig. 13. Empirical relationships between published MN frequency in Tradescantia (direct contact exposures) and the level of soil contamination with various metals (ppm dry weight). All metal concentrations are total extractable metal, and all values were obtained from two published studies [76,77] (see Appendix B). All values were log transformed to meet the assumptions of least-squares regression. The overlaid information shows the results of the linear regression analysis. Minimum, maximum, and mean metal contamination values are summarized in Table 4. 
increase in SCE frequency in Vicia, but no significant increase in MN frequency [68].

Table 17 also summarizes studies that employed a variety of other plants assays to investigate the mutagenic hazards of contaminated soils in France [89], Uzbekistan [297], the United States [298,299], and Italy [300]. Chenon et al. employed a reverse somatic mutation assay in Tobacco (Nicotiana tabacum) that assesses mutations at two chloroplast differentiation loci $a_{1}$ and $a_{2}$ [89,301]. The assay system, initially developed by Dulieu [301], examines reversions of greenish-yellow double heterozygotes $\left(a_{1}^{+} / a_{1} a_{2}^{+} / a_{2}\right)$ to green, and the clonal expansion of green cells reveals green spots on greenish-yellow leaves [301]. The test can score a very large number of cells on each individual leaf and has been shown to be very sensitive to low levels of atmospheric pollutants [89,302]. However, direct contact with municipal sewage sludge amended soil for 45 days did not significantly increase the somatic mutation rate over background [89]. Abdullaev et al. employed a root tip CA assay in Gossypium hirsutum (cotton) to investigate the mutagenic effects of repeated herbicide (i.e., cotoran also known as fluometuron and toluin also known as trifluralin) applications [297]. Inspection of primary sprout rootlets from seeds of plants raised in agricultural areas that received repeated pesticide applications revealed an increase in aberrations over background. In addition, the aberration frequency increased with each successive year of application. These results are not surprising since both herbicides have been reported to induce chromosome damage in plants [303,304].

Two studies used flow cytometry to investigate nuclear alterations in Trifolium repens (white clover) and Zea mays (maize) exposed to soils collected near a steel founding operation, and soils amended with coal fly ash, respectively [299,300]. The flow cytometer was employed to measure the fluorescence intensity and DNA content of nuclei stained with fluorochromes such as DAPI (4,6-diamidino-2-phenylindole) or propidium iodide [305]. The results revealed nuclear alterations in maize following exposure to soils amended with high levels of coal fly ash (70 t/ha) [299]. The soil collected near a steel founding operation was found to induce significant quantities of debris (e.g., broken or disrupted nuclei) in clover following direct contact for 15 days [300]. The latter 
study also used AFLP (amplified fragment length polymorphism) analysis to assess DNA sequence changes $[306,307]$ in clover. The results revealed a significant effect from heavy metal contaminated soils collected close to the steel founding operation [300].

A recent study by Rogstad et al. investigated the mutation rate at minisatellite loci in dandelions (Taraxucum officinale) exposed to soils contaminated with a variety of toxic metals [298]. More specifically, VNTR (variable number tandem repeat) DNA probes were employed to assess parent-offspring transmission (i.e., leaf versus seed) of mutations in specimens collected from 16 regions with various levels of metal contamination (e.g., $\mathrm{Cr}, \mathrm{Cd}, \mathrm{Pb}, \mathrm{Mn}, \mathrm{Zn}, \mathrm{Ni}, \mathrm{Cu}$, and $\mathrm{Fe})$. Although the authors did not detect any empirical relationships between mutation rate and metal concentration in the soil, they did detect significant relationships between leaf metal concentration (i.e., $\mathrm{Cd}, \mathrm{Fe}, \mathrm{Mn}, \mathrm{Ni}$ ) and minisatellite mutation rate [298].

\section{Other eukaryotic assays used for soil genotoxicity assessment}

\subsection{In vitro eukaryotic assays}

Table 18 provides a summary of 10 studies that employed a variety of other eukaryotic in vitro assays to assess the genotoxicity of contaminated soils or soil extracts $[40,42,49,54,65,116,146,166,308,309]$. Seven of these studies employed yeast or fungal (e.g., Aspergillus sp., Saccharomyces sp.) assays to assess mutagenic and/or clastogenic effects. These simple eukaryotic organisms are easy to culture and maintain, and have been widely used in genetic research [310]. They have the distinct advantage of being able to exist in both haploid and diploid state, and consequently can provide a comprehensive range of endpoints including forward mutation, reverse mutation, mitotic recombination, aneuploidy, and gene conversion [94,311-316]. Several works by Donnelly et al. and Brown et al. used haploid Aspergillus nidulans for the detection of forward mutations at methionine suppressor loci [94,95,315], and/or diploid Aspergillus nidulans for the detection of mitotic recombination and nondisjunction events [314,316], to examine soils contaminated with wood preserving wastes [42,49,317], refinery wastes $[49,166]$, and munitions [54]. The results obtained show that exposures to extracts of agricultural soils can yield up to 3.5 methionine suppressor mutants per $10^{6}$ survivors. Although this is significantly above the solvent control value of approximately 0.7 mutants per $10^{6}$ survivors (without S9), it is substantially lower than that obtained following exposures to extracts of soils amended with a variety of hazardous wastes [40]. Examinations of soils amended with refinery wastes or wood preserving wastes revealed significant levels of mutagenic activity in both the haploid and diploid assay. Extracts of wasteamended soils yielded approximately 100 to 300 mutants (per $10^{6}$ survivors) for refinery wastes (i.e., storm-water runoff impoundment waste, separator sludge and slop-oil emulsion solids), and approximately 30 to 174 mutants (per $10^{6}$ survivors) for wood preserving wastes $[42,49,166]$. Additional Salmonella mutagenicity analysis of the soils amended with woodpreserving wastes suggested that the Aspergillus mutation endpoint may be more sensitive [42]. Although the refinery wastes might be expected to contain PAHs [318], refinery amended soils did not show increased mutagenic activity in the presence of S9. However, addition of S9 did increase the mutagenic activity of the soils amended with wood preserving wastes, and additional chemical analysis did identify mutagenic PAHs and heterocyclics compounds (e.g., fluoranthene, dibenzothiophene) [42,319].

Examination of extracts from the soils amended with refinery wastes also elicited moderate mutagenic activity ( $<3$-fold above control) in the Aspergillus diploid assay (e.g., mitotic cross-overs, non-disjunction) [49]. Testing of extracts from soils amended with wood-preserving wastes in the same diploid assay system yielded responses 2- to 4-fold above the control [49]. Additional examinations of the unaltered wood preserving waste (i.e., a soil/sludge mix from a waste lagoon) revealed extreme mutagenic activity in the haploid assay with S9 activation (i.e., $>20,000$ induced mutants per $10^{6}$ survivors), and moderate clastogenic activity in the diploid assay (i.e., induced segregation index $<5$-fold above control) [49,317]. Comparison of various waste fractions showed that the acid fraction (without S9) induced the major chromosomal abnormalities and the base fraction induced minor deletions or insertions (without S9). In contrast, the mutagenic endpoint in haploid Aspergillus was more sensitive to the neutral fraction (with and without S9). However, 
Table 18

Miscellaneous soil mutagenicity results — eukaryotic in vitro assays

\begin{tabular}{|c|c|c|c|}
\hline Site(s) examined & Bioassay employed & Results obtained & Reference \\
\hline \multirow[t]{2}{*}{$\begin{array}{l}\text { Combined } \mathrm{API}^{\mathrm{a}} \text { separator sludge and } \\
\text { slop-oil emulsion solids }\end{array}$} & $\begin{array}{l}\text { Aspergillus nidulans haploid forward } \\
\text { mutation assay }{ }^{\mathrm{b}} \text { on DCM extracts }\end{array}$ & $\begin{array}{l}\text { Potent mutagenic activity with and without } S 9 \text {. } \\
\text { Potency } \sim 109-180 \text { mutants (per } 10^{6} \text { survivors) } \\
\text { per gram soil. Slight increase with S9 }\end{array}$ & {$[49,166]$} \\
\hline & $\begin{array}{l}\text { Aspergillus nidulans diploid mutation } \\
\text { assay }^{\mathrm{c}} \text { on DCM and MetOH extracts }\end{array}$ & $\begin{array}{l}\text { Moderate genotoxic activity in several fractions } \\
(<3 \text { times background) }\end{array}$ & {$[49,166]$} \\
\hline \multirow[t]{2}{*}{$\begin{array}{l}\text { Storm-water runoff impoundment } \\
\text { (SWRI) waste }\end{array}$} & $\begin{array}{l}\text { Aspergillus nidulans haploid forward } \\
\text { mutation assay on DCM extracts }\end{array}$ & $\begin{array}{l}\text { Potent mutagenic activity with and without } S 9 \text {. } \\
\text { Potency } \sim 127-308 \text { mutants (per } 10^{6} \text { survivors) } \\
\text { per gram soil. No increase with } S 9\end{array}$ & {$[49,166]$} \\
\hline & $\begin{array}{l}\text { Aspergillus nidulans diploid mutation } \\
\text { assay on DCM and MetOH extracts }\end{array}$ & $\begin{array}{l}\text { Moderate genotoxic activity in several fractions } \\
\text { ( }<3 \text { times background) }\end{array}$ & {$[49,166]$} \\
\hline $\begin{array}{l}\text { Agricultural soils } \\
\text { (row crops and grazing land) }\end{array}$ & $\begin{array}{l}\text { Aspergillus nidulans haploid forward } \\
\text { mutation assay on DCM extracts }\end{array}$ & $\begin{array}{l}\text { Weak activity with and without } S 9 . \text { Higher } \\
\text { activity on grazing land. Potency } \approx 0.04-3.5 \\
\text { mutants (per } 10^{6} \text { survivors) per gram soil }\end{array}$ & {$[40]$} \\
\hline \multirow[t]{2}{*}{$\begin{array}{l}\text { Wood-preserving bottom sediment } \\
\text { (surface impoundment) }^{\mathrm{e}}\end{array}$} & $\begin{array}{l}\text { Aspergillus nidulans haploid forward } \\
\text { mutation assay on DCM extracts }\end{array}$ & $\begin{array}{l}\text { Potent mutagenic activity with and without } \mathrm{S} 9 \\
\text { Potency } \sim 27-56 \times 10^{3} \text { mutants (per } 10^{6} \text { survivors) } \\
\text { per gram soil. Significant increase with S9 }\end{array}$ & {$[42,49,317]$} \\
\hline & $\begin{array}{l}\text { Aspergillus nidulans diploid mutation } \\
\text { assay on DCM and MetOH extracts }\end{array}$ & $\begin{array}{l}\text { Positive response on acid, base, and neutral } \\
\text { fractions. ISI }{ }^{\mathrm{f}} 2-5 \text { times control }\end{array}$ & {$[42,49,317]$} \\
\hline \multirow[t]{2}{*}{$\begin{array}{l}\text { Soils amended with wood } \\
\text { preserving waste }\end{array}$} & $\begin{array}{l}\text { Aspergillus nidulans haploid forward } \\
\text { mutation assay on DCM extracts }\end{array}$ & $\begin{array}{l}\text { Potent mutagenic activity with and without S9. } \\
\text { Potency } \sim 30-174 \text { mutants (per } 10^{6} \text { survivors) } \\
\text { per gram soil. Significant increase with S9 }\end{array}$ & {$[42,49]$} \\
\hline & $\begin{array}{l}\text { Aspergillus nidulans diploid mutation } \\
\text { assay on DCM and MetOH extracts }\end{array}$ & $\begin{array}{l}\text { Positive response on acid, base, and neutral } \\
\text { fractions. ISI }{ }^{\mathrm{f}} 2-4 \text { times control }\end{array}$ & [49] \\
\hline
\end{tabular}

Soils from surface impoundments Aspergillus nidulans diploid genotoxicity contaminated with munitions wastewater assay on DCM and MetOH extracts

Urban soils from Yana, Sesavtchy, $\quad$ Saccharomyces cerivisiae (diploid) D7

Lokorsko (Bulgaria)

and $\mathrm{D} 7 t s l^{\mathrm{g}}$ mutation and mitotic

recombination assay on toluene extracts

Positive response for soil from two impoundments.

2- to 4-fold above background

Dose related increase in mutagenic and

recombinogenic activity in D7ts1 strain from the

least contaminated (Lokorsko) to the most contaminated (Yana) 


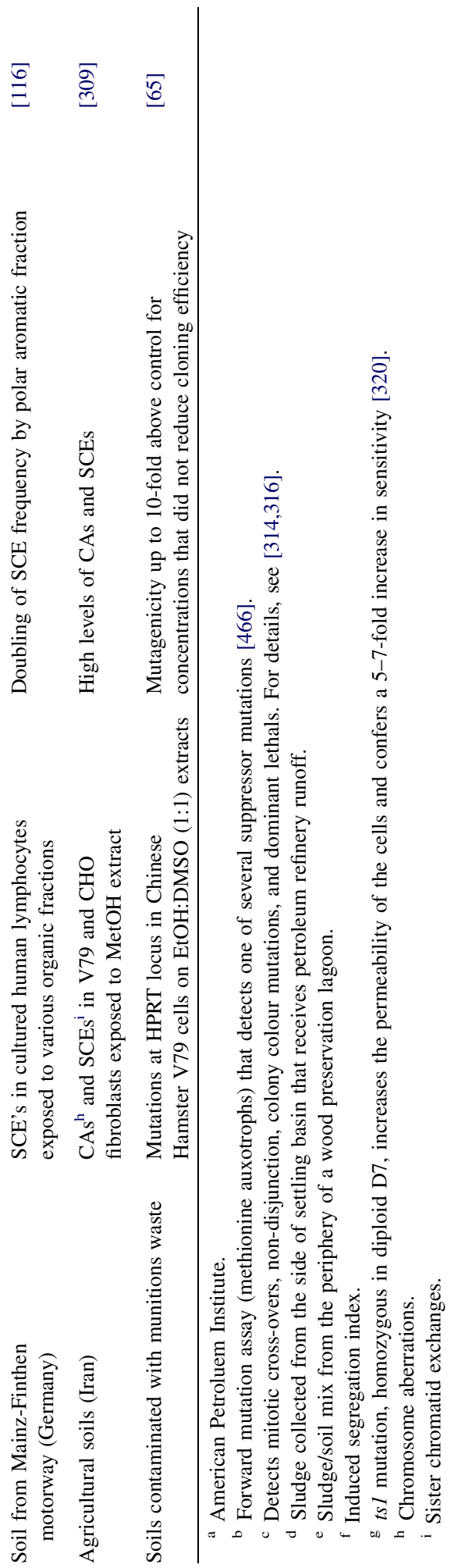

although this study detected differences in the response patterns for Salmonella, B. subtilus (differential survival), and Aspergillus, the authors' described the overall assessments of waste mutagenicity as "comparable" [317].

Donnelly et al. also used the diploid assay to examine DCM and MetOH extracts of soils from surface impoundments receiving munitions wastewaters [54]. For two of the four impoundments examined, the results revealed 2- to 4-fold increases in clastogenic effects over that observed for an extract of background soil. Chemical analysis revealed TNT concentrations of $225-1290 \mathrm{ppm}$ for the two sites that yielded positive samples.

Terziyska et al. employed a permeable strain of Saccharomyces cerivisiae to examine the mutagenic and clastogenic activity of toluene extracts of several soils collected from urban locations in Bulgaria [308]. The strain employed in the study, S. cerivisiae D7ts1, displays increased permeability and substantially enhanced sensitivity to a variety of chemical mutagens over that observed for the standard D7 tester strain [96,320]. The soil results confirmed the increased sensitivity of the D7ts1 strain, and showed a doserelated increase in mutagenic and recombinogenic activity from the least contaminated soil, collected at Lokorsko, to the most contaminated soil collected at Yana. Comparison with the negative Salmonella mutagenicity results suggested enhanced sensitivity of the S. cerivisiae D7ts1 assay.

Only three published studies employed mammalian cells to assess the mutagenicity of contaminated soils and soil extracts [65,116,309]. Zia'ee and Sabouni employed Chinese Hamster ovary (i.e., CHO) and V79 lung cells to investigate the genotoxicity of a $\mathrm{MetOH}$ extract of an agricultural soil [309]. The results revealed that low doses of the MetOH extracts induced both CAs and SCEs. However, they did not detect a significant induction of alkali-labile DNA damage. Berthe-Corti et al. employed the hprt assay in V79 cells to investigate the mutagenicity of EtOH/DMSO extracts of a soil contaminated with munitions compounds including TNT and hexogen (hexahydro-1,3,5-trinitro-1,3,5-triazine) [65]. The results revealed activity as high as 10 -fold above the control for concentrations that did not reduce cloning efficiency. One study employed an SCE assay in cultured human lymphocytes to examine the geno- 
Table 19

Miscellaneous soil mutagenicity results — eukaryote in vivo assays

\begin{tabular}{lll}
\hline Site(s) examined & Bioassay employed & Results obtained \\
\hline Soil from Mainz-Finthen motorway (Germany) & Bone marrow MN in mice exposed to & No increase in MNPCE (micronucleated
\end{tabular}

Soil from Mainz-Finthen motorway (Germany) Bone marrow MN in mice exposed to organic fractions (oral gavage)

No increase in MNPCE (micronucleated

[116]

Coal tar amended soil, fresh or aged for 9 months

Bulky DNA adducts in liver and lung of F344 rats exposed via diet for 17 days

Highly significant increase in adduct

frequency in lung and liver. Lung

3 -fold greater than liver. Aging has no effect

Soils from urban/industrial sites (Czech Republic)

Soils from swampy area near concrete factory (Kazakhstan)

Soils of unknown origin

Radioactive soils (7000 Bq/kg) from Chernobyl

Soil amended with municipal sludge (France)

Two soils contaminated with metals and solvents, or PAHs (France)
Somatic mutation and recombination test in Drosophila melanogaster ${ }^{\mathrm{a}}$ on aqueous and DCM extracts

Somatic mutations in Drosophila melanogaster exposed to organic extracts

Somatic mutations in Drosophila melanogaster (wing spots) exposed to various soils (12)

Dominant lethals and sex-linked recessive lethals in Drosophila melanogaster

$\mathrm{MN}$ in Xenopus laevis exposed to aqueous leachates

$\mathrm{MN}$ in Xenopus laevis exposed to aqueous leachates/percolates
Significant positive response for four of nine DCM extracts and six of eight aqueous extracts

No significant effect

No significant effect

14-day exposure contributed to an increase early embryonic dominant lethals and sex-linked recessive lethals

Significant effect at several

elevated leachate concentrations

Significant increase in MN for leachate of the PAH contaminated soil

\footnotetext{
${ }^{\text {a }}$ Drosophila wing spot test $[92,467]$.
} 
toxicity of organic fractions from a soil collected at a highway junction that receives heavy vehicle traffic [116]. The results revealed that fractions containing polar aromatics such as nitroarenes induced significant increases ( 2-fold above control) in SCE frequency both with and without S9.

\subsection{In vivo eukaryote assays}

Table 19 summarizes eight studies that employed in vivo assays to assess the genotoxic activity of contaminated soils. Three of these studies employed the somatic mutation and recombination test (SMART) in Drosophila melanogaster [68,203,321]. The assay, sometimes referred to as the wing spot test, can detect both somatic mutations and recombination in individuals that are trans-heterozygous for two wing morphology mutations, multiple wing hairs $(m w h)$ and flare $(f r)[92,322,323]$. The study by Chroust et al. exposed Drosophila eggs to DCM or water extracts of soils collected in close proximity to a pharmaceutical manufacturing plant and a coal tar conversion facility [68]. Examination of adults raised from the exposed eggs revealed significant increases in wing spot frequency for DCM extracts of all four soils collected near the coal-tar facility. Two of the water extracts yielded weak positive responses. Additional chemical analysis revealed that three of the four tested samples had PAH levels above $700 \mathrm{ppb}$. Only two of the four soils collected near the pharmaceutical manufacturing facility yielded DCM extracts that elicited a positive response in the wing spot assay. These results corresponded to those obtained using the Arabidopsis gene mutation assay and the SCE assay in Vicia faba. DCM extracts of all four coal tar soils induced a positive response in the Arabidopsis assay, and water extracts induced significant increases in SCEs in Vicia faba.

Two Russian studies used the SMART (wing spot) to examine the genotoxicity of contaminated soils. Gevirkian et al. examined the mutagenic activity of organic extracts of soils collected from a swampy area near a damaged waste pipe from a concrete production facility in Khazakstan [321]. The results indicate no significant increase in wing spot frequency over the control. Pererva et al. employed the SMART to examine the mutagenicity of extracts from 12 unidentified soil samples [203]. None of the samples elicited a significant positive response. A third Russian study employed the sex-linked recessive and dominant lethal assays in Drosophila to examine the mutagenic hazards of a radionuclide-contaminated soil [324]. The assays, first conceived in the late 1920s, can assess the frequency of heritable (paternal) mutations, and sequential mating can assess the susceptibility of different germ cells stages (e.g., spermatagonia, spermatocytes, spermatids) [325]. The results revealed that a 14-h exposure of males to soils containing $7 \mathrm{~Bq} /$ g significantly increased ( $\sim 2$-fold) the frequency of sex-linked recessive lethals. Using a sequential brooding pattern the dominant lethal assay revealed that the maximum was associated with the pre-meiotic spermatogonial stage.

Two studies employed an erythrocyte MN assay in the clawed frog Xenopus laevis to assess the mutagenic activity of contaminated industrial soils. Chenon et al. exposed Xenopus larvae (i.e., tadpoles) to aqueous extracts from soils amended with sewage sludge [89]. Examination of blood after a 12-day exposure failed to reveal a significant increase in $\mathrm{MN}$ frequency. Békaert et al. exposed Xenopus larvae to a range of dilutions of aqueous extracts/leachates of two soils, the first contaminated with solvents and metals, the second contaminated with PAHs [88]. The results revealed a significant increase in the frequency of micronucleated erythrocytes (6-50\%) in animals treated with aqueous leachates of the PAH contaminated soil ( $\sim 240 \mathrm{ppm})$. An aqueous percolate through a column containing $30 \mathrm{~kg}$ of the metal contaminated soil also elicited a significant increase in the frequency of micronucleated blood cells (3\%).

Two studies attempted to employ in vivo mammalian assays to investigate the genotoxic hazards of a contaminated soil. Wesp et al. employed the mouse peripheral blood $\mathrm{MN}$ assay to assess the mutagenic activity of various organic fractions from a soil collected along a heavily trafficked motorway [116]. Gavage exposure of 7-12-week-old NMRI mice to polar neutrals (e.g., trinitrotoluene), non-polar neutrals (PAHs), and polar aromatics (e.g., nitroarenes) at $2000 \mathrm{mg} / \mathrm{kg}$ followed failed to reveal any increase in the frequency of micronucleated PCEs (polychromatic erythrocytes) over the vehicle control. Bordelon et al. fed Fisher 344 rats a diet that was supplemented with coal-tar amended soil ( $0.35 \%$ by weight) for 17 days and examined the frequency of bulky DNA adducts in 
Summary of soil mutagenicity results published only as conference abstracts

\begin{tabular}{lll}
\hline Site(s) examined & Bioassay(s) employed & Results obtained \\
\hline $\begin{array}{l}\text { Soils from Tokyo, Bangkok, } \\
\text { Chaing Mai, and Manila }\end{array}$ & Salmonella mutagenicity ${ }^{\mathrm{a}}$ (TA100 and & Increased activity with S9. TA98 +S9: \\
Agricultural soils (Illinois, USA). & TA98), benzene-EtOH (3:1) extract & Tokyo $>$ Manila $>$ Chaing Mai $>$ Bangkok \\
\hline [327] & Salmonella mutagenicity (preincubation & Water extract: no activity. Organic extract
\end{tabular}

\section{PAH contaminated soils (Czech Republic)}

16 contaminated soils (PAHs, metals)

(Lumbardy region, Italy)

Heavily contaminated (Superfund) soils (USA) Tradescantia MN test and CA test in Allium

Heavily contaminated (Superfund) soils (USA) CA test in Allium cepa root tip

Soil (ex situ) amended with municipal wastewater sludge

Contaminated soils (not described)

Rubber factory mire (China)

Soils contaminated with heavy cycle oils

Sewage sludge extracts applied to native clay loam

Pesticide and wood preserving waste contaminated soils

Street soils from metropolitan Manila (Philippines)

Soils from rural, low density traffic areas in Germany

Urban soils (Japan)

Salmonella mutagenicity, Tradescantia $\mathrm{MN}^{\mathrm{b}}$ cepa root tip cells on aqueous extracts cells on aqueous extracts

with TA98), water extract, combined MetOH-acetone

(1:1), MetOH-acetone-benzene (1:1:1) extract

Salmonella mutagenicity (TA100 and

TA98) and SOS Chromotest

test, $\mathrm{CAs}^{\mathrm{c}}$ in Allium cepa root

Salmonella mutagenicity (TA98 with S9)

on aqueous leachate and hexane-acetone extract

Tradescantia MN and SHM test, in situ incubations

Tradescantia MN on mire extracts (solvent not specified)

Salmonella TA100 mutagenicity on

organic and aqueous extracts

Salmonella TA98 mutagenicity on DCM extracts

In situ Tradescantia $\mathrm{MN}$ and Zea

mays waxy locus assay

$\mathrm{rec}^{-}$differential survival assay, MN assay (organism not specified) on organic extracts

Salmonella TA98 and TA100 mutagenicity

on hexane/acetone extracts

Salmonella mutagenicity (TA100, TA98,

TA98NR, TA98/1,8DNP 6 ) on organic extract with S9: 3.5-5-fold increase over background

With S9 activation: positive responses

on TA98, TA100 and SOS Chromotest

Several positive responses. Details not provided

No response on Tradescantia MN test, dose-related increases in CAs in Allium

Dose-related increases in CAs in Allium

Positive response on leachate and organic extract of soil and sludge

Not described

[286]

Significant increase in MN frequency above contro

Positive response without S9

Significantly higher MN frequency than control.

Toxic effect inhibited maize growth

Significant mutagenicity and clastogenicity

with metabolic activation

TA98 mutagenicity exceeded control for a variety of samples. Lower TA100 mutagenicity. Response not related to soil PAH concentration (0.03-2.6 ppm)

Highest activity in TA98NR and TA100 without S9

\footnotetext{
Standard plate incorporation assay, unless otherwise noted.

${ }^{\mathrm{b}}$ Micronuclei.
}

${ }^{\mathrm{c}}$ Chromosomal aberrations. 
lung and liver (dose $\sim 184$ to $251 \mu \mathrm{g} \mathrm{PAH} / \mathrm{g}$ rodent chow) [326]. The results revealed a significant increase in adduct frequency and a 3-fold greater adduct frequency in lung versus liver. Moreover, no declines in adduct frequency were seen in a group exposed to coal tar amended soil that was aged for 9 months prior to dosing. Additional analyses showed that several of the bulky adducts detected using ${ }^{32} \mathrm{P}$ post-labelling correspond to the metabolized products of benzo[a]pyrene, benzo[b]fluoranthene, benzo[j]fluoranthene, and chrysene.

\section{Miscellaneous soil genotoxicity results}

The peer-reviewed literature also contains abstracts of 20 studies that examined the genotoxic activity of contaminated soils and soil extracts. Table 20 contains a summary of these studies. Of the 20 studies listed, the majority (9) employed the Salmonella mutagenicity test, 5 used the Tradescantia MN test, 3 assessed anaphase aberrations in Allium root tip cells, one examined waxy locus mutations in Zea mays, one examined differential survival in $\mathrm{rec}^{-}$B. subtilus, and one employed the SOS Chromotest. Despite a lack of detailed information about these studies and the results obtained, the table does contain some interesting and useful information. For example, the Salmonella mutagenicity results obtained for extracts of urban soils [327], and soils known to be contaminated with PAHs [328,329] are consistent with the results already discussed (i.e., S9-activated positive responses in TA100 and TA98 accompanies PAH contamination).

Two studies that employed the Tradescantia MN assay and the Allium anaphase aberration assay to examine aqueous extracts of heavily contaminated Superfund soils revealed a lack of response in the Tradescantia assay and a significant positive on the Allium assay [330,331]. This result is consistent with the Tradescantia results already discussed in Section 8.5 (i.e., Tradescantia $\mathrm{MN}$ assay is less responsive to aqueous extracts). In addition, two of the listed studies did not detect significant induction of $\mathrm{MN}$ in Tradescantia tetrads following direct contact exposures [285,332], or exposures to soil organic extracts [286]. This is also consistent with the results presented in Section 8.5.

\section{Remediation of genotoxic soils}

Contaminated soils can be remediated using a variety of techniques that fall into four basic categories: physical, chemical, thermal, and biological [333]. Physical techniques include a variety of methods for excavation, entombment, or covering of contaminated areas [333,334]. Excavation involves removal for on- or off-site destruction, disposal or storage. Entombment involves construction of a properly sealed landfill used to retain highly contaminated soils and prevent movement of toxic contaminants. Covering, a method that is not acceptable for highly contaminated areas, simply involves covering the contaminated material with fresh soil, concrete, or asphalt.

Chemical methods include a wide range of techniques to neutralize or remove toxic substances. Common strategies include soil washing, vacuum extraction, electro-reclamation for metal removal, contaminant oxidation, precipitation, or reduction, and contaminant adsorption to activated carbon [335-338]. Thermal techniques essentially involve detoxification via combustion. Commonly used techniques include fluidized bed or rotary kiln combustion [333,337].

Biological remediation techniques involve the use of organisms (e.g., bacteria, fungi, plants) to detoxify and/or destroy toxic contaminants. The strategy is mainly applied to soils contaminated with organic materials and a wide range of techniques are currently available [333,337-344]. The popular bioremediation techniques can essentially be sub-divided into four ex situ categories: biopile, bioslurry, composting, and land farming; and three in situ categories: attenuated bioremediation, passive bioremediation, and phytoremediation [333, 337,338,340-343,345-347]. Biopile treatment involves excavation, piling the contaminated material in mounds, and incubating the material under natural conditions for extended periods of time [348350]. The method usually involves supplementation with air, and sometimes nutrients, minerals, and water are added to speed degradation [349,350]. In addition, organisms selected for their ability to degrade particular contaminants (e.g., petroleum hydrocarbons) are sometimes added [348]. Composting, a method that is similar to biopiling, involves supplementation of the soil with manure (e.g., bovine, equine) and/or dry plant material (e.g., agricultural waste, sawdust) to provide a source of 
organic carbon and enhance the concentration of nutrients such as phosphorus and nitrogen [66,188,350-352]. The strategy is designed to provide temperature, moisture content, aeration, and nutrient concentrations that promote degradation. The bioslurry technique is a controlled, sophisticated variation on the biopile technique. Treatment by bioslurry involves mixing the soil with water, nutrients, and air and incubating the resulting slurry in a bioreactor under controlled conditions [44]. The incubation temperature is controlled, and the mixture is often continually supplemented with nutrients and air. The technique also frequently involves the addition of microbes selected for their ability to degrade selected contaminants $[353,354]$. Land treatment or land farming, a technique that is fairly similar to biopiling, involves tilling of the contaminated soil with nearby uncontaminated soils, followed by incubation and monitoring for an extended period of time. The material is usually tilled and irrigated at some predetermined frequency to enhance degradation by indigenous organisms $[44,115,355,356]$. In areas with marginal or acidic soils the tilled mixture is often amended with buffering agents and/or nutrients.

In situ bioremediation techniques involve degradation of soil and/or groundwater contaminants by the native fauna, or augmented native fauna, without site excavation. A popular and effective technique, known as accelerated natural attenuation (ANA), involves injection of compounds that accelerate the degradation of toxic contaminants by natural microbial flora. For example, researchers have developed, and are now successfully marketing, compounds that release oxygen for accelerated in situ aerobic degradation, or hydrogen for accelerated in situ anaerobic degradation [357-359]. Two products developed to enhance in situ aerobic or anaerobic remediation, ORC $^{\circledR}$ (oxygen releasing compound) and $\mathrm{HRC}^{\circledR}$ (hydrogen releasing compound), can be pressure injected into the contaminated area for ANA (see www.regenesis.com/products). This strategy is particularly effective for stimulation of reductive dechlorination and remediation of sites contaminated with chlorinated solvents such as tetrachloroethene (also known as tetrachloroethylene or perchloroethylene) [357]. In addition to supplementation with oxygenand hydrogen-releasing compounds, ANA can also involve introduction of organisms selected for their ability to degrade particular substances. Recently isolated bacteria belonging to the genus Dehalococoides effectively accelerate the degradation of trichlro- and tetrachloroethene, generating only ethene, biomass, and inorganic chloride [360,361].

The term phytoremediation encompasses a wide range of techniques that employ plants to extract, degrade, transform, or sequester toxic contaminants in soils. Various terms have been employed to describe specific applications and strategies used in phytoremediation. These include phytoextraction, phytodegradation, phytotransformation, phytovolatilization, and rhizodegradation [340]. Phytoextraction involves the use of carefully selected plants to accumulate toxic contaminants (e.g., metals) in above ground biomass. The plants are then harvested, incinerated, and the ashes properly disposed $[362,363]$. Phytodegradation and phytotransformation involve uptake of soil pollutants and metabolic transformation into less toxic or non-toxic compounds [364]. A specific form of phytotransformation known as phytovolatilization, involves atmospheric release of toxic contaminants or their metabolites via plant transpiration [340,365]. Rhizodegradation, a variation of the same theme, involves degradation in the microbe-rich zone around the root system of a vascular plant (i.e., the rhizosphere). This technique has been successfully applied to soils contaminated with PAHs and petroleum hydrocarbons [366].

A detailed overview of the remediation technologies used at sites contaminated with mutagenic substances is clearly beyond the scope of this work. For detailed information on the various soil remediation technologies readers can consult Terry and Banuelos [367], Suthersan [368], Sara [369], Singh and Jain [340], Sims [337] or Ritter and Scarborough [339].

Table 21 summarizes the results of published studies that investigated the ability to remediate soils contaminated with genotoxic substances. The table summarizes the results of 30 remediation assessments from 26 studies. Six assessments examined soils contaminated with petrochemical wastes (e.g., slopoil emulsion, oil-water separator sludge) or petroleum distillates (e.g., diesel oil, used motor oil) $[59,64,121$, 154,157,166]. Nine assessments examined soils contaminated with wood preservation wastes or creosote $[44,56,64,115,120,121,177,370]$. Five studies examined soils contaminated with PAH-rich 
Table 21

Summary of studies investigating the (bio)remediation of mutagen-contaminated soils

\begin{tabular}{|c|c|c|c|c|c|c|}
\hline Sample/site & Contamination & Assay(s) employed & Remediation process & $\begin{array}{l}\text { Treatment } \\
\text { time (days) }\end{array}$ & Results obtained & Reference \\
\hline $\begin{array}{l}\text { Soil (sandy loam) amended with } \\
\text { petrochemical wastes (slop } \\
\text { oil emulsion) }\end{array}$ & $\begin{array}{l}\text { PAHs }^{\mathrm{a}}(\sim 6000 \mathrm{ppm}) \text {, oil and } \\
\text { grease, heavy hydrocarbons }\end{array}$ & $\begin{array}{l}\text { Salmonella TA98 mutagenicity on } \\
\text { DCM }^{\mathrm{b}} \text { extracts }\end{array}$ & $\begin{array}{l}\text { Batch reactor degradation. } \\
\text { Water content adjusted. } \\
\text { Temperature }=20^{\circ} \mathrm{C}\end{array}$ & 354 & $\begin{array}{l}\text { Mutagenicity }(+\mathrm{S} 9 \text { and }-\mathrm{S} 9) \text { reduced } \\
\text { to below detection. } 43 \% \text { reduction in } \\
\text { PAH concentration }\end{array}$ & [121] \\
\hline $\begin{array}{l}\text { Soil (sandy clay loam) amended } \\
\text { with API oil-water separator sludge }\end{array}$ & Heavy hydrocarbons, PAHs & $\begin{array}{l}\text { Salmonella TA98 mutagenicity on } \\
\text { DCM and MetOH extracts }\end{array}$ & $\begin{array}{l}\text { Incubation in barrel lysimeters }{ }^{\mathrm{c}} \\
\text { exposed to normal rainfall }\end{array}$ & 350 & $\begin{array}{l}\text { Slight increase in mutagenicity (+S9) } \\
\text { at } 180 \text { days. Decrease to background } \\
\text { by } 350 \text { days }\end{array}$ & [64] \\
\hline $\begin{array}{l}\text { Soils (sandy clay and clay) amended } \\
\text { with petrochemical wastes (SWRI }_{\text {waste }^{\mathrm{d}} \text { and slop-oil emulsion solids) }}\end{array}$ & Petroleum hydrocarbons, PAHs & $\begin{array}{l}\text { Salmonella TA98 mutagenicity and } \\
\text { forward mutation induction in } \\
\text { Aspergillus nidulans (DCM extracts) }\end{array}$ & $\begin{array}{l}\text { Incubation in wooden boxes. } \\
\text { Periodic moisture adjustment }\end{array}$ & $360-1000$ & $\begin{array}{l}\text { Steady decline in mutagenicity }(+\mathrm{S} 9) \\
\text { over time }\end{array}$ & {$[166]$} \\
\hline $\begin{array}{l}\text { Soil (clay loam) amended with } \\
\text { petrochemical sludge }\end{array}$ & PAHs (473-3782 ppm) & Salmonella TA98 on ACN extracts & $\begin{array}{l}\text { Laboratory bioremediation. } \\
\text { Adjusted moisture and temperature }\end{array}$ & 373 & $\begin{array}{l}\text { Marked decline in }-S 9 \text { response. Initial } \\
\text { increase in }+S 9 \text { response followed by } \\
\text { slower decline }\end{array}$ & [59] \\
\hline $\begin{array}{l}\text { Soil contaminated with } \\
\text { used motor oil }\end{array}$ & Petroleum hydrocarbons, PAHs & $\begin{array}{l}\text { Salmonella TA1535 and TA1537 } \\
\text { mutagenicity on aqueous extracts }\end{array}$ & $\begin{array}{l}\text { Inoculation with bacteria and } \\
\text { incubation in plastic containers } \\
\text { at } 25^{\circ} \mathrm{C} \text {. Moisture adjusted and } \\
\text { nutrients added }\end{array}$ & 84 & $\begin{array}{l}\text { Steady decline in mutagenicity to } \\
\text { below detection (-S9) }\end{array}$ & [154] \\
\hline $\begin{array}{l}\text { Soil (sandy loam) amended } \\
\text { with diesel oil }\end{array}$ & Diesel oil (PAHs) & $\begin{array}{l}\text { Salmonella TA98 mutagenicity } \\
\text { on DCM extracts }\end{array}$ & $\begin{array}{l}\text { Bioremediation (liming, fertilization, } \\
\text { and tilling) in outdoor lysimeters }\end{array}$ & $\sim 140$ & $\begin{array}{l}\text { Bioremediation treatment eliminated } \\
\text { mutagenicity (-S9) and PAHs } \\
\text { in } 12 \text { weeks }\end{array}$ & [157] \\
\hline $\begin{array}{l}\text { Soils collected near a coke } \\
\text { production facility }\end{array}$ & PAHs (600-800 ppm). & $\begin{array}{l}\text { SOS Chromotest, Salmonella TA98 } \\
\text { mutagenicity on organic extracts }\end{array}$ & Unspecified biodegradation process & 210 & $\begin{array}{l}\text { Large reductions in mutagenicity } \\
(-\mathrm{S} 9 \text { and }+\mathrm{S} 9) \text { and PAH contamination }\end{array}$ & {$[153]$} \\
\hline $\begin{array}{l}\text { Composted soil from a former } \\
\text { gas-works site (Czech Republic) }\end{array}$ & $\begin{array}{l}\text { PAHs ( } 610 \mathrm{ppm} \text { in unaltered } \\
\text { soil), metals }\end{array}$ & SOS Chromotest on DCM extract & $\begin{array}{l}4 \text { to } 1 \text { (wet weight) mixture of } \\
\text { compost (wheat straw, chicken } \\
\text { manure, gypsum) and soil }\end{array}$ & 54 & $\begin{array}{l}\text { Slight reduction in genotoxicity } \\
(+ \text { S9) in upper portions of composted } \\
\text { pile. 20-60\% reduction in PAHs }\end{array}$ & [188] \\
\hline $\begin{array}{l}\text { Soil (Lima loam) amended with } \\
\text { coal tar extract }\end{array}$ & PAHs (400-1400 ppm). & $\mathrm{Rfp}^{\mathrm{e}}$ in Pseudomonas putida (in situ) & $\begin{array}{l}\text { Biodegradation in situ } \\
\text { (land treatment) and ex situ } \\
\text { (laboratory) }\end{array}$ & $59-180$ & $\begin{array}{l}\text { Marked decline in PAH concentration } \\
\text { and mutagenicity by } 147 \text { days. PAH } \\
\text { reduction not related to genotoxicity } \\
\text { changes }\end{array}$ & [90] \\
\hline Soil near coke oven work (Portugal) & PAHs (1141 ppm) & Mutatox ${ }^{\mathbb{B}}$ assay ${ }^{\mathrm{f}}$ on aqueous eluates & $\begin{array}{l}\text { Environmentally controlled } \\
\text { landfarming greenhouse }\end{array}$ & 150 & $\begin{array}{l}60 \% \text { reduction in total PAHs. } 80 \% \\
\text { reduction in 2-, 3-, and 4-ring PAHs. } \\
\text { Weak mutagenicity in eluate from } \\
\text { untreated sample only }\end{array}$ & [201] \\
\hline Coal tar contaminated soil & $\begin{array}{l}\text { Variety of 3-, 4-, 5-, and } \\
6 \text {-ring PAHs }\end{array}$ & SOS Chromotest on aqueous leachate & $\begin{array}{l}\text { Incubation at } 30^{\circ} \mathrm{C} \text { in } 1 \mathrm{~L} \\
\text { stirred (glass) reactors }\end{array}$ & $50-90$ & $\begin{array}{l}\text { No genotoxicity detected (-S9 and } \\
+ \text { S9). } 20-70 \% \text { reduction in } \\
\text { concentration of mutagenic PAHs }\end{array}$ & [189] \\
\hline $\begin{array}{l}\text { Soil (sandy loam) amended with } \\
\text { wood preserving wastes } \\
\text { (creosote sludge) }\end{array}$ & $\begin{array}{l}\text { PCP }^{\mathrm{g}}(\sim 2500 \mathrm{ppm}), \text { creosote }^{\mathrm{h}}, \\
\text { PAHs, dioxins }\end{array}$ & $\begin{array}{l}\text { Salmonella TA98 mutagenicity } \\
\text { on DCM extracts }\end{array}$ & $\begin{array}{l}\text { Batch reactor degradation. } \\
\text { Water content adjusted. } \\
\text { Temperature }=20^{\circ} \mathrm{C}\end{array}$ & 354 & $\begin{array}{l}\text { Mutagenicity }(+S 9) \text { reduced to } \\
\text { below detection. } 71 \% \text { reduction } \\
\text { in PAH concentration }\end{array}$ & [121] \\
\hline $\begin{array}{l}\text { Contaminated soil (loam or sandy } \\
\text { loam) from a wood-preserving } \\
\text { facility }\end{array}$ & $\begin{array}{l}\text { PCP (31-176 ppm), carcinogenic } \\
\text { PAHs (126-279 ppm), Cu, Cr, } \\
\text { and As }\end{array}$ & $\begin{array}{l}\text { Salmonella TA98 mutagenicity } \\
\text { on DCM and MetOH extracts }\end{array}$ & $\begin{array}{l}\text { Bioremediation (tilling, } \\
\text { inoculation, and nutrient } \\
\text { addition) in an } \mathrm{LTU}^{\mathrm{i}}\end{array}$ & $\sim 90$ & $\begin{array}{l}\text { Mutagenicity }(+S 9) \text { of most samples } \\
\text { reduced to acceptable levels } \\
(<150 \mathrm{rev} / \mathrm{g}) \text { within } 3 \text { months }\end{array}$ & {$[115]$} \\
\hline
\end{tabular}




\begin{tabular}{|c|c|c|c|c|c|c|}
\hline Sample/site & Contamination & Assay(s) employed & Remediation process & $\begin{array}{l}\text { Treatment } \\
\text { time (days) }\end{array}$ & Results obtained & Reference \\
\hline $\begin{array}{l}\text { Contaminated soil from a } \\
\text { wood-preserving facility }\end{array}$ & Creosote, $\mathrm{Zn}$, PAHs, dioxins & $\begin{array}{l}\text { Salmonella TA98 mutagenicity } \\
\text { on DCM extracts }\end{array}$ & $\begin{array}{l}\text { Bioremediation in an LTU } \\
\text { (12 separate cells) }\end{array}$ & $\sim 240$ & $\begin{array}{l}\text { Mutagenicity }(+\mathrm{S} 9) \text { increased in } \\
\text { nine of } 12 \text { LTU cells. Six } \\
\text { increases }>2 \text {-fold }\end{array}$ & [56] \\
\hline $\begin{array}{l}\text { Soil (clay loam) amended } \\
\text { with wood-preserving waste sludge }\end{array}$ & PCP, creosote, PAHs, dioxins & $\begin{array}{l}\text { Salmonella TA98 mutagenicity } \\
\text { on DCM/MetOH extracts }\end{array}$ & Incubation in barrel lysimeters & 350 & $\begin{array}{l}\text { Increase in mutagenicity to } 180 \text { days, } \\
\text { following by a decline below initial } \\
\text { for }+ \text { S9 only }\end{array}$ & [370] \\
\hline $\begin{array}{l}\text { Soil (sandy clay loam) amended with } \\
\text { sludge from a wood-preserving } \\
\text { plant impoundment }\end{array}$ & Creosote, PCP, PAHs, dioxins & $\begin{array}{l}\text { Salmonella TA98 mutagenicity } \\
\text { on DCM and MetOH extracts }\end{array}$ & $\begin{array}{l}\text { Incubation in barrel lysimeters } \\
\text { exposed to normal rainfall }\end{array}$ & 350 & $\begin{array}{l}\text { Increase in mutagenicity at } 180 \text { days } \\
(-\mathrm{S} 9 \text { and }+\mathrm{S} 9) \text {. Some decline } \\
\text { by } 350 \text { days }\end{array}$ & [64] \\
\hline Creosote contaminated soil & PCP, PAHs, creosote, dioxins & $\begin{array}{l}\text { Salmonella TA98, TA100, TA97, } \\
\text { TA102, TA104, YG1042 and } \\
\text { YG1042 mutagenicity on DCM extracts }\end{array}$ & $\begin{array}{l}\text { Biopilej, bioslurry }^{\mathrm{k}} \text {, compost }{ }^{\mathrm{j}} \text {, } \\
\text { and land treatment }\end{array}$ & $\begin{array}{l}140,41,84, \\
\text { and } 175\end{array}$ & $\begin{array}{l}\text { Large increase }(-\mathrm{S} 9 \text { and }+\mathrm{S} 9) \text { in } \\
\text { bioslurry sample. Moderate increase } \\
(-\mathrm{S} 9 \text { and }+\mathrm{S} 9) \text { in biopile sample }\end{array}$ & [44] \\
\hline Creosote contaminated soil & $\begin{array}{l}\text { PCP, PAHs (>5000 ppm), } \\
\text { dioxins }\end{array}$ & Tradescantia MN test on aqueous extracts & $\begin{array}{l}\text { Fungal inoculation and } \\
\text { simulated land treatment }\end{array}$ & 56 & $\begin{array}{l}\text { Remediation resulted in reductions } \\
\text { in soil PAH content and soil } \\
\text { clastogenic activity }\end{array}$ & [120] \\
\hline $\begin{array}{l}\text { Wood preserving bottom } \\
\text { sediment (EPA K001) }\end{array}$ & PCP, creosote & $\begin{array}{l}\text { Salmonella TA98 mutagenicity on } \\
\text { DCM/MetOH extracts }\end{array}$ & $\begin{array}{l}\text { Potassium polyethylene glycol } \\
\text { treatment (KPEG) at } 38,48,80 \\
\text { and } 120^{\circ} \mathrm{C}\end{array}$ & $<1$ & $\begin{array}{l}\text { Slight increase in mutagenicity } \\
(+S 9) \text { followed by rapid decline } \\
\text { within } 30 \mathrm{~min}\end{array}$ & [177] \\
\hline $\begin{array}{l}\text { Wood preserving bottom } \\
\text { sediment (EPA K001) }\end{array}$ & PCP, creosote & $\begin{array}{l}\text { E. coli prophage induction assay on } \\
\text { DCM/MetOH extracts }\end{array}$ & $\begin{array}{l}\text { Potassium polyethylene glycol } \\
\text { treatment (KPEG) at } 38,48,80 \\
\text { and } 120^{\circ} \mathrm{C}\end{array}$ & $<1$ & $\begin{array}{l}\text { High toxicity, difficult to interpret } \\
\text { and determined effects of remediation }\end{array}$ & [177] \\
\hline $\begin{array}{l}\text { Soil (fine loam) amended with } \\
\text { municipal wastewater sludge } \\
\text { (activated) }\end{array}$ & Unknown & $\begin{array}{l}\text { Salmonella TA98 and TA100 } \\
\text { mutagenicity on ethylene } \\
\text { dichloride extracts }\end{array}$ & $\begin{array}{l}\text { Eight week incubation with } \\
\text { periodic additions of water }\end{array}$ & 56 & $\begin{array}{l}\text { Increase in mutagenicity (-S9) } \\
\text { for the first } 7 \text { days, decline to } \\
\text { background after } 21-42 \text { days }\end{array}$ & [372] \\
\hline $\begin{array}{l}\text { Soil (sandy clay and sandy loam) } \\
\text { amended with sewage sludge }\end{array}$ & Unknown & $\begin{array}{l}\text { Salmonella TA98 mutagenicity on } \\
\text { DCM and/or MetOH extracts }\end{array}$ & $\begin{array}{l}\text { Incubation in undisturbed } \\
\text { barrel lysimeters }\end{array}$ & 717 & $\begin{array}{l}\text { Some increase in mutagenicity } \\
(+S 9) \text { during the first } \sim 40 \text { days. } \\
\text { Decrease }(-S 9 \text { and }+S 9) \text { to } \\
\text { background by } 700 \text { days }\end{array}$ & [179] \\
\hline $\begin{array}{l}\text { Soils (sandy clay and sandy loam) } \\
\text { amended with sewage sludge. }\end{array}$ & Unknown & $\begin{array}{l}\text { Salmonella TA98 mutagenicity on } \\
\text { DCM and MetOH extracts }\end{array}$ & $\begin{array}{l}\text { Incubation in undisturbed } \\
\text { barrel lysimeters }\end{array}$ & 510 & $\begin{array}{l}\text { Increase in mutagenicity ( }+\mathrm{S} 9 \text { only) } \\
\text { to } 154 \text { days, followed by slow } \\
\text { decline to background by } 510 \text { days }\end{array}$ & [156] \\
\hline $\begin{array}{l}\text { Soils amended with municipal } \\
\text { wastewater }\end{array}$ & Unknown & $\begin{array}{l}\text { Salmonella TA98 mutagenicity on } \\
\text { DCM extracts }\end{array}$ & $\begin{array}{l}\text { Soils amended with wastewater } \\
\text { extracts incubated at room } \\
\text { temperature }\end{array}$ & 2 & $\begin{array}{l}\text { Some decline in mutagenicity } \\
(-S 9) \text { within two days }\end{array}$ & [175] \\
\hline $\mathrm{PCB}^{\mathrm{n}}$ contaminated soil & Aroclor 1260 ( 2200 ppm) & $\begin{array}{l}\text { Salmonella TA98 and TA100 } \\
\text { mutagenicity on DCM extracts }\end{array}$ & $\begin{array}{l}\text { Base-catalyzed dechlorination } \\
\text { at } 250-350^{\circ} \mathrm{C}\end{array}$ & $<1$ & $\begin{array}{l}50 \% \text { reduction in TA98 } \\
\text { mutagenicity ( }-\mathrm{S} 9 \text { and }+\mathrm{S} 9 \text { ) }\end{array}$ & [41] \\
\hline PCB contaminated soil & Aroclor $1260(\sim 2200 \mathrm{ppm})$ & $\begin{array}{l}\text { E. coli prophage induction assay } \\
\text { on DCM extracts }\end{array}$ & $\begin{array}{l}\text { Base-catalyzed dechlorination } \\
\text { at } 250-350^{\circ} \mathrm{C}\end{array}$ & $<1$ & $\begin{array}{l}\text { No appreciable reduction in } \\
\text { genotoxic activity }(-\mathrm{S} 9 \text { and }+\mathrm{S} 9)\end{array}$ & [41] \\
\hline PCB contaminated soil & $\begin{array}{l}\text { Aroclor } 1260(\sim 150 \mathrm{ppm}) \text {, } \\
\text { PAHs, dioxins }\end{array}$ & CAs in Allium cepa & Pilot-scale solvent extraction & $<1$ & $\begin{array}{l}99 \% \text { reduction in PCBs. Increase } \\
\text { in clastogenicity and phytotoxicity }\end{array}$ & [254] \\
\hline $\begin{array}{l}\text { Soils contaminated with } \\
\text { solvent-recovery wastes and } \\
\text { paint sludge }\end{array}$ & Xylene, toluene, heavy metals & $\begin{array}{l}\text { Salmonella TA98 mutagenicity on } \\
\text { DCM and MetOH extracts }\end{array}$ & $\begin{array}{l}\text { Physical removal of visible } \\
\text { contamination }\end{array}$ & Unknown & $\begin{array}{l}\text { Dramatic reductions in soil } \\
\text { mutagenicity }(-S 9 \text { and }+S 9 \text { ), } \\
\text { but levels remained } \sim 30 \text {-fold } \\
\text { background }\end{array}$ & [114] \\
\hline
\end{tabular}




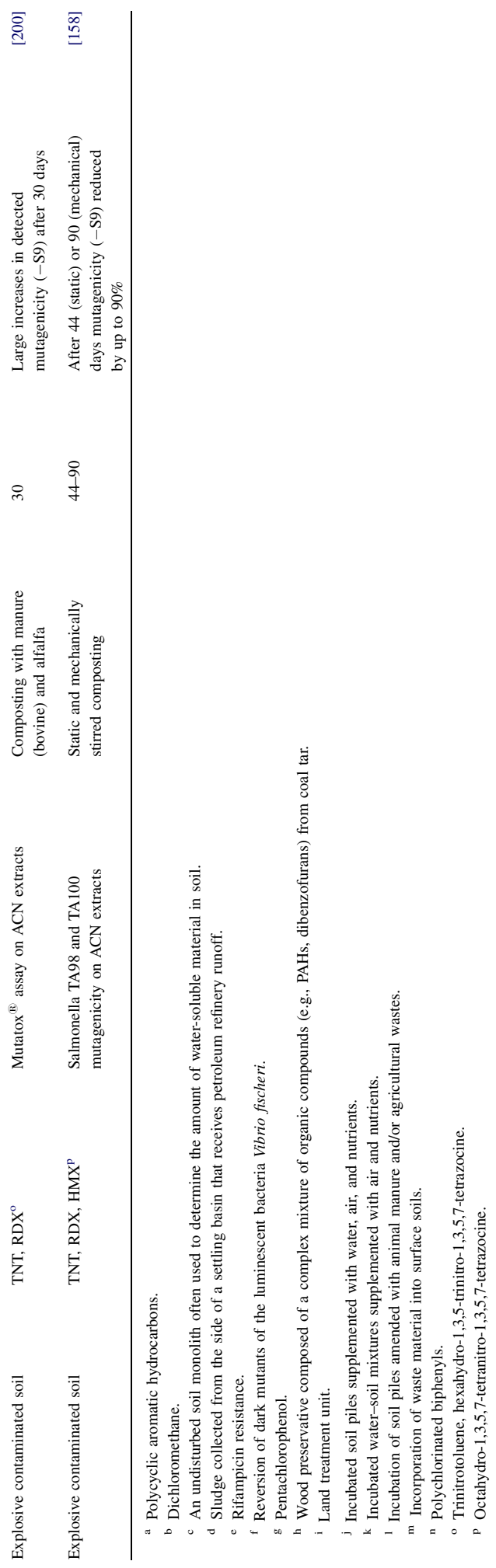

wastes such as coal tar or coke oven emissions [153,188,189,201,371]. Four studies examined soils amended with sewage sludge or municipal wastewaters [156,175,179,372]. Three assessments in two studies examined PCB-contaminated soils, two studies examined soils contaminated with munitions waste or explosives $[158,200]$, and the final study examined a soil contaminated with solvent recovery wastes and paint sludge [114].

The first six entries in Table 21 suggest that the mutagenic hazards associated with soils containing petrochemical wastes or petroleum distillates such as diesel oil and motor oil can be effectively remediated. The two studies that employed bioremediation with nutrient supplementation for soil contaminated with motor oil or diesel oil showed relatively rapid declines in mutagenicity to below detection within 7-12 weeks $[154,157]$. The studies that examined soils contaminated with more complex petrochemical wastes containing an assortment of heavy hydrocarbons and aromatic substances showed effective remediation within one year $[59,64,121,166]$. It is interesting to note that one study that followed petroleum waste amended soils incubated in barrel lysimeters (i.e., soil monoliths), noted a moderate increase (i.e., 1.8-fold) in S9-activated mutagenicity during the first 180 days that may be due to the liberation or formation of mutagenic compounds during the remediation process [64]. Although this study did not investigate the accumulation of any mutagenic degradation byproducts or the persistence of any contaminants, a recent bioslurry study of a PAH-contaminated soil from a former gasworks site noted the persistence of alky-PAHs and $N$-heterocyclics, as well as an increase in the concentration of oxygen-containing PAHs over the course of the remediation [353].

Five of the listed studies investigated the ability to remediate the genotoxic hazard associated with $\mathrm{PAH}-$ containing wastes such as coal tar or coke oven emissions [90,153,188,189,201]. The results obtained in these studies indicate that large reductions in the concentrations of 3- and 4-ring PAHs can be achieved within 200 days. Two studies observed 20-70\% reductions in PAH concentrations within 50-100 days. However, a reduction in genotoxic activity did not always correspond to the noted reductions in PAH concentration. For example, compost remediation of PAH-contaminated soils ( $>600 \mathrm{ppm})$ from a former 
gas-works site resulted in a 20-60\% reduction in PAHs in 54 days, but very little reduction in the SOS genotoxicity of a DCM soil extract [188]. However, two similar studies that examined a soil collected near coke production facility (PAHs $\sim 600-800 \mathrm{ppm}$ ), and a soil amended with coal tar extract (PAHs 400-1400 ppm), both noted large reductions in both mutagenicity and PAH concentration within 147 and 210 days, respectively $[90,153]$. In addition, the latter study observed a lack of relationship between PAH concentration decline and the decline in mutagenicity (i.e., induction of rifampicin resistance in Pseudomonas putida) [90]. The seeming incongruence of these results is likely due to wide variations in the efficacy of bioremediation for the removal of PAHs and mutagenic activity from soils contaminated with coal tar and coke oven emissions. Several studies have demonstrated that the efficacy of PAH removal via bioremediation is heavily influenced by PAH composition, the selected bioremediation process, the physical, chemical, and biological properties of the soil, and the environmental conditions during remediation [341,373,374]. Moreover, cross-study comparisons of mutagenicity values recorded before, during and after the aforementioned remediations is complicated by variations in extraction solvent and endpoint selection.

Eight studies investigated the ability of bioremediation to remove the genotoxic hazards associated with soils contaminated by wood preserving wastes. It is interesting to note that four of these studies recorded substantial increases in mutagenic activity during the remediation $[44,56,64,370]$. For example, the study by Hughes et al. of a creosote contaminated soil from the Reilly Tar Site noted that DCM extracts failed to elicit significant positive responses on Salmonella strains TA98, YG1041 and YG1042, and elicited only a weak response on TA100 (without S9) [44]. However, after bioslurry remediation, DCM extracts elicited significant positive responses on YG1041 and YG1042, as well as TA98 with S9. Additional positive responses were observed following biopile remediation (YG1041 with and without S9, YG1041 with S9, TA100 with and without S9) and composting (YG1041, YG1042, TA98 and TA100 without S9). Additional analyses of the bioslurry sample indicated that the putative mutagens included nitroarenes. Studies by Barbee et al. showed a moderate increase in S9-activated TA98 mutagenicity and a substantial increase in direct-acting TA98 mutagenicity after 180 days in a barrel lysimeter exposed to normal rainfall $[64,370]$. Although this was followed by a decline in mutagenic activity, the directacting activity after 350 days was still substantially above that recorded before remediation. Neither the Hughes et al. nor the Barbee et al. studies determined the source(s) of the increased mutagenic activity. However, Hughes et al. suggested that materials (e.g., nutrients, manure, plant biomass) added to the bioslurry, biopile, and compost mixtures may have contributed mutagenic compounds. This assertion is not supported by other studies, such as the works of Kazunga et al. and Lundstedt et al., which noted that bioremediation of PAH-contaminated soils can result in the formation of oxygen containing PAHs and these compounds can accumulate over the course of the remediation $[353,375]$. Some of these compounds, such as a variety ortho-quinones and ketones, are known to be potent direct-acting Salmonella mutagens (TA98) [376-378], as well as mammalian cell mutagens $(t k$ locus in human lymphoblastoid cells expressing several P450 enzymes) [379].

It is interesting to note that two additional studies on soils contaminated with wood-preserving wastes observed substantial declines in mutagenic activity to levels deemed to be acceptable (e.g., $<0.15$ reverants/ $\mathrm{mg}$ ) within as little as 90 days $[115,121]$. For example, Donnelly et al. noted that bioremediation in a land treatment unit supplemented with nutrient and lyophilized bacteria resulted in substantial mutagenicity reduction within 3 months [115]. April et al. noted that batch reactor incubation of soils amended with wood-preserving wastes for 354 days resulted in a decline in Salmonella mutagenicity to below detection [121]. An aggressive chemical remediation method employing potassium polyethylene glycol (KPEG) at temperatures up to $120^{\circ} \mathrm{C}$ was employed by Hong et al. to remediate a wood preservation site impoundment sediment [177]. The results revealed substantial reductions in PCP concentration $(>80 \%)$ within $30 \mathrm{~min}$, and corresponding reductions in $\mathrm{S} 9$-activated TA98 mutagenic activity.

One study by Donnelly et al. investigated the mutagenic potential of soils collected before and after remediation of an abandoned solvent recovery site [114]. Visual inspection of the remediated site indicated that all visible signs of contamination had been removed; moreover, the TA98 mutagenic activity 
of $\mathrm{DCM} / \mathrm{MetOH}$ extracts showed a marked reduction. However, extracts of soils collected from a runoff ditch still exhibited mutagenic activity up to 30 -fold above background.

Four studies investigated the ability to remediate mutagenic soils that have been amended with municipal waste water or sewage sludge $[156,175$, 179,372]. Three of these studies noted an initial, but short-lived (i.e., 7-154 days) increase in mutagenic activity, followed by a marked decline to background. The fourth study only followed the remediation for two days, but did note some decline in mutagenicity $[175,372]$. The time required to reach background mutagenic activity varied between the three aforementioned studies. Angle and Baudler noted an increase in the direct-acting TA98 and TA100 mutagenic activity of extracts from soil amended with sewage sludge, followed by decline to background levels within 21-42 days [372]. In two similar studies, Donnelly et al. noted initial increases in the S9-activated TA98 mutagenicity of sludge-amended soils during the first 50-150 days in an undisturbed lysimeter $[156,179]$. This was followed by a decline to background (TA98 with and without S9) within 510 to 770 days. Thus, the time required for complete removal of mutagenicity could be as long as two years.

Two studies employed aggressive extraction or thermal degradation strategies to remediate the mutagenic activity and PCB content of contaminated soils [41,254]. DeMarini et al. demonstrated that basecatalyzed dechlorination of PCB-contaminated soils at $250-350{ }^{\circ} \mathrm{C}(\sim 8 \mathrm{~h})$ removed $99 \%$ of the PCB contamination and reduced the TA98 mutagenic activity (with and without S9) by approximately 50\% [41]. However, the same study noted that the basecatalyzed dechlorination process did not reduce the genotoxic activity measured using the prophage induction assay. Meier et al. demonstrated that a pilot-scale soil washing procedure effectively removed PCB contamination from soils collected from a former transformer storage site [254]. However, remediation resulted in an increase in the clastogenic activity as measured using the Allium anaphase aberration assay. This increase was removed following a water rinse step, and the authors suggest that residual wash solvent caused the initial increase in clastogenic activity.

Although explosives and munitions wastes (e.g., TNT, RDX, HMX, hexogen) are noted for their mutagenic activity, toxicity and environmental persistence, few studies have attempted to investigate the ability to remediate the mutagenic hazards of munitions contaminated soils. Two of the studies listed in Table 21 used composting to remediate the mutagenic hazards of soils contaminated with a variety of munitions and explosive residues. However, the two studies reached opposite conclusions. The study by Jarvis et al. observed marked increases in direct-acting mutagenicity (Mutatox ${ }^{\circledR}$ ) following 30day composting (20\% soil by weight) in an adiabatic reactor [200]. Simultaneous chemical analysis noted marked reductions in TNT, RDX, 2-amino-DNT and 4-amino-DNT. The authors suggest that degradation of the explosives may have resulted in the formation of mutagenic contaminants that were not detected using routine chemical analyses. The study by Robidoux et al. (see Table 11) also had difficulty reconciling the results of chemical analysis and the direct-acting genotoxic activity (SOS Chromotest) of elutriates from munitions contaminated soils [193]. In contrast, the study by Griest et al. noted substantial decreases in the TA98 and TA100 direct-acting mutagenicity in ACN extracts of soils remediated by static or mechanically stirred composting for 44 or 90 days, respectively (10\% soil by weight) [158]. Simultaneous chemical analysis showed that the TA98 and TA100 direct-acting mutagenic activity at the start of the experiment (i.e., compost day 0) was consistent with the measured concentration of TNT, and moreover, that the decline in mutagenicity was accompanied by a corresponding decline in TNT concentration. The seemingly incompatible outcomes of these two studies may be related to oxygen concentration, the soil concentration in the compost, and the composition of the microbial community in the compost pile. Several researchers have previously noted large variations in the ability of microbial assemblages to degrade explosives such as TNT, RDX and HMX, as well as increased mineralization rates in the absence of oxygen [346,354].

\section{Summary and discussion}

A wide range of human activities (e.g., industrial, municipal, rural, urban) has contributed to the contamination of land. Industrial practices including 
improper use and storage of hazardous materials, wastewater discharge, waste disposal, waste storage, and accidental spills or leaks have resulted in serious contamination problems in industrialized nations. Use of industrial and municipal wastewaters for irrigation and heavy use of herbicides, fungicides and insecticides have contributed to contamination in rural, agricultural regions. In addition, combinations of activities, including fossil fuel combustion and surface deposition of combustion by-products, solid waste disposal, and waste incineration, have contributed to the contamination of soils in urban areas. The fate of these substances depends on complex dynamic processes that are controlled by environmental conditions (e.g., climate), soil physical properties (e.g., texture, water content, cation exchange capacity, organic matter content), soil biological properties (e.g., microbial community structure), and the physical-chemical properties of the contaminants (e.g., $K_{\text {ow }}$, vapour pressure, speciation, charge, stability). Persistent, insoluble organic compounds are virtually immobile in soil and will remain in place for an extended period of time (i.e., years to decades) [5,7]. Although the mobility of these compounds will be partly determined by water movement, soil porosity, and soil organic matter content, organic compounds with $\log K_{\text {ow }}$ values greater than 4.0 (e.g., PCBs, PCP, BaP) are generally considered to be immobile [5]. Substances with $\log K_{\text {ow }}$ values less than 2.5 (e.g., tetrachloroethane, benzene) are often highly mobile and can move to the water-saturated zone with relative ease. Stable organics with high vapour pressures and low water solubility (i.e., high Henry's law constant $K_{\mathrm{h}}$ ) will tend to volatilize, move through soil pores, and exit the soil as a vapour [5,7]. The mobility of toxic metals (e.g., $\mathrm{Pb}, \mathrm{Cd}, \mathrm{Cr}, \mathrm{Zn}, \mathrm{Sb}, \mathrm{Ni}$, $\mathrm{Hg}$ ) is a complex function of soil redox (Eh), soil texture and cation exchange capacity (e.g., clay content), soil $\mathrm{pH}$, and metal speciation. As a general rule cations, including many divalent metals that are highly toxic, have low mobility in silt and clay soils, and moderate mobility in sandy soils $[5,7]$.

The risk of adverse health effects attributable to contaminants in soils will be determined by environmental fate, exposure, and toxicity. Substances that are rapidly mineralized will present little opportunity for exposure and adverse effect. The route and magnitude of exposure to toxic substances in soil depends on the properties of the substance, as well as the life history and physiology of the organism under consideration. Exposures to volatile substances generally occur via inhalation and/or dermal absorption [380-384], and exposures to mobile organics and metals commonly occurs through the ingestion of contaminated groundwater [380,385-387]. Exposures to persistent immobile contaminants that are strongly adhered to soil particles, including many mutagenic substances (e.g., PAHs, creosote, petrochemical waste), can occur via inhalation, non-dietary ingestion of soil particles [388-392], or ingestion of contaminated biota [393]. Current risk assessment guidelines employ standard residential, non-dietary soil ingestion values of $100 \mathrm{mg} /$ day for adults and $200 \mathrm{mg} /$ day for children [391,394]. For commercial/institutional or outdoor industrial exposures of adults, $50 \mathrm{mg} /$ day and $480 \mathrm{mg} /$ day are used, respectively [394]. Although direct exposure via the consumption of contaminated soil organisms seems unlikely, wildlife and humans can be exposed to soil contaminants via the consumption of terrestrial biota which accumulate persistent soil contaminants (e.g., arctic caribou) [393,395,396]. Moreover, humans can be exposed via consumption of produce grown in contaminated soils. Several studies examining animals (e.g., pigs, sheep, quail) fed grain grown on land amended with sewage sludge showed elevated organ (e.g., kidney, liver) levels of $\mathrm{Cd}$ and Ni [397-399]. In addition, Telford et al. showed that sheep fed sugar beets grown on sludge amended soils excreted mutagenic metabolites via the bile and urine [400], and Shane et al. showed that the tissues of lettuce and endives grown in flyash-amended soils contained S9-activated TA98 mutagens [401].

Volatile contaminants in soil can constitute an extreme hazard if environmental conditions permit sufficient exposure via air or water. The most familiar scenario whereby a volatile soil constituent can enhance the risk of mutagenic and carcinogenic effects is radon gas exposure. Radioactive isotopes of radon, a by-product of the ${ }^{238} \mathrm{U}$ decay series, can seep into buildings and dramatically enhance the risk of mutagenic effects and lung cancer [402,403]. Beyond radon, there are very few well-documented, nonoccupational accounts of exposure and adverse effects attributable to non-radioactive, volatile pollutants in soils. Although several studies have documented adverse health effects in individuals inhabiting regions in close proximity to hazardous waste dump sites who 
have complained of household odours and ill health (e.g., respiratory distress, eye and skin irritations, gastrointestinal disorders, cancer, birth anomalies, neurological effects), connections, either empirical or otherwise, to the presumed source of contamination are tenuous [384,404-407].

Mobile metals and organic contaminants in soils can readily contaminate groundwaters, and there are well documented accounts of serious adverse health effects (e.g., cancer, neurological defects, skin disorders, reproductive problems) in communities exposed to groundwaters that have become contaminated via nearby industrial activities and associated soil contamination problems [80,384,385,387,405, $408,409]$. Exposures generally occur via ingestion of contaminated groundwater; however, dermal absorption and inhalation during bathing and showering have recently been noted as potential routes of exposure [384]. Nevertheless, although the connections between exposures to mobile soil contaminants (i.e., exposure via groundwater) and adverse health effects are more convincing, empirical connections are often weak and mechanistic connections are lacking [410-413]. One noteworthy exception is the welldocumented link between a variety of serious adverse health effects, including cancer, neurological disorders and skin lesions, and exposure to arsenic in contaminated groundwater [414].

Many known mutagens are expected to be strongly adsorbed to soil particulate matter. Thus, adverse health effects attributable to these substances would require exposures to the actual soil particles via ingestion or inhalation. Although the aforementioned risk assessment guidelines do acknowledge nondietary ingestion as a well-documented route of soil exposure in commercial, residential, and industrial settings [394,415], it is difficult to determine the likelihood of human exposure to soil particles from a contaminated area. Consequently, it is difficult to accurately calculate the mutagenic risks associated with contaminated soils, or habitation in close proximity to a contaminated site. Nevertheless, three studies by Najem et al. investigating the suggested excess cancer mortality in the state of New Jersey revealed that for several cancers, including breast and gastrointestinal, there is a statistically significant positive correlation between cancer mortality and the distribution of hazardous chemical waste disposal sites (HCWDS) [416-418]. A similar study by Budnick et al. concluded that although bladder cancer mortality rates in white males from Clinton County, Pennsylvania, a county contaminated with mutagenic carcinogens from a Superfund site, are elevated, there is no consistent pattern of environmental exposure and "causal inferences cannot be made" [407]. In addition, a study by Vine et al. noted that although 40-59-year-old residents living within one mile of a pesticide dump site in North Carolina had increased levels of serum DDE, residential location was "not consistently associated" with the frequency of $\mathrm{MN}$ in peripheral blood lymphocytes [419].

Despite this difficulty in quantifying the risk of adverse health effects attributable to soil contamination, a great deal of effort has been expended to assess site contamination, estimate risk, and remediate contaminated sites. Indeed, this work is a review of 1312 assessments of soil genotoxic hazard. Although some of the reviewed studies were indeed motivated by well-documented risks associated with mobile contaminants, most studies appear to have been motivated solely by presumed risk and the associated liability. The US National Oil and Hazardous Substances Pollution Contingency Plan, the regulation that implements CERCLA and establishes the approach for determining potential health risks and appropriate remedial action, calculates risks associated with exposures of on-site workers in direct contact with contaminated soils, current (nearby) residents exposed to the site via contaminated air (i.e., volatiles and soil particles) and water, future residents in direct contact with the site, and even future residents exposed via consumption of contaminated fish from on-site water bodies [420]. The comprehensive nature of the risk assessments required under CERCLA and, the liability for injury and loss of natural resources set forth in section 9607(a) of Title 42 US Code Chapter 103 , i.e., that the "owner and operator of the vessel or facility causing the release of a toxic substances is liable", rationalizes a cautious approach to site assessment and site management [421]. It is this cautious approach, as well as the desire to recover contaminated land that may have substantial value, that has encouraged and supported assessments of soil genotoxicity.

An evaluation of the stated objectives in the 118 publications examined for this review reveals that 
most of the studies were indeed motivated by a requirement to assess the genotoxic hazards of current contaminated sites, determine the mobility of the genotoxic contamination, and evaluate the efficacy of current remediation efforts. For example, of the 19 works published by KC Donnelly and colleagues at Texas A\&M University, 17 of the papers described site assessment, investigations of genotoxicity mobility, investigations of remediation efficacy, and evaluations of current waste treatment practices $[40,42,47-49,54$, $56,64,114,115,117,118$,

$146,156,165,166,179,317,370]$ as the study objective. The remaining two papers constituted a comparative evaluation of short-term microbial assays for the examination of soil genotoxicity [146,317]. In general, over $45 \%$ of the publications examined for this review appeared to be primarily motivated by a requirement to assess potential genotoxic hazard. With several studies also investigating the leachability of genotoxic material $[48,61,174,283]$. This is quite distinct from the situation encountered in a recent review of the sediment mutagenicity literature. The review by Chen and White [422] noted that most studies assessing the mutagenic activity of contaminated aquatic sediments are motivated by an abnormally high frequency of idiopathic lesions, including hepatocellular carcinoma, in indigenous fishes. Thus, the documented effect had already been observed, and the motivating factor behind sediment examinations was disease etiology.

The data collected for this review clearly indicates that soils at most contaminated industrial sites, as well as urban sites, are genotoxic and an enhanced risk of mutagenic effect would likely accompany exposure to these soils. Of course, the magnitude of the risk will depend on the potency of the contaminated soil, as well as the magnitude and route of exposure. The collected Salmonella data presented in Fig. 3 and Table 8 indicate that the mutagenic hazard (i.e., TA98 with and without S9, TA100 with S9) associated with soils from contaminated industrial areas can readily be more than two orders of magnitude above those at rural/agricultural locations. Whether these risks are actually realized is entirely dependent on the magnitude and frequency of exposure. With the exception of particular situations, residential exposures to contaminated soils at properly managed hazardous waste sites seem unlikely. The aforemen- tioned daily soil ingestion rates routinely employed for risk assessment are only 100 and $200 \mathrm{mg}$ for adults and children respectively, and even at the RME (reasonable maximum exposure), only a small fraction of this daily value will include fugitive dusts and tracked soil from the contaminated area. Exceptions would include industrial workers at the site and residents that are not aware of the hazard and frequently enter the contaminated area. This can be particularly serious for children who venture on to the site for recreational purposes. The scenario of the illinformed resident from the nearby community can be a serious issue, and proper risk communication can be difficult. For example, cancer risk communication in Canada's arctic, a region that contains orphaned military sites contaminated with PCBs and petroleum hydrocarbons, requires the creation of new words in the local language to explain terms like "pollution" and "contamination".

An additional $23 \%$ of the studies examined were motivated by genotoxic hazard assessment and remediation evaluations, and 5\% investigated the likelihood of future hazards associated with current or planned waste disposal practices. For example, four studies examined the genotoxic hazards associated with long-term applicatsions of municipal wastewaters or sewage sludge on agricultural lands $[60,165,176,179]$. The summarized remediation efforts (Table 21) suggest that some bioremediation strategies employed for soils contaminated with recalcitrant genotoxins (e.g., nitroaromatic explosives, creosote) are unable to remove the hazard. Moreover, in some cases hazard was notably increased. Although the mechanistic details controlling this phenomenon are not known, it is reasonable to assume that the phenomenon results from the formation of transient breakdown products that are, in toto, more mutagenic than the starting material. The supposition is supported by the detailed analytical works of Lundstedt et al. and Brooks et al. [22,353]. Their analyses of bioslurry treatments for gas-works soil and soil from a wood-preservation site, respectively, showed the formation of PAH derivatives, some of which are known to be mutagenic (e.g., ketones and quinones). Although remediation of soils contaminated with other PAH-rich wastes can induce relatively short-lived increases in mutagenic hazard (i.e., weeks to months), the hazards appear to be 
effectively removed within one year. Thus, if the site is properly managed (i.e., restricted access, runoff collection, HDPE liner), and site recovery is not urgent, it would appear that the less sophisticated remediation options (e.g., land treatment, biopile, compost) are the most parsimonious. Nevertheless, it should be noted that many researchers advocating the use of bioreactor treatments such as the bioslurry, emphasize the advantage of short treatment time [346]. It should also be noted that this type of strategy would not be appropriate for sites that are contaminated with mutagenic metals. Changes in oxidation state, speciation and complexation could liberate mutagenic metals, and effective remediation strategies should include a technique such cation solidification to immobilize mutagenic metals [337].

A small number of studies specifically evaluated protocols for the extraction and handling of contaminated soils for mutagenicity assessment. For example, Wang et al. compared four solvent systems (i.e., hexane/acetone, DCM/acetone, hexane/2-propanol, DCM) for their ability to extract S9-activated Salmonella mutagens (TA98 and TA100) from soils collected at a hazardous landfill [423]. The results showed a relatively low response on both strains for the DCM extracts, and roughly equivalent responses for the other three solvents on TA100. The TA98 results indicated that hexane/acetone and DCM/ acetone were more effective than hexane/2-propanol. The results summarized in Table 7 indicate that DCM frequently provides samples that are more mutagenic on TA98 (with S9). Thus, it is not possible to select a solvent or solvent system that is suitable for all situations. Similar conclusions have been recorded for other complex environmental matrices. Lee et al. found that acetone was superior to DCM for extracting Salmonella mutagens from airborne particulate matter; however, Kiel et al. did not detect any difference in the Salmonella mutagenicity of coal-tar contaminated sediment extracts prepared using DCM or acetone/hexane [424,425]. Solvent choice, therefore, must be study-specific and consider the source of the soil sample and the physical-chemical properties of the purported contaminants. However, it should be noted that the results of several works such as that of Ehrlichmann et al. [174] on the bacterial genotoxicity of aqueous soil extracts, and many studies that employed plant assays, definitively indicate that solvent extraction is essential for reliable genotoxicity assessment of soils contaminated with organic contaminants.

In the absence of a generally applicable rule regarding solvent choice, it seems prudent to choose a solvent or system that can dissolve a wide range on compounds (e.g., polar aromatics, non-polar aromatics, neutral compounds, etc.). A recent investigation by Lundstedt et al revealed that newer methods such as accelerated solvent extraction (ASE) with binary solvent mixtures such as acetone/hexane (1:1, $\mathrm{v} / \mathrm{v})$ are preferred for effective extraction of organics from PAH-contaminated soils [426]. Moreover, these authors noted that the ASE-hexane/acetone combination reduces solvent use, avoids chlorinated solvents, and provides an extract that is easily handled in subsequent clean-up or fractionation steps.

Although the data discussed in this review indicate that the Salmonella mutagenicity test is the most commonly employed bioassay for the examination of contaminated soils (Fig. 1), few researchers have actually attempted comparative evaluations of assay performance. Three studies evaluated the efficacy of the Salmonella assay for assessments of soils contaminated with chlorinated substances. Cizmas et al. noted that the prophage induction assay detected significant genotoxic activity in an acid fraction of a wood preserving waste extract (PCP $472 \mathrm{ppm}$ ) that did not induce a positive response on TA98 with S9 [151]. The examination of a PCB-contaminated soil also showed differential responses between the Salmonella mutagenicity assay and the prophage induction test, and the authors attribute the difference to the previously observed sensitivity of the prophage induction assay to chlorinated compounds [41]. Donnelly et al. compared the rec ${ }^{-}$differential survival assay and the Salmonella assay (TA98 with S9) for examinations of a wood preserving waste extract and revealed strong responses for both assays to acid and base fractions [146]. However, although the neutral fraction induced the strongest response on TA98 with S9, no significant response was obtained for the $\mathrm{rec}^{-}$ assay. The same waste extract was employed to compare the Salmonella assay with mutagenicity and clastogenicity endpoints in haploid and diploid Aspergillus sp. [317]. The results revealed potent mutagenicity in haploid Aspergillus (with S9) for the basic fraction, and potent responses in the 
diploid assay to both the acid and base fractions. This response pattern is quite distinct from the aforementioned pattern observed in Salmonella TA98 (i.e., maximum for the neutral fraction). Collectively, these results indicate that complex samples such as extracts of contaminated soil will yield different responses in different assay systems with different endpoints. This is not surprising since wood preserving waste is known to contain a complex mixture of chlorinated compounds (e.g., PCP), PAHs, PAH derivatives, and heterocyclic aromatic compounds [427]. A comparative evaluation of TA98 mutagenicity and differential survival in repair deficient $E$. coli by Aleem and Malik [60] indicated very similar responses for a series of extracts from soils irrigated with industrial and municipal wastewaters.

An interesting study by Malachova et al. suggested that Salmonella TA98 (with and without S9) is more sensitive than the SOS Chromotest response, and the differential responses could yield completely opposite conclusions regarding the efficacy of a bioremediation exercise for a coke oven contaminated soil [153].

Although it is not clear whether these differential responses in genotoxicity are generally applicable, it is clear that the conclusions of the research can be seriously effected by bioassay choice. However, it should be noted that a detailed overview on the mutation spectra of complex environmental mixtures (e.g., drinking water, urban air, cigarette smoke) suggests that observed differences between the response patterns of assays with similar endpoints (i.e., mutation) will be overshadowed by similarities in the induced mutation pattern [129].

The collected data also indicate that collectively, plant assays are as popular as the Salmonella mutagenicity test for assessing the genotoxic hazards of contaminated soils. The endpoints routinely employed include gene mutation in stamen hairs (Tradescantia) or second-generation embryos (Arabidopsis), chromosome aberrations in root tips (Allium), MN in Tradescantia tetrads, and sister chromatid exchanges (Vicia). The method of exposure used in the plant publications is highly varied and includes exposures to aqueous extracts or leachates, soil slurries, organic extracts, as well as direct soil contact.

Some researchers performed comparative evaluations of the popular plant assay systems. Knasmüller et al. noted that the Vicia MN assay was incapable of detecting genotoxicity in metal contaminated soils that was readily detected using the Tradescantia MN assay (direct contact) [76]. That study, and the results of the data analyses conducted here, also noted relatively small differences in the mean Tradescantia MN response to aqueous soil leachates. As already mentioned (section 8.6), the study by Cotelle et al noted that comparisons of MN assays in Vicia, Allium and Tradescantia revealed both equivalent responses (i.e., PAH contamination) and differential responses (i.e., Vicia $>$ Allium $>$ Tradescantia for PCB contamination) [83]. Three studies by Cabrera et al. compared the Allium aberration test, the Tradescantia SHM test and the Tradescantia MN test for examinations of leachates from samples of composted garbage, soils irrigated with wastewater, and soil from a municipal landfill [66,67,283]. The results indicated clear differences in the response pattern, with a stronger response for the Tradescantia MN assay, and weaker or insignificant responses for the Tradescantia SHM and Allium assays. Kong and Ma's examination of aqueous soil extracts for sites contaminated with pesticides or metals revealed an identical response patter for the Allium CA assay and the Tradescantia MN assay [247]. Comparisons of the Tradescantia SHM assay and the waxy mutation assay in Zea mays for analysis of soils in the vicinity of a lead smelter, a petrochemical complex, and an oil refinery (directcontact exposure) revealed very similar response patterns, but increased sensitivity and a far greater response range for the Zea mays assay [70,71].

Although it is difficult to draw general conclusions from these comparative assessments, the results presented in this review do permit some general comments. First, it appears that the direct-contact assessment is far more effective for soil genotoxicity assessment than immersion of cuttings or roots in aqueous leachates or extracts. Unfortunately, there was not enough data for a definitive evaluation of organic extraction, although some limited evidence (e.g., $[66,68,69])$ suggests that organic extracts may be suitable for the analysis of soils contaminated with combustion by-products (e.g., PAHs) or other organics. Second, the Allium CA assay and Zea mays waxy locus assay are preferable to the other assays (i.e., Tradescantia MN, Tradescantia SHM). The mean response ranges of these assays are approximately 5to 10 -fold above control, with values reported in the 
literature as high as 25-fold above control [71]. Moreover, average cross-study variations in mean responses for these assays are relatively low. Despite these advantages, the Allium CA assay and the waxy mutation assay in Zea are more technically challenging. Scoring of CAs requires specialized training, and cultivation of Zea mays requires large amounts of space and 6-12 weeks before the results can be obtained (i.e., seed to tassel) [71]. However, it might be noted that the extended direct contact exposure employed in the Zea mays waxy locus assay may be partly responsible for the responsiveness of this assay system.

Very few researchers have attempted to evaluate the popular Salmonella endpoint via comparisons with mammalian in vitro or in vivo endpoints. Berthe-Corti et al. observed close correspondence between Salmonella mutagenicity (TA98 and TA100 with and without S9) and the induction of hprt mutations in Chinese Hamster V79 cells for a DMSO/EtOH extract of a munitions contaminated soil [65], and additional chemical analysis showed the presence of TNT, hexogen and several DNTs. Wesp et al. examined fractions of soils contaminated with emissions from gasoline- and diesel-powered vehicles and showed significant induction of SCEs in cultured human lymphocytes (with and without S9), but no induction of $\mathrm{MN}$ in mouse bone marrow following gavage exposure [116]. Simultaneous analyses showed potent direct-acting Salmonella TA98 activity attributable to nitroarenes, and the authors reconcile the lack of correspondence using suppositions about threshold concentrations and antagonism of mixtures components. However, the observed differences between the microbial and mammalian results are likely caused by differences in the ability to reduce the nitroaromatics. Nitroreduction is a critical step in the activation of nitroarenes and the specific activity in bacterial systems is known to be far greater than that of mammalian systems [428-430]. Therefore, confirmation of animal hazard via in vivo testing appears to be an essential step in hazard confirmation and risk assessment. Surprisingly, only one published study successfully demonstrated an adverse effect following ingestion of contaminated soil particles. Dietary exposures of rats to coal-tar amended soils showed significant induction of bulky (i.e., PAH) DNA adducts in both liver and lung [326], thus confirming genotoxic hazard.
A surprisingly small proportion of the reviewed studies $(\sim 8 \%)$ were primarily concerned with identifying the major source(s) of the soil genotoxicity. Several Japanese studies investigated the mutagenic hazards of urban soils and evaluated the contributions of DNPs from diesel emissions, as well as PAHs from automobile exhaust and studded tires [50,51,119, $124,431]$. These works ultimately showed that DNPs can account for up to $27 \%$ of the direct acting TA98 mutagenic activity in extracts of urban soils [50$52,124]$. Using the combined data from five studies, the analysis conducted here (Fig. 5) confirmed a strong empirical relationship between direct-acting TA98 mutagenicity and DNP contamination across 37 sites. Two German studies investigated the sources of mutagenic activity in a variety of soils and concluded that urban soils are contaminated via airborne deposition of combustion by-products such as PAHs and related compounds (e.g., 2-nitrofluorene) [55,116]. This conclusion is similar to that of Schoen et al. [432] who concluded that urban soils collected from the St. Lawrence River riparian region downstream from Montreal are primarily contaminated with unsubstituted, homocyclic PAHs. Although this study did not include chemical analysis, TA98 and TA100 S9activated Salmonella mutagenicity were roughly equivalent and the metabolically enhanced strains YG1041 and YG1042 showed no increase in response. It is interesting to note that although one of the aforementioned German studies [116] highlighted combustion by-products from gasoline and diesel powered vehicles as the likely source of the soil mutagenicity, they did not detect a significant correlation between soil mutagenic activity (TA98 with S9) and PAH concentration. Moreover, the authors concluded that the bulk of the mutagenic activity (up to $54 \%$ ) in fractions of soils exposed to motorway exhaust is associated with polar organics such as nitroarenes.

Examinations of coal-tar amended soils by Alexander et al. also failed to reveal a relationship between mutagenic activity and the concentration of selected carcinogenic PAHs [90]. The results presented in this review (Fig. 4) did show a statistically significant $(p<0.0001)$, albeit fairly weak, relationship $\left(r^{2}=0.17\right.$ to 0.25$)$ between S9-activated TA98 mutagenicity and soil PAH concentration (59-80 observations from 13 studies). Close scrutiny of the relationship suggests that restricted subsets of the data 
are unlikely to yield a statistically significant relationship. Therefore, although $17-25 \%$ of the cross-study variations in S9-activated frameshift activity can be explained by $\mathrm{PAH}$ concentration, the results of individual studies indicate that the commonly measured mutagenic PAHs (e.g., benzo[ $[a]$ pyrene, benzo[b]fluoranthene, dibenz $[a, h]$ anthracene) cannot account for the bulk of soil TA98 S9-activated mutagenic hazard.

The results presented here also showed empirical relationships between mutagenic and clastogenic effects in plants (e.g., Allium and Arabidopsis) and radionuclide or chemical contamination (e.g., ${ }^{137} \mathrm{Cs}$ or PAHs). These relationships confirm the use of plants for monitoring sites contaminated by radioactive substances. Although the relationship between Tradescantia MN and PAH contamination would not be significant without the Baud-Grasset et al. [120] observation, it is intriguing that Tradescantia appears to have the metabolic capacity to activate the mutagenic components in creosote-contaminated soil. Numerous studies of creosote-contaminated soils have noted potent Salmonella mutagenicity (TA98 and TA100) that is greatly enhanced by the addition of S9, and further enhanced by S9 concentrations above the standard concentration (i.e., 30\% S9 v/v in mix) $[42,146]$. Several researchers have documented the ability of plants and algae to metabolize and activate mutagenic substances including PAHs [433-436], and the observed plant responses summarized throughout this work indicates that selected plants (e.g., Zea mays) can be useful for assessing the likelihood of adverse ecological effects caused by DNA damage.

A surprisingly small number of the reviewed studies employed bioassay-directed fraction to isolate and identify the putative mutagens in contaminated soils. The strategy has been successfully employed to isolate novel mutagens in contaminated sediments and surface waters [23,144,437]; however, although many studies employed a coarse fractionation procedure (i.e., acid, base, neutral) in their analysis of soil extracts $[42,118,146,151,317]$, very few researchers have attempted detailed bioassay-directed fractionation and compound identification. This may be due to the complexity of contaminated soils and the analytical challenge of isolating and identifying soil mutagens. Two studies that used a thorough bioassay-directed fractionation approach to isolate and identify Salmonella mutagens in soils contaminated by wood-preserving wastes (e.g., creosote) were unable to definitively identify the putative mutagens. Brooks et al. subjected 40 fractions of untreated and bioremediated creosote-contaminated soil to detailed mutagenicity and chemical analyses, and the final results revealed over 100 compounds or compound groups several of which have never been assessed for mutagenic activity [22]. Nevertheless, the results did identify a range of known Salmonella mutagens. These included PAHs, Ncontaining heterocyclics, S-containing heterocyclics, and oxygenated PAH derivatives (e.g., quinones) $[134,141,142,319,376,378,379]$. Wesp et al. employed a less sophisticated fractionation procedure and a variety of metabolically manipulated Salmonella strains (e.g., TA98NR, YG1021, YG1024, YG1026 and YG1029) to determine the chemical class of mutagens in soils exposed to automobile emissions [116]. The results showed that most of the mutagenic activity (55-65\%) is attributable to polar aromatics such as nitroarenes, and only $10 \%$ is attributable to nonpolar neutrals such as homocyclic, unsubstituted PAHs. Therefore, although few studies have employed detailed fractionation protocols to isolate and identify soil mutagens, these studies did confirm that a substantial fraction of the mutagenic activity in urban soils is attributable to nitroarenes and other PAH derivatives.

It is unfortunate that few studies even attempt to interpret genotoxicity results in a broader, systemlevel focus. For example, an examination of the soil depth where mutagenic hazard is highest would permit researchers investigating urban sites to determine whether contamination arriving via dry deposition is recent. One study did present a depth profile of Salmonella mutagenic activity for soils exposed to vehicular emissions [116]. The results reveal a clear decline in mutagenic activity (with and without S9, several strains) for depths below $10 \mathrm{~cm}$, and some indication of a maximum between 5 and $10 \mathrm{~cm}$. Although this likely indicates maximal deposition of airborne mutagens at some point in the past, it is impossible to assess the time frame without detailed information about the site's physical history. At industrial or hazardous waste dumpsites, depth profiles can determine the ability of the contamination to move through the various soil horizons eventually impacting the groundwater. Examinations of soil 
borings collected at an abandoned chemical manufacturing site by Donnelly et al. revealed slightly higher S9-activated TA98 mutagenicity in surface soils $(0-0.6 \mathrm{~m})$, as compared to samples collected between 1 and $4 \mathrm{~m}$ [47]. However, the samples collected between 1 and $4 \mathrm{~m}$ also showed substantial mutagenic activity, and the authors were unable to chemically identify the mutagenic substances or offer an explanation for the noted activity profile.

Although other variables such as soil texture, grain size distribution and organic matter content would be expected to effect extraction efficiency and the bioavailability of mutagenic metals, few studies attempted to assess the impact of soil properties on the results obtained. Some studies do note sampling depth [50,54,60,68,77,114,115,118,193], and/or soil texture $[40,48]$ and grain size distribution $[40,48,50,65]$; however, this information is rarely used to interpret the results. One exception is the study of Majer et al. that investigated correlations between soil mutagenicity (MN induction in Tradescantia by directcontact) and a variety of parameters used to describe the vitality of the soil microbial community [77]. The results showed negative correlations between MN induction and both microbial biomass and dehydrogenase activity, and a positive correlation between MN induction and metabolic quotient (i.e., microbial activity to biomass ratio). This may simply indicate that the mutagenic metals in the samples are also toxic to bacteria, accounting for a drop in overall biomass and enzyme activity, and an increase in overall metabolic quotient when MN induction activity is observed. Additional analysis showed a positive correlation between metabolic quotient and As concentration.

None of the papers examined attempted to interpret the results obtained in an ecosystem health or ecotoxicological context. One would suspect that an enhancement in the mutagenic hazards of a terrestrial environment would have repercussions for the indigenous biota. Mutation frequencies should increase and this would be expected to have evolutionary as well as ecological consequences. Several researchers have suggested that continued accumulation of deleterious mutations in sufficiently small populations can initiate a phenomenon, known as mutational meltdown, that has the ability to drive populations to extinction [438-440]. The likelihood of this phenomenon at sites heavily contaminated with mutagenic substances is completely unknown. However, it is known that contaminated soils can induce DNA damage and CAs in indigenous rodents [326,441], DNA damage in earthworms [442], and changes in microbial community structure [443]. Moreover, recent finding show that chronic in situ exposures to radionuclide or chemical contamination is capable of inducing epigenetic and heritable adaptive responses in vertebrates (e.g., fish) and plants (i.e., Arabidopsis) [444,445].

\section{Conclusions and future prospects}

To our knowledge, the first published work documenting the mutagenic hazards of soils was published in 1981 [446], less than one year after the US government enacted CERCLA, also known as the Superfund Act. This act provided the motivation and funding for research investigating the mutagenic hazards associated with contaminated land. Since 1981, some 118 publications encompassing over 1300 assessments of soil genotoxicity have been published. Most of these studies were motivated by a need for effective assessment of genotoxic hazard. However, an assessment of the actual risk for mutagenic or carcinogenic effects associated with contaminated soils requires accurate knowledge of exposure. Although current risk assessment guidelines do provide soil exposure values for adults and children in different settings, it is extremely difficult to assess the proportion of a daily exposure that would be represented by soil particles from a contaminated area. Nevertheless, the precautionary approach seeks to eliminate all exposures and liability for damages, and this elimination can be achieved via access restriction, site remediation and rehabilitation.

In urban settings widespread exposure is far more likely and accurate assessment of risk requires more reliable exposure estimates for both adults and children in a variety of settings (i.e., residential, commercial, institutional, outdoor). Although values are available in the literature, there are technical challenges associated with values that differentiate between exposures to soil particles and exposures to indoor dust [415,447] (see also Maertens et al., this issue [448]). Very little research has attempted to investigate the effects of contaminated urban soils 
following non-dietary ingestion or inhalation. The only available studies suggest a possibility of greatly enhanced levels of DNA damage in liver and lung resulting from ingestion of PAH-contaminated material [326]. Thus, efforts to improve the accuracy of mutagenicity and carcinogenicity risk estimates for urban residents exposed to soils contaminated through dry deposition of airborne particulate matter seems to be a promising area for further research.

Although a great deal of progress has been made regarding the ability to remediate and rehabilitate sites contaminated with mutagenic substances such as munitions, creosote and coal tar, it is not clear whether chemical-specific monitoring of remediation progress is effective. In some cases, chemical monitoring showed dramatic declines in prioritized substances (e.g., TNT), although total genotoxic hazard remained largely unchanged. Perhaps future research should employ bioassays to monitor remediation progress, and subsequently employ a bioassay-directed fractionation strategy to isolate and identify putative mutagens that are problematic. These hitherto unknown compounds can be prioritized for subsequent remedial action and inclusion in risk assessments. In addition, modern genetic tools could be used to identify the genetic and biochemical attributes of a remediation system that enhance the likelihood of risk removal. For example, biochemical screening of environmental isolates has permitted the isolation and identification of pentaerythritol tetranitrate (PETN) and glycerol trinitrate, two bacterial nitrate ester reductases that are capable of degrading mutagenic explosives [449]. These two enzymes have recently been integrated into the genome of tobacco and this transgenic plant can provide an effective and affordable means to remediate soils contaminated with explosives [450]. Recent work by $\mathrm{He}$ et al. has employed 16S rRNA gene-based tools to identify a population of Dehalococcoides capable of completely mineralizing chlorinated substances such as tetrachloroethene and vinyl chloride [360,451]. The organism is now commercially available under the name Bio-Dechlor INOCULUM ${ }^{\mathrm{TM}}$, a lyophilized microbial consortium that can accelerate mineralization of chlorinated solvents in contaminated soils (see www.regenesis.com).

Finally, it is clear that there is a paucity of information on the ecological hazards of genotoxic soils. Although a few studies have documented effects on earthworms and rodents [441,442], the nature and magnitude of the effects on community structure and population viability are completely unknown. Assessment of exposure levels, bioavailability, and effects on terrestrial organisms is another promising area for future research.

\section{Acknowledgements}

We would like to thank several people for providing essential assistance. Prof. Kirby Donnelly of Texas A\&M University, Prof. Katerina Malachova of the University of Ostrava, and Dr. Osamu Endo of the Japanese National Institute of Public Health provided access to unpublished information. Dr. Tamara Grummt of the German Umweltbundesamt, Außenstelle Bad Elster provided information about contaminated sites in Germany. Prof. Takeshi Ohe of Kyoto Womens University provided several Japanese publications. The Government of Canada translation office provided translation of Spanish, Italian and Russian manuscripts. The US National Research Council (under the Research Associateship Program), the Natural Sciences and Engineering Research Council of Canada (under the visiting fellowship program), and Health Canada (under the Investing in Biotechnology program) provided funding. This work was also partly funded by the US Environmental Protection Agency. It has been subjected to review by the National Health and Environmental Effects Research Laboratory and approved for publication. Approval does not signify that the contents reflect the views of the Agency, nor does mention of trade names or commercial products constitute endorsement or recommendation for use. 


\section{Appendix A}

Salmonella mutagenicity data collected from the literature

\begin{tabular}{|c|c|c|c|c|c|c|c|c|c|}
\hline \multirow[t]{2}{*}{ Site/sample description } & \multicolumn{4}{|c|}{$\begin{array}{l}\text { Salmomella mutagenic potency } \\
\text { in revertents per gram dry soil }\end{array}$} & \multirow[t]{2}{*}{$\begin{array}{l}\text { Extraction } \\
\text { solvent }^{\mathrm{a}}\end{array}$} & \multirow{2}{*}{$\begin{array}{l}\text { EOM } \\
(\mathrm{mg} / \mathrm{g} \text { dry } \\
\text { soil })^{\mathrm{b}}\end{array}$} & \multicolumn{2}{|c|}{ Suspected contaminants } & \multirow[t]{2}{*}{ References } \\
\hline & $\begin{array}{l}\text { TA98 } \\
\text { no S9 }\end{array}$ & $\begin{array}{l}\text { TA98 } \\
\text { with S9 }\end{array}$ & $\begin{array}{l}\text { TA100 } \\
\text { no S9 }\end{array}$ & $\begin{array}{l}\text { TA100 } \\
\text { with S9 }\end{array}$ & & & Name & ppm dry weight $^{\mathrm{c}}$ & \\
\hline \multicolumn{10}{|c|}{ I. Sites not contaminated by industrial/urban activities (i.e., rural and/or agricultural) } \\
\hline Row crops (hops) & 504.0 & 504.0 & 636.0 & 986.0 & $\mathrm{Ac} / \mathrm{Hex}$ & $\mathrm{NA}^{\mathrm{d}}$ & $\mathrm{PAHs}^{\mathrm{e}} /$ pesticides $^{\mathrm{f}}$ & PAHs: 2.5 & {$[57]^{\mathrm{g}}$} \\
\hline Row crops (asparagus) & 493.0 & 471.0 & 526.0 & 756.0 & $\mathrm{Ac} / \mathrm{Hex}$ & NA & PAHs/pesticides & PAHs: $>0.1$ & [57] \\
\hline Row crops (rye) & 132.0 & 137.0 & 230.0 & 241.0 & $\mathrm{Ac} / \mathrm{Hex}$ & NA & Pesticides & & [57] \\
\hline Row crops (maize) & 208.0 & 214.0 & 285.0 & 241.0 & $\mathrm{Ac} / \mathrm{Hex}$ & NA & PAHs/pesticides & PAHs: $>0.07$ & [57] \\
\hline Row crops (oats) & 99.0 & 93.0 & 153.0 & 186.0 & $\mathrm{Ac} / \mathrm{Hex}$ & NA & & & [57] \\
\hline Pasture & 132.0 & 137.0 & 252.0 & 263.0 & $\mathrm{Ac} / \mathrm{Hex}$ & NA & PAHs & PAHs: $>0.01$ & [57] \\
\hline Meadow & 115.0 & 115.0 & 219.0 & 351.0 & $\mathrm{Ac} / \mathrm{Hex}$ & NA & & & [57] \\
\hline Rincon series loam & 36.0 & 298.0 & 33.0 & 73.0 & $\mathrm{ACN}$ & NA & & & [58] \\
\hline Rincon series loam & NA & 72.0 & NA & 22.0 & MetOH & NA & & & [58] \\
\hline Rincon series loam & NA & 33.0 & NA & 34.0 & DCM & NA & & & [58] \\
\hline Rincon series loam & NA & 4.0 & NA & 9.0 & Water $(\mathrm{pH}=2)$ & NA & & & [58] \\
\hline Field (no agriculture) & NA & 254.0 & NA & 66.0 & $\mathrm{ACN}$ & NA & & & [58] \\
\hline Field $(20 \mathrm{~cm}$ depth $)$ & NA & 119.0 & NA & 49.0 & $\mathrm{ACN}$ & NA & & & [58] \\
\hline Field 2 (no agriculture) & NA & 232.0 & NA & 46.0 & $\mathrm{ACN}$ & NA & & & [58] \\
\hline Garden 1 (organic) & NA & 141.0 & NA & 83.0 & ACN & NA & & & [58] \\
\hline Garden 2 (organic) & NA & 217.0 & NA & 44.0 & $\mathrm{ACN}$ & NA & & & [58] \\
\hline Forest edge & $\mathrm{ND}^{\mathrm{h}}$ & 50.0 & ND & 230.0 & DCM & NA & & & [432] \\
\hline Bastrop soil (rangeland) & 88.7 & 98.8 & 69.9 & 132.9 & DCM & 0.23 & Pesticides & & {$[40,48,49]$} \\
\hline Sassafrass soil (row crops) & 1.0 & 4.0 & 6.3 & 3.9 & DCM & 0.025 & Pesticides & & {$[40,49]$} \\
\hline Norwood soil (row crops) & 0.3 & 2.0 & 1.9 & 0.8 & DCM & 0.057 & Pesticides & & {$[40,42,49,166]$} \\
\hline Rural forest (Wales) & $\mathrm{NT}^{\mathrm{i}}$ & 78.0 & NT & 95.0 & DCM & NA & PAHs & PAHs: 2.2 & [39] \\
\hline Pasture (Wales) & NT & 46.0 & NT & 106.0 & DCM & NA & PAHs & PAHs: 0.2 & [39] \\
\hline Grazing land (Wales) & NT & 42.0 & NT & 96.0 & DCM & NA & PAHs & PAHs: 0.3 & [39] \\
\hline Ploughed/grazing (Wales) & NT & 39.0 & NT & 93.0 & DCM & NA & PAHs & PAHs: 0.3 & [39] \\
\hline Weswood soil (row crops) & 42.0 & 14.0 & NA & NA & MetOH & 1.31 & & & {$[64,165]$} \\
\hline Weswood soil (row crops) & 2.0 & 2.0 & NA & NA & DCM & 0.16 & & & {$[64,165]$} \\
\hline Weswood soil (row crops) & 0.3 & 2.0 & NA & NA & DCM & 0.057 & & & [48] \\
\hline Weswood soil (row crops) & 19.0 & 3.0 & NT & NT & DCM/MetOH & 1.48 & & & [64] \\
\hline Parkland (Azerbaijan 11) & NT & 7.0 & NT & NT & $\mathrm{Ac} / \mathrm{Hex}$ & 9.39 & PAHs & PAHs: 14.5 & [56] \\
\hline Padina soil (pasture) & 12.0 & 2.0 & NA & NA & MetOH & 0.46 & & & [165] \\
\hline Padina soil (pasture) & 7.0 & 6.0 & NA & NA & DCM & 0.57 & & & {$[165]$} \\
\hline Hechtsheim & 155.0 & 220.0 & 340.0 & 420.0 & $\mathrm{ACN}$ & NA & & & [55] \\
\hline
\end{tabular}


Appendix A. (Continued)

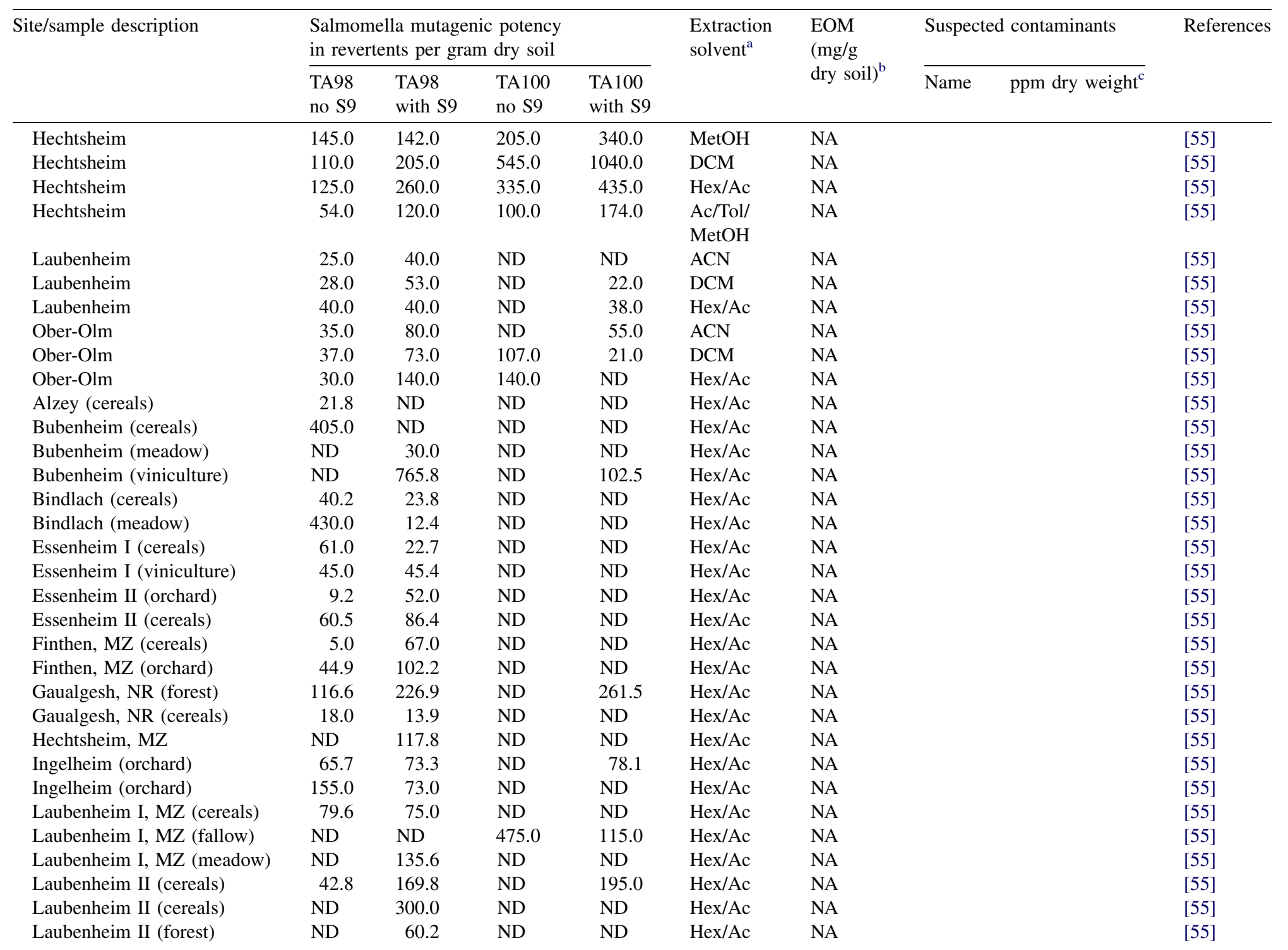




\begin{tabular}{|c|c|c|c|c|c|c|}
\hline Mainzer sand, NR (forest) & 28.2 & 31.0 & ND & 140.0 & $\mathrm{Hex} / \mathrm{Ac}$ & NA \\
\hline Mainzer sand, NR (fallow) & 100.0 & 160.2 & ND & ND & $\mathrm{Hex} / \mathrm{Ac}$ & NA \\
\hline Neukirchen (meadow) & 30.0 & ND & ND & ND & $\mathrm{Hex} / \mathrm{Ac}$ & NA \\
\hline Ober-Olm (orchard) & ND & ND & 265.0 & ND & $\mathrm{Hex} / \mathrm{Ac}$ & NA \\
\hline Ober-Olm (forest) & 266.9 & 60.8 & 263.5 & ND & $\mathrm{Hex} / \mathrm{Ac}$ & NA \\
\hline Ober-Olm (cereals) & ND & 82.8 & ND & ND & $\mathrm{Hex} / \mathrm{Ac}$ & NA \\
\hline Rauhenberg (cereals) & 44.6 & ND & ND & ND & $\mathrm{Hex} / \mathrm{Ac}$ & NA \\
\hline Scheckenhof (cereals) & 480.0 & 86.4 & ND & ND & $\mathrm{Hex} / \mathrm{Ac}$ & NA \\
\hline Scheckenhof (meadow) & 144.0 & 181.6 & ND & ND & $\mathrm{Hex} / \mathrm{Ac}$ & NA \\
\hline Bubenheim (rye) & 43.0 & 12.0 & 33.0 & 25.0 & $\mathrm{Hex} / \mathrm{Ac}$ & NA \\
\hline Bubenheim (rye) & 50.0 & 51.0 & 52.0 & 54.0 & $\mathrm{Hex} / \mathrm{Ac}$ & NA \\
\hline Bubenheim (rye) & 117.0 & 70.0 & 85.0 & 70.0 & $\mathrm{Hex} / \mathrm{Ac}$ & NA \\
\hline Bubenheim (rye) & 418.0 & 71.0 & 146.0 & 145.0 & $\mathrm{Hex} / \mathrm{Ac}$ & NA \\
\hline Bubenheim (rye) & 80.0 & 99.0 & 75.0 & 121.0 & $\mathrm{Hex} / \mathrm{Ac}$ & NA \\
\hline Bubenheim (rye) & 43.0 & 35.0 & 70.0 & 91.0 & $\mathrm{Hex} / \mathrm{Ac}$ & NA \\
\hline Bubenheim (rye) & 165.0 & 125.0 & 270.0 & 80.0 & Hex/Ac & NA \\
\hline Essenheim I (rye) & 7.0 & 18.0 & 79.0 & 36.0 & Hex/Ac & NA \\
\hline Essenheim I (rye) & 105.0 & 44.0 & 115.0 & 105.0 & $\mathrm{Hex} / \mathrm{Ac}$ & NA \\
\hline Essenheim I (rye) & 75.0 & 75.0 & 185.0 & 130.0 & $\mathrm{Hex} / \mathrm{Ac}$ & NA \\
\hline Essenheim I (rye) & 245.0 & 130.0 & 249.0 & 108.0 & $\mathrm{Hex} / \mathrm{Ac}$ & NA \\
\hline Essenheim I (rye) & 85.0 & 55.0 & 58.0 & 60.0 & $\mathrm{Hex} / \mathrm{Ac}$ & NA \\
\hline Essenheim I (rye) & 100.0 & 33.0 & 80.0 & 95.0 & $\mathrm{Hex} / \mathrm{Ac}$ & NA \\
\hline Essenheim I (rye) & 130.0 & 60.0 & 144.0 & 315.0 & $\mathrm{Hex} / \mathrm{Ac}$ & NA \\
\hline Essenheim II (rye) & 31.0 & 30.0 & 135.0 & 123.0 & Hex/Ac & NA \\
\hline Essenheim II (rye) & 52.0 & 51.0 & 150.0 & 94.0 & $\mathrm{Hex} / \mathrm{Ac}$ & NA \\
\hline Essenheim II (rye) & 255.0 & 70.0 & 242.0 & 86.0 & $\mathrm{Hex} / \mathrm{Ac}$ & NA \\
\hline Essenheim II (rye) & 185.0 & 216.0 & 245.0 & 167.0 & $\mathrm{Hex} / \mathrm{Ac}$ & NA \\
\hline Essenheim II (rye) & 91.0 & 135.0 & 60.0 & 65.0 & $\mathrm{Hex} / \mathrm{Ac}$ & NA \\
\hline Essenheim II (rye) & 76.0 & 30.0 & 95.0 & 40.0 & $\mathrm{Hex} / \mathrm{Ac}$ & NA \\
\hline Essenheim II (rye) & 175.0 & 158.0 & 185.0 & 235.0 & Hex/Ac & NA \\
\hline Finthen, MZ (rye) & 42.0 & 19.0 & 90.0 & 31.0 & Hex/Ac & NA \\
\hline Finthen, MZ (rye) & 30.0 & 40.0 & 31.0 & 59.0 & $\mathrm{Hex} / \mathrm{Ac}$ & NA \\
\hline Finthen, MZ (rye) & 52.0 & 54.0 & 175.0 & 230.0 & $\mathrm{Hex} / \mathrm{Ac}$ & NA \\
\hline Finthen, MZ (rye) & 145.0 & 119.0 & 107.0 & 151.0 & $\mathrm{Hex} / \mathrm{Ac}$ & NA \\
\hline Finthen, MZ (rye) & 116.0 & 107.0 & 156.0 & 178.0 & $\mathrm{Hex} / \mathrm{Ac}$ & NA \\
\hline Finthen, MZ (rye) & 89.0 & 102.0 & 48.0 & 95.0 & $\mathrm{Hex} / \mathrm{Ac}$ & NA \\
\hline Finthen, MZ (rye) & 54.0 & 85.0 & 95.0 & 169.0 & $\mathrm{Hex} / \mathrm{Ac}$ & NA \\
\hline Gaualgesheimer (rye) & 12.0 & 18.0 & 55.0 & 66.0 & $\mathrm{Hex} / \mathrm{Ac}$ & NA \\
\hline Gaualgesheimer (rye) & 49.0 & 36.0 & 88.0 & 44.0 & $\mathrm{Hex} / \mathrm{Ac}$ & NA \\
\hline Gaualgesheimer (rye) & 19.0 & 42.0 & 55.0 & 65.0 & Hex/Ac & NA \\
\hline
\end{tabular}


Appendix A. (Continued)

\begin{tabular}{|c|c|c|c|c|c|c|c|c|}
\hline \multirow[t]{2}{*}{ Site/sample description } & \multicolumn{4}{|c|}{$\begin{array}{l}\text { Salmomella mutagenic potency } \\
\text { in revertents per gram dry soil }\end{array}$} & \multirow[t]{2}{*}{$\begin{array}{l}\text { Extraction } \\
\text { solvent }^{\mathrm{a}}\end{array}$} & \multirow{2}{*}{ 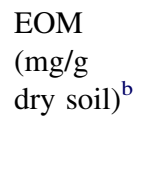 } & Suspected contaminants & \multirow[t]{2}{*}{ References } \\
\hline & $\begin{array}{l}\text { TA98 } \\
\text { no S9 }\end{array}$ & $\begin{array}{l}\text { TA98 } \\
\text { with S9 }\end{array}$ & $\begin{array}{l}\text { TA100 } \\
\text { no S9 }\end{array}$ & $\begin{array}{l}\text { TA100 } \\
\text { with S9 }\end{array}$ & & & ppm dry weight $^{\mathrm{c}}$ & \\
\hline Gaualgesheimer (rye) & 120.0 & 191.0 & 163.0 & 98.0 & $\mathrm{Hex} / \mathrm{Ac}$ & NA & & {$[55]$} \\
\hline Gaualgesheimer (rye) & 64.0 & 110.0 & 135.0 & 81.0 & $\mathrm{Hex} / \mathrm{Ac}$ & NA & & {$[55]$} \\
\hline Gaualgesheimer (rye) & 23.0 & 30.0 & 45.0 & 33.0 & $\mathrm{Hex} / \mathrm{Ac}$ & NA & & {$[55]$} \\
\hline Gaualgesheimer (rye) & 70.0 & 50.0 & 155.0 & 175.0 & $\mathrm{Hex} / \mathrm{Ac}$ & NA & & [55] \\
\hline Hechtsheim, MZ (rye) & 73.0 & 155.0 & 235.0 & 110.0 & $\mathrm{Hex} / \mathrm{Ac}$ & NA & & {$[55]$} \\
\hline Hechtsheim, MZ (rye) & 90.0 & 96.0 & 227.0 & 124.0 & $\mathrm{Hex} / \mathrm{Ac}$ & NA & & {$[55]$} \\
\hline Hechtsheim, MZ (rye) & 95.0 & 38.0 & 88.0 & 205.0 & $\mathrm{Hex} / \mathrm{Ac}$ & NA & & [55] \\
\hline Hechtsheim, MZ (rye) & 100.0 & 152.0 & 78.0 & 197.0 & $\mathrm{Hex} / \mathrm{Ac}$ & NA & & {$[55]$} \\
\hline Hechtsheim, MZ (rye) & 37.0 & 105.0 & 56.0 & 170.0 & $\mathrm{Hex} / \mathrm{Ac}$ & NA & & {$[55]$} \\
\hline Hechtsheim, MZ (rye) & 110.0 & 135.0 & 90.0 & 355.0 & $\mathrm{Hex} / \mathrm{Ac}$ & NA & & [55] \\
\hline Laubenheim I, MZ (rye) & 48.0 & 12.0 & 145.0 & 19.0 & $\mathrm{Hex} / \mathrm{Ac}$ & NA & & [55] \\
\hline Laubenheim I, MZ (rye) & 50.0 & 18.0 & 59.0 & 135.0 & $\mathrm{Hex} / \mathrm{Ac}$ & NA & & {$[55]$} \\
\hline Laubenheim I, MZ (rye) & 70.0 & 255.0 & 130.0 & 60.0 & $\mathrm{Hex} / \mathrm{Ac}$ & NA & & {$[55]$} \\
\hline Laubenheim I, MZ (rye) & 40.0 & 570.0 & 530.0 & 140.0 & $\mathrm{Hex} / \mathrm{Ac}$ & NA & & {$[55]$} \\
\hline Laubenheim I, MZ (rye) & 41.0 & 77.0 & 200.0 & 121.0 & $\mathrm{Hex} / \mathrm{Ac}$ & NA & & {$[55]$} \\
\hline Laubenheim I, MZ (rye) & 75.0 & 155.0 & 265.0 & 105.0 & $\mathrm{Hex} / \mathrm{Ac}$ & NA & & {$[55]$} \\
\hline Laubenheim II, MZ (rye) & 32.0 & 26.0 & 108.0 & 31.0 & $\mathrm{Hex} / \mathrm{Ac}$ & NA & & {$[55]$} \\
\hline Laubenheim II, MZ (rye) & 85.0 & 98.0 & 73.0 & 132.0 & $\mathrm{Hex} / \mathrm{Ac}$ & NA & & [55] \\
\hline Laubenheim II, MZ (rye) & 60.0 & 79.0 & 136.0 & 154.0 & $\mathrm{Hex} / \mathrm{Ac}$ & NA & & [55] \\
\hline Laubenheim II, MZ (rye) & 120.0 & 120.0 & 207.0 & 291.0 & $\mathrm{Hex} / \mathrm{Ac}$ & NA & & [55] \\
\hline Laubenheim II, MZ (rye) & 97.0 & 194.0 & 135.0 & 220.0 & $\mathrm{Hex} / \mathrm{Ac}$ & NA & & {$[55]$} \\
\hline Laubenheim II, MZ (rye) & 93.0 & 58.0 & 140.0 & 73.0 & $\mathrm{Hex} / \mathrm{Ac}$ & NA & & {$[55]$} \\
\hline Laubenheim II, MZ (rye) & 55.0 & 105.0 & 270.0 & 135.0 & $\mathrm{Hex} / \mathrm{Ac}$ & NA & & {$[55]$} \\
\hline Laubenheim II, MZ (rye) & 32.0 & 10.0 & 85.0 & 15.0 & $\mathrm{Hex} / \mathrm{Ac}$ & NA & & {$[55]$} \\
\hline Laubenheim II, MZ (rye) & 60.0 & 47.0 & 153.0 & 124.0 & $\mathrm{Hex} / \mathrm{Ac}$ & NA & & {$[55]$} \\
\hline Laubenheim II, MZ (rye) & 130.0 & 15.0 & 207.0 & 79.0 & $\mathrm{Hex} / \mathrm{Ac}$ & NA & & [55] \\
\hline Laubenheim II, MZ (rye) & 125.0 & 72.0 & 370.0 & 325.0 & $\mathrm{Hex} / \mathrm{Ac}$ & NA & & [55] \\
\hline Laubenheim II, MZ (rye) & 45.0 & 125.0 & 595.0 & 88.0 & $\mathrm{Hex} / \mathrm{Ac}$ & NA & & {$[55]$} \\
\hline
\end{tabular}


Ober-Olm (rye)

Ober-Olm (rye)

Ober-Olm (rye)

Ober-Olm (rye)

Ober-Olm (rye)

Ober-Olm (rye)

Ober-Olm (rye)

Agricultural soil (Iran)

Aligarh Soil 1

Aligarh Soil 1

Aligarh Soil 1

II. Urban and/or residential sites River edge (urban/industrial) Marsh (urban loaction)

River edge (urban/industrial)

River edge (urban/residential)

River edge (urban location)

River edge (urban/industrial)

River edge (urban/industrial)

River edge (urban/industrial)

Grassland (residential)

Woodland (urban/industrial)

Grassland (residential)

Park (urban)

Grassland (urban/industrial)

Pasture (urban/industrial)

Roadside (urban/residential)

Industrial site (background)

Urban park (Nara)

Urban park (Mino)

Urban park (Ibaraki)

Urban park (Sumiyoshi-ku)

$\begin{array}{rcc}31.0 & 16.0 & 89.0 \\ 40.0 & 61.0 & 78.0 \\ 25.0 & 42.0 & 155.0 \\ 90.0 & 156.0 & 262.0 \\ 78.0 & 120.0 & 128.0 \\ 35.0 & 30.0 & 48.0 \\ 80.0 & 60.0 & 110.0 \\ 284.0 & \mathrm{NT} & 2.8 \\ 62.0 & 67.0 & \mathrm{ND} \\ 64.0 & 79.0 & \mathrm{ND} \\ 52.0 & 49.0 & \mathrm{ND}\end{array}$

88.0
140.0
210.0
310.0
180.0
70.0
145.0
NT
ND
ND
ND

Hex/Ac

Hex/Ac

$\mathrm{Hex} / \mathrm{Ac}$

$\mathrm{Hex} / \mathrm{Ac}$

$\mathrm{Hex} / \mathrm{Ac}$

Hex/Ac

$\mathrm{Hex} / \mathrm{Ac}$

MetOH

$\mathrm{MetOH}$

$\mathrm{ACN}$

Acetone

NA

NA

NA

NA

NA

NA

NA

NA

NA

NA

NA

ND $\quad 540.0$

ND $\quad 260.0$

ND $\quad 170.0$

ND $\quad 130.0$

ND $\quad 80.0$

ND $\quad 70.0$

ND $\quad 60.0$

ND $\quad 60.0$

NT $\quad 61.0$

NT

NT

50.0

NT 48.0

NT 43.0

NT 41.0

NT

NA

ND

ND

84.0

5600.0
ND $\quad 2450.0 \quad$ DCM $\quad$ NA

ND $\quad 1800.0 \quad$ DCM NA

ND $\quad 620.0 \quad$ DCM $\quad$ NA

ND $\quad 1000.0 \quad$ DCM

ND $\quad 580.0 \quad$ DCM NA

ND $230.0 \quad$ DCM $\quad$ NA

ND $\quad 240.0 \quad$ DCM $\quad$ NA

ND $\quad 160.0 \quad$ DCM NA

$\begin{array}{lrll}\text { NT } & 88.0 & \text { DCM } & \text { NA }\end{array}$

$\begin{array}{lll}\text { NT } & 106.0 & \text { DCM }\end{array}$

$\begin{array}{llll}\text { NT } & 93.0 & \text { DCM } & \text { NA }\end{array}$

$\begin{array}{lll}\text { NT } & 79.0 \quad \text { DCM } & \text { NA }\end{array}$

NT $82.0 \quad$ DCM NA

$\begin{array}{llll}\text { NT } & 119.0 & \text { DCM } & \text { NA }\end{array}$

$\begin{array}{lrll}\text { NT } & 119.0 & \text { DCM } & \text { NA } \\ \text { NT } & 87.0 & \text { DCM } & \text { NA }\end{array}$

NA NA DCM/MetOH NA

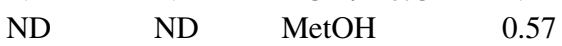

ND ND $\quad$ MetOH 1.07

$88.0 \quad 140.0$

600.0

2400.0

$\mathrm{MetOH}$

$\mathrm{MetOH}$

1.07
0.85
0.75

Urban park (Minato-ku)

5900.0

5500.0

530.0

2500.0

MetOH

\begin{tabular}{|c|c|c|}
\hline & & $\begin{array}{l}{[55]} \\
{[55]} \\
{[55]} \\
{[55]} \\
{[55]} \\
{[55]} \\
{[55]} \\
{[309]} \\
{[60]} \\
{[60]} \\
{[60]}\end{array}$ \\
\hline & & $\begin{array}{l}{[432]} \\
{[432]} \\
{[432]} \\
{[432]} \\
{[432]} \\
{[432]} \\
{[432]} \\
{[432]}\end{array}$ \\
\hline PAHs & PAHs: 0.7 & [39] \\
\hline PAHs & PAHs: 54.5 & [39] \\
\hline PAHs & PAHs: 7.0 & [39] \\
\hline PAHs & PAHs: 3.8 & [39] \\
\hline PAHs & PAHs: 1.0 & [39] \\
\hline PAHs & PAHs: 5.4 & [39] \\
\hline PAHs & PAHs: 8.3 & [39] \\
\hline Creosote & & {$[45]$} \\
\hline Nitroarenes & & [124] \\
\hline Nitroarenes & & [124] \\
\hline Nitroarenes & & [124] \\
\hline Nitroarenes ${ }^{\mathrm{j}}$ & $\begin{array}{l}1,6-\mathrm{DNP}: \\
1.9 \times 10^{-3} \\
1,8-\mathrm{DNP}: \\
2.2 \times 10^{-3}\end{array}$ & [124] \\
\hline Nitroarenes & $\begin{array}{l}1,6-\mathrm{DNP}: \\
1.7 \times 10^{-3} \\
1,8-\mathrm{DNP} \\
2.2 \times 10^{-3}\end{array}$ & [124] \\
\hline
\end{tabular}


Appendix A. (Continued)

\begin{tabular}{|c|c|c|c|c|c|c|c|c|c|}
\hline \multirow[t]{2}{*}{ Site/sample description } & \multicolumn{4}{|c|}{$\begin{array}{l}\text { Salmomella mutagenic potency } \\
\text { in revertents per gram dry soil }\end{array}$} & \multirow[t]{2}{*}{$\begin{array}{l}\text { Extraction } \\
\text { solvent }^{\mathrm{a}}\end{array}$} & \multirow{2}{*}{$\begin{array}{l}\text { EOM } \\
(\mathrm{mg} / \mathrm{g} \\
\text { dry soil })^{\mathrm{b}}\end{array}$} & \multicolumn{2}{|c|}{ Suspected contaminants } & \multirow[t]{2}{*}{ References } \\
\hline & $\begin{array}{l}\text { TA98 } \\
\text { no S9 }\end{array}$ & $\begin{array}{l}\text { TA98 } \\
\text { with S9 }\end{array}$ & $\begin{array}{l}\text { TA100 } \\
\text { no S9 }\end{array}$ & $\begin{array}{l}\text { TA100 } \\
\text { with S9 }\end{array}$ & & & Name & ppm dry weight $^{\mathrm{c}}$ & \\
\hline Urban Park (Takarazuka) & ND & 58.0 & ND & ND & MetOH & 0.18 & Nitroarenes & & {$[124]$} \\
\hline Urban soil (Azerbaijan 1) & NT & 84.0 & NT & NT & $\mathrm{Ac} / \mathrm{Hex}$ & 0.84 & PAHs & PAHs: 7.3 & {$[56]$} \\
\hline Urban soil (Azerbaijan 2) & NT & 19.0 & NT & NT & $\mathrm{Ac} / \mathrm{Hex}$ & 3.36 & PAHs & PAHs: 51.3 & {$[56]$} \\
\hline Urban soil (Azerbaijan 3) & NT & 21.0 & NT & NT & Ac/Hex & 2.22 & PAHs & PAHs: 11.7 & {$[56]$} \\
\hline Urban soil (Azerbaijan 6) & NT & 23.0 & NT & NT & Ac/Hex & 1.66 & PAHs & PAHs: 8.79 & [56] \\
\hline Urban soil (Azerbaijan 7) & NT & 158.0 & NT & NT & Ac/Hex & 0.60 & PAHs & PAHs: 2.93 & {$[56]$} \\
\hline Urban soil (Azerbaijan 9) & NT & 8.0 & NT & NT & Ac/Hex & 8.38 & PAHs & PAHs: 11.72 & {$[56]$} \\
\hline Urban soil (Azerbaijan 10) & NT & 15.0 & NT & NT & Ac/Hex & 5.18 & PAHs & PAHs: 2.93 & {$[56]$} \\
\hline Urban soil (Sendai City) & 77.0 & 408.0 & 241.0 & 347.0 & NA & NA & Hydrocarbons & & [431] \\
\hline Urban soil (Kitakyushu city) & 440.0 & 800.0 & NT & NT & NA & NA & Tar/PAHs & PAHs: 0.96 & [119] \\
\hline Urban soil (Kyushu hway) & 530.0 & 820.0 & NT & NT & NA & NA & Tar/PAHs & PAHs: 0.34 & [119] \\
\hline Urban soil (Chugoku tunnel) & 2600.0 & 6100.0 & NT & NT & NA & NA & Tar/PAHs & PAHs: 0.28 & [119] \\
\hline Urban soil (Kakei-nishi) & 3860.0 & 8980.0 & NT & NT & NA & NA & Tar/PAHs & PAHs: 0.35 & [119] \\
\hline Urban soil (Kakei-higashi) & 2800.0 & 7030.0 & NT & NT & NA & NA & Tar/PAHs & PAHs: 0.13 & [119] \\
\hline Urban soil (Yoneyama) & 817.0 & 1590.0 & NT & NT & NA & NA & Tar/PAHs & PAHs: 0.11 & [119] \\
\hline Mainz-Finthem Motorway & 65.0 & 0.503 & 395.0 & 361.0 & DCM/Ac/Tol:DEK & 4.50 & PAHs & & {$[116]$} \\
\hline Mainz-Finthem Motorway & 89.0 & 0.510 & 533.0 & 756.0 & DCM/Ac/Tol:DEK & 7.78 & PAHs & & {$[116]$} \\
\hline Mainz-Finthem Motorway & 472.0 & 1.890 & 4890.0 & 3427.0 & DCM/Ac/Tol:DEK & 4.29 & PAHs & PAHs: 17.3 & {$[116]$} \\
\hline A60, exit Großerg & 450.0 & 448.0 & NT & NT & DCM/Ac/Tol:DEK & NA & PAHs & & {$[116]$} \\
\hline A60, exit Großberg & 1170.0 & 292.0 & NT & NT & DCM/Ac/Tol:DEK & NA & PAHs & & {$[116]$} \\
\hline Saarstraße near Mainz & ND & 564.0 & NT & NT & DCM/Ac/Tol:DEK & NA & PAHs & & {$[116]$} \\
\hline Saarstraße near Mainz & 1060.0 & 600.0 & NT & NT & DCM/Ac/Tol:DEK & NA & PAHs & & {$[116]$} \\
\hline Bundesstraße 9 near Labenheim & ND & 1240.0 & NT & NT & DCM/Ac/Tol:DEK & NA & PAHs & & [116] \\
\hline Bundesstra $\beta$ e 9 near Labenheim & 600.0 & 450.0 & NT & NT & DCM/Ac/Tol:DEK & NA & PAHs & & {$[116]$} \\
\hline Bundesstraße 9 near Labenheim & 181.0 & 474.0 & NT & NT & DCM/Ac/Tol:DEK & NA & PAHs & & {$[116]$} \\
\hline Landstraße L431 & 1030.0 & 1700.0 & NT & NT & DCM/Ac/Tol:DEK & NA & PAHs & & {$[116]$} \\
\hline Landstraße L431 & 1100.0 & 519.0 & NT & NT & DCM/Ac/Tol:DEK & NA & PAHs & & {$[116]$} \\
\hline Landstraße L431 & 1100.0 & 1850.0 & NT & NT & DCM/Ac/Tol:DEK & NA & PAHs & & {$[116]$} \\
\hline
\end{tabular}




\begin{tabular}{|c|c|c|c|c|c|}
\hline Landstraße L422 & 32.0 & 190.0 & NT & NT & DCM/Ac/Tol:DEK \\
\hline Tokyo soil (commercial) & 226.0 & 325.0 & NT & NT & Benzene/EtOH \\
\hline Tokyo soil (residential) & 147.0 & 290.0 & NT & NT & Benzene/EtOH \\
\hline Tokyo Shinagawa-ku & 319.0 & NT & NT & NT & $\mathrm{MetOH}$ \\
\hline Higashimurayama & 438.0 & NT & NT & NT & $\mathrm{MetOH}$ \\
\hline Hachioji & 380.0 & NT & NT & NT & $\mathrm{MetOH}$ \\
\hline Nagoya & 180.0 & NT & NT & NT & $\mathrm{MetOH}$ \\
\hline Gifu & 260.0 & NT & NT & NT & $\mathrm{MetOH}$ \\
\hline Uji & 3300.0 & NT & NT & NT & $\mathrm{MetOH}$ \\
\hline Osaka Sumiyoshi-ku & 9780.0 & NT & NT & NT & $\mathrm{MetOH}$ \\
\hline Higashiosaka & 248.0 & NT & NT & NT & MetOH \\
\hline Sapporo 1 & 360.0 & 582.0 & 383.0 & 2092.0 & MetOH \\
\hline Sapporo 2 & 606.0 & 825.0 & 594.0 & 1793.0 & $\mathrm{MetOH}$ \\
\hline Sapporo 3 & 381.0 & 502.0 & 414.0 & 1641.0 & $\mathrm{MetOH}$ \\
\hline Sapporo 4 & 214.0 & 306.0 & 225.0 & 732.0 & MetOH \\
\hline Sapporo 5 & 512.0 & 664.0 & 516.0 & 752.0 & MetOH \\
\hline Sapporo 6 & 214.0 & 582.0 & 320.0 & 357.0 & MetOH \\
\hline Sapporo 7 & 912.0 & 1076.0 & 772.0 & 912.0 & MetOH \\
\hline Sapporo 8 & 472.0 & 615.0 & 508.0 & 448.0 & MetOH \\
\hline Muroran 1 & 194.0 & 428.0 & 424.0 & 700.0 & MetOH \\
\hline Muroran 2 & 404.0 & 1368.0 & 876.0 & 2420.0 & MetOH \\
\hline Muroran 3 & 366.0 & 2135.0 & 558.0 & 5259.0 & $\mathrm{MetOH}$ \\
\hline Muroran 4 & 624.0 & 2400.0 & 616.0 & 2676.0 & $\mathrm{MetOH}$ \\
\hline Muroran 5 & 372.0 & 1952.0 & 560.0 & 6360.0 & MetOH \\
\hline Muroran 6 & 130.0 & 135.0 & 286.0 & 294.0 & $\mathrm{MetOH}$ \\
\hline Asahikawa 1 & 206.0 & 336.0 & 265.0 & 741.0 & $\mathrm{MetOH}$ \\
\hline Asahikawa 2 & 488.0 & 704.0 & 668.0 & 968.0 & MetOH \\
\hline Asahikawa 3 & 454.0 & 570.0 & 790.0 & 2054.0 & MetOH \\
\hline Asahikawa 4 & 129.0 & 132.0 & 177.0 & 726.0 & $\mathrm{MetOH}$ \\
\hline Asahikawa 5 & 191.0 & 186.0 & 219.0 & 772.0 & MetOH \\
\hline
\end{tabular}

$\begin{array}{lll}\text { PAHs } & & {[116]} \\ \text { PAHs } & \text { BaP }{ }^{k} 0.20 & {[327]} \\ \text { PAHs } & \text { BaP: } 0.16 & {[327]} \\ \text { PAHs, DNPs } & \text { DNPs: } & {[52]} \\ & 0.18 \times 10^{-3} & \\ \text { PAHs, DNPs } & \text { DNPs: } & {[52]} \\ & 0.05 \times 10^{-3} & \\ \text { PAHs, DNPs } & \text { DNPs: } & {[52]} \\ & 0.07 \times 10^{-3} & \\ \text { PAHs, DNPs } & \text { DNPs: } & {[52]} \\ & 0.04 \times 10^{-3} & \\ \text { PAHs, DNPs } & \text { DNPs: } & {[52]} \\ & 0.21 \times 10^{-3} & \\ \text { PAHs, DNPs } & \text { DNPs: } & {[52]} \\ & 1.81 \times 10^{-3} & \\ \text { PAHs, DNPs } & \text { DNPs: } & {[52]} \\ & 9.40 \times 10^{-3} & \\ \text { PAHs, DNPs } & \text { DNPs: } & {[52]} \\ & 0.12 \times 10^{-3} & \\ \text { PAHs, DNPs } & & {[53]} \\ \text { PAHs, DNPs } & & {[53]} \\ \text { PAHs, DNPs } & & {[53]} \\ \text { PAHs, DNPs } & & {[53]} \\ \text { PAHs, DNPs } & & {[53]} \\ \text { PAHs, DNPs } & & {[53]} \\ \text { PAHs, DNPs } & & {[53]} \\ \text { PAHs, DNPs } & & {[53]} \\ \text { PAHs, DNPs } & & {[53]} \\ \text { PAHs, DNPs } & & {[53]} \\ \text { PAHs, DNPs } & & {[53]} \\ \text { PAHs, DNPs } & & {[53]} \\ \text { PAHs, DNPs } & & {[53]} \\ \text { PAHs, DNPs } & & {[53]} \\ \text { PAHs, DNPs } & & {[53]} \\ \text { PAHs, DNPs } & & {[53]} \\ \text { PAHs, DNPs } & & {[53]} \\ \text { PAHs, DNPs } & & {[53]} \\ \text { PAHs, DNPs } & & {[53]}\end{array}$


Appendix A. (Continued)

\begin{tabular}{|c|c|c|c|c|c|c|c|c|c|}
\hline \multirow[t]{2}{*}{ Site/sample description } & \multicolumn{4}{|c|}{$\begin{array}{l}\text { Salmomella mutagenic potency } \\
\text { in revertents per gram dry soil }\end{array}$} & \multirow[t]{2}{*}{$\begin{array}{l}\text { Extraction } \\
\text { solvent }^{\mathrm{a}}\end{array}$} & \multirow{2}{*}{$\begin{array}{l}\text { EOM } \\
(\mathrm{mg} / \mathrm{g} \\
\text { dry soil })^{\mathrm{b}}\end{array}$} & \multicolumn{2}{|c|}{ Suspected contaminants } & \multirow[t]{2}{*}{$\overline{\text { References }}$} \\
\hline & $\begin{array}{l}\text { TA98 } \\
\text { no S9 }\end{array}$ & $\begin{array}{l}\text { TA98 } \\
\text { with S9 }\end{array}$ & $\begin{array}{l}\text { TA100 } \\
\text { no S9 }\end{array}$ & $\begin{array}{l}\text { TA100 } \\
\text { with S9 }\end{array}$ & & & Name & $\overline{\text { ppm dry weight }}{ }^{\mathrm{c}}$ & \\
\hline Kushiro 1 & 170.0 & 194.0 & 261.0 & 648.0 & MetOH & NA & PAHs, DNPs & & [53] \\
\hline Kushiro 2 & 212.0 & 210.0 & 240.0 & 336.0 & MetOH & NA & PAHs, DNPs & & {$[53]$} \\
\hline Kushiro 3 & 177.0 & 285.0 & 265.0 & 350.0 & MetOH & NA & PAHs, DNPs & & {$[53]$} \\
\hline Kushiro 4 & 114.0 & 254.0 & 239.0 & 414.0 & MetOH & NA & PAHs, DNPs & & {$[53]$} \\
\hline Tokyo 1 & 1240.0 & 885.0 & 937.0 & 735.0 & MetOH & NA & PAHs, DNPs & & {$[53]$} \\
\hline Tokyo 2 & 324.0 & 335.0 & 252.0 & 281.0 & MetOH & NA & PAHs, DNPs & & {$[53]$} \\
\hline Tokyo 3 & 596.0 & 648.0 & 242.0 & 501.0 & MetOH & NA & PAHs, DNPs & & [53] \\
\hline Tokyo 4 & 508.0 & 588.0 & 743.0 & 300.0 & MetOH & NA & PAHs, DNPs & & [53] \\
\hline Tokyo 5 & 425.0 & 528.0 & 279.0 & 581.0 & MetOH & NA & PAHs, DNPs & & {$[53]$} \\
\hline Tokyo 6 & 282.0 & 445.0 & 198.0 & 357.0 & MetOH & NA & PAHs, DNPs & & {$[53]$} \\
\hline Tokyo 7 & 2310.0 & 1300.0 & 1800.0 & 1390.0 & MetOH & NA & PAHs, DNPs & & [53] \\
\hline Tokyo 8 & 303.0 & 435.0 & 372.0 & 227.0 & MetOH & NA & PAHs, DNPs & & [53] \\
\hline Kawasaki & 315.0 & 431.0 & 732.0 & 496.0 & MetOH & NA & PAHs, DNPs & & [53] \\
\hline Yokohama 1 & 345.0 & 403.0 & 428.0 & 727.0 & MetOH & NA & PAHs, DNPs & & {$[53]$} \\
\hline Yokohama 2 & 1060.0 & 1310.0 & 539.0 & 989.0 & $\mathrm{MetOH}$ & NA & PAHs, DNPs & & [53] \\
\hline Yokohama 3 & 204.0 & 252.0 & 141.0 & 477.0 & MetOH & NA & PAHs, DNPs & & {$[53]$} \\
\hline Ebina & 243.0 & 347.0 & 693.0 & 251.0 & MetOH & NA & PAHs, DNPs & & {$[53]$} \\
\hline Warabi & 440.0 & 755.0 & 511.0 & 568.0 & MetOH & NA & PAHs, DNPs & & {$[53]$} \\
\hline Omiya & 934.0 & 995.0 & 587.0 & 1300.0 & MetOH & NA & PAHs, DNPs & & {$[53]$} \\
\hline Kumagaya & 395.0 & 383.0 & 389.0 & 598.0 & MetOH & NA & PAHs, DNPs & & {$[53]$} \\
\hline Funabashi & 184.0 & 247.0 & 268.0 & 484.0 & MetOH & NA & PAHs, DNPs & & {$[53]$} \\
\hline Tsukuba & 468.0 & 444.0 & 574.0 & 445.0 & MetOH & NA & PAHs, DNPs & & [53] \\
\hline Maebashi & 195.0 & 310.0 & 84.0 & 391.0 & MetOH & NA & PAHs, DNPs & & {$[53]$} \\
\hline Nagoya 1 & 139.0 & 261.0 & 29.0 & 80.0 & MetOH & NA & PAHs, DNPs & & {$[53]$} \\
\hline Nagoya 2 & 61.0 & 363.0 & 151.0 & 154.0 & MetOH & NA & PAHs, DNPs & & {$[53]$} \\
\hline Nagoya 3 & 213.0 & 237.0 & 285.0 & 226.0 & MetOH & NA & PAHs, DNPs & & {$[53]$} \\
\hline Nagoya 4 & 629.0 & 949.0 & 613.0 & 607.0 & MetOH & NA & PAHs, DNPs & & {$[53]$} \\
\hline Nagoya 5 & 168.0 & 493.0 & 240.0 & 339.0 & MetOH & NA & PAHs, DNPs & & {$[53]$} \\
\hline Ogaki 1 & 56.0 & 93.0 & 149.0 & 69.0 & MetOH & NA & PAHs, DNPs & & [53] \\
\hline Ogaki 2 & 347.0 & 560.0 & 603.0 & 445.0 & MetOH & NA & PAHs, DNPs & & {$[53]$} \\
\hline Ogaki 3 & 341.0 & 1060.0 & 861.0 & 875.0 & MetOH & NA & PAHs, DNPs & & {$[53]$} \\
\hline
\end{tabular}




\begin{tabular}{|c|c|c|c|c|c|}
\hline Okazaki 1 & 461.0 & 316.0 & 181.0 & 148.0 & MetOH \\
\hline Okazaki 2 & 180.0 & 648.0 & 587.0 & 635.0 & MetOH \\
\hline Okazaki 3 & 376.0 & 587.0 & 319.0 & 619.0 & MetOH \\
\hline Hekinan 1 & 168.0 & 136.0 & 139.0 & 147.0 & MetOH \\
\hline Hekinan 2 & 26300.0 & 10400.0 & 4600.0 & 6720.0 & MetOH \\
\hline Ichinomiya 1 & 477.0 & 805.0 & 398.0 & 539.0 & MetOH \\
\hline Ichinomiya 2 & 373.0 & 665.0 & 408.0 & 424.0 & MetOH \\
\hline Nakatsugawa 1 & 141.0 & 159.0 & 91.0 & 63.0 & MetOH \\
\hline Nakatsugawa 2 & 147.0 & 408.0 & 248.0 & 224.0 & MetOH \\
\hline Shinshiro 1 & 256.0 & 253.0 & 117.0 & 144.0 & MetOH \\
\hline Shinshiro 2 & 440.0 & 597.0 & 239.0 & 299.0 & MetOH \\
\hline Toyohashi 1 & 357.0 & 325.0 & 64.0 & 123.0 & MetOH \\
\hline Toyohashi 2 & 117.0 & 304.0 & 159.0 & 132.0 & MetOH \\
\hline Inasa & 220.0 & 312.0 & 147.0 & 467.0 & MetOH \\
\hline Kariya & 379.0 & 445.0 & 232.0 & 320.0 & MetOH \\
\hline Kaizu & 339.0 & 608.0 & 385.0 & 301.0 & MetOH \\
\hline Moriyama & 46.0 & 98.0 & ND & 47.0 & MetOH \\
\hline Kusatsu & 66.0 & 101.0 & ND & 0.0 & MetOH \\
\hline Otsu 1 & 256.0 & 629.0 & ND & 120.0 & MetOH \\
\hline Otsu 2 & 52.0 & 92.0 & ND & 69.0 & MetOH \\
\hline Kyoto 1 & & 83.0 & ND & 0.0 & MetOH \\
\hline Kyoto 2 & 87.0 & 173.0 & ND & 55.0 & MetOH \\
\hline Gose & 98.0 & 260.0 & ND & 0.0 & MetOH \\
\hline Nara & ND & 34.0 & ND & 0.0 & MetOH \\
\hline Minoo & 84.0 & 95.0 & 51.0 & 0.0 & MetOH \\
\hline Ibaraki & 64.0 & 138.0 & 92.0 & 132.0 & MetOH \\
\hline Takatsuki & 325.0 & 830.0 & 86.0 & 201.0 & MetOH \\
\hline Osaka 1 & 6735.0 & 6515.0 & 585.0 & 2672.0 & MetOH \\
\hline Osaka 2 & 5963.0 & 4255.0 & 527.0 & 2397.0 & MetOH \\
\hline Osaka 3 & 225.0 & 702.0 & ND & 141.0 & MetOH \\
\hline Tararazuka & ND & 32.0 & ND & 0.0 & MetOH \\
\hline Ashiya & 103.0 & 272.0 & ND & 153.0 & MetOH \\
\hline Nishinomiya & 1532.0 & 3965.0 & 144.0 & 745.0 & MetOH \\
\hline Amagasaki & 380.0 & 884.0 & ND & 284.0 & MetOH \\
\hline Kobe 1 & 10167.0 & 4302.0 & 720.0 & 3275.0 & MetOH \\
\hline Kobe 2 & 162.0 & 552.0 & 82.0 & 67.0 & MetOH \\
\hline Kitakyushu 1 & 370.0 & 419.0 & 155.0 & 470.0 & MetOH \\
\hline
\end{tabular}

PAHs, DNPs

PAHs, DNPs

PAHs, DNPs

PAHs, DNPs

PAHs, DNPs

PAHs, DNPs

PAHs, DNPs

PAHs, DNPs

PAHs, DNPs

PAHs, DNPs

PAHs, DNPs

PAHs, DNPs

PAHs, DNPs

PAHs, DNPs

PAHs, DNPs

PAHs, DNPs

PAHs, DNPs

PAHs, DNPs

PAHs, DNPs

PAHs, DNPs

PAHs, DNPs

PAHs, DNPs

PAHs, DNPs

PAHs, DNPs

PAHs, DNPs

PAHs, DNPs

PAHs, DNPs

PAHs, DNPs

PAHs, DNPs

PAHs, DNPs

PAHs, DNPs

PAHs, DNPs

PAHs, DNPs

PAHs, DNPs

PAHs, DNPs

PAHs, DNPs

PAHs, DNPs
DNPs:

$4.97 \times 10^{-3}$

DNPs:

$5.94 \times 10^{-3}$

DNPs:

$5.54 \times 10^{-3}$ 
Appendix A. (Continued)

\begin{tabular}{|c|c|c|c|c|c|c|c|c|c|}
\hline \multirow[t]{2}{*}{ Site/sample description } & \multicolumn{4}{|c|}{$\begin{array}{l}\text { Salmomella mutagenic potency } \\
\text { in revertents per gram dry soil }\end{array}$} & \multirow[t]{2}{*}{$\begin{array}{l}\text { Extraction } \\
\text { solvent }^{\mathrm{a}}\end{array}$} & \multirow{2}{*}{$\begin{array}{l}\text { EOM } \\
(\mathrm{mg} / \mathrm{g} \\
\text { dry soil })^{\mathrm{b}}\end{array}$} & \multicolumn{2}{|c|}{ Suspected contaminants } & \multirow[t]{2}{*}{ References } \\
\hline & $\begin{array}{l}\text { TA98 } \\
\text { no S9 }\end{array}$ & $\begin{array}{l}\text { TA98 } \\
\text { with S9 }\end{array}$ & $\begin{array}{l}\text { TA100 } \\
\text { no S9 }\end{array}$ & $\begin{array}{l}\text { TA100 } \\
\text { with S9 }\end{array}$ & & & Name & ppm dry weight $^{c}$ & \\
\hline Kitakyushu 2 & 581.0 & 726.0 & 367.0 & 598.0 & MetOH & NA & PAHs, DNPs & & {$[53]$} \\
\hline Dazaifu 1 & 331.0 & 600.0 & 127.0 & 509.0 & MetOH & NA & PAHs, DNPs & & [53] \\
\hline Dazaifu 2 & 176.0 & 287.0 & 111.0 & 251.0 & $\mathrm{MetOH}$ & NA & PAHs, DNPs & & [53] \\
\hline Fukuoka 1 & 381.0 & 571.0 & 308.0 & 457.0 & MetOH & NA & PAHs, DNPs & & [53] \\
\hline Fukuoka 2 & 330.0 & 388.0 & 153.0 & 486.0 & MetOH & NA & PAHs, DNPs & & [53] \\
\hline Fukuoka 3 & 224.0 & 458.0 & 111.0 & 480.0 & MetOH & NA & PAHs, DNPs & & {$[53]$} \\
\hline Fukuoka 4 & 348.0 & 449.0 & 205.0 & 436.0 & MetOH & NA & PAHs, DNPs & & [53] \\
\hline Kurume 1 & 349.0 & 598.0 & 169.0 & 519.0 & MetOH & NA & PAHs, DNPs & & [53] \\
\hline Kurume 2 & 284.0 & 308.0 & 118.0 & 327.0 & $\mathrm{MetOH}$ & NA & PAHs, DNPs & & [53] \\
\hline Kurume 3 & 84.0 & 252.0 & 36.0 & 159.0 & MetOH & NA & PAHs, DNPs & & [53] \\
\hline Yame 1 & 409.0 & 645.0 & 346.0 & 476.0 & $\mathrm{MetOH}$ & NA & PAHs, DNPs & & [53] \\
\hline Yame 2 & 272.0 & 595.0 & 276.0 & 485.0 & $\mathrm{MetOH}$ & NA & PAHs, DNPs & & [53] \\
\hline Tosu 1 & 421.0 & 982.0 & 198.0 & 537.0 & $\mathrm{MetOH}$ & NA & PAHs, DNPs & & {$[53]$} \\
\hline Tosu 2 & 393.0 & 621.0 & 308.0 & 663.0 & MetOH & NA & PAHs, DNPs & & {$[53]$} \\
\hline Ohmuta 1 & 417.0 & 661.0 & 302.0 & 517.0 & MetOH & NA & PAHs, DNPs & & [53] \\
\hline Ohmuta 2 & 782.0 & 1405.0 & 586.0 & 806.0 & MetOH & NA & PAHs, DNPs & & [53] \\
\hline Ohmuta 3 & 648.0 & 1491.0 & 481.0 & 686.0 & MetOH & NA & PAHs, DNPs & & [53] \\
\hline Ohmuta 4 & 549.0 & 922.0 & 435.0 & 657.0 & MetOH & NA & PAHs, DNPs & & {$[53]$} \\
\hline Ohmuta 5 & 666.0 & 669.0 & 639.0 & 554.0 & MetOH & NA & PAHs, DNPs & & [53] \\
\hline Ohmuta 6 & 412.0 & 792.0 & 330.0 & 662.0 & $\mathrm{MetOH}$ & NA & PAHs, DNPs & & [53] \\
\hline Hekinan 1 & NT & 34300.0 & NT & NT & MetOH & NA & PAHs, DNPs & $\begin{array}{l}\text { DNPs: } \\
0.12 \times 10^{-3}\end{array}$ & {$[51]$} \\
\hline Hekinan 2 & NT & 46800.0 & NT & NT & MetOH & NA & PAHs, DNPs & $\begin{array}{l}\text { DNPs: } \\
15.67 \times 10^{-3}\end{array}$ & {$[51]$} \\
\hline Kurume site 1 & 528.0 & 679.0 & ND & 424.0 & MetOH & NA & PAHs, Metals & PAHs: 0.60 & {$[122]$} \\
\hline Kurume site 2 & 327.0 & 394.0 & ND & 302.0 & MetOH & NA & PAHs, Metals & PAHs: 0.21 & {$[122]$} \\
\hline Kurume site 3 & 95.0 & 79.0 & ND & ND & $\mathrm{MetOH}$ & NA & PAHs, Metals & PAHs: 0.03 & {$[122]$} \\
\hline Kurume site 4 & 151.0 & 71.0 & ND & ND & $\mathrm{MetOH}$ & NA & PAHs, Metals & PAHs: 0.008 & {$[122]$} \\
\hline Kurume site 5 & 221.0 & 125.0 & ND & ND & $\mathrm{MetOH}$ & NA & PAHs, Metals & PAHs: 0.25 & {$[122]$} \\
\hline Kurume site 6 & 541.0 & 649.0 & 198.0 & 343.0 & $\mathrm{MetOH}$ & NA & PAHs, Metals & PAHs: 1.07 & {$[122]$} \\
\hline Kurume site 7 & 903.0 & 808.0 & 195.0 & 386.0 & MetOH & NA & PAHs, Metals & PAHs: 0.69 & {$[122]$} \\
\hline Kurume site 8 & 598.0 & 750.0 & 231.0 & 437.0 & MetOH & NA & PAHs, Metals & PAHs: 0.18 & {$[122]$} \\
\hline Kurume site 9 & 289.0 & 349.0 & ND & 203.0 & $\mathrm{MetOH}$ & NA & PAHs, Metals & PAHs: 0.14 & {$[122]$} \\
\hline Kurume site 10 & 463.0 & 604.0 & 367.0 & 550.0 & MetOH & NA & PAHs, Metals & PAHs: 0.10 & {$[122]$} \\
\hline
\end{tabular}




\begin{tabular}{|c|c|c|c|c|c|}
\hline Kurume site 11 & 721.0 & 840.0 & 234.0 & 366.0 & MetOH \\
\hline Kurume site 12 & 432.0 & 570.0 & ND & 306.0 & MetOH \\
\hline Kurume site 13 & 724.0 & 279.0 & ND & ND & MetOH \\
\hline Kokagun Kokacho & 81.0 & 81 & ND & 120.0 & MetOH \\
\hline Kokagun Minakuchicho & 193.0 & 470.0 & 81.0 & 193.0 & MetOH \\
\hline Kusatu & 103.0 & 256.0 & ND & 161.0 & MetOH \\
\hline Moriyama 1 & 194.0 & 483.0 & ND & 212.0 & MetOH \\
\hline Moriyama 2 & 120.0 & 158.0 & ND & 159.0 & MetOH \\
\hline Omihachiman & 47.0 & 81.0 & ND & 81.0 & MetOH \\
\hline Otsu & 158.0 & 354.0 & 77.0 & 227.0 & MetOH \\
\hline Kameoka & 30.0 & 118.0 & 122.0 & 162.0 & MetOH \\
\hline Kyoto Fushimi-ku & 288.0 & 142.0 & 109.0 & 156.0 & MetOH \\
\hline Kyoto Kamigyo-ku & 294.0 & 931.0 & 230.0 & 1067.0 & MetOH \\
\hline Kyoto Ukyo-ku & 258.0 & 368.0 & 184.0 & 244.0 & MetOH \\
\hline Kyoto Yamashina-ku & 2325.0 & 2727.0 & 501.0 & 1139.0 & MetOH \\
\hline Nagaokakyo & 3000.0 & 877.0 & 314.0 & 384.0 & MetOH \\
\hline Sonobecho & 280.0 & 525.0 & 117.0 & 277.0 & MetOH \\
\hline Uji & 4797.0 & 2829.0 & 462.0 & 1674.0 & MetOH \\
\hline Nara & 71.0 & 91.0 & 70.0 & 133.0 & MetOH \\
\hline Tenri & 154.0 & 615.0 & 71.0 & 352.0 & MetOH \\
\hline Yamatokoriyama & 252.0 & 483.0 & 119.0 & 373.0 & MetOH \\
\hline Ibaraki 1 & 202.0 & 541.0 & ND & 143.0 & MetOH \\
\hline Ibaraki 2 & 1104.0 & 4256.0 & 274.0 & 960.0 & MetOH \\
\hline Izumi 1 & 1598.0 & 2032.0 & 343.0 & 1236.0 & MetOH \\
\hline Izumi 2 & 146.0 & 309.0 & ND & 111.0 & MetOH \\
\hline Kadoma & 448.0 & 309.0 & ND & 259.0 & MetOH \\
\hline Kishiwada & 1627.0 & 10898.0 & 607.0 & 2057.0 & MetOH \\
\hline Moriguchi & 1979.0 & 5619.0 & 239.0 & 1325.0 & MetOH \\
\hline Neyagawa & 534.0 & 776.0 & ND & 432.0 & MetOH \\
\hline Osaka Abeno-ku & 3056.0 & 3152.0 & 411.0 & 1271.0 & MetOH \\
\hline Osaka Chuo-ku & 146.0 & 260.0 & ND & 212.0 & MetOH \\
\hline Osaka Fukushima-ku & 579.0 & 749.0 & 92.0 & 664.0 & MetOH \\
\hline Osaka Higashinari-ku & 1627.0 & 1488.0 & 320.0 & 976.0 & MetOH \\
\hline Osaka Higashisumiyoshi-ku & 130.0 & 160.0 & 235.0 & 190.0 & MetOH \\
\hline
\end{tabular}

PAHs, Metals

PAHs, Metals

PAHs, Metals

PAHs, DNPs

PAHs, DNPs

PAHs, DNPs

PAHs, DNPs

PAHs, DNPs

PAHs, DNPs

PAHs, DNPs

PAHs, DNPs

PAHs, DNPs

PAHs, DNPs

PAHs, DNPs

PAHs, DNPs

PAHs, DNPs

PAHs, DNPs

PAHs, DNPs

PAHs, DNPs

PAHs, DNPs

PAHs, DNPs

PAHs, DNPs

PAHs, DNPs

PAHs, DNPs

PAHs, DNPs

PAHs, DNPs

PAHs, DNPs

PAHs, DNPs

PAHs, DNPs

PAHs, DNPs

PAHs, DNPs

PAHs, DNPs

PAHs, DNPs

PAHs, DNPs
PAHs: 1.11

PAHs: 0.15 [122]

PAHs: $0.04 \quad$ [122]

[50]

[50]

[50]

[50]

[50]

$[50]$
$[50]$

[50]

[50]

[50]

[50]

[50]

[50]

[50]

DNPs:

$2.84 \times 10^{-3}$

DNPs:
$0.03 \times 10^{-3}$

DNPs:

$0.20 \times 10^{-3}$

$$
\text { [50] }
$$

DNPs:

$3.07 \times 10^{-3}$

DNPs:

$0.37 \times 10^{-3}$

DNPs:

$0.11 \times 10^{-3}$

DNPs: 
Appendix A. (Continued)

\begin{tabular}{|c|c|c|c|c|c|c|c|c|c|}
\hline \multirow[t]{2}{*}{ Site/sample description } & \multicolumn{4}{|c|}{$\begin{array}{l}\text { Salmomella mutagenic potency } \\
\text { in revertents per gram dry soil }\end{array}$} & \multirow[t]{2}{*}{$\begin{array}{l}\text { Extraction } \\
\text { solvent }^{\mathrm{a}}\end{array}$} & \multirow{2}{*}{ 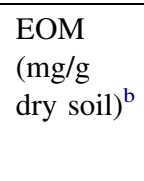 } & \multicolumn{2}{|c|}{ Suspected contaminants } & \multirow[t]{2}{*}{ References } \\
\hline & $\begin{array}{l}\text { TA98 } \\
\text { no S9 }\end{array}$ & $\begin{array}{l}\text { TA98 } \\
\text { with S9 }\end{array}$ & $\begin{array}{l}\text { TA100 } \\
\text { no S9 }\end{array}$ & $\begin{array}{l}\text { TA100 } \\
\text { with S9 }\end{array}$ & & & $\overline{\text { Name }}$ & ppm dry weight $^{\mathrm{c}}$ & \\
\hline Osaka Higashiyodogawa-ku & 2710.0 & 1296.0 & 116.0 & 969.0 & $\mathrm{MetOH}$ & NA & PAHs, DNPs & $\begin{array}{l}\text { DNPs: } \\
2.24 \times 10^{-3}\end{array}$ & {$[50]$} \\
\hline Osaka Ikuno-ku & 334.0 & 716.0 & 107.0 & 1271.0 & $\mathrm{MetOH}$ & NA & PAHs, DNPs & $\begin{array}{l}\text { DNPs: } \\
0.28 \times 10^{-3}\end{array}$ & {$[50]$} \\
\hline Osaka Joto-ku & 1136.0 & 2314.0 & 400.0 & 760.0 & $\mathrm{MetOH}$ & NA & PAHs, DNPs & $\begin{array}{l}\text { DNPs: } \\
0.66 \times 10^{-3}\end{array}$ & {$[50]$} \\
\hline Osaka Kita-ku & 4232.0 & 1842.0 & 109.0 & 2156.0 & MetOH & NA & PAHs, DNPs & $\begin{array}{l}\text { DNPs: } \\
2.59 \times 10^{-3}\end{array}$ & {$[50]$} \\
\hline Osaka Konohana-ku & 229.0 & 747.0 & 186.0 & 528.0 & MetOH & NA & PAHs, DNPs & & [50] \\
\hline Osaka Minato-ku & 5963.0 & 2981.0 & 307.0 & 1515.0 & $\mathrm{MetOH}$ & NA & PAHs, DNPs & $\begin{array}{l}\text { DNPs: } \\
5.39 \times 10^{-3}\end{array}$ & [50] \\
\hline Osaka Miyakojima-ku & 110.0 & 472.0 & ND & 603.0 & MetOH & NA & PAHs, DNPs & & {$[50]$} \\
\hline Osaka Naniwa-ku & 224.0 & 423.0 & 115.0 & 491.0 & MetOH & NA & PAHs, DNPs & $\begin{array}{l}\text { DNPs: } \\
0.10 \times 10^{-3}\end{array}$ & {$[50]$} \\
\hline Osaka Nishi-ku & 1420.0 & 3430.0 & 473.0 & 1900.0 & $\mathrm{MetOH}$ & NA & PAHs, DNPs & $\begin{array}{l}\text { DNPs: } \\
0.32 \times 10^{-3}\end{array}$ & {$[50]$} \\
\hline Osaka Nishinari-ku & 224.0 & 947.0 & ND & 528.0 & MetOH & NA & PAHs, DNPs & & [50] \\
\hline Osaka Suminoe-ku & 6075.0 & 7085.0 & 980.0 & 1869.0 & MetOH & NA & PAHs, DNPs & $\begin{array}{l}\text { DNPs: } \\
2.97 \times 10^{-3}\end{array}$ & [50] \\
\hline Osaka Sumiyoshi-ku & 1595.0 & 2629.0 & 765.0 & 1349.0 & MetOH & NA & PAHs, DNPs & & {$[50]$} \\
\hline Osaka Tennoji-ku & 129.0 & 458.0 & ND & 293.0 & MetOH & NA & PAHs, DNPs & & {$[50]$} \\
\hline Osaka Tsurumi-ku & 112.0 & 544.0 & ND & 384.0 & MetOH & NA & PAHs, DNPs & & [50] \\
\hline Sakai 1 & 3073.0 & 3659.0 & 448.0 & 1957.0 & MetOH & NA & PAHs, DNPs & $\begin{array}{l}\text { DNPs: } \\
2.41 \times 10^{-3}\end{array}$ & [50] \\
\hline Sakai 2 & 1302.0 & 4804.0 & 158.0 & 1027.0 & MetOH & NA & PAHs, DNPs & $\begin{array}{l}\text { DNPs: } \\
0.04 \times 10^{-3}\end{array}$ & {$[50]$} \\
\hline Sakai 3 & 4092.0 & 4656.0 & 616.0 & 2941.0 & $\mathrm{MetOH}$ & NA & PAHs, DNPs & $\begin{array}{l}\text { DNPs: } \\
0.90 \times 10^{-3}\end{array}$ & {$[50]$} \\
\hline Sakai 4 & 1208.0 & 2352.0 & 212.0 & 458.0 & MetOH & $\mathrm{NA}$ & PAHs, DNPs & & {$[50]$} \\
\hline Suita & 425.0 & 630.0 & ND & 557.0 & $\mathrm{MetOH}$ & NA & PAHs, DNPs & $\begin{array}{l}\text { DNPs: } \\
0.04 \times 10^{-3}\end{array}$ & [50] \\
\hline Takatsuki & 2408.0 & 1552.0 & 338.0 & 830.0 & MetOH & NA & PAHs, DNPs & $\begin{array}{l}\text { DNPs: } \\
0.69 \times 10^{-3}\end{array}$ & {$[50]$} \\
\hline
\end{tabular}




\begin{tabular}{|c|c|c|c|c|c|c|c|c|c|}
\hline Takaishi & 2581.0 & 2128.0 & 407.0 & 1779.0 & MetOH & NA & PAHs, DNPs & $\begin{array}{l}\text { DNPs: } \\
0.91 \times 10^{-3}\end{array}$ & {$[50]$} \\
\hline Toyonaka & 2768.0 & 2755.0 & 379.0 & 1000.0 & MetOH & NA & PAHs, DNPs & & {$[50]$} \\
\hline Amagasaki & 691.0 & 1197.0 & 106.0 & 507.0 & MetOH & NA & PAHs, DNPs & $\begin{array}{l}\text { DNPs: } \\
0.33 \times 10^{-3}\end{array}$ & {$[50]$} \\
\hline Itami & 382.0 & 529.0 & 86.0 & 366.0 & MetOH & NA & PAHs, DNPs & & {$[50]$} \\
\hline Kobe Nada-ku & 755.0 & 642.0 & 71.0 & 363.0 & MetOH & NA & PAHs, DNPs & & {$[50]$} \\
\hline Kobe Nagata-ku & 496.0 & 1168.0 & 181.0 & 1392.0 & MetOH & NA & PAHs, DNPs & $\begin{array}{l}\text { DNPs: } \\
0.32 \times 10^{-3}\end{array}$ & {$[50]$} \\
\hline Nishinomiya & 183.0 & 775.0 & 128.0 & 459.0 & MetOH & NA & PAHs, DNPs & & {$[50]$} \\
\hline Kainan 1 & 117.0 & 443.0 & ND & 189.0 & MetOH & NA & PAHs, DNPs & & {$[50]$} \\
\hline Kainan 2 & 403.0 & 2239.0 & 186.0 & 741.0 & MetOH & NA & PAHs, DNPs & & {$[50]$} \\
\hline Wakayama 1 & 744.0 & 2057.0 & ND & 542.0 & MetOH & NA & PAHs, DNPs & & {$[50]$} \\
\hline Wakayama 2 & 545.0 & 1182.0 & 104.0 & 415.0 & MetOH & NA & PAHs, DNPs & & {$[50]$} \\
\hline 8 & 1 site & (includin & sune & ite & & & & & \\
\hline Superfund soil (3) & NA & 376237.6 & NA & NA & DCM & NA & PAHs & PAHs: $35-530$ & {$[46]$} \\
\hline Superfund soil (10) & NA & 242038.2 & NA & NA & DCM & NA & PAHs & PAHs: $35-530$ & [46] \\
\hline Superfund soil (5) & NA & 238993.7 & NA & NA & DCM & NA & PAHs & PAHs: $35-530$ & [46] \\
\hline Superfund soil (2) & NA & 136200.7 & NA & NA & $\mathrm{DCM}$ & NA & PAHs & PAHs: $35-530$ & [46] \\
\hline Superfund soil (4) & NA & 121019.1 & NA & NA & $\mathrm{DCM}$ & NA & PAHs & PAHs: $35-530$ & [46] \\
\hline Superfund soil (9) & NA & 116564.4 & NA & NA & DCM & NA & PAHs & PAHs: $35-530$ & [46] \\
\hline Superfund soil (10) & NA & 104683.2 & NA & NA & Cyclohex & NA & PAHs & PAHs: $35-530$ & {$[46]$} \\
\hline Superfund soil (7) & NA & 88993.0 & NA & NA & $\mathrm{DCM}$ & NA & PAHs & PAHs: $35-530$ & {$[46]$} \\
\hline Superfund soil (6) & NA & 77079.1 & NA & NA & DCM & NA & PAHs & PAHs: $35-530$ & [46] \\
\hline Superfund soil (5) & NA & 37076.7 & NA & NA & Cyclohex & NA & PAHs & PAHs: $35-530$ & [46] \\
\hline Superfund soil (9) & NA & 33989.3 & NA & NA & Cyclohex & NA & PAHs & PAHs: $35-530$ & [46] \\
\hline Superfund soil (3) & NA & 31746.0 & NA & NA & Cyclohex & NA & PAHs & PAHs: $35-530$ & [46] \\
\hline Superfund soil (8) & NA & 27818.4 & NA & NA & DCM & NA & PAHs & PAHs: $35-530$ & {$[46]$} \\
\hline Superfund soil (6) & NA & 27676.6 & NA & NA & Cyclohex & NA & PAHs & PAHs: $35-530$ & [46] \\
\hline Superfund soil (8) & NA & 16740.1 & NA & NA & Cyclohex & NA & PAHs & PAHs: $35-530$ & [46] \\
\hline Superfund soil (2) & NA & 13446.6 & NA & NA & Cyclohex & NA & PAHs & PAHs: $35-530$ & [46] \\
\hline Wood-preserving site & NA & 23518.0 & NA & NA & DCM/MetOH & 53.90 & $\begin{array}{l}\text { PAHs, PCDFs, } \\
\text { PCDDs }^{\mathrm{m}}\end{array}$ & $\begin{array}{l}\text { PCDFs + PCDDs: } \sim 2 \times 10^{-3} \\
\text { PAHs: } 12267.0\end{array}$ & {$[45]$} \\
\hline Amended soil (creosote) & 367.0 & 23480.0 & NA & 21475.0 & DCM & 134.20 & Creosote, PAHs & & {$[42]$} \\
\hline
\end{tabular}


Appendix A. (Continued)

\begin{tabular}{|c|c|c|c|c|c|c|c|c|c|}
\hline \multirow[t]{2}{*}{ Site/sample description } & \multicolumn{4}{|c|}{$\begin{array}{l}\text { Salmomella mutagenic potency } \\
\text { in revertents per gram dry soil }\end{array}$} & \multirow[t]{2}{*}{$\begin{array}{l}\text { Extraction } \\
\text { solvent }^{\mathrm{a}}\end{array}$} & \multirow{2}{*}{$\begin{array}{l}\text { EOM } \\
(\mathrm{mg} / \mathrm{g} \\
\text { dry soil })^{\mathrm{b}}\end{array}$} & \multicolumn{2}{|l|}{ Suspected contaminants } & \multirow[t]{2}{*}{ References } \\
\hline & $\begin{array}{l}\text { TA98 } \\
\text { no S9 }\end{array}$ & $\begin{array}{l}\text { TA98 } \\
\text { with S9 }\end{array}$ & $\begin{array}{l}\text { TA100 } \\
\text { no S9 }\end{array}$ & $\begin{array}{l}\text { TA100 } \\
\text { with S9 }\end{array}$ & & & Name & ppm dry weight $^{c}$ & \\
\hline Amended soil (creosote) & 140.0 & 9921.0 & NA & 5632.0 & DCM & 135.00 & Creosote, PAHs & & {$[42]$} \\
\hline Amended soil (petroleum) & NA & 4804.0 & NA & NA & DCM & 11.38 & PAHs & & {$[166]$} \\
\hline Amended soil (petroleum) & NA & 3856.0 & NA & NA & DCM & 14.18 & PAHs & & {$[166]$} \\
\hline Amended soil (petroleum) & NA & 2155.0 & NA & NA & $\mathrm{DCM}$ & 9.58 & Hydrocarbons PAHs & & {$[166]$} \\
\hline Amended soil (petroleum) & NA & 1459.0 & NA & NA & DCM & 4.33 & Hydrocarbons PAHs & & {$[166]$} \\
\hline Industrial site (DCT 24) & 734.0 & 664.0 & NA & NA & DCM & 1.26 & Dyes, Pesticides & $\begin{array}{l}\text { 2,3,6-TCBA }{ }^{\mathrm{n}} \text { : } \\
\text { 16.0 ABN-X: } \\
16.3\end{array}$ & [47] \\
\hline Industrial site (DCT 38) & 438.0 & 456.0 & NA & NA & DCM & 1.78 & Dyes, Pesticides & $\begin{array}{l}\text { 2-M-5-NBA: } \\
0.1 \text { ABN-X: } \\
\text { 1.42-NA: } 0.3\end{array}$ & [47] \\
\hline Industrial site (DCT 24) & 352.0 & 412.0 & NA & NA & MetOH & 0.28 & Dyes, Pesticides & $\begin{array}{l}\text { 2,3,6-TCBA: } \\
16.0 \text { ABN-X: } \\
16.3\end{array}$ & {$[47]$} \\
\hline Industrial site (DCT 31) & 197.0 & 263.0 & NA & NA & DCM & 0.28 & Dyes, Pesticides & & {$[47]$} \\
\hline Industrial site (DCT 25) & 143.0 & 161.0 & NA & NA & $\mathrm{MetOH}$ & 0.075 & Dyes, Pesticides & & {$[47]$} \\
\hline Industrial site (DCT 26) & 170.0 & 135.0 & NA & NA & $\mathrm{DCM}$ & 0.074 & Dyes, Pesticides & & {$[47]$} \\
\hline Industrial site (DCT 26) & 124.0 & 132.0 & NA & NA & $\mathrm{MetOH}$ & 0.050 & Dyes, Pesticides & & [47] \\
\hline Industrial site (DCT 32) & 81.0 & 94.0 & NA & NA & MetOH & 0.029 & Dyes, Pesticides & & {$[47]$} \\
\hline Industrial site (DCT 38) & 101.0 & 86.0 & NA & NA & $\mathrm{MetOH}$ & 0.037 & Dyes, Pesticides & $\begin{array}{l}\text { 2-M-5-NBA: } \\
0.1 \text { ABN-X: } \\
\text { 1.42-NA: } 0.3\end{array}$ & {$[47]$} \\
\hline Industrial site (DCT 25) & 40.0 & 42.0 & NA & NA & DCM & 0.014 & Dyes, Pesticides & & {$[47]$} \\
\hline Industrial site (DCT 32) & 15.0 & 20.0 & NA & NA & DCM & 0.008 & Dyes, Pesticides & & {$[47]$} \\
\hline Industrial site (DCT 31) & 2.0 & 3.0 & NA & NA & $\mathrm{MetOH}$ & 0.001 & Dyes, Pesticides & & [47] \\
\hline Industrial site $\left(\right.$ Soil 505) ${ }^{\mathrm{o}}$ & ND & 194.0 & NT & NT & $\mathrm{MetOH}$ & 2.40 & Solvent, metals, paint sludge & & [114] \\
\hline Industrial site (Soil 506) & 80.0 & ND & NT & NT & $\mathrm{MetOH}$ & 1.27 & Solvent, metals, paint sludge & & [114] \\
\hline Industrial site (Soil 302) & 2449.0 & ND & NT & NT & $\mathrm{MetOH}$ & 5.43 & Solvent, metals, paint sludge & & [114] \\
\hline Industrial site (Soil 302) & 2370.0 & ND & NT & NT & $\mathrm{DCM}$ & 5.43 & Solvent, metals, paint sludge & & {$[114]$} \\
\hline Industrial site (Soil 303) & 1204.0 & ND & NT & NT & $\mathrm{MetOH}$ & 3.22 & Solvent, metals, paint sludge & & {$[114]$} \\
\hline Industrial site (Soil 303) & 2394.0 & ND & NT & NT & DCM & 4.45 & Solvent, metals, paint sludge & & [114] \\
\hline Industrial site (Soil 204) & 1380.0 & ND & NT & NT & DCM & 11.90 & Solvent, metals, paint sludge & & {$[114]$} \\
\hline Industrial site (Soil 402) & 1356.0 & ND & NT & NT & DCM & 7.14 & Solvent, metals, paint sludge & & [114] \\
\hline Industrial site (Soil 502) & 741.0 & ND & NT & NT & $\mathrm{MetOH}$ & 4.49 & Solvent, metals, paint sludge & & [114] \\
\hline Industrial site (Soil 502) & 532.0 & ND & NT & NT & DCM & 9.50 & Solvent, metals, paint sludge & & [114] \\
\hline
\end{tabular}


Industrial site (Soil 005)

Industrial site (Soil 005)

Industrial site (Soil 503)

Industrial site (Soil 110)

Industrial site (Soil 110)

PCB contaminated soil

PCB contaminated soil

Amended soil (creosote)

Amended soil (refinery)

Industrial site (Soil 201)

Industrial site (Soil 001)

Industrial site (Soil 002)

Industrial site (Soil 003)

Industrial site (Soil 102)

Industrial site (Soil 103)

Industrial site (Soil 104)

Industrial site (Soil 105)

Industrial site (Soil 108)

Industrial site (Soil 202)

Industrial site (Soil 203)

Industrial site (Soil 204)

Industrial site (Soil 205)

Industrial site (Soil 206)

Industrial site (Soil 201)

Industrial site (Soil 001)

Industrial site (Soil 002)

Industrial site (Soil 003)

Industrial site (Soil 102)

Industrial site (Soil 103)

Industrial site (Soil 104)

Industrial site (Soil 105)

Industrial site (Soil 108)

Industrial site (Soil 202)

Industrial site (Soil 203)

Industrial site (Soil 204)

Industrial site (Soil 205)

Industrial site (Soil 206)
523.0

1192.0

ND

105.0 NT

162.0 NT

77.0 NT

791.0

1041.0

122.0

$22.0 \mathrm{NT}$

ND NT

$197.0 \mathrm{ND}$

58.0

120.0 ND

$25.0 \quad 782.5 \quad \mathrm{NT}$

ND $\quad 329.0 \quad$ NT

$329.0 \mathrm{NT}$
$16.0 \mathrm{NT}$

$28183.0 \quad \mathrm{NT}$

175195.0 NT

$178488.0 \quad \mathrm{NT}$

38622.0 NT

$28498.0 \quad$ NT

72518.0 NT

4890.0 NT

$51403.0 \quad \mathrm{NT}$

181847.0 NT

161892.0 NT

206039.0 NT

$80119.0 \quad$ NT

ND $252877.0 \quad$ NT

$\begin{array}{lll}45.0 & 32.0 & \mathrm{NT}\end{array}$

ND $24919.0 \quad$ NT

ND $\quad 5502.0 \quad$ NT

ND $\quad 14786.0 \quad$ NT

ND $\quad 5749.0 \quad$ NT

ND $\quad 758.0 \quad$ NT

ND $\quad 1801.0 \quad$ NT

ND $\quad 337.0 \quad$ NT

ND $24637.0 \quad$ NT

ND $\quad 4322.0$ NT

9536.0 NT

4654.0 NT

$7304.0 \quad \mathrm{NT}$

10222.0 NT

$\begin{array}{lll}\text { NT } & \text { MetOH } & 5.53 \\ \text { NT } & \text { DCM } & 10.12 \\ \text { NT } & \text { DCM } & 1.75 \\ \text { NT } & \text { MetOH } & 11.30 \\ \text { NT } & \text { DCM } & 25.39 \\ \text { ND } & \text { DCM } & 3.58\end{array}$

$$
\text { ND }
$$

DCM

1.36

NT DCM/MetOH NA

NT DCM/MetOH NA

NT DCM 0.20

NT DCM $\quad 276.30$

NT DCM $\quad 141.29$

NT DCM $\quad 815.01$

NT DCM

NT DCM

\section{NT DCM}

NT DCM

\section{NT DCM}

NT DCM

NT DCM

\section{NT DCM}

NT DCM

\section{NT DCM}

NT MetOH

\section{NT MetOH}

\section{NT MetOH}

NT MetOH

NT MetOH

NT MetOH

NT MetOH

NT MetOH

NT MetOH

NT MetOH

NT MetOH

NT MetOH

NT MetOH

NT MetOH

459.64

659.25

116.43

634.61

790.64

700.83

865.71

340.93

909.63

0.46

307.64

250.09

122.20

6.78

12.23

9.38

2.81

13.47

6.32

12.94

5.16

9.40

17.84
Solvent, metals, paint sludge

Solvent, metals, paint sludge

Solvent, metals, paint sludge

Solvent, metals, paint sludge

Solvent, metals, paint sludge

PCBs

PCBs

Creosote

PAHs

PAHs

PAHs

PAHs

PAHs

PAHs

PAHs
PAHs

PAHs

PAHs

PAHs

PAHs

PAHs

PAHs

PAHs

PAHs

PAHs

PAHs

PAHs

PAHs

PAHs

PAHs

PAHs

PAHs

PAHs

PAHs

PAHs

PAHs

PAHs
Aroclor

1260: 2000

Aroclor

1260: 2000

[64]

[64]

[118]

[118]

[118]

[118]

[118]

[118]

[118]

[118]

[118]

[118]

PAHs: 2168.0

PAHs: 2533.0

PAHs: 1802.0

[118]
[118]

[118]

[118]

[118]

[118]

[118]

[118]

[118]

[118]

[118]

[118]

[118]

[118]

PAHs: 581.0

[118]

PAHs: 443.0

[118]

PAHs: 895.0

[118] 
Appendix A. (Continued)

\begin{tabular}{|c|c|c|c|c|c|c|c|c|c|}
\hline \multirow[t]{2}{*}{ Site/sample description } & \multicolumn{4}{|c|}{$\begin{array}{l}\text { Salmomella mutagenic potency } \\
\text { in revertents per gram dry soil }\end{array}$} & \multirow[t]{2}{*}{$\begin{array}{l}\text { Extraction } \\
\text { solvent }^{\mathrm{a}}\end{array}$} & \multirow{2}{*}{ 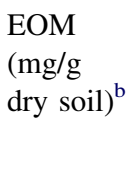 } & \multicolumn{2}{|l|}{ Suspected contaminants } & \multirow[t]{2}{*}{ References } \\
\hline & $\begin{array}{l}\text { TA98 } \\
\text { no S9 }\end{array}$ & $\begin{array}{l}\text { TA98 } \\
\text { with S9 }\end{array}$ & $\begin{array}{l}\text { TA100 } \\
\text { no S9 }\end{array}$ & $\begin{array}{l}\text { TA100 } \\
\text { with S9 }\end{array}$ & & & Name & ppm dry weight $^{\mathrm{c}}$ & \\
\hline Amended soil (sewage sludge) & 246.0 & 105.0 & NT & NT & DCM & NA & & & [179] \\
\hline Amended soil (sewage sludge) & 106.3 & 70.0 & NT & NT & DCM & NA & & & [179] \\
\hline Amended soil (sewage sludge) & 234.0 & 98.0 & NT & NT & DCM & NA & & & [179] \\
\hline Amended soil (sewage sludge) & 215.0 & 78.0 & NT & NT & DCM & NA & & & [179] \\
\hline Amended soil (sewage sludge) & 23.0 & 15.0 & NT & NT & $\mathrm{MetOH}$ & NA & & & [179] \\
\hline Amended soil (sewage sludge) & 80.0 & 58.0 & NT & NT & $\mathrm{MetOH}$ & NA & & & [179] \\
\hline Amended soil (sewage sludge) & 58.0 & 43.0 & NT & NT & $\mathrm{MetOH}$ & NA & & & [179] \\
\hline Hazardous waste site (S2) & ND & 1.0 & NT & NT & DCM & 0.088 & Solvents, paint, PAHs & PAHs: 1.0 & [117] \\
\hline Hazardous waste site (S4) & ND & 595.0 & NT & NT & DCM & 23.8 & Solvents, paint, PAHs & & {$[117]$} \\
\hline Hazardous waste site (S6) & ND & 27.0 & NT & NT & DCM & NA & Solvents, paint, PAHs & & {$[117]$} \\
\hline Hazardous waste site (S8) & ND & 37.0 & NT & NT & DCM & 0.55 & Solvents, paint, PAHs & PAHs: 0.5 & [117] \\
\hline Hazardous waste site (S10) & ND & 71.0 & NT & NT & DCM & 0.46 & Solvents, paint, PAHs & PAHs: 15.3 & {$[117]$} \\
\hline Hazardous waste site (S14) & ND & 2.0 & NT & NT & DCM & 0.14 & Background & & [117] \\
\hline Hazardous waste site (S4) & ND & 162.0 & NT & NT & MetOH & 2.19 & Solvents, paint, PAHs & & {$[117]$} \\
\hline Hazardous waste site (S6) & ND & 44.0 & NT & NT & $\mathrm{MetOH}$ & 0.55 & Solvents, paint, PAHs & & {$[117]$} \\
\hline Hazardous waste site (S8) & ND & 15.0 & NT & NT & MetOH & 0.71 & Solvents, paint, PAHs & PAHs: 0.5 & {$[117]$} \\
\hline Hazardous waste site (S10) & ND & 32.0 & NT & NT & $\mathrm{MetOH}$ & 0.35 & Solvents, paint, PAHs & PAHs: 15.3 & [117] \\
\hline Hazardous waste site (S12) & ND & 248.0 & NT & NT & $\mathrm{MetOH}$ & 1.77 & Solvents, paint, PAHs & PAHs: 74.0 & {$[117]$} \\
\hline Hazardous waste site (S14) & ND & 8.0 & NT & NT & MetOH & 0.35 & Background & & [117] \\
\hline Amended soil (sewage sludge) & 154.0 & 81.0 & NT & NT & DCM & NA & & & {$[156]$} \\
\hline Amended soil (sewage sludge) & 122.0 & 87.0 & NT & NT & DCM & NA & & & {$[156]$} \\
\hline Amended soil (sewage sludge) & 105.0 & 147.0 & NT & NT & $\mathrm{MetOH}$ & NA & & & {$[156]$} \\
\hline Amended soil (sewage sludge) & 170.0 & 426.0 & NT & NT & $\mathrm{MetOH}$ & NA & & & {$[156]$} \\
\hline Amended soil (sewage sludge) & 310.0 & 371.0 & NT & NT & DCM/MetOH & NA & & & {$[156]$} \\
\hline Amended soil (sewage sludge) & 422.0 & 509.0 & NT & NT & $\mathrm{DCM} / \mathrm{MetOH}$ & NA & & & {$[156]$} \\
\hline Amended soil (creosote) & 21.0 & 779.0 & NT & NT & $\mathrm{DCM} / \mathrm{MetOH}$ & NA & Creosote, $\mathrm{PCP}$ & & {$[370]$} \\
\hline Land treatment soil (005) & ND & 113.0 & NT & NT & DCM & 2.3 & PAHs, PCP & $\begin{array}{l}\text { PAHs: } \sim 126 \\
\text { PCP: } \sim 31\end{array}$ & [115] \\
\hline Land treatment soil (007) & $\mathrm{ND}$ & 146.0 & NT & NT & DCM & 1.8 & PAHs, PCP & $\begin{array}{l}\text { PAHs: } \sim 126 \\
\text { PCP: } \sim 31\end{array}$ & [115] \\
\hline
\end{tabular}




\begin{tabular}{|c|c|c|c|c|c|c|c|c|c|}
\hline Land treatment soil $(008)$ & ND & 174.0 & NT & NT & DCM & 2.1 & PAHs, PCP & $\begin{array}{l}\text { PAHs: } \sim 126 \\
\text { PCP: } \sim 31\end{array}$ & [115] \\
\hline Land treatment soil (009) & ND & 124.0 & NT & NT & DCM & 2.7 & PAHs, PCP & $\begin{array}{l}\text { PAHs: } \sim 126 \\
\text { PCP: } \sim 31\end{array}$ & [115] \\
\hline Land treatment soil $(010)$ & ND & 67.0 & NT & NT & DCM & 1.2 & PAHs, PCP & $\begin{array}{l}\text { PAHs: } \sim 126 \\
\text { PCP: } \sim 31\end{array}$ & [115] \\
\hline Land treatment soil $(011)$ & ND & 68.0 & NT & NT & DCM & 0.9 & PAHs, PCP & $\begin{array}{l}\text { PAHs: } \sim 126 \\
\text { PCP: } \sim 31\end{array}$ & [115] \\
\hline Land treatment soil $(012)$ & ND & 67.0 & NT & NT & DCM & 1.2 & PAHs, PCP & $\begin{array}{l}\text { PAHs: } \sim 126 \\
\text { PCP: } \sim 31\end{array}$ & [115] \\
\hline Land treatment soil $(013)$ & ND & 77.0 & NT & NT & DCM & 0.9 & PAHs, PCP & $\begin{array}{l}\text { PAHs: } \sim 126 \\
\text { PCP: } \sim 31\end{array}$ & [115] \\
\hline Land treatment soil $(014)$ & ND & 97.0 & NT & NT & DCM & 2.1 & PAHs, PCP & $\begin{array}{l}\text { PAHs: } \sim 279 \\
\text { PCP: } \sim 176\end{array}$ & [115] \\
\hline Land treatment soil $(015)$ & ND & 114.0 & NT & NT & DCM & 3.0 & PAHs, PCP & $\begin{array}{l}\text { PAHs: } \sim 279 \\
\text { PCP: } \sim 176\end{array}$ & [115] \\
\hline Land treatment soil $(016)$ & ND & 71.0 & NT & NT & DCM & 0.6 & PAHs, PCP & $\begin{array}{l}\text { PAHs: } \sim 279 \\
\text { PCP: } \sim 176\end{array}$ & [115] \\
\hline Land treatment soil (017) & ND & 66.0 & NT & NT & DCM & 0.4 & Background & & [115] \\
\hline Land treatment soil (023) & ND & 10.0 & NT & NT & DCM & 0.7 & Background & & [115] \\
\hline Land treatment soil $(005)$ & ND & 21.0 & NT & NT & MetOH & 0.5 & PAHs, PCP & $\begin{array}{l}\text { PAHs: } \sim 126 \\
\text { PCP: } \sim 31\end{array}$ & [115] \\
\hline Land treatment soil (006) & ND & 331.0 & NT & NT & $\mathrm{MetOH}$ & 6.9 & PAHs, PCP & $\begin{array}{l}\text { PAHs: } \sim 126 \\
\text { PCP: } \sim 31\end{array}$ & [115] \\
\hline Land treatment soil $(007)$ & ND & 77.0 & NT & NT & MetOH & 0.9 & PAHs, PCP & $\begin{array}{l}\text { PAHs: } \sim 126 \\
\text { PCP: } \sim 31\end{array}$ & [115] \\
\hline Land treatment soil $(008)$ & ND & 43.0 & NT & NT & $\mathrm{MetOH}$ & 0.5 & PAHs, PCP & $\begin{array}{l}\text { PAHs: } \sim 126 \\
\text { PCP: } \sim 31\end{array}$ & [115] \\
\hline Land treatment soil (009) & ND & 34.0 & NT & NT & MetOH & 0.6 & PAHs, PCP & $\begin{array}{l}\text { PAHs: } \sim 126 \\
\text { PCP: } \sim 31\end{array}$ & [115] \\
\hline Land treatment soil $(010)$ & ND & 5.0 & NT & NT & $\mathrm{MetOH}$ & 0.3 & PAHs, PCP & $\begin{array}{l}\text { PAHs: } \sim 126 \\
\text { PCP: } \sim 31\end{array}$ & [115] \\
\hline Land treatment soil $(011)$ & ND & 46.0 & NT & NT & MetOH & 0.7 & PAHs, PCP & $\begin{array}{l}\text { PAHs: } \sim 126 \\
\text { PCP: } \sim 31\end{array}$ & [115] \\
\hline Land treatment soil $(012)$ & ND & 47.0 & NT & NT & MetOH & 1.1 & PAHs, PCP & $\begin{array}{l}\text { PAHs: } \sim 126 \\
\text { PCP: } \sim 31\end{array}$ & [115] \\
\hline Land treatment soil $(013)$ & ND & 70.0 & NT & NT & MetOH & 1.3 & PAHs, PCP & $\begin{array}{l}\text { PAHs: } \sim 126 \\
\text { PCP: } \sim 31\end{array}$ & [115] \\
\hline Land treatment soil (014) & ND & 77.0 & NT & NT & $\mathrm{MetOH}$ & 1.5 & PAHs, PCP & $\begin{array}{l}\text { PAHs: } \sim 279 \\
\text { PCP: } \sim 176\end{array}$ & [115] \\
\hline
\end{tabular}


Appendix A. (Continued)

\begin{tabular}{|c|c|c|c|c|c|c|c|c|c|}
\hline \multirow[t]{2}{*}{ Site/sample description } & \multicolumn{4}{|c|}{$\begin{array}{l}\text { Salmomella mutagenic potency } \\
\text { in revertents per gram dry soil }\end{array}$} & \multirow[t]{2}{*}{$\begin{array}{l}\text { Extraction } \\
\text { solvent }^{\mathrm{a}}\end{array}$} & \multirow{2}{*}{$\begin{array}{l}\text { EOM } \\
(\mathrm{mg} / \mathrm{g} \\
\text { dry soil) }\end{array}$} & \multicolumn{2}{|c|}{ Suspected contaminants } & \multirow[t]{2}{*}{ References } \\
\hline & $\begin{array}{l}\text { TA98 } \\
\text { no S9 }\end{array}$ & $\begin{array}{l}\text { TA98 } \\
\text { with S9 }\end{array}$ & $\begin{array}{l}\text { TA100 } \\
\text { no S9 }\end{array}$ & $\begin{array}{l}\text { TA100 } \\
\text { with S9 }\end{array}$ & & & Name & ppm dry weight $^{c}$ & \\
\hline Land treatment soil (015) & ND & 102.0 & NT & NT & $\mathrm{MetOH}$ & 3.0 & PAHs, PCP & $\begin{array}{l}\text { PAHs: } \sim 279 \\
\text { PCP: } \sim 176\end{array}$ & [115] \\
\hline Land treatment soil $(016)$ & ND & 1.0 & NT & NT & $\mathrm{MetOH}$ & 0.5 & PAHs, PCP & $\begin{array}{l}\text { PAHs: } \sim 279 \\
\text { PCP: } \sim 176\end{array}$ & [115] \\
\hline Land treatment soil $(023)$ & ND & 8.0 & NT & NT & $\mathrm{MetOH}$ & 1.0 & Background & & {$[115]$} \\
\hline Land treatment soil (Cell 1) & NA & 328.0 & NT & NT & DCM & NA & PAHs, PCP & & {$[56]$} \\
\hline Land treatment soil (Cell 2) & NA & 594.0 & NT & NT & DCM & NA & PAHs, PCP & & {$[56]$} \\
\hline Land treatment soil (Cell 3) & NA & 440.0 & NT & NT & DCM & NA & PAHs, PCP & & {$[56]$} \\
\hline Land treatment soil (Cell 4) & NA & 380.0 & NT & NT & DCM & NA & PAHs, PCP & & {$[56]$} \\
\hline Land treatment soil (Cell 5) & NA & 475.0 & NT & NT & DCM & NA & PAHs, PCP & & {$[56]$} \\
\hline Land treatment soil (Cell 6) & NA & 523.0 & NT & NT & DCM & NA & PAHs, PCP & & [56] \\
\hline Land treatment soil (Cell 7) & NA & 978.0 & NT & NT & DCM & NA & PAHs, PCP & PAHs: 88.0 & [56] \\
\hline Land treatment soil (Cell 10) & NA & 337.0 & NT & NT & DCM & NA & PAHs, PCP & & [56] \\
\hline Land treatment soil (Cell 11) & NA & 333.0 & NT & NT & DCM & NA & PAHs, PCP & & [56] \\
\hline Land treatment soil (Cell 12) & NA & 311.0 & NT & NT & DCM & NA & PAHs, PCP & & {$[56]$} \\
\hline Munitions site (Soil 001) & 32670 & 3277 & NT & NT & DCM & 9.93 & Nitroaromatics & & [54] \\
\hline Munitions site (Soil 002) & 2935 & 371 & NT & NT & DCM & 1.16 & Nitroaromatics & & [54] \\
\hline Munitions site (Soil 003) & 177559 & ND & NT & NT & DCM & 105.7 & Nitroaromatics & & [54] \\
\hline Munitions site (Soil 004) & 126008 & 19067 & NT & NT & DCM & 82.9 & Nitroaromatics & & [54] \\
\hline Munitions site (Soil 005) & 58073 & 7743 & NT & NT & DCM & 25.8 & Nitroaromatics & & [54] \\
\hline Munitions site (Soil 006) & ND & 16.0 & NT & NT & DCM & 0.13 & Background & & [54] \\
\hline Munitions site (Soil 101) & 119130 & 16281 & NT & NT & DCM & 39.7 & Nitroaromatics & & {$[54]$} \\
\hline Munitions site (Soil 102) & 235165 & 22711 & NT & NT & DCM & 73.3 & Nitroaromatics & & {$[54]$} \\
\hline Munitions site (Soil 103) & 20217 & 8959 & NT & NT & DCM & 1.2 & Nitroaromatics & & {$[54]$} \\
\hline Munitions site (Soil 104) & 9531 & 1517 & NT & NT & DCM & 0.74 & Nitroaromatics & & [54] \\
\hline Munitions site (Soil 105) & 288350 & 103806 & NT & NT & DCM & 115.3 & Nitroaromatics & & [54] \\
\hline Munitions site (Soil 106) & 179516 & 22365 & NT & NT & DCM & 29.8 & Nitroaromatics & & [54] \\
\hline Munitions site (Soil 107) & 279896 & 24194 & NT & NT & DCM & 47.4 & Nitroaromatics & & [54] \\
\hline Munitions site (Soil 108) & 15532 & 2410 & NT & NT & DCM & 2.06 & Nitroaromatics & & [54] \\
\hline Munitions site (Soil 109) & 1200 & ND & NT & NT & DCM & 0.06 & Background & & {$[54]$} \\
\hline Munitions site (Soil 001) & 19397 & 5726 & NT & NT & MetOH & 3.31 & Nitroaromatics & & [54] \\
\hline Munitions site (Soil 002) & 7823 & 1522 & NT & NT & MetOH & 1.18 & Nitroaromatics & & [54] \\
\hline Munitions site (Soil 003) & 50115 & 8327 & NT & NT & $\mathrm{MetOH}$ & 15.4 & Nitroaromatics & & [54] \\
\hline Munitions site (Soil 004) & 36951 & 5297 & NT & NT & $\mathrm{MetOH}$ & 12.9 & Nitroaromatics & & [54] \\
\hline Munitions site (Soil 005) & 105117 & 40900 & NT & NT & $\mathrm{MetOH}$ & 8.56 & Nitroaromatics & & {$[54]$} \\
\hline
\end{tabular}




\begin{tabular}{|c|c|c|c|c|c|c|c|c|c|}
\hline Munitions site (Soil 101) & 24897 & 1081 & NT & NT & $\mathrm{MetOH}$ & 3.86 & Nitroaromatics & & {$[54]$} \\
\hline Munitions site (Soil 102) & 46982 & 11509 & NT & NT & $\mathrm{MetOH}$ & 2.78 & Nitroaromatics & & {$[54]$} \\
\hline Munitions site (Soil 103) & 14523 & 1620 & NT & NT & $\mathrm{MetOH}$ & 1.78 & Nitroaromatics & & {$[54]$} \\
\hline Munitions site (Soil 104) & 24286 & 4687 & NT & NT & $\mathrm{MetOH}$ & 0.72 & Nitroaromatics & & {$[54]$} \\
\hline Munitions site (Soil 105) & 43737 & 14722 & NT & NT & $\mathrm{MetOH}$ & 2.39 & Nitroaromatics & & [54] \\
\hline Munitions site (Soil 106) & 18681 & 7285 & NT & NT & MetOH & 0.73 & Nitroaromatics & & [54] \\
\hline Munitions site (Soil 107) & 74256 & 35700 & NT & NT & $\mathrm{MetOH}$ & 3.57 & Nitroaromatics & & {$[54]$} \\
\hline Munitions site (Soil 108) & 48365 & 14954 & NT & NT & MetOH & 2.29 & Nitroaromatics & & [54] \\
\hline Munitions site (Soil 109) & 21.0 & ND & NT & NT & MetOH & 0.21 & Background & & {$[54]$} \\
\hline Amended soil (sewage sludge) & 153.0 & NT & 103.0 & NT & EDC & NA & & & {$[476]$} \\
\hline Wood preserving (sludge/soil) & ND & 250410 & ND & 925110 & DCM & 528.0 & Creosote, PCP & & [146] \\
\hline Wood preserving (sludge/soil) & ND & NT & ND & 20 & DCM & 0.057 & Background & & {$[146]$} \\
\hline SWRI waste ${ }^{\mathrm{p}}$ & ND & 76150 & ND & 425970 & DCM & 210.0 & Hydrocarbons & & [49] \\
\hline COMBO waste ${ }^{\mathrm{p}}$ & 19950 & 33120 & ND & 86920 & DCM & 410.0 & Hydrocarbons & & [49] \\
\hline Amended soil (creosote) & ND & 21144.0 & 466872.0 & ND & DCM & 135.00 & Creosote, PAHs & & [49] \\
\hline Amended soil (creosote) & ND & 16369.0 & 220423.0 & ND & DCM & 139.00 & Creosote, PAHs & & [49] \\
\hline Amended soil (refinery) & 1336.0 & 22598.0 & ND & ND & DCM & 41.00 & PAHs & & [49] \\
\hline Amended soil (refinery) & 146.0 & 8120.0 & ND & ND & DCM & 53.00 & PAHs & & [49] \\
\hline Amended soil (refinery) & 86.0 & 4498.0 & ND & ND & DCM & 23.00 & PAHs & & [49] \\
\hline Amended soil (refinery) & ND & 5299.0 & ND & ND & DCM & 34.00 & PAHs & & [49] \\
\hline Amended soil (creosote) & ND & 13925.0 & NT & NT & DCM & & PAHs & PAHs: 2769 & {$[121]$} \\
\hline Amended soil (slop oil solids) & 1890.0 & 537.0 & NT & NT & DCM & & PAHs & PAHs: 6646 & {$[121]$} \\
\hline Diesel contaminated soil & 115800 & ND & ND & ND & DCM & & Hydrocarbons, PAHs & PAHs: 115 & {$[157]$} \\
\hline Hazardous waste landfill & NT & 2330.0 & NT & 2740.0 & DCM & $\sim 149.0$ & Solvents, Metals & & [423] \\
\hline Hazardous waste landfill & NT & 4110.0 & NT & 3650.0 & DCM & $\sim 149.0$ & Solvents, Metals & & [423] \\
\hline Hazardous waste landfill & NT & 3040.0 & NT & 1693.0 & Ac/Hex & $\sim 149.0$ & Solvents, Metals & & [423] \\
\hline Hazardous waste landfill & NT & 2960.0 & NT & 2200.0 & Ac/Hex & $\sim 149.0$ & Solvents, Metals & & {$[423]$} \\
\hline Hazardous waste landfill & NT & 2540.0 & NT & 1680.0 & Ac/Hex & $\sim 149.0$ & Solvents, Metals & & [423] \\
\hline Hazardous waste landfill & NT & 2533.0 & NT & 2180.0 & $\mathrm{Ac} / \mathrm{DCM}$ & $\sim 149.0$ & Solvents, Metals & & {$[423]$} \\
\hline Hazardous waste landfill & NT & 1903.0 & NT & 1893.0 & Hex/Prop & $\sim 149.0$ & Solvents, Metals & & {$[423]$} \\
\hline Hazardous waste landfill & NT & 1645.0 & NT & 1313.0 & DCM & $\sim 149.0$ & Solvents, Metals & & {$[423]$} \\
\hline Munitions site & 81100 & 99300 & 6200 & 8750 & EtOH/DMSO & & Nitroaromatics & $\begin{array}{l}\text { TNT }^{\mathrm{q}}: \\
\text { 156 DNTs: } 6.6\end{array}$ & {$[65]^{\mathrm{r}}$} \\
\hline Petrochemical plant & NT & 459.0 & NT & NT & Ac/Hex & 0.48 & $\mathrm{PAHs}^{\mathrm{s}}$ & & {$[56]$} \\
\hline Tokyo soil (industrial) & 125.0 & 283.0 & NT & NT & Benz/EtOH & NA & PAHs & BaP: 0.21 & {$[476]$} \\
\hline Katsushika-ku, Tokyo & 278.0 & 959.0 & NT & NT & Benz/EtOH & NA & PAHs & BaP: 0.21 & {$[476]$} \\
\hline Munitions site & 284000 & 56900 & 259000 & 163000 & $\mathrm{ACN}$ & NA & Nitroaromatics & TNT: 12200 & {$[158]$} \\
\hline Petrochem. Sludge amended 1 & 211.8 & 218.1 & NT & NT & $\mathrm{ACN}$ & NA & PAHs & PAHs: 473 & [59] \\
\hline Petrochem. Sludge amended 2 & 394.6 & 343.3 & NT & NT & $\mathrm{ACN}$ & NA & PAHs & PAHs: 946 & [59] \\
\hline Petrochem. Sludge amended 3 & 801.4 & 1511.2 & NT & NT & $\mathrm{ACN}$ & NA & PAHs & PAHs: 1892 & [59] \\
\hline
\end{tabular}


Appendix A. (Continued)

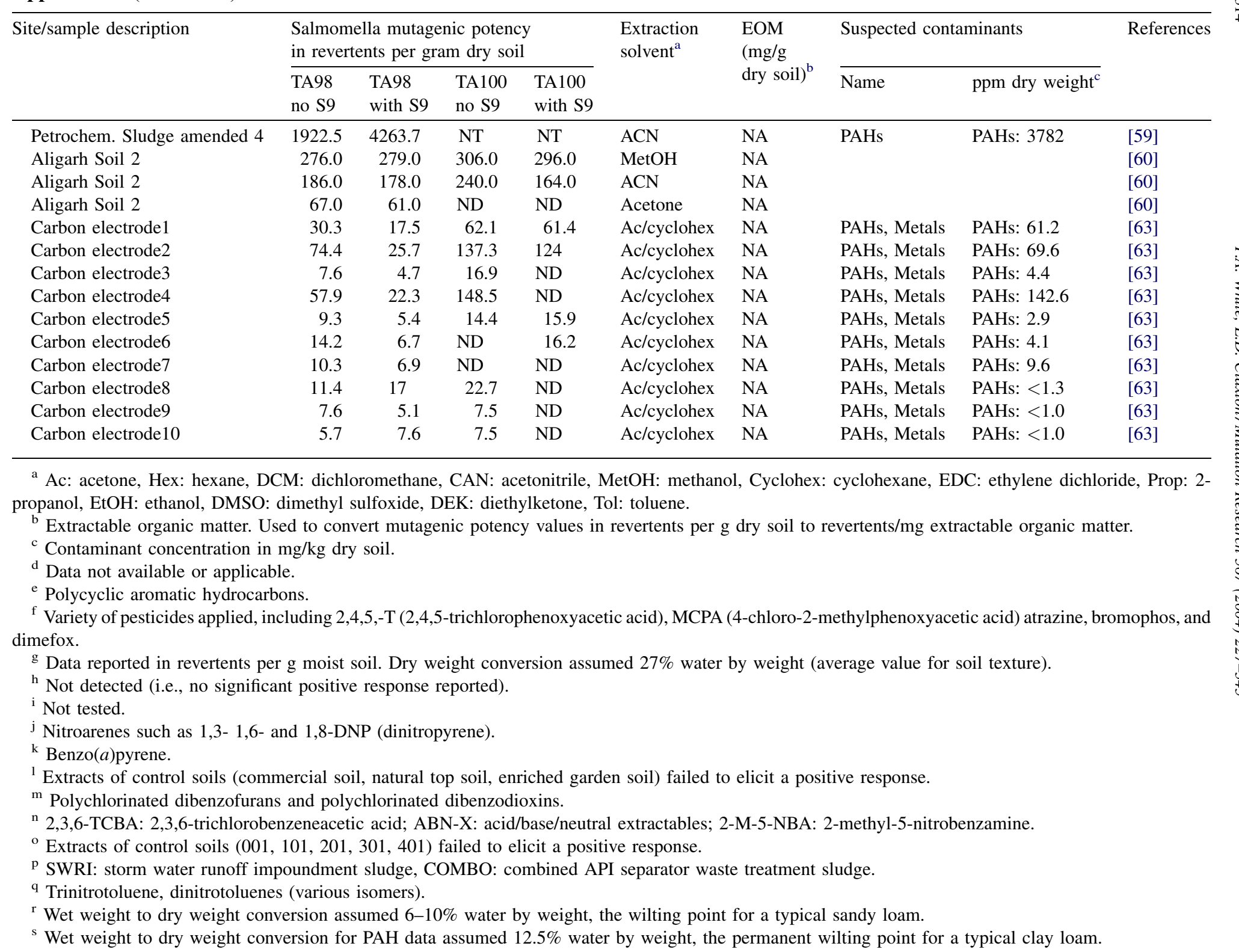




\section{Appendix B}

Plant clastogenicity and mutagenicity data collected from the literature

\begin{tabular}{|c|c|c|c|c|c|}
\hline \multirow[t]{2}{*}{ Site/sample description ${ }^{\mathrm{a}}$} & \multirow{2}{*}{$\begin{array}{l}\text { Maximum } \\
\text { response observed }\end{array}$} & \multirow[t]{2}{*}{ Exposure medium $^{\mathrm{c}}$} & \multicolumn{2}{|c|}{ Suspected contaminants } & \multirow[t]{2}{*}{ References } \\
\hline & & & Name & 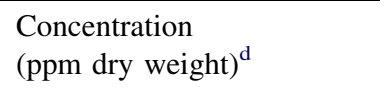 & \\
\hline \multicolumn{6}{|c|}{ 1. Sister chromatid exchanges in Vicia faba } \\
\hline \multicolumn{6}{|l|}{ 1.1. Industrial vicinity } \\
\hline Czech soil 11VM & 30.1 & Aqueous extract & PAHs & PAHs: 1.1 & [68] \\
\hline Czech soil $14 \mathrm{VM}$ & 28.7 & Aqueous extract & PAHs & PAHs: 0.8 & {$[68]$} \\
\hline Czech soil 4L & 28.3 & Aqueous extract & PAHs & & {$[68]$} \\
\hline Czech soil 4VM & 28.3 & Aqueous extract & PAHs & PAHs: 11.2 & [68] \\
\hline Czech soil 20VM & 25.1 & Aqueous extract & PAHs & PAHs: 0.2 & [68] \\
\hline Czech soil 3L & 21.2 & Aqueous extract & PAHs & & [68] \\
\hline Czech soil 1L & 19.2 & Aqueous extract & PAHs & & [68] \\
\hline Czech soil $2 \mathrm{~L}$ & 19.0 & Aqueous extract & PAHs & & {$[68]$} \\
\hline \multicolumn{6}{|l|}{ 2. Micronuclei in Vicia faba } \\
\hline \multicolumn{6}{|l|}{ 2.1. Industrial vicinity } \\
\hline Czech soil 4L & 2.7 & Aqueous extract & PAHs & & [68] \\
\hline Czech soil 1L & 1.7 & Aqueous extract & PAHs & & [68] \\
\hline Czech soil 4VM & 1.7 & Aqueous extract & PAHs & PAHs: 11.2 & [68] \\
\hline Czech soil 3L & 1.3 & Aqueous extract & PAHs & & [68] \\
\hline Czech soil 2L & 1.1 & Aqueous extract & PAHs & & [68] \\
\hline Czech soil $14 \mathrm{VM}$ & 1.1 & Aqueous extract & PAHs & PAHs: 0.8 & [68] \\
\hline Czech soil 11VM & 0.8 & Aqueous extract & PAHs & PAHs: 1.1 & {$[68]$} \\
\hline Czech soil 20VM & 0.6 & Aqueous extract & PAHs & PAHs: 0.2 & {$[68]$} \\
\hline $\mathrm{Cr}$ contaminated soil & 27.2 & Aqueous extract & Chromium & Cr: 2.9 & {$[82]$} \\
\hline $\mathrm{Cr}$ contaminated soil & 26.0 & Aqueous extract & Chromium & Cr: 2.8 & {$[82]$} \\
\hline $\mathrm{Cr}$ contaminated soil & 13.2 & Aqueous extract & Chromium & Cr: 1.8 & [82] \\
\hline $\mathrm{Cr}$ contaminated soil & 12.6 & Aqueous extract & Chromium & Cr: 1.9 & {$[82]$} \\
\hline Cr contaminated soil & 11.8 & Aqueous extract & Chromium & Cr: 2.0 & {$[82]$} \\
\hline $\mathrm{Cr}$ contaminated soil & 9.2 & Aqueous extract & Chromium & Cr: 1.1 & {$[82]$} \\
\hline $\mathrm{Cr}$ contaminated soil & 7.9 & Aqueous extract & Chromium & Cr: 1.2 & {$[82]$} \\
\hline Slovakian soil & 0.6 & Direct contact & Metals & Cr: 22.9, Pb: 69.5, As: 2940 & [76] \\
\hline
\end{tabular}


Appendix B. (Continued)

\begin{tabular}{|c|c|c|c|c|c|}
\hline \multirow[t]{2}{*}{ Site/sample description ${ }^{\mathrm{a}}$} & \multirow{2}{*}{$\begin{array}{l}\text { Maximum } \\
\text { response observed }^{\mathrm{b}}\end{array}$} & \multirow[t]{2}{*}{ Exposure medium $^{\mathrm{c}}$} & \multicolumn{2}{|c|}{ Suspected contaminants } & \multirow[t]{2}{*}{$\overline{\text { References }}$} \\
\hline & & & Name & $\begin{array}{l}\text { Concentration } \\
{\text { (ppm dry weight })^{\mathrm{d}}}^{\text {(ppm }}\end{array}$ & \\
\hline Arnoldstein soil & 0.2 & Direct contact & Metals & Cr: 25.1, Pb: 10779, As: 110 & {$[76]$} \\
\hline Brixlegg soil & 0.2 & Direct contact & Metals & Cr: 25.3, Pb: 2057, As: 0.2 & {$[76]$} \\
\hline Industrial soil A & 7.7 & Aqueous extract & PAHs/Metals & PAHs: 292.6, Cr: 2.2 (in leachate) & {$[83]$} \\
\hline Industrial soil B & 3.9 & Aqueous extract & PAHs/Metals & PAHs: 6978, Cr: 0.2 (in leachate) & {$[83]$} \\
\hline Flyash amended soil & 4.6 & Direct contact & Metals & Cr: 130.7, Ni: 31.4, Pb: 69.1, Zn: 78.3 & {$[79]$} \\
\hline Composted flyash soil & 3.9 & Direct contact & Metals & Cr: 117.8, Ni: 28.7, Pb: 56.9, Zn: 69.1 & {$[79]$} \\
\hline \multicolumn{6}{|l|}{ 2.2. Others } \\
\hline Potting soil & 0.2 & Direct contact & & & [76] \\
\hline Saualpe soil & 1.1 & Direct contact & Metals & Cr: 56.2, Pb: 55.4, As: 1540 (geogenic) & [76] \\
\hline Control soil/dung mix & 0.4 & Direct contact & Metals & Cr: 12.2, Ni: 18.1, Pb: 15, Zn: 24.3 & [79] \\
\hline Compost soil/dung mix & 0.3 & Direct contact & Metals & Cr: 7.4, Ni: 9.4, Pb: 10.3, Zn: 20.3 & [79] \\
\hline \multicolumn{6}{|c|}{ 3. Micronuclei in Tradescantia (clone 4430 unless otherwise noted) } \\
\hline \multicolumn{6}{|l|}{ 3.1 Industrial Vicinity } \\
\hline Solid waste landfill 1 & 7.0 & Aqueous extract & Metals, organics & & {$[283]$} \\
\hline Solid waste landfill 2 & 5.9 & Aqueous extract & Metals, organics & & {$[283]$} \\
\hline Solid waste landfill 5 & 5.5 & Aqueous extract & Metals, organics & & {$[283]$} \\
\hline Solid waste landfill 3 & 5.3 & Aqueous extract & Metals, organics & & {$[283]$} \\
\hline Solid waste landfill 4 & 3.9 & Aqueous extract & Metals, organics & & {$[283]$} \\
\hline Solid waste landfill 6 & 3.4 & Aqueous extract & Metals, organics & & {$[283]$} \\
\hline Solid waste compost & 2.8 & DMSO extract & Metals, organics & & {$[66]$} \\
\hline Solid waste compost & 2.7 & DMSO extract & Metals, organics & & {$[66]$} \\
\hline Solid waste compost & 2.1 & DMSO extract & Metals, organics & & {$[66]$} \\
\hline Solid waste compost & 1.1 & DMSO extract & Metals, organics & & {$[66]$} \\
\hline Industrial soil A & 11.1 & Aqueous extract & PAHs/Metals & PAHs: 292.6, Cr: 2.2 (in leachate) & {$[83]$} \\
\hline Industrial soil B & 7.5 & Aqueous extract & PAHs/Metals & PAHs: 6978, Cr: 0.2 (in leachate) & {$[83]$} \\
\hline Mine tailings & 6.9 & Aqueous extract & Metals, PAHs & $\mathrm{Cr}: \sim 114, \mathrm{~Pb}: \sim 8200$, As: $\sim 268$ & {$[81]$} \\
\hline Mine tailings & 6.4 & Aqueous extract & Metals, PAHs & $\mathrm{Cr}: \sim 114, \mathrm{~Pb}: \sim 8200, \mathrm{As}: \sim 268$ & {$[81]$} \\
\hline Mine tailings & 6.1 & Aqueous extract & Metals, PAHs & $\mathrm{Cr}: \sim 114, \mathrm{~Pb}: \sim 8200, \mathrm{As}: \sim 268$ & {$[81]$} \\
\hline Mine tailings & 4.9 & Aqueous extract & Metals, PAHs & $\mathrm{Cr}: \sim 114, \mathrm{~Pb}: \sim 8200, \mathrm{As}: \sim 268$ & {$[81]$} \\
\hline Letna soil & 11.6 & DMSO extract & & & [69] \\
\hline Letna soil & 9.2 & DMSO extract & & & {$[69]$} \\
\hline Florenc soil & 8.7 & DMSO extract & & & [69] \\
\hline
\end{tabular}




$\begin{array}{lr}\text { Florenc soil } & 6.9 \\ \text { Brixlegg soil } & 100.0 \\ \text { Arnoldstein soil } & 72.0 \\ \text { Slovakian soil } & 28.0 \\ \text { Brixlegg soil } & 4.3 \\ \text { Arnoldstein soil } & 4.4 \\ \text { Slovakian soil } & 4.3 \\ \text { Brixlegg soil } & 3.0 \\ \text { Arnoldstein soil } & 3.7 \\ \text { Slovakian soil } & 3.7 \\ \text { Mitterghutten 1 } & 8.1 \\ \text { Mitterghutten 2 } & 12.9 \\ \text { Ramingstein 1 } & 15.6 \\ \text { Ramingstein 2 } & 5.7 \\ \text { Bleiberg 1 } & 6.4 \\ \text { Bleiberg 2 } & 7.5 \\ \text { Bleiberg 3 } & 9.7 \\ \text { Arnoldstein 1 } & 4.8 \\ \text { Arnoldstein 2 } & 9.2 \\ \text { Arnoldstein 3 } & 8.2 \\ \text { Meza 1 } & 9.2 \\ \text { Meza 2 } & 4.5 \\ \text { Bitterfield 1 } & 4.4 \\ \text { Bitterfield 2 } & 6.1 \\ \text { Carbon electrode 1 } & 6.2 \\ \text { Carbon electrode 2 } & 1.9 \\ \text { Carbon electrode 3 } & 15.3 \\ \text { Carbon electrode } 4 & 5.9 \\ \text { Carbon electrode 5 } & 3.8 \\ \text { Carbon electrode 6 } & 3.7 \\ \text { Carbon electrode } 7 & 9.5 \\ \text { Carbon electrode } 8 & 5.9 \\ \text { Carbon electrode } 9 & \\ \text { Carbon electrode 10 } & \end{array}$

Direct contact

Aq. leachate $(\mathrm{pH} 4)$

Direct contact

Metals

Direct contact

Metals

Direct contact

Direct contact

Direct contact

Direct contact

Direct contact

Direct contact

Direct contact

Direct contact

Direct contact

Direct contact

Direct contact

Direct contact

Aqueous extract

Aqueous extract

Aqueous extract

Aqueous extract

Aqueous extract

Aqueous extract

Aqueous extract

Aqueous extract

Aqueous extract

Aqueous extract
Metals

Metals

Metals

Metals

Metals

Metals

Metals

Metals

Metals

Metals

Metals

Metals

Metals/PAHs

Metals/PAHs

Metals/PAHs

Metals/PAHs

Metals/PAHs

Metals/PAHs

Metals/PAHs

Metals/PAHs

Metals/PAHs

Metals/PAHs
Cr: 37, Pb: 59, As: 52.9, Cd: 0.3

Cr: 10, Pb: 148, As: 903, Cd: 0.7

Cr: 31, Pb: 104, As: 24.5, Cd: 0.8

Cr: 29, Pb: 13604, As: 232, Cd: 51.1

Cr: 53, Pb: 83, As: 2.1, Cd: 0.3

Cr: $13, \mathrm{~Pb}: 1731$, As: $4.4, \mathrm{Cd}: 34.4$

Cr: 22, Pb: 4199, As: 7.0, Cd: 62.1

Cr: 37, Pb: 78, As: 8.4, Cd: 0.6

Cr: 32, Pb: 4013, As: 150, Cd: 31.2

Cr: 31, Pb: 28144, As: 106, Cd: 89.9

Cr: 56, Pb: 52, As: 15.0, Cd: 0.3

Cr: 124, Pb: 694, As: 13.9, Cd: 7.4

Cr: $27, \mathrm{~Pb}: 39$, As: 16.0

Cr: 214, Pb: 295, As: 62

Pb: 483.7, Zn: 655.6, PAHs: 61.2

$\mathrm{Pb}: 130.7, \mathrm{Zn}: 432.8$, PAHs: 69.6

$\mathrm{Pb}: 62.2, \mathrm{Zn}: 100.6$, PAHs: 4.4

Pb: 136.5, Zn: 609.1, PAHs: 142.6

$\mathrm{Pb}: 35.0, \mathrm{Zn}: 80.0$, PAHs: 2.9

$\mathrm{Pb}: 73.3, \mathrm{Zn}: 162.5$, PAHs: 4.1

$\mathrm{Pb}: 145.6, \mathrm{Zn}: 374.0$, PAHs: 9.6

$\mathrm{Pb}: 49.4, \mathrm{Zn}:$ 88.9, PAHs: $<1.3$

Pb: 68.1, Zn: 107.0, PAHs: $<1.0$

$\mathrm{Pb}$ : 48.2, Zn: 72.3, PAHs: $<1.0$ 
Appendix B. (Continued)

\begin{tabular}{|c|c|c|c|c|c|}
\hline \multirow[t]{2}{*}{ Site/sample description $^{\mathrm{a}}$} & \multirow{2}{*}{$\begin{array}{l}\text { Maximum } \\
\text { response observed }^{\text {b }}\end{array}$} & \multirow[t]{2}{*}{ Exposure medium $^{\mathrm{c}}$} & \multicolumn{2}{|c|}{ Suspected contaminants } & \multirow[t]{2}{*}{ References } \\
\hline & & & Name & 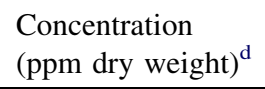 & \\
\hline \multicolumn{6}{|c|}{ 3.2. Heavily contaminated sites (e.g., hazardous waste landfill, superfund sites, etc.) } \\
\hline Creosote contamination & 43.0 & Aqueous extract & Creosote, PAHs & PAHs: 5749 & {$[120]$} \\
\hline Waste compost & 8.4 & DMSO extract & Metals, organics & & {$[66]$} \\
\hline Waste compost & 6.3 & EtOH extract & Metals, organics & & {$[66]$} \\
\hline Waste compost & 6.2 & DMSO extract & Metals, organics & & {$[66]$} \\
\hline Waste compost & 5.8 & DMSO extract & Metals, organics & & [66] \\
\hline Waste compost & 5.3 & DMSO extract & Metals, organics & & {$[66]$} \\
\hline Waste compost & 5.3 & DMSO extract & Metals, organics & & [66] \\
\hline Waste compost & 5.2 & Aqueous extract & Metals, organics & & {$[66]$} \\
\hline Waste compost & 5.1 & EtOH extract & Metals, organics & & [66] \\
\hline Waste compost & 4.2 & DMSO extract & Metals, organics & & [66] \\
\hline Superfund Plot 3B & 23.8 & Direct contact (slurry) & Pesticides & DDT: up to 1200 & {$[78]$} \\
\hline Superfund Plot NC1 & 19.3 & Direct contact (slurry) & Pesticides & DDT: up to 1200 & {$[78]$} \\
\hline Superfund Plot 2 & 17.9 & Direct contact (slurry) & Pesticides & DDT: up to 1200 & {$[78]$} \\
\hline Superfund Plot 3A & 14.3 & Direct contact (slurry) & Pesticides & DDT: up to 1200 & [78] \\
\hline Superfund Plot 4A & 11.4 & Direct contact (slurry) & Pesticides & DDT: up to 1200 & {$[78]$} \\
\hline Superfund Plot 3 & 10.8 & Direct contact & Pesticides & DDT: up to 1200 & [78] \\
\hline Superfund Plot 4 & 9.8 & Direct contact & Pesticides & DDT: up to 1200 & [78] \\
\hline Superfund Plot 5 & 9.6 & Direct contact & Pesticides & DDT: up to 1200 & {$[78]$} \\
\hline Superfund Plot 1 & 9.3 & Direct contact & Pesticides & DDT: up to 1200 & [78] \\
\hline Superfund Plot 1B & 8.3 & Direct contact (slurry) & Pesticides & DDT: up to 1200 & {$[78]$} \\
\hline Superfund Plot 2A & 7.9 & Direct contact (slurry) & Pesticides & DDT: up to 1200 & {$[78]$} \\
\hline Superfund Plot 2B & 6.7 & Direct contact (slurry) & Pesticides & DDT: up to 1200 & [78] \\
\hline Superfund Plot 5A & 5.7 & Direct contact (slurry) & Pesticides & DDT: up to 1200 & [78] \\
\hline Superfund Plot 5B & 5.1 & Direct contact (slurry) & Pesticides & DDT: up to 1200 & [78] \\
\hline Superfund Plot 1A & 4.7 & Direct contact (slurry) & Pesticides & DDT: up to 1200 & [78] \\
\hline Superfund Plot 4B & 3.5 & Direct contact (slurry) & Pesticides & DDT: up to 1200 & {$[78]$} \\
\hline Rubber factory mire & 7.3 & Aqueous extract & Organics & & {$[286]$} \\
\hline Waste site A (Pavia) & 2.5 & Aqueous extract & Organics & & {$[178]$} \\
\hline Waste site B (Pavia) & 5.5 & Aqueous extract & Organics & & {$[178]$} \\
\hline Waste site D (Pavia) & 5.9 & Aqueous extract & Organics & & {$[178]$} \\
\hline
\end{tabular}

3.3. Sites contaminated with mutagenic metals of geogenic origin
Saualpe soil
77.0
Direct contact
Metals
Cr: 56.2, Pb: 55.4, As: 1540 
Saualpe soil 5.6

Saualpe soil $\quad 3.1$

Feistritz $1 \quad 11.0$

Feistritz $2 \quad 16.3$

3.4. Agricultural sites Agricultural soil 6

Agricultural soil 5

Agricultural soil 4

Agricultural soil 3

Agricultural soil 2

Agricultural soil 1

MPC soil

MPC soil

Vienna 1

Vienna 2

Vienna 3

Monroe soil

Monroe soil

Allison soil

Allison soil

Sprayed soil (high)

Sprayed soil (high)

Sprayed soil (medium)

Sprayed soil (medium)

Sprayed soil (low)

Sprayed soil (low)

Untertiefenbach

Reisenberg

3.5. Reference (control) sites

Karlovka soil

Karlovka soil

Control soil

Control soil

Control soil

Control soil

Control soil

Potting soil

$\begin{array}{ll}\text { Aq. leachate }(\mathrm{pH} 4) & \text { Metals } \\ \text { Aq. leachate }(\mathrm{pH} \mathrm{7)} & \text { Metals } \\ \text { Direct contact } & \text { Metals } \\ \text { Direct contact } & \text { Metals }\end{array}$

Metals

Metals

Metals

Metals, organics

Metals, organics

Metals, organics

Metals, organics

Metals, organics

Metals, organics

Pesticides

Pesticides

Pesticides

Pesticides

Pesticides

Pesticides

Pesticides

Pesticides

Pesticides

Captan, diazinon, etc.

Captan, diazinon, etc.

Captan, diazinon, etc.

Captan, diazinon, etc.

Captan, diazinon, etc.

Captan, diazinon, etc.

\section{Metals}

Metals $\begin{array}{ll}\text { Cr: } 56.2, \text { Pb: 55.4, As: } 1540 & {[76]} \\ \text { Cr: 56.2, Pb: 55.4, As: } 1540 & {[76]} \\ \text { Cr: 26, Pb: 34, As: 36, Cd: } 0.1 & {[77]} \\ \text { Cr: 67, Pb: 54, As: } 150, \text { Cd: } 0.2 & \text { [77] }\end{array}$

\begin{tabular}{|c|c|}
\hline & {$[67]$} \\
\hline & {$[67]$} \\
\hline & {$[67]$} \\
\hline & {$[67]$} \\
\hline & {$[67]$} \\
\hline & [67] \\
\hline & [252] \\
\hline & [252] \\
\hline & [252] \\
\hline & [252] \\
\hline & [252] \\
\hline & [474] \\
\hline & [474] \\
\hline & [474] \\
\hline & [474] \\
\hline & {$[85]$} \\
\hline & {$[85]$} \\
\hline & {$[85]$} \\
\hline & {$[85]$} \\
\hline & {$[85]$} \\
\hline & {$[85]$} \\
\hline As: $4.1, \mathrm{~Pb}: 29, \mathrm{Cr}: 43, \mathrm{Cd}: 0.3$ & {$[77]$} \\
\hline As: $4.4, \mathrm{~Pb}: 37, \mathrm{Cr}: 75, \mathrm{Cd}: 0.7$ & {$[77]$} \\
\hline
\end{tabular}

DMSO extract

DMSO extract

[69]

[69]

[78]

[78]

[78]

Direct contact

Direct contact (slurry)

Direct contact

[78]

[76]

Direct contact 
Appendix B. (Continued)

\begin{tabular}{|c|c|c|c|c|c|}
\hline \multirow[t]{2}{*}{ Site/sample description ${ }^{\mathrm{a}}$} & \multirow{2}{*}{$\begin{array}{l}\text { Maximum } \\
\text { response observed }^{\mathrm{b}}\end{array}$} & \multirow[t]{2}{*}{ Exposure medium $^{\mathrm{c}}$} & \multicolumn{2}{|c|}{ Suspected contaminants } & \multirow[t]{2}{*}{ References } \\
\hline & & & Name & $\begin{array}{l}\text { Concentration } \\
{\text { (ppm dry weight })^{\mathrm{d}}}\end{array}$ & \\
\hline Potting soil & 4.3 & Aq. leachate (pH 4) & & & [76] \\
\hline Potting soil & 4.1 & Aq. leachate $(\mathrm{pH} 7)$ & & & [76] \\
\hline APF soil & 2.7 & Aqueous extract & & & {$[474]$} \\
\hline Control soil & 4.0 & Aqueous extract & & & {$[85]$} \\
\hline Control soil & 4.9 & Aqueous extract & & & [286] \\
\hline Potting soil 1 & 4.5 & Direct contact & & & {$[77]$} \\
\hline Potting soil 2 & 6.4 & Direct contact & & & [77] \\
\hline Potting soil 3 & 2.8 & Direct contact & & & {$[77]$} \\
\hline Waste control (Pavia) & 1.5 & Aqueous extract & & & {$[178]$} \\
\hline \multicolumn{6}{|l|}{ 4. Micronuclei in Allium cepa } \\
\hline Industrial soil A & 6.2 & Aqueous extract & PAHs/Metals & PAHs: $292.6, \mathrm{Cr}: 2.2$ (in leachate) & {$[83]$} \\
\hline Industrial soil B & 2.7 & Aqueous extract & PAHs/Metals & PAHs: $6978, \mathrm{Cr}: 0.2$ (in leachate) & {$[83]$} \\
\hline \multicolumn{6}{|c|}{ 5. Anaphase aberrations in Alliu cepa root tips } \\
\hline \multicolumn{6}{|c|}{ 5.1. Industrial vicinity } \\
\hline Solid waste landfill & 6.3 & Aqueous extract & Metals, organics & & [283] \\
\hline Solid waste landfill & 4.0 & Aqueous extract & Metals, organics & & [283] \\
\hline Solid waste landfill & 3.3 & Aqueous extract & Metals, organics & & [283] \\
\hline Solid waste landfill & 3.0 & Aqueous extract & Metals, organics & & [283] \\
\hline Solid waste landfill & 1.3 & Aqueous extract & Metals, organics & & [283] \\
\hline Waste compost & 2.0 & DMSO extract & Metals, organics & & {$[66]$} \\
\hline Waste compost & 0.7 & DMSO extract & Metals, organics & & {$[66]$} \\
\hline Chernobyl soil 1 & 3.4 & Direct contact & ${ }^{137} \mathrm{Cs},{ }^{232} \mathrm{Th},{ }^{90} \mathrm{Sr}$ & ${ }^{137} \mathrm{Cs}: 145 \mathrm{~Bq} / \mathrm{kg}$ & [257] \\
\hline Chernobyl soil 2 & 3.1 & Direct contact & ${ }^{137} \mathrm{Cs},{ }^{232} \mathrm{Th},{ }^{90} \mathrm{Sr}$ & ${ }^{137} \mathrm{Cs}: 188 \mathrm{~Bq} / \mathrm{kg}$ & {$[257]$} \\
\hline Chernobyl soil 3 & 6.7 & Direct contact & ${ }^{137} \mathrm{Cs},{ }^{232} \mathrm{Th},{ }^{90} \mathrm{Sr}$ & ${ }^{137} \mathrm{Cs}: 575 \mathrm{~Bq} / \mathrm{kg}$ & [257] \\
\hline Chernobyl soil 4 & 6.0 & Direct contact & ${ }^{137} \mathrm{Cs},{ }^{232} \mathrm{Th},{ }^{90} \mathrm{Sr}$ & ${ }^{137} \mathrm{Cs}: 582 \mathrm{~Bq} / \mathrm{kg}$ & [257] \\
\hline Bhopal soil 1 & 5.8 & Aqueous extract & $\mathrm{MIC}^{\mathrm{e}}$ & & {$[477]$} \\
\hline Bhopal soil 2 & 1.6 & Aqueous extract & MIC & & [477] \\
\hline \multicolumn{6}{|c|}{ 5.2. Heavily contaminated sites (e.g., hazardous waste landfill, Superfund sites, etc.) } \\
\hline Waste compost & 2.2 & DMSO extract & Metals, organics & & {$[66]$} \\
\hline Waste compost & 1.6 & DMSO extract & Metals, organics & & {$[66]$} \\
\hline Chernobyl soil 5 & 13.7 & Direct contact & ${ }^{137} \mathrm{Cs},{ }^{232} \mathrm{Th},{ }^{90} \mathrm{Sr}$ & ${ }^{137} \mathrm{Cs}: 2287 \mathrm{~Bq} / \mathrm{kg}$ & [257] \\
\hline
\end{tabular}


Chernobyl soil $6 \quad 14.9$

Chernobyl soil 7

PCB contaminated soil

3.2

5.3. Agricultural sites Agricultural soil 2

Agricultural soil 3

Agricultural soil 4

Agricultural soil 5

Agricultural soil 6

Vienna 1

Vienna 2

Vienna 3

MPC soil

Ukrainian soil 37.1

Ukrainian soil 37

Ukrainian soil 18

Ukrainian soil 30

Ukrainian soil 16

Ukrainian soil 14

Ukrainian soil 2

Ukrainian soil 27

Ukrainian soil 34

Ukrainian soil 4

Ukrainian soil 15

Ukrainian soil 7

Ukrainian soil 11

Ukrainian soil 33

Ukrainian soil 37.2

Ukrainian soil 12

Ukrainian soil 32

Ukrainian soil 35

Ukrainian soil 10

Ukrainian soil 21

Ukrainian soil 20

Ukrainian soil 39

Ukrainian soil 8

Ukrainian soil 37.3

Ukrainian soil 5
Direct contact

Direct contact

Aqueous extract

DMSO extract

DMSO extract

DMSO extract

DMSO extract

DMSO extract

Aqueous extract

Aqueous extract

Aqueous extract

Aqueous extract

Direct contact

Direct contact

Direct contact

Direct contact

Direct contact

Direct contact

Direct contact

Direct contact

Direct contact

Direct contact

Direct contact

Direct contact

Direct contact

Direct contact

Direct contact

Direct contact

Direct contact

Direct contact

Direct contact

Direct contact

Direct contact

Direct contact

Direct contact

Direct contact

Direct contact
${ }^{137} \mathrm{Cs},{ }^{232} \mathrm{Th},{ }^{90} \mathrm{Sr}$

${ }^{137} \mathrm{Cs},{ }^{232} \mathrm{Th},{ }^{90} \mathrm{Sr}$

PCBs

Cs: $2543 \mathrm{~Bq} / \mathrm{kg}$

${ }^{137} \mathrm{Cs}: 6549 \mathrm{~Bq} / \mathrm{kg}$

[257]

[254]

Metals, organics

Metals, organics

[67]

Metals, organics

Metals, organics

Metals, organics

Pesticides

Pesticides

Pesticides

Pesticides 
Appendix B. (Continued)

\begin{tabular}{|c|c|c|c|c|c|}
\hline \multirow[t]{2}{*}{ Site/sample description ${ }^{\mathrm{a}}$} & \multirow{2}{*}{$\begin{array}{l}\text { Maximum } \\
\text { response observed }\end{array}$} & \multirow[t]{2}{*}{ Exposure medium $^{\mathrm{c}}$} & \multicolumn{2}{|c|}{ Suspected contaminants } & \multirow[t]{2}{*}{ References } \\
\hline & & & Name & $\begin{array}{l}\text { Concentration } \\
(\mathrm{ppm} \text { dry weight })^{\mathrm{d}}\end{array}$ & \\
\hline Ukrainian soil 36 & 1.1 & Direct contact & & & [74] \\
\hline Ukrainian soil 3 & 1.0 & Direct contact & & & [74] \\
\hline Ukrainian soil 40 & 1.0 & Direct contact & & & [74] \\
\hline Ukrainian soil 19 & 1.0 & Direct contact & & & [74] \\
\hline Ukrainian soil 31 & 0.8 & Direct contact & & & [74] \\
\hline Ukrainian soil 1 & 0.6 & Direct contact & & & [74] \\
\hline Uzbekistan Soil 1 & 3.8 & Direct contact & & & [75] \\
\hline Uzbekistan Soil 2 & 2.9 & Direct contact & & & [75] \\
\hline Uzbekistan Soil 3 & 4.9 & Direct contact & & & [75] \\
\hline Uzbekistan Soil 4 & 0.8 & Direct contact & & & [75] \\
\hline Uzbekistan Soil 5 & 5.1 & Direct contact & & & [75] \\
\hline Uzbekistan Soil 6 & 6.1 & Direct contact & & & [75] \\
\hline Uzbekistan Soil 7 & 1.7 & Direct contact & & & [75] \\
\hline Uzbekistan Soil 8 & 2.6 & Direct contact & & & [75] \\
\hline Uzbekistan Soil 9 & 3.8 & Direct contact & & & [75] \\
\hline Uzbekistan Soil 10 & 1.0 & Direct contact & & & [75] \\
\hline Uzbekistan Silt 1 & 5.3 & Direct contact & & & [75] \\
\hline Uzbekistan Silt 2 & 4.2 & Direct contact & & & [75] \\
\hline Uzbekistan Silt 3 & 2.5 & Direct contact & & & [75] \\
\hline Uzbekistan Silt 4 & 2.7 & Direct contact & & & [75] \\
\hline Uzbekistan Silt 5 & 5.4 & Direct contact & & & [75] \\
\hline Uzbekistan Silt 6 & 6.9 & Direct contact & & & [75] \\
\hline Uzbekistan Silt 7 & 4.2 & Direct contact & & & [75] \\
\hline Uzbekistan Silt 8 & 4.0 & Direct contact & & & [75] \\
\hline Uzbekistan Silt 9 & 4.2 & Direct contact & & & [75] \\
\hline Uzbekistan Silt 10 & 3.0 & Direct contact & & & [75] \\
\hline Uzbekistan Soil 11 & 4.6 & Direct contact & & & {$[75]$} \\
\hline Uzbekistan Soil 12 & 5.3 & Direct contact & & & [75] \\
\hline Uzbekistan Soil 13 & 2.8 & Direct contact & & & [75] \\
\hline Uzbekistan Soil 14 & 2.6 & Direct contact & & & [75] \\
\hline Uzbekistan Soil 15 & 5.0 & Direct contact & & & [75] \\
\hline Uzbekistan Soil 16 & 4.0 & Direct contact & & & [75] \\
\hline Uzbekistan Soil 17 & 4.1 & Direct contact & & & [75] \\
\hline Uzbekistan Soil 18 & 6.4 & Direct contact & & & [75] \\
\hline Uzbekistan Soil 19 & 3.3 & Direct contact & & & [75] \\
\hline
\end{tabular}


Uzbekistan Soil 20

Uzbekistan Silt 11

Uzbekistan Silt 12

Uzbekistan Silt 13

Uzbekistan Silt 14

Uzbekistan Silt 15

Uzbekistan Silt 17

Uzbekistan Silt 18

Uzbekistan Silt 19

Uzbekistan Silt 20

5.4. Reference (control) sites

Uzbekistan control 1

Uzbekistan control 2

Chernobyl control soil

Pesticide-free control

PCB Reference soil
Uzbekistan Silt 16

4.2
3.6
4.4
2.1
4.0
5.6
4.5
6.2
4.2
6.5
4.2

Direct contact

Direct contact

Direct contact

Direct contact

Direct contact

Direct contact

Direct contact

Direct contact

Direct contact

Direct contact

Direct contact

Direct contact

Direct contact

Direct contact

Aqueous extract

Aqueous extract
6. Gametic mutations in Arabidopsis thaliana (Müller embryo test)

6.1. Industrial vicinity

$\begin{array}{lr}\text { Czech soil 20VM } & 35.0 \\ \text { Czech soil 4VM } & 34.5 \\ \text { Czech soil 4VM } & 34.4 \\ \text { Czech soil 11VM } & 28.6 \\ \text { Czech soil 20VM } & 27.1 \\ \text { Czech soil 11VM } & 27.1 \\ \text { Czech soil 2VM } & 24.6 \\ \text { Czech soil 4L } & 24.3 \\ \text { Czech soil 14VM } & 20.3 \\ \text { Czech soil 14VM } & 19.8 \\ \text { Czech soil 3L } & 9.4 \\ \text { Czech soil 2L } & 6.4 \\ \text { Czech soil 1L } & 5.9 \\ \text { Czech soil 4L } & 5.2 \\ \text { Czech soil 3L } & 3.5 \\ \text { Czech soil 1L } & 1.6 \\ \text { Czech soil 2L } & 0.7\end{array}$

DCM extract

DCM extract

PAHs: 0.2

Aqueous extract

Aqueous extract

Aqueous extract

DCM extract

DCM extract

Aqueous extract

DCM extract

Aqueous extract

DCM extract

DCM extract

DCM extract

DCM extract

Aqueous extract

Aqueous extract

Aqueous extract

$\begin{array}{ll}\text { PAHs } & \text { PAHs: } 0.2 \\ \text { PAHs } & \text { PAHs: } 11.2 \\ \text { PAHs } & \text { PAHs: } 11.2 \\ \text { PAHs } & \text { PAHs: } 1.1 \\ \text { PAHs } & \\ \text { PAHs } & \text { PAHs: } 1.1 \\ \text { PAHs } & \\ \text { PAHs } & \\ \text { PAHs } & \text { PAHs: } 0.8 \\ \text { PAHs } & \text { PAHs: } 0.8 \\ \text { PAHs } & \\ \text { PAHs } & \\ \text { PAHs } & \\ \text { PAHs } & \\ \text { PAHs } & \\ \text { PAHs } & \\ \text { PAHs } & \end{array}$


Appendix B. (Continued)

\begin{tabular}{|c|c|c|c|c|c|}
\hline \multirow[t]{2}{*}{ Site/sample description ${ }^{\mathrm{a}}$} & \multirow{2}{*}{$\begin{array}{l}\text { Maximum } \\
\text { response observed }\end{array}$} & \multirow[t]{2}{*}{ Exposure medium $^{\mathrm{c}}$} & \multicolumn{2}{|c|}{ Suspected contaminants } & \multirow[t]{2}{*}{ References } \\
\hline & & & Name & $\begin{array}{l}\text { Concentration } \\
(\text { ppm dry weight })^{\mathrm{d}}\end{array}$ & \\
\hline \multicolumn{6}{|c|}{ 6.2. Heavily contaminated sites (e.g., hazardous waste landfill, Superfund sites, etc.) } \\
\hline Chernobyl soil 1 & 8.2 & In situ & Radioactive Cs & ${ }^{134} \mathrm{Cs}+{ }^{137} \mathrm{Cs}: 217 \mathrm{~Bq} / \mathrm{kg}$ & [258] \\
\hline Chernobyl soil 1 & 20.2 & In situ & Radioactive Cs & ${ }^{134} \mathrm{Cs}+{ }^{137} \mathrm{Cs}: 1025 \mathrm{~Bq} / \mathrm{kg}$ & [258] \\
\hline Chernobyl soil 1 & 51.6 & In situ & Radioactive Cs & ${ }^{134} \mathrm{Cs}+{ }^{137} \mathrm{Cs}: 2529 \mathrm{~Bq} / \mathrm{kg}$ & [258] \\
\hline \multirow{2}{*}{\multicolumn{6}{|c|}{$\begin{array}{l}\text { 7. Zea mays - pollen mutations at waxy locus }{ }^{\mathrm{f}} \\
\text { 7.1. Industrial vicinity }\end{array}$}} \\
\hline & & & & & \\
\hline Wood river \#1 (1978) & 72.5 & Direct contact & Petrochemicals & & [71] \\
\hline Wood river \#1 (1979) & 41.6 & Direct contact & Petrochemicals & & [71] \\
\hline Beaumont TX \#1 & 29.9 & Direct contact & Petrochemicals & & [71] \\
\hline Beaumont TX \#2 & 29.0 & Direct contact & Petrochemicals & & [71] \\
\hline Wood river \#1 (1979) & 5.0 & Direct contact & Petrochemicals & & [71] \\
\hline Wood river \#1 (1980) & 20.0 & Direct contact & Petrochemicals & & [71] \\
\hline Wood river \#2 (1978) & 22.8 & Direct contact & Petrochemicals & & [71] \\
\hline Smelter $1978(0.3 \mathrm{~km})$ & 34.6 & Direct contact & Lead & & [70] \\
\hline Smelter $1976(1.7 \mathrm{~km})$ & 28.3 & Direct contact & Lead & & [70] \\
\hline Smelter $1976(0.3 \mathrm{~km})$ & 22.0 & Direct contact & Lead & & [70] \\
\hline Smelter $1978(1.7 \mathrm{~km})$ & 12.1 & Direct contact & Lead & & [70] \\
\hline Smelter $1977(3.2 \mathrm{~km})$ & 8.6 & Direct contact & Lead & & [70] \\
\hline Smelter $1977(1.7 \mathrm{~km})$ & 7.3 & Direct contact & Lead & & [70] \\
\hline Smelter $1977(0.3 \mathrm{~km})$ & 6.7 & Direct contact & Lead & & [70] \\
\hline Smelter 1978 (3.2 km) & 3.7 & Direct contact & Lead & & [70] \\
\hline Sludge amended soil & 18.5 & Direct contact & Metals, organics & & {$[72]^{\mathrm{g}}$} \\
\hline \multicolumn{6}{|l|}{ 7.2. Agricultural sites } \\
\hline Moderate pesticide & 6.0 & Direct contact & & Captan & {$[84]^{\mathrm{h}}$} \\
\hline Moderate pesticide & 5.9 & Direct contact & & Captan + diazinon & {$[84]^{\mathrm{h}}$} \\
\hline Broadcast pesticide & 7.7 & Direct contact & & $\begin{array}{l}\text { Above + cyanazine, } \\
\text { metalochlor, chlorpyrifos, } \\
\text { and lindane }\end{array}$ & {$[84]^{\mathrm{h}}$} \\
\hline Broadcast pesticide & 8.5 & Direct contact & & $\begin{array}{l}\text { Above }+ \text { cyanazine, } \\
\text { metalochlor, chlorpyrifos, } \\
\text { and lindane }\end{array}$ & {$[84]^{\mathrm{h}}$} \\
\hline Herbicide application & 4.21 & Direct contact & & Alachlor: $6.00 \mathrm{~kg} / \mathrm{ha}$ & [270] \\
\hline
\end{tabular}


Herbicide application

Herbicide application

Herbicide application

Herbicide application

Herbicide application

Herbicide application

Herbicide application

Herbicide application

Herbicide application

Herbicide application

Herbicide application

Herbicide application

Herbicide application

Herbicide application

Herbicide application

Herbicide application

Herbicide application

Herbicide application

Herbicide application

Herbicide application

Herbicide application

Herbicide application

Insecticide application

Insecticide application

Insecticide application

Insecticide application

Insecticide application

Insecticide application

Insecticide application

Insecticide application

Insecticide application

Insecticide application

7.3. Reference (control) sites

$\begin{array}{lr}\text { Reference soil } & 5.5 \\ \text { Reference soil } & 2.6 \\ \text { Reference soil } & 2.6 \\ \text { Smelter reference 1976 } & 12.9 \\ \text { Reference soil } & 8.3 \\ \text { Reference soil } & 6.5\end{array}$

Direct contact

Direct contact

Direct contact

Direct contact

Direct contact

Direct contact

Direct contact

Direct contact

Direct contact

Direct contact

Direct contact

Direct contact

Direct contact

Direct contact

Direct contact

Direct contact

Direct contact

Direct contact

Direct contact

Direct contact

Direct contact

Direct contact

Direct contact

Direct contact

Direct contact

Direct contact

Direct contact

Direct contact

Direct contact

Direct contact

Direct contact

Direct contact

Direct contact

Direct contact

Direct contact

Direct contact

Direct contact

Direct contact
Alachlor + dicamba: $2.34+0.56 \mathrm{~kg} / \mathrm{ha}$

Atrazine: $3.84 \mathrm{~kg} / \mathrm{ha}$ [270]

Bifenox: $2.24 \mathrm{~kg} / \mathrm{ha} \quad$ [270]

Bifenox+alachlor: $1.40+2.29 \mathrm{~kg} / \mathrm{ha}$ (means) [270]

Butylate: $7.20 \mathrm{~kg} / \mathrm{ha}$ [270]

Butylate + atrazine: $4.80+1.92 \mathrm{~kg} / \mathrm{ha}$

Butylate + cyanazine: $4.80+2.24 \mathrm{~kg} / \mathrm{ha} \quad$ [270]

Cyanazine: $4.19 \mathrm{~kg} / \mathrm{ha}$ (mean) [270]

Dicamba: $0.56 \mathrm{~kg} / \mathrm{ha}$ [270]

Eradicane: $7.20 \mathrm{~kg} / \mathrm{ha}$ [270]

Eradicane + atrazine: $40 \mathrm{~kg} / \mathrm{ha}$

Eradicane + cyanazine: $3.60+2.40 \mathrm{~kg} / \mathrm{ha}$ [270]

Metolachlor: $8.40 \mathrm{~kg} / \mathrm{ha}$ [270]

Metolachlor + atrazine: $3.00+2.40 \mathrm{~kg} / \mathrm{ha} \quad$ [270]

Metolachlor + cyanazine: $4.80+4.80 \mathrm{~kg} / \mathrm{ha} \quad$ [270]

Metalachlor + dicamba: $3.00+0.60 \mathrm{~kg} / \mathrm{ha} \quad$ [270]

Procyazine: $3.58 \mathrm{~kg} / \mathrm{ha}$ [270]

Procyazine + metolachlor: $2.24+2.24 \mathrm{~kg} / \mathrm{ha} \quad$ [270]

Propachlor: $3.36 \mathrm{~kg} / \mathrm{ha}$

Propachlor + cyanazine: $4.80+2.24 \mathrm{~kg} / \mathrm{ha} \quad$ [270]

SD50093: $4.64 \mathrm{~kg} / \mathrm{ha}$ (mean) [270]

Simazine: $3.80 \mathrm{~kg} / \mathrm{ha}$ [270]

Carbofuran: $2.24 \mathrm{~kg} / \mathrm{ha}$

Chlordane: $2.24 \mathrm{~kg} / \mathrm{ha}$

Chlorpyrifos: $2.24 \mathrm{~kg} / \mathrm{ha}$

Curacron: $2.24 \mathrm{~kg} / \mathrm{ha}$

Ethoprop: $2.24 \mathrm{~kg} / \mathrm{ha}$

Fonofos: $2.24 \mathrm{~kg} / \mathrm{ha}$

Heptachlor: $1.12 \mathrm{~kg} / \mathrm{ha}$ [271]

Metham: $2.24 \mathrm{~kg} / \mathrm{ha}$

Phorate: $2.24 \mathrm{~kg} / \mathrm{ha}$

Terbufos: $2.24 \mathrm{~kg} / \mathrm{ha}$ 
Appendix B. (Continued)

\begin{tabular}{|c|c|c|c|c|c|}
\hline \multirow[t]{2}{*}{ Site/sample description ${ }^{\mathrm{a}}$} & \multirow{2}{*}{$\begin{array}{l}\text { Maximum } \\
\text { response observed }^{\mathrm{b}}\end{array}$} & \multirow[t]{2}{*}{ Exposure medium $^{\mathrm{c}}$} & \multicolumn{2}{|c|}{ Suspected contaminants } & \multirow[t]{2}{*}{ References } \\
\hline & & & Name & $\begin{array}{l}\text { Concentration } \\
(\mathrm{ppm} \text { dry weight })^{\mathrm{d}}\end{array}$ & \\
\hline Smelter reference 1977 & 4.6 & Direct contact & & & [70] \\
\hline Reference & 3.1 & Direct contact & & & [84] \\
\hline No pesticide & 4.4 & Direct contact & & & [84] \\
\hline Reference soil & 1.8 & Direct contact & & & {$[72]^{\mathrm{g}}$} \\
\hline Reference soil & 4.1 & Direct contact & & & {$[270]$} \\
\hline Reference soil & 4.0 & Direct contact & & & [271] \\
\hline \multicolumn{6}{|c|}{$\begin{array}{l}\text { 8. Stamen hair mutations inTradescantia } \text { sp. }^{\text {i }} \\
\text { 8.1. Industrial vicinity }\end{array}$} \\
\hline Beaumont TX 1.2 & 7.2 & Direct contact & Petrochemicals & & [71] \\
\hline Beaumont TX 1.4 & 6.0 & Direct contact & Petrochemicals & & [71] \\
\hline Beaumont TX 1.1 & 5.5 & Direct contact & Petrochemicals & & [71] \\
\hline Beaumont TX 1.3 & 5.3 & Direct contact & Petrochemicals & & [71] \\
\hline Beaumont TX 1.11 & 5.3 & Direct contact & Petrochemicals & & [71] \\
\hline Beaumont TX 1.5 & 5.1 & Direct contact & Petrochemicals & & [71] \\
\hline Beaumont TX 1.10 & 4.7 & Direct contact & Petrochemicals & & [71] \\
\hline Beaumont TX 1.6 & 4.6 & Direct contact & Petrochemicals & & [71] \\
\hline Beaumont TX 1.7 & 4.5 & Direct contact & Petrochemicals & & [71] \\
\hline Beaumont TX 1.8 & 3.4 & Direct contact & Petrochemicals & & [71] \\
\hline Beaumont TX 1.9 & 3.4 & Direct contact & Petrochemicals & & [71] \\
\hline Wood river & 4.8 & Direct contact & Petrochemicals & & [71] \\
\hline Granite city & 3.9 & Direct contact & Petrochemicals & & [71] \\
\hline Smelter $1977(0.3 \mathrm{~km})$ & 4.9 & Direct contact & Lead & & {$[70]$} \\
\hline Smelter $1977(1.7 \mathrm{~km})$ & 4.8 & Direct contact & Lead & & [70] \\
\hline Smelter $1978(1.7 \mathrm{~km})$ & 4.6 & Direct contact & Lead & & [70] \\
\hline Smelter $1977(3.2 \mathrm{~km})$ & 4.4 & Direct contact & Lead & & [70] \\
\hline Smelter 1977 (0.3 km) & 4.1 & Direct contact & Lead & & [70] \\
\hline Smelter 1977 (3.2 km) & 3.9 & Direct contact & Lead & & [70] \\
\hline Smelter 1978 (7.4 km) & 3.9 & Direct contact & Lead & & [70] \\
\hline Smelter $1977(1.7 \mathrm{~km})$ & 3.7 & Direct contact & Lead & & {$[70]$} \\
\hline Smelter $1978(3.2 \mathrm{~km})$ & 3.5 & Direct contact & Lead & & [70] \\
\hline Smelter 1978 (7.4 km) & 3.4 & Direct contact & Lead & & [70] \\
\hline Smelter $1978(0.3 \mathrm{~km})$ & 3.0 & Direct contact & Lead & & [70] \\
\hline Smelter $1977(1.7 \mathrm{~km})$ & 2.9 & Direct contact & Lead & & [70] \\
\hline Smelter $1978(3.2 \mathrm{~km})$ & 2.9 & Direct contact & Lead & & [70] \\
\hline Smelter $1977(0.3 \mathrm{~km})$ & 2.8 & Direct contact & Lead & & [70] \\
\hline
\end{tabular}




$\begin{array}{ll}\text { Smelter 1977 }(3.2 \mathrm{~km}) & 2.7 \\ \text { Smelter 1976 }(1.7 \mathrm{~km}) & 2.6 \\ \text { Smelter 1978 }(1.7 \mathrm{~km}) & 2.6 \\ \text { Smelter 1976 }(0.3 \mathrm{~km}) & 2.2 \\ \text { Smelter 1976 }(0.3 \mathrm{~km}) & 2.1 \\ \text { Bikini Islands B1-6 } & 2.9 \\ \text { Bikini Islands B1-8 } & 2.6 \\ \text { Bikini Islands B1-4 } & 2.6 \\ \text { Bikini Islands B1-9 } & 2.6 \\ \text { Bikini Islands B1-2 } & 2.6 \\ \text { Bikini Islands B1-7 } & 2.5 \\ \text { Bikini Islands B1-3 } & 2.4 \\ \text { Bikini Islands B1-5 } & 2.4 \\ \text { Bikini Islands B1-1 } & 1.8 \\ \text { Bikini Islands B2-5 } & 2.2 \\ \text { Bikini Islands B2-1 } & 2.3 \\ \text { Bikini Islands B2-2 } & 2.2 \\ \text { Bikini Islands B2-6 } & 2.1 \\ \text { Bikini Islands B2-8 } & 2.1 \\ \text { Bikini Islands B2-9 } & 2.0 \\ \text { Bikini Islands B2-7 } & 1.9 \\ \text { Bikini Islands B2-4 } & 1.7 \\ \text { Bikini Islands B2-3 } & 1.6 \\ \text { Letna soil } & 1.9 \\ \text { Letna soil } & 1.2 \\ \text { Florenc soil } & 1.4 \\ \text { Florenc soil } & 0.9 \\ \text { Mine tailings } & 5.8 \\ \text { Mine tailings } & 4.1 \\ \text { Mine tailings } & 4.1 \\ \text { Mine tailings } & 3.7 \\ \text { Waste compost } & 2.8 \\ \text { Waste compost } & 1.8 \\ \text { Waste compost } & 1.7 \\ \text { Waste compost } & 1.7 \\ \text { Solid waste landfill } & 3.5 \\ \text { Solid waste landfill } & 3.4 \\ \text { Solid waste landfill } & 3.3\end{array}$

$\begin{array}{ll}\text { Direct contact } & \text { Lead } \\ \text { Direct contact } & \text { Lead } \\ \text { Direct contact } & \text { Lead } \\ \text { Direct contact } & \text { Lead } \\ \text { Direct contact } & \text { Lead } \\ \text { Direct contact } & \text { Radionuclides } \\ \text { Direct contact } & \text { Radionuclides } \\ \text { Direct contact } & \text { Radionuclides } \\ \text { Direct contact } & \text { Radionuclides } \\ \text { Direct contact } & \text { Radionuclides } \\ \text { Direct contact } & \text { Radionuclides } \\ \text { Direct contact } & \text { Radionuclides } \\ \text { Direct contact } & \text { Radionuclides } \\ \text { Direct contact } & \text { Radionuclides } \\ \text { Direct contact } & \text { Radionuclides } \\ \text { Direct contact } & \text { Radionuclides } \\ \text { Direct contact } & \text { Radionuclides } \\ \text { Direct contact } & \text { Radionuclides } \\ \text { Direct contact } & \text { Radionuclides } \\ \text { Direct contact } & \text { Radionuclides } \\ \text { Direct contact } & \text { Radionuclides } \\ \text { Direct contact } & \text { Radionuclides } \\ \text { Direct contact } & \text { Radionuclides } \\ \text { DiSO extract } & \end{array}$

DMSO extract

DMSO extract

DMSO extract

DMSO extract

Aqueous extract

Aqueous extract

Aqueous extract

Aqueous extract

DMSO extract

DMSO extract

DMSO extract

DMSO extract

Aqueous extract

Aqueous extract

Aqueous extract
Metals, PAHs

Metals, PAHs

Metals, PAHs

Metals, PAHs

Metals, organics

Metals, organics

Metals, organics

Metals, organics

Metals, organics

Metals, organics

Metals, organics 
Appendix B. (Continued)

\begin{tabular}{|c|c|c|c|c|c|}
\hline \multirow[t]{2}{*}{ Site/sample description ${ }^{\mathrm{a}}$} & \multirow{2}{*}{$\begin{array}{l}\text { Maximum } \\
\text { response observed }\end{array}$} & \multirow[t]{2}{*}{ Exposure medium $^{\mathrm{c}}$} & \multicolumn{2}{|c|}{ Suspected contaminants } & \multirow[t]{2}{*}{ References } \\
\hline & & & Name & $\begin{array}{l}\text { Concentration } \\
(\text { ppm dry weight })^{\mathrm{d}}\end{array}$ & \\
\hline Solid waste landfill & 3.3 & Aqueous extract & Metals, organics & & [283] \\
\hline Solid waste landfill & 2.9 & Aqueous extract & Metals, organics & & [283] \\
\hline \multicolumn{6}{|c|}{ 8.2. Heavily contaminated sites (e.g., hazardous waste landfill, Superfund sites, etc.) } \\
\hline Waste compost & 2.4 & DMSO extract & Metals, organics & & [66] \\
\hline Waste compost & 1.8 & DMSO extract & Metals, organics & & [66] \\
\hline Waste compost & 1.8 & DMSO extract & Metals, organics & & [66] \\
\hline Waste compost & 1.7 & DMSO extract & Metals, organics & & [66] \\
\hline \multicolumn{6}{|l|}{ 8.3. Agricultural sites } \\
\hline Agricultural soil 6 & 7.2 & DMSO extract & Metals, organics & & [67] \\
\hline Agricultural soil 5 & 5.2 & DMSO extract & Metals, organics & & [67] \\
\hline Agricultural soil 4 & 5.1 & DMSO extract & Metals, organics & & [67] \\
\hline Agricultural soil 2 & 3.6 & DMSO extract & Metals, organics & & [67] \\
\hline Agricultural soil 1 & 3.6 & DMSO extract & Metals, organics & & [67] \\
\hline Agricultural soil 3 & 3.4 & DMSO extract & Metals, organics & & [67] \\
\hline Ukrainian soil & 2.4 & Direct contact & & & {$[74]^{\mathrm{k}}$} \\
\hline Ukrainian soil & 2.0 & Direct contact & & & {$[74]^{\mathrm{k}}$} \\
\hline Ukrainian soil & 1.6 & Direct contact & & & {$[74]^{\mathrm{k}}$} \\
\hline Ukrainian soil & 1.5 & Direct contact & & & {$[74]^{\mathrm{k}}$} \\
\hline Ukrainian soil & 0.9 & Direct contact & & & {$[74]^{\mathrm{k}}$} \\
\hline Ukrainian soil & 0.3 & Direct contact & & & {$[74]^{\mathrm{k}}$} \\
\hline Uzbekistan Soil 1 & 3.0 & Direct contact & & & {$[75]^{\mathrm{k}}$} \\
\hline Uzbekistan Soil 2 & 1.6 & Direct contact & & & {$[75]^{\mathrm{k}}$} \\
\hline Uzbekistan Soil 3 & 1.5 & Direct contact & & & {$[75]^{\mathrm{k}}$} \\
\hline Uzbekistan Soil 4 & 1.2 & Direct contact & & & {$[75]^{\mathrm{k}}$} \\
\hline Uzbekistan Soil 5 & 1.5 & Direct contact & & & {$[75]^{\mathrm{k}}$} \\
\hline \multicolumn{6}{|c|}{ 8.4. Reference (control) sites } \\
\hline Karlovka soil & 1.3 & DMSO extract & & & [69] \\
\hline Karlovka soil & 1.2 & Aqueous extract & & & [69] \\
\hline Control soil & 2.3 & Direct contact & & & {$[73]^{j}$} \\
\hline Control soil & 1.9 & Direct contact & & & {$[73]^{\mathrm{j}}$} \\
\hline Control soil & 1.8 & Direct contact & & & {$[73]^{\mathrm{j}}$} \\
\hline Control soil & 1.8 & Direct contact & & & {$[73]^{\mathrm{j}}$} \\
\hline Control soil & 1.7 & Direct contact & & & {$[73]^{\mathrm{j}}$} \\
\hline
\end{tabular}




\begin{tabular}{|c|c|c|c|}
\hline Control soil & 1.7 & Direct contact & {$[73]^{\mathrm{j}}$} \\
\hline Control soil & 1.7 & Direct contact & {$[73]^{\mathrm{j}}$} \\
\hline Control soil & 1.6 & Direct contact & {$[73]^{\mathrm{j}}$} \\
\hline Control soil & 1.6 & Direct contact & {$[73]^{\mathrm{j}}$} \\
\hline Vidor TX & 3.9 & Direct contact & [71] \\
\hline Control soil & 1.3 & Direct contact & [71] \\
\hline Columbia MO & 1.3 & Direct contact & [71] \\
\hline Smelter control 1977 & 3.5 & Direct contact & [70] \\
\hline Smelter control 1977 & 3.4 & Direct contact & [70] \\
\hline Smelter control 1978 & 2.4 & Direct contact & [70] \\
\hline Smelter control 1976 & 2.0 & Direct contact & {$[70]$} \\
\hline Control soil & 3.2 & Direct contact & [70] \\
\hline Control soil & 2.8 & Direct contact & [70] \\
\hline Control soil & 2.6 & Direct contact & [70] \\
\hline Control soil & 2.5 & Direct contact & [70] \\
\hline Control soil & 1.7 & Direct contact & [70] \\
\hline Control soil & 1.7 & Direct contact & [70] \\
\hline
\end{tabular}

${ }^{a}$ Sites are divided into control/reference sites, sites that are primarily agricultural, sites selected for their proximity to large industries, heavily contaminated waste disposal and/or containment sites, and sites containing mutagenic metals of geologic origin.

${ }^{\mathrm{b}}$ Units are as follows: Tradescantia micronucleus assay - micronuclei per 100 tetrads; Vicia faba micronucleus assay — micronuclei per 1000 cells; sister chromatid exchanges in Vicia faba - SCEs per cell; chromosomal aberrations in Allium cepa - total aberrations per 100 cells; stamen hair mutation assay in Tradescantia - mutants per 1000 hairs; waxy mutants in Zea mays — waxy locus mutations in mutants $\times 10^{5}$; Arabidopsis gametic mutations — mutation frequency in $\%$.

${ }^{c}$ Includes aqueous extracts, aqueous leachates, diluted organic extracts, direct contact soil exposures, and exposures to aqueous soil slurries.

d Concentration in the original soil sample, unless otherwise noted.

e Methylisocyanate and related break-down products.

${ }^{\mathrm{f}}$ Reverse mutation at the $w x$-C allele in inbred line W22 unless otherwise noted.

Reverse mutation at the $w x-\mathrm{C}$ or $w x$-90 allele in inbred line M14.

${ }^{\mathrm{h}}$ Forward waxy locus mutation in Early-Early Synthetic variety.

${ }^{i}$ Stamen hair mutations in Tradescantia clone 4430 unless otherwise noted.

j Stamen hair mutations in Tradescantia clone BNL02 (Brookhaven National Laboratory 02).

${ }^{\mathrm{k}}$ Stamen hair mutations in an undescribed isolate of Tradescantia poludosa. 


\section{References}

[1] D. Warshawsky, Environmental sources, carcinogenicity, mutagenicity, metabolism, and DNA binding of nitrogen and sulfur heterocyclic aromatics, J. Environ. Sci. Health C10 (1992) 1-71.

[2] G. Becker, U. Nilsson, A. Colmsjo, C. Ostman, Determination of polycyclic aromatic sulfur heterocyclic compounds in airborne particulate by gas chromatography with atomic emission and mass spectrometric detection, J. Chromatogr. A 826 (1998) 57-66.

[3] G. Grimmer, F. Pott, Occurrence of PAHs, in: G. Grimmer (Ed.), Environmental Carcinogens, Polycyclic Aromatic Hydrocarbons: Chemistry, Occurrence, Biochemistry, Carcinogenicity, CRC Press, Boca Raton, FL, 1983, pp. 61-129.

[4] K.C. Donnelly, C.S. Anderson, G.C. Barbee, D.J. Manek, Soil toxicology, in: L.G. Cockerham, B.S. Shane (Eds.), Basic Environmental Toxicology, CRC Press, Boca Raton, FL, 1994, pp. 321-352.

[5] D. Winegardner, An Introduction to Soils for Environmental Professionals, CRC Press LLC, Boca Raton, FL, 1995, pp. 270.

[6] C. Brady, The Nature and Properties of Soils, eighth ed. Macmillan Publishing Co., Inc., New York, NY, 1974, pp. 639.

[7] J. Dragun, The Soil Chemistry of Hazardous Materials, Amherst Scientific Publishers, Amherst, MA, 1998, pp. 862.

[8] W. Stumm, Chemistry of the Solid-Water Interface. Processes at the Mineral-Water and Particle-Water Interface in Natural Systems, John Wiley and Sons Inc., New York, NY, 1992, pp. 448.

[9] R. Young, A. Mohamed, B. Warkentin, Principles of Contaminant Transport in Soils, Elsevier, Amsterdam, The Netherlands, 1992, pp. 328.

[10] B. Yaron, Soil Pollution-Processes Dynamics, Springer Verlag, Heidelberg, Germany, 1996, pp. 320.

[11] C. Menzie, R. Efroymson, S. Ells, G. Henningsen, B. Hope, Risk assessment and risk management, in: R. Lanno (Ed.), Contaminated Soils: From Soil-Chemical Interactions to Ecosystem Management, SETAC Press, Pensacola, FL, 2003, pp. 11-72.

[12] R. Gilbert, Statistical Methods for Environmental Pollution Monitoring, John Wiley and Sons, Hoboken, NJ, 1997, pp. 336.

[13] B. Mason, Preparation of Soil Sampling Protocols: Sampling Techniques and Strategies, Environmental Monitoring Systems Laboratory, US Environmental Protection Agency, Las Vegas, NV, 1992, p. 169.

[14] W. Cochran, Sampling Techniques, John Wiley and Sons, New York, 1977, pp. 427.

[15] J. Boulding, Description and Sampling of Contaminated Soils. A Field Guide, CRC Press LLC, Boca Raton, FL, 1994, pp. 150

[16] United States Environmental Protection Agency (USEPA), Description and Sampling of Contaminated Soils: A Field Pocket Guide, Environmental Monitoring Systems Laboratory, US Environmental Protection Agency, Las Vegas, NV, 1991
[17] American Society for Testing Materials (ASTM), ASTM Standards Related to the Phase II Environmental Site Assessment Process, ASTM International, West Conshohocken, PA, 2001, pp. 320.

[18] American Society for Testing Materials (ASTM), ASTM Standards Related to Environmental Site Characterization, ASTM International, West Conshohocken, PA, 2002, pp. 1827.

[19] V. Houk, The genotoxicity of industrial wastes and effluents. A review, Mutat. Res. 277 (1992) 91-138.

[20] A. Brouwer, A. Murk, J. Koeman, Biochemical and physiological approaches in ecotoxicology, Funct. Ecol. 4 (1990) 275-281.

[21] J. Lewtas, Complex mixtures of air pollutants: characterizing the cancer risk of polycyclic organic matter, Environ. Health Perspect. 100 (1993) 211-218.

[22] L.R. Brooks, T.J. Hughes, L.D. Claxton, B. Austern, R. Brenner, F. Kremer, Bioassay-directed fractionation and chemical identification of mutagens in bioremediated soils, Environ. Health Perspect. 106 (Suppl. 6) (1998) 1435-1440.

[23] C.H. Marvin, L. Allan, B.E. McCarry, D.W. Bryant, Chemico/biological investigation of contaminated sediment from the Hamilton Harbour area of western Lake Ontario, Environ. Mol. Mutagen. 22 (1993) 61-70.

[24] P.A. White, J.B. Rasmussen, C. Blaise, Genotoxic substances in the St. Lawrence system. II. Genotoxic substances in fish and macroinvertebrates from the St. Lawrence and Saguenay rivers (Canada), Environ. Toxicol. Chem. 17 (1998) 304-316.

[25] P.A. White, J.B. Rasmussen, C. Blaise, Genotoxic substances in the St. Lawrence system. I. Industrial genotoxins sorbed to particulate matter in the St. Lawrence, St. Maurice, and Saguenay Rivers, Canada, Environ. Toxicol. Chem. 17 (1998) 286-303.

[26] D. DeMarini, Environmental mutagens/complex mixtures, in: A. Li, R. Heflich (Eds.), Genetic Toxicology, CRC Press, Boca Raton, FL, 1991, pp. 285-302.

[27] L. Claxton, The integration of bioassay and physiochemical information for complex mixtures, in: M. Waters, S. Sandhu, J. Lewtas, L. Claxton, N. Chernoff, S. Nesnow (Eds.), Shortterm Bioassays in the Analysis of Complex Environmental Mixtures III, Plenum Press, New York, NY, 1983, pp. 153162.

[28] L. Claxton, The development, validation, and analysis of Salmonella mutagenicity test methods for environmental situations, in: P. Wells, K. Lee, C. Blaise (Eds.), Microscale Testing in Aquatic Toxicology. Advances, Techniques, and Practice, CRC Press, Boca Raton, FL, 1997, pp. 591-606.

[29] L. Claxton, S. George, Challenges and approaches for identifying carcinogens in contaminated media, in: G. Sunahara, A. Renoux, C. Thellen, A. Pilon (Eds.), Environmental Analysis of Contaminated Sites, John Wiley \& Sons, West Sussex, UK, 2002, pp. 73-93.

[30] I. Alfheim, A. Bjørseth, M. Møller, Characterizations of microbial mutagens in complex samples-methodology and applications, CRC Crit. Rev. Environ. Control 14 (1984) 91-150. 
[31] J. Lewtas, Genotoxicity of complex mixtures: strategies for the identification and comparative assessment of airborne mutagens and carcinogens from combustion sources, Fundam. Appl. Toxicol. 10 (1988) 571-589.

[32] G.C. Balch, C.D. Metcalfe, S.Y. Huestis, Identification of potential fish carcinogens in sediment from Hamilton Harbour, Ontario, Canada, Environ. Toxicol. Chem. 14 (1995) 79-91.

[33] K. Mortelmans, E. Zeiger, The Ames Salmonella/microsome mutagenicity assay, Mutat. Res. 455 (2000) 29-60.

[34] B.N. Ames, J. McCann, E. Yamasaki, Methods for detecting carcinogens and mutagens with the Salmonella/mammalianmicrosome mutagenicity test, Mutat. Res. 31 (1975) 347364.

[35] B. Ames, F. Lee, W.D. Durston, An improved bacterial system for the detection and classification of mutagens and carcinogens, Proc. Natl. Acad. Sci. U.S.A. 70 (1973) 782786.

[36] D. Maron, B.N. Ames, Revised methods for the Salmonella mutagenicity test, Mutat. Res. 113 (1983) 173-215.

[37] R. Heflich, Chemical mutagens, in: A. Li, R. Heflich (Eds.), Genetic Toxicology, CRC Press, Boca Raton, FL, 1991, pp. 285-302.

[38] M.G. Zemanek, S.J. Pollard, S.L. Kenefick, S.E. Hrudey, Toxicity and mutagenicity of component classes of oils isolated from soils at petroleum- and creosote-contaminated sites, J. Air Waste Manage. Assoc. 47 (1997) 1250-1258.

[39] K.C. Jones, E.A. Peace, The Ames mutagenicity assay applied to a range of soils, Chemosphere 18 (1989) 16571664.

[40] K.W. Brown, K.C. Donnelly, J.C. Thomas, P. Davol, B.R. Scott, Mutagenicity of three agricultural soils, Sci. Total Environ. 41 (1985) 173-186.

[41] D.M. DeMarini, V.S. Houk, A. Kornel, C.J. Rogers, Effect of a base-catalyzed dechlorination process on the genotoxicity of PCB-contaminated soil, Chemosphere 24 (1992) 17131720.

[42] K.C. Donnelly, P. Davol, K.W. Brown, M. Estiri, J.C. Thomas, Mutagenic activity of two soils amended with a woodpreserving waste, Environ. Sci. Technol. 21 (1987) 57-64.

[43] L.A. Maggard, K.W. Brown, K.C. Donnelly, The efficiency of two standardized procedures for extracting mutagenic chemicals from soils, Chemosphere 16 (1987) 1243-1255.

[44] T.J. Hughes, L.D. Claxton, L. Brooks, S. Warren, R. Brenner, F. Kremer, Genotoxicity of bioremediated soils from the Reilly Tar site, St. Louis Park, Minnesota, Environ. Health Perspect. 106 (Suppl. 6) (1998) 1427-1433.

[45] K.C. Donnelly, S.H. Safe, K. Randerath, E. Randerath, Bioassay-based risk assessment of complex mixtures, J. Hazard Mater. 41 (1995) 341-350.

[46] A.E. McDaniels, A.L. Reyes, L.J. Wymer, C.C. Rankin, G.N. Stelma, Genotoxic activity detected in soils from a hazardous waste site by the Ames test and the SOS Chromotest, Environ. Mol. Mutagen. 22 (1993) 115-122.

[47] K.C. Donnelly, K.W. Brown, C.S. Anderson, J.C. Thomas, B.R. Scott, Bacterial mutagenicity and acute toxicity of solvent and aqueous extracts of soil samples from an aban- doned chemical manufacturing site, Environ. Toxicol. Chem. 10 (1991) 1123-1132.

[48] P. Davol, K.C. Donnelly, K.W. Brown, J.C. Thomas, M. Estiri, D.H. Jones, Mutagenic potential of runoff water from soils amended with three hazardous industrial wastes, Environ. Toxicol. Chem. 8 (1989) 189-200.

[49] K. Brown, K. Donnelly, J. Thomas, Use of Short-term Bioassays to Evaluate Environmental Impact of Land Treatment of Hazardous Industrial Waste, US EPA Robert S. Kerr Environmental Research Laboratory, Ada, OK, 1984, pp. 357.

[50] T. Watanabe, T. Hasei, Y. Takahashi, S. Otake, T. Murahashi, T. Takamura, T. Hirayama, K. Wakabayashi, Mutagenic activity and quantification of nitroarenes in surface soil in the Kinki region of Japan, Mutat. Res. 538 (2003) 121-131.

[51] T. Watanabe, S. Goto, Y. Matsumoto, M. Asanoma, T. Hirayama, N. Sera, Y. Takahashi, O. Endo, S. Sakai, K. Wakabayashi, Mutagenic activity of surface soil and quantification of 1,3-1,6-, and 1,8-dinitropyrene isomers in soil in Japan, Chem. Res. Toxicol. 13 (2000) 281-286.

[52] T. Watanabe, T. Hirayama, Genotoxicity of soil, J. Health Sci. 47 (2001) 433-438.

[53] S. Goto, O. Endo, Y. Matsumoto, S. Sakai, T. Akutagawa, M. Asanoma, T. Hirayama, T. Watanabe, N. Sera, H. Tsukatani, A. Tada, K. Wakabayashi, Mutagenicity of airborne particle, river water and soil in Japan, Environ. Mutagen. Res. 22 (2000) 45-54.

[54] K.C. Donnelly, K.W. Brown, C.S. Giam, B.R. Scott, Acute and genetic toxicity of extracts of munitions wastewater contaminated soils, Chemosphere 27 (1993) 1439-1450.

[55] R. Edenharder, M. Ortseifen, M. Koch, H.F. Wesp, Soil mutagens are airborne mutagens: variation of mutagenic activities induced in Salmonella typhimurium TA 98 and TA 100 by organic extracts of agricultural and forest soils in dependence on location and season, Mutat. Res. 472 (2000) 23-36.

[56] S. Garcia, K. Donnelly, Genotoxicity analysis of contaminated environmental media, in: G. Sunahara, A. Renoux, C. Thellen, C. Gaudet, A. Pilon (Eds.), Environmental Analysis of Contaminated Sites, John Wiley \& Sons, Inc., Hoboken, NJ, 2002, pp. 490.

[57] W. Göggelmann, P. Spitzauer, Mutagenic activity in agricultural soils, in: H.F. Stich (Ed.), Carcinogens and Mutagens in the Environment: 3. Naturally Occurring Compounds: Epidemiology and Distribution, CRC Press, Boca Raton, FL, 1983, pp. 177-183.

[58] M.G. Knize, B.T. Takemoto, P.R. Lewis, J.S. Felton, The characterization of the mutagenic activity of soil, Mutat. Res. 192 (1987) 23-30.

[59] I.S. Morelli, G.I. Vecchioli, M.T. Del Panno, M.T. Painceira, Effect of petrochemical sludge concentrations of changes in mutagenic activity during soil bioremediation process, Environ. Toxicol. Chem. 20 (2001) 2179-2183.

[60] A. Aleem, A. Malik, Genotoxic hazards of long-term application of wastewater on agricultural soil, Mutat. Res. 538 (2003) 145-154. 
[61] H.J. Kool, C.F. van Kreyl, S. Persad, Mutagenic activity in groundwater in relation to mobilization of organic mutagens in soil, Sci. Total Environ. 84 (1989) 185-199.

[62] L. Lopez, J. Moretton, Study of the genotoxicity of environmental complex mixtures with two bacterial tests, Rev. Argent Microbiol. 28 (1996) 1-8.

[63] S. Monarca, D. Feretti, I. Zerbini, A. Alberti, C. Zani, S. Resola, U. Gelatti, G. Nardi, Soil contamination detected using bacterial and plant mutagenicity tests and chemical analyses, Environ. Res. 88 (2002) 64-69.

[64] G.C. Barbee, K.W. Brown, K.C. Donnelly, Fate of mutagenic chemicals in soil amended with petroleum and wood preserving sludges, Waste Manage. Res. 10 (1992) 73-85.

[65] L. Berthe-Corti, H. Jacobi, S. Kleihauer, I. Witte, Cytotoxicity and mutagenicity of a 2,4,6-trinitrotoluene (TNT) and hexogen contaminated soil in S. typhimurium and mammalian cells, Chemosphere 37 (1998) 209-218.

[66] G.L. Cabrera, D.M. Rodriguez, A.B. Maruri, Genotoxicity of the extracts from the compost of the organic and the total municipal garbage using three plant bioassays, Mutat. Res. 426 (1999) 201-206.

[67] G.L. Cabrera, D.M. Rodriguez, Genotoxicity of soil from farmland irrigated with wastewater using three plant bioassays, Mutat. Res. 426 (1999) 211-214.

[68] K. Chroust, P. Kuglik, J. Relichova, I. Holoubek, J. Caslavsky, R. Veselska, M. Ryskova, J. Benedik, Drosophila melanogaster, Vicia faba and Arabidopsis thaliana short-term bioassays in genotoxicity evaluation of air and soil samples from sites surrounding two industrial factories in the Czech Republic, Folia Biol Praha 43 (1997) 71-78.

[69] T. Gichner, J. Velemínsky, Monitoring the genotoxicity of soil extracts from two heavily polluted sites in Prague using the Tradescantia stamen hair and micronucleus (MNC) assays, Mutat. Res. 426 (1999) 163-166.

[70] W.R. Lower, W.A. Thompson, V.K. Drobney, A.F. Yanders, Mutagenicity in the vicinity of a lead smelter, Teratog. Carcinog. Mutagen. 3 (1983) 231-253.

[71] W.R. Lower, V.K. Drobney, B.J. Aholt, R. Politte, Mutagenicity of the environments in the vicinity of an oil refinery and a petrochemical complex, Teratog. Carcinog. Mutagen. 3 (1983) 65-73.

[72] M.J. Plewa, Genetic assays of maize for environmental pollution control, in: F. Zimmermann, R. TaylorMayer (Eds.), Mutagenicity Testing in Environmental Pollution Control, Ellis Horwood, Chichester, UK, 1985, pp. 147 165.

[73] S. Ichikawa, C. Ishii, Somatic mutation frequencies in the stamen hairs of Tradescantia grown in soil samples from the Bikini Island, Jpn. J. Genet. 66 (1991) 27-40.

[74] A.I. Kurinnyi, E.S. Zubko, A.P. Kravchuk, A comparative ecological-genetic assessment of the mutagenic background in 2 agricultural districts of the Transcarpathian Province, Tsitol Genet. 27 (1993) 13-18.

[75] A.I. Kurinnyi, A.P. Kravchuk, E.S. Zubko, An evaluation of the mutagenic background and mutational variability of the population in a region with a high intensity of pesticide use, Tsitol Genet. 27 (1993) 82-86.

[76] S. Knasmüller, E. Gottmann, H. Steinkellner, A. Fomin, C. Pickl, A. Paschke, R. Göd, M. Kundi, Detection of genotoxic effects of heavy metal contaminated soils with plant bioassays, Mutat. Res. 420 (1998) 1-3.

[77] B.J. Majer, D. Tscherko, A. Paschke, R. Wennrich, M. Kundi, E. Kandeler, S. Knasmüller, Effects of heavy metal contamination of soils on micronucleus induction in Tradescantia and on microbial enzyme activities: a comparative investigation, Mutat. Res. 515 (2002) 111-124.

[78] B. Gill, S. Sandhu, L. Backer, B. Casto, Application of a plant test system in the identification of potential genetic hazards at chemical waste sites, in: J.W. Gorsuch, W.R. Lower, W. Wang, M.A. Lewis (Eds.), Plants for Toxicity Assessment, vol. 2, American Society for Testing and Materials, Philadelphia, PA, 1991, pp. 309-317.

[79] K. Jain, J. Singh, L.K. Chauhan, R.C. Murthy, S.K. Gupta, Modulation of flyash-induced genotoxicity in Vicia faba by vermicomposting, Ecotoxicol. Environ. Saf. 59 (2004) 8994.

[80] S. Chandra, L.K. Chauhan, P.N. Pande, S.K. Gupta, Cytogenetic effects of leachates from tannery solid waste on the somatic cells of Vicia faba, Environ. Toxicol. 19 (2004) 129133.

[81] A. Fomin, A. Paschke, U. Arndt, Assessment of the genotoxicity of mine-dump material using the Tradescantia-stamen hair (Trad-SHM) and the Tradescantia-micronucleus (Trad-MCN) bioassays, Mutat. Res. 426 (1999) 173181.

[82] H. Wang, Clastogenicity of chromium contaminated soil samples evaluated by Vicia root-micronucleus assay, Mutat. Res. 426 (1999) 147-149.

[83] S. Cotelle, J.-F. Masfaraud, J.-F. Férard, Assessment of the genotoxicity of contaminated soil with the Allium/Viciamicronucleus and the Tradescantia-micronucleus assays, Mutat. Res. 426 (1999) 167-171.

[84] G.S. Rodrigues, D. Pimentel, L.H. Weinstein, In situ assessment of pesticide genotoxicity in an integrated pest management program. II. Maize waxy mutation assay, Mutat. Res. 412 (1998) 245-250.

[85] G.S. Rodrigues, D. Pimentel, L.H. Weinstein, In situ assessment of pesticide genotoxicity in an integrated pest management program. I. Tradescantia micronucleus assay, Mutat. Res. 412 (1998) 235-244.

[86] R.G. Stahl, The genetic toxicology of organic compounds in natural waters and wastewaters, Ecotoxicol. Environ. Saf. 22 (1991) 94-125.

[87] P.A. White, The genotoxicity of priority polycyclic aromatic hydrocarbons in complex mixtures, Mutat. Res. 515 (2002) 85-98.

[88] C. Békaert, V. Ferrier, J. Marty, A. Pfohl-Leszkowicz, A. Bispo, M.J. Jourdain, M. Jauzein, L. Lambolez-Michel, H. Billard, Evaluation of toxic and genotoxic potential of stabilized industrial waste and contaminated soils, Waste Manage. 22 (2002) 241-247. 
[89] P. Chenon, L. Gauthier, P. Loubieres, A. Severac, M. Delpoux, Evaluation of the genotoxic and teratogenic potential of a municipal sludge and sludge-amended soil using the amphibian Xenopus laevis and the tobacco: Nicotiana tabacum L. var. xanthi Dulieu, Sci. Total Environ. 301 (2003) 139-150.

[90] R.R. Alexander, J. Tang, M. Alexander, Genotoxicity is unrelated to total concentration of priority carcinogenic polycyclic aromatic hydrocarbons in soils undergoing biological treatment, J. Environ. Qual. 31 (2002) 150-154.

[91] T.H. Ma, G.L. Cabrera, A. Cebulska-Wasilewska, R. Chen, F. Loarca, A.L. Vandenberg, M.F. Salamone, Tradescantia stamen hair mutation bioassay, Mutat. Res. 310 (1994) 211-220.

[92] U. Graf, H. Frei, A. Kagi, A.J. Katz, F.E. Wurgler, Thirty compounds tested in the Drosophila wing spot test, Mutat. Res. 222 (1989) 359-373.

[93] A.W. Hsie, D.A. Casciano, D.B. Couch, D.F. Krahn, J.P. O'Neill, B.L. Whitfield, The use of Chinese hamster ovary cells to quantify specific locus mutation and to determine mutagenicity of chemicals. A report of the gene-tox program, Mutat. Res. 86 (1981) 193-214.

[94] W. Gajewski, J. Litwinska, Methionine loci and their suppressors in Aspergillus nidulans, Mol. Gen. Genet. 102 (1968) 210-220.

[95] L.J. Lilly, An investigation of the suitability of the suppressors of meth 1 in Aspergillus nidulans for the study of induced and spontaneous mutation, Mutat. Res. 2 (1965) 192-195.

[96] F.K. Zimmermann, R.C. von Borstel, E.S. von Halle, J.M. Parry, D. Siebert, G. Zetterberg, R. Barale, N. Loprieno, Testing of chemicals for genetic activity with Saccharomyces cerevisiae: a report of the US Environmental Protection Agency Gene-Tox Program, Mutat. Res. 133 (1984) 199-244.

[97] F.J. Couch, Genetic epidemiology of BRCA1, Cancer Biol. Ther. 3 (2004) 509-514.

[98] M. Olivier, S.P. Hussain, C. Caron de Fromentel, P. Hainaut, C.C. Harris, TP53 mutation spectra and load: a tool for generating hypotheses on the etiology of cancer, IARC Sci. Publ. 157 (2004) 247-270.

[99] V. Bataille, Genetic epidemiology of melanoma, Eur. J. Cancer 39 (2003) 1341-1347.

[100] S. Narayan, D. Roy, Role of APC and DNA mismatch repair genes in the development of colorectal cancers, Mol. Cancer 2 (2003) 41.

[101] H. Norppa, Cytogenetic biomarkers and genetic polymorphisms, Toxicol. Lett. 149 (2004) 309-334.

[102] L. Hagmar, U. Stromberg, H. Tinnerberg, Z. Mikoczy, Epidemiological evaluation of cytogenetic biomarkers as potential surrogate end-points for cancer, IARC Sci. Publ. 157 (2004) 207-215.

[103] B.J. Majer, B. Laky, S. Knasmuller, F. Kassie, Use of the micronucleus assay with exfoliated epithelial cells as a biomarker for monitoring individuals at elevated risk of genetic damage and in chemoprevention trials, Mutat. Res. 489 (2001) 147-172.

[104] M. Bilban, Mutagenic testing of workers exposed to toluenediisocyanates during plastics production process, Am. J. Ind. Med. 45 (2004) 468-474.
[105] S.M. Galloway, M.J. Armstrong, C. Reuben, S. Colman, B. Brown, C. Cannon, A.D. Bloom, F. Nakamura, M. Ahmed, S. Duk, et al. Chromosome aberrations and sister chromatid exchanges in Chinese hamster ovary cells: evaluations of 108 chemicals, Environ. Mol. Mutagen. 10 (Suppl. 10) (1987) $1-175$.

[106] S. Bonassi, C. Lando, M. Ceppi, S. Landi, A.M. Rossi, R. Barale, No association between increased levels of highfrequency sister chromatid exchange cells (HFCs) and the risk of cancer in healthy individuals, Environ. Mol. Mutagen. 43 (2004) 134-136.

[107] T. Kada, K. Tutikawa, Y. Sadaie, In vitro and host-mediated "rec-assay" procedures for screening chemical mutagens; and phloxine, a mutagenic red dye detected, Mutat. Res. 16 (1972) 165-174.

[108] T. Kada, K. Tutikawa, Y. Sadaie, In vitro and host-mediated "rec-assay" procedures for screening chemical mutagens; and phloxine, a mutagenic red dye detected, Mutat. Res. 16 (1972) 165-174.

[109] P. Quillardet, O. Huisman, R. D’Ari, M. Hofnung, SOS chromotest, a direct assay of induction of an SOS function in Escherichia coli K-12 to measure genotoxicity, Proc. Natl. Acad. Sci. U.S.A. 79 (1982) 5971-5975.

[110] P. Quillardet, M. Hofnung, The SOS Chromotest, a colorimetric bacterial assay for genotoxins, procedures, Mutat. Res. 147 (1985) 65-78.

[111] Y. Oda, S. Nakamura, I. Oki, T. Kato, H. Shinagawa, Evaluation of the new system (umu-test) for the detection of environmental mutagens and carcinogens, Mutat. Res. 147 (1985) 219-229.

[112] T.G. Rossman, M. Molina, L.W. Meyer, The genetic toxicology of metal compounds. I. Induction of lambda prophage in E. coli WP2s(lambda), Environ. Mutagen. 6 (1984) 59-69.

[113] K.C. Jones, J.A. Stratford, K.S. Waterhouse, N.B. Vogt, Organic contaminants in Welsh soils: polynuclear aromatic hydrocarbons, Environ. Sci. Technol. 23 (1989) 540-550.

[114] K.C. Donnelly, J.C. Thomas, K.W. Brown, Mutagenic potential of environmental samples before and after remediation of a solvent-contaminated site, Environ. Toxicol. Chem. 14 (1995) 1281-1286.

[115] K.C. Donnelly, C.S. Anderson, J.C. Thomas, K.W. Brown, D.J. Manek, S.H. Safe, Bacterial mutagenicity of soil extracts from a bioremediation facility treating wood-preserving waste, J. Hazard. Mater. 30 (1992) 71-81.

[116] H.F. Wesp, X. Tang, R. Edenharder, The influence of automobile exhausts on mutagenicity of soils: contamination with, fractionation, separation, and preliminary identification of mutagens in the Salmonella/reversion assay and effects of solvent fractions on the sister-chromatid exchanges in human lymphocyte cultures and in the in vivo mouse bone marrow micronucleus assay, Mutat. Res. 472 (2000) 1-21.

[117] K.C. Donnelly, K.W. Brown, D.G. Di Giullio, Mutagenic characterization of soil and water samples from a Superfund site, Nucl. Chem. Waste Manage. 8 (1988) 135-142.

[118] K.C. Donnelly, K.W. Brown, K.V. Markiewicz, C.S. Anderson, D.J. Manek, J.C. Thomas, C.S. Giam, The use of short- 
term bioassays to evaluate the health and environmental risk posed by an abandoned coal gasification site, Hazard. Waste Hazard. Mater. 10 (1993) 59-70.

[119] K. Arashidani, T. Someya, M. Yoshikawa, Y. Kodama, Polynuclear aromatic hydrocarbon concentration and mutagenic activity in soils sampled at the roadsides, J. Jpn. Soc. Air Pollut. 27 (1992) 190-197.

[120] S. Baud-Grasset, F. Baud-Grasset, J.M. Bifulco, J.R. Meier, T.H. Ma, Reduction of genotoxicity of a creosote-contaminated soil after fungal treatment determined by the Tradescantia-micronucleus test, Mutat. Res. 303 (1993) 77-82.

[121] W. Aprill, R.C. Sims, J.L. Sims, J.E. Matthews, Assessing detoxification and degradation of wood preserving and petroleum wastes in contaminated soil, Waste Manage. Res. 8 (1990) 45-65.

[122] H. Tsukatani, Y. Tanaka, N. Sera, N. Shimizu, S. Kitamori, N. Inoue, Mutagenic activity in roadside soils, J. Toxicol. Sci. 27 (2002) 183-189.

[123] L.H. Keith, W.A. Telliard, Priority pollutants. I. A perspective view, Environ. Sci. Technol. 13 (1979) 416-423.

[124] T. Watanabe, S. Ishida, H. Minami, T. Kasai, S. Ogawa, K. Wakabayashi, T. Hirayama, Identification of 1,6- and 1,8dinitropyrene isomers as major mutagens in organic extracts of soil from Osaka, Japan, Chem. Res. Toxicol. 11 (1998) 1501-1507.

[125] SAS Institute, The SAS System for Windows Release 8.02, SAS Institute, Cary, NC, 2000.

[126] D. Gujarati, Basic Econometrics, McGraw-Hill Inc., New York, NY, 1988, pp. 705.

[127] SAS Institute, SAS/STAT User's Guide, Version 6, fourth ed., SAS Institute, Cary, NC, 1989, pp. 1686.

[128] J. Neter, W. Wasserman, M. Kutner, Applied Linear Statistical Models. Regression, Analysis of Variance, and Experimental Designs, Richard D. Irwin, Inc., Boston, MA, 1990, pp. 1181.

[129] D.M. DeMarini, Mutation spectra of complex mixtures, Mutat. Res. 411 (1998) 11-18.

[130] D.M. DeMarini, Induction of mutation spectra by complex mixtures: approaches, problems, and possibilities, Environ. Health Perspect. 102 (Suppl. 4) (1994) 127-130.

[131] J. Lewtas, L.D. Claxton, H.S. Rosenkranz, D. Schuetzle, M. Shelby, H. Matsushita, F.E. Wurgler, F.K. Zimmermann, G. Lofroth, W.E. May, et al. Design and implementation of a collaborative study of the mutagenicity of complex mixtures in Salmonella typhimurium, Mutat. Res. 276 (1992) 3-9.

[132] L.D. Kier, D.J. Brusick, A.E. Auletta, E.S. Von Halle, M.M. Brown, V.F. Simmon, V. Dunkel, J. McCann, K. Mortelmans, L.E. Kier, et al. The Salmonella typhimurium/mammalian microsomal assay. A report of the US Environmental Protection Agency Gene-Tox Program, Mutat. Res. 168 (1986) 69240.

[133] M. Waters, L. Claxton, H. Stack, T. Graedel, Genetic activity profiles - application in assessing potential carcinogenicity of complex environmental mixtures, in: H. Vainio, M. Sorsa, A. McMichael (Eds.), Complex Mixtures and Cancer Risk, International Agency for Research on Cancer, Lyon, France, 1990, pp. 75-88.
[134] M. Sakai, D. Yoshida, S. Mizusaki, Mutagenicity of polycyclic aromatic hydrocarbons and quinones on Salmonella typhimurium TA97, Mutat. Res. 156 (1985) 61-67.

[135] M. Moller, I. Alfheim, Mutagenicity and PAH-analysis of airborne particulate matter, Atmos. Environ. 14 (1980) 8388.

[136] M. Moller, I. Hagen, T. Ramdahl, Mutagenicity of polycyclic aromatic compounds (PAC) identified in source emissions and ambient air, Mutat. Res. 157 (1985) 149-156.

[137] T. Sugimura, S. Takayama, Biological actions of nitroarenes in short-term tests on Salmonella, cultured mammalian cells and cultured human tracheal tissues: possible basis for regulatory control, Environ. Health Perspect. 47 (1983) 171176.

[138] H. Tokiwa, Y. Ohnishi, Mutagenicity and carcinogenicity of nitroarenes and their sources in the environment, Crit. Rev. Toxicol. 17 (1986) 23-60.

[139] T. Ohe, Quantification of mutagenic/carcinogenic heterocyclic amines, MeIQx, Trp-P-1, Trp-P-2 and PhIP, contributing highly to genotoxicity of river water, Mutat. Res. 393 (1997) 73-79.

[140] D.M. DeMarini, M.L. Shelton, J.G. Levine, Mutation spectrum of cigarette smoke condensate in Salmonella: comparison to mutations in smoking-associated tumors, Carcinogenesis 16 (1995) 2535-2542.

[141] K. Wakabayashi, I.S. Kim, R. Kurosaka, Z. Yamaizumi, H. Ushiyama, M. Takahashi, S. Koyota, A. Tada, H. Nukaya, S. Goto, et al. Identification of new mutagenic heterocyclic amines and quantification of known heterocyclic amines, Princess Takamatsu Symp. 23 (1995) 39-49.

[142] R.A. Pelroy, D.L. Stewart, Y. Tominaga, M. Iwao, R.N. Castle, M.L. Lee, Microbial mutagenicity of 3- and 4-ring polycyclic aromatic sulfur heterocycles, Mutat. Res. 117 (1983) 31-40.

[143] C.H. Marvin, B.E. McCarry, J. Villella, L.M. Allan, D.W. Bryant, Chemical and biological profiles of sediments as indicators of sources of genotoxic contamination in Hamilton Harbour. Part I. Analysis of polycyclic aromatic hydrocarbons and thia-arene compounds, Chemosphere 41 (2000) 979-988.

[144] A. Oguri, T. Shiozawa, Y. Terao, H. Nukaya, J. Yamashita, T. Ohe, H. Sawanishi, T. Katsuhara, T. Sugimura, K. Wakabayashi, Identification of a 2-phenylbenzotriazole (PBTA)-type mutagen, PBTA-2, in water from the Nishitakase River in Kyoto, Chem. Res. Toxicol. 11 (1998) 1195-1200.

[145] T. Shiozawa, K. Suyama, K. Nakano, H. Nukaya, H. Sawanishi, A. Oguri, K. Wakabayashi, Y. Terao, Mutagenic activity of 2-phenylbenzotriazole derivatives related to a mutagen, PBTA-1, in river water, Mutat. Res. 442 (1999) 105-111.

[146] K.C. Donnelly, K.W. Brown, D. Kampbell, Chemical and biological characterization of hazardous industrial waste. I. Prokaryotic bioassays and chemical analysis of a woodpreserving bottom-sediment waste, Mutat. Res. 180 (1987) 31-42. 
[147] K. Malachova, Using short-term mutagenicity tests for the evaluation of genotoxicity of contaminated soils, J. Soil Contam. 8 (1999) 667-680.

[148] S. Litten, J.G. Babish, M. Pastel, M.B. Werner, B. Johnson, Relationship between fluorescence of polynuclear aromatic hydrocarbons in complex environmental mixtures and sample mutagenicity, Bull. Environ. Contam. Toxicol. 28 (1982) $141-148$

[149] O. Ivanchenko, O. Il'inskaya, N. Karamova, I. Kostyukevich, Mutagen potential as a complex index of soil contamination by oil-products, Pochvovedenie 11 (1996) 1394-1398.

[150] O.B. Ivanchenko, O.N. Il'inskaya, N.S. Karamova, I. Kostyukevich, Mutagenic potential as an integral index of soil pollution by oil components, Eurasian Soil Sci. 29 (1996) 1300-1304.

[151] L. Cizmas, R. Barhoumi, R.C. Burghardt, W.R. Reeves, L. He, T.J. McDonald, K.C. Donnelly, A comparison of two methods for fractionating complex mixtures in preparation for toxicity analysis, J. Toxicol. Environ. Health A 66 (2003) 1351-1370.

[152] S. Engl, M.J. Plewa, P.K. Hopke, Analysis of the genotoxicity of municipal sewage sludge extracts with sister chromatid exchange in cultured human lymphocytes, Water Air Soil Pollut. 42 (1988) 117-128.

[153] K. Malachova, D. Lednicka, L. Dobias, Bacterial assays of mutagenicity in estimating the effectiveness of biological decontamination of soils, Biologia 53 (1998) 699-704.

[154] W. Blodgett, Water-soluble mutagen production during the bioremediation of oil-contaminated soil, Florida Sci. 60 (1997) 28-36.

[155] S. Sato, A. Matsumura, Y. Urushigawa, M. Metwally, S. AlMuzaini, Type analysis and mutagenicity of petroleum oil extracted from sediment and soil samples in Kuwait, Environ. Int. 24 (1998) 67-76.

[156] K.C. Donnelly, K.W. Brown, J.C. Thomas, Mutagenic potential of municipal sewage sludge amended soils, Water Air Soil Pollut. 48 (1989) 435-450.

[157] X. Wang, X. Yu, R. Bartha, Effect of bioremediation on polycyclic aromatic hydrocarbon residues in soil, Environ. Sci. Technol. 24 (1990) 1086-1089.

[158] W.H. Griest, A.J. Stewart, R.L. Tyndall, J.E. Caton, C.H. Ho, K.S. Ironside, W.M. Caldwell, E. Tan, Chemical and toxicological testing of composted explosives-contaminated soil, Environ. Toxicol. Chem. 12 (1993) 1105-1116.

[159] B. Lachance, P.Y. Robidoux, J. Hawari, G. Ampleman, S. Thiboutot, G.I. Sunahara, Cytotoxic and genotoxic effects of energetic compounds on bacterial and mammalian cells in vitro, Mutat. Res. 444 (1999) 25-39.

[160] S.E. George, G. Huggins-Clark, L.R. Brooks, Use of a Salmonella microsuspension bioassay to detect the mutagenicity of munitions compounds at low concentrations, Mutat. Res. 490 (2001) 45-56.

[161] International Agency for Research on Cancer (IARC), Occupational Exposures in Petroleum Refining; Crude Oil and Major Petroleum Fuels, IARC Press, Lyon, France, 1989,pp. 322.
[162] G.R. Blackburn, R.A. Deitch, C.A. Schreiner, C.R. Mackerer, Predicting carcinogenicity of petroleum distillation fractions using a modified Salmonella mutagenicity assay, Cell. Biol. Toxicol. 2 (1986) 63-84.

[163] R.H. McKee, R.T. Plutnick, R.T. Przygoda, The carcinogenic initiating and promoting properties of a lightly refined paraffinic oil, Fundam. Appl. Toxicol. 12 (1989) $748-756$.

[164] R.H. McKee, M.A. Amoruso, J.J. Freeman, R.T. Przygoda, Evaluation of the genetic toxicity of middle distillate fuels, Environ. Mol. Mutagen. 23 (1994) 234-238.

[165] K.C. Donnelly, K.W. Brown, J.C. Thomas, Bacterial mutagenicity of leachate water from municipal sewage sludgeamended soils, Environ. Toxicol. Chem. 9 (1990) 443-452.

[166] K.W. Brown, K.C. Donnelly, J.C. Thomas, P. Davol, B.R. Scott, Mutagenic activity of soils amended with two refinery wastes, Water Air Soil Pollut. 29 (1986) 1-13.

[167] K.C. Jones, R.A. Page, Short-term mutagenicity bioassays applied to evaluating contaminated land, Chemosphere 18 (1989) 2423-2432.

[168] S.B. Hawthorne, C.B. Grabanski, E. Martin, D.J. Miller, Comparisons of soxhlet extraction, pressurized liquid extraction, supercritical fluid extraction and subcritical water extraction for environmental solids: recovery, selectivity and effects on sample matrix, J. Chromatogr. A 892 (2000) 421-433.

[169] G.L. Northcott, K.C. Jones, Partitioning, extractability, and formation of nonextractable PAH residues in soil. 1. Compound differences in aging and sequestration, Environ. Sci. Technol. 35 (2001) 1103-1110.

[170] Y.F. Song, X. Jing, S. Fleischmann, B.M. Wilke, Comparative study of extraction methods for the determination of PAHs from contaminated soils and sediments, Chemosphere 48 (2002) 993-1001.

[171] P. Einisto, Role of bacterial nitroreductase and $O$-acetyltransferase in urine mutagenicity assay of rats exposed to 2,4,6-trinitrotoluene (TNT), Mutat. Res. 262 (1991) 167169.

[172] P. Einisto, M. Watanabe, M. Ishidate Jr., T. Nohmi, Mutagenicity of 30 chemicals in Salmonella typhimurium strains possessing different nitroreductase or $O$-acetyltransferase activities, Mutat. Res. 259 (1991) 95-102.

[173] M. Watanabe, M. Ishidate, T. Nohmi, Sensitive method for the detection of mutagenic nitroarenes and aromatic amines: new derivatives of Salmonella typhimurium tester strains possessing elevated $O$-acetyltransferase levels, Mutat. Res. 234 (1990) 337-348.

[174] H. Ehrlichmann, W. Dott, A. Eisentraeger, Assessment of the water-extractable genotoxic potential of soil samples from contaminated sites, Ecotoxicol. Environ. Saf. 46 (2000) 7380.

[175] P.K. Hopke, M.J. Plewa, P. Stapleton, Reduction of mutagenicity of municipal wastewaters by land treatment, Sci. Total Environ. 66 (1987) 193-202.

[176] R. Blevins, L. Brennan, Fate and mutagenic activity during conventional treatment of municipal wastewater sludge, Arch. Environ. Contam. Toxicol. 19 (1990) 657-664. 
[177] M. Hong, L. He, B. Dale, K. Donnelly, Genotoxicity profiles and reaction characteristics of potassium polyethylene glycol dehalogenation of wood preserving waste, Environ. Sci. Technol. 29 (1995) 702-708.

[178] C. Meloni, R. Marchetti, C. Marena, S. Monarca, M. Garavani, Evaluation of 2 indicators for the presence of toxic substances in land used as unauthorized dumpsites, Ig Sanita Publ. 60 (2004) 51-62.

[179] K.C. Donnelly, J.C. Thomas, C.S. Anderson, K.W. Brown, The influence of application rate on the bacterial mutagenicity of soil amended with municipal sewage sludge, Environ. Pollut. 68 (1990) 147-160.

[180] D.A. Pagano, E. Zeiger, Conditions for detecting the mutagenicity of divalent metals in Salmonella typhimurium, Environ Mol Mutagen 19 (1992) 139-146.

[181] G.C. Walker, The SOS response of Escherichia coli, in: F.C. Neidhardt, J.L. Ingraham, B. Magasanik, K.B. Low, M. Schaechter, H.E. Umbarger (Eds.), Escherichia coli and Salmonella typhimurium, Cellular and Molecular Biology, American Society for Microbiology, Washington, DC, 1987, pp. 1346-1357.

[182] G.C. Walker, Mutagenesis and inducible responses to deoxyribonucleic acid damage in Escherichia coli, Microbiol. Rev. 48 (1984) 60-93.

[183] P. Quillardet, M. Hofnung, The SOS chromotest: a review, Mutat. Res. 297 (1993) 235-279.

[184] T. Kada, M. Moriya, Y. Shirasu, Screening of pesticides for DNA interactions by "rec-assay" and mutagenesis testing, and frameshift mutagens detected, Mutat. Res. 26 (1974) 243-248.

[185] K.C. Donnelly, K.W. Brown, R.M. Saltarelli, The use of a B subtilis in a pre-incubation assay for the detection of DNAmodifying agents, Res. Commun. Chem. Pathol. Pharmacol. 42 (1983) 135-143.

[186] D.M. DeMarini, H.G. Brooks, D.G. Parkes Jr., Induction of prophage lambda by chlorophenols, Environ. Mol. Mutagen. 15 (1990) $1-9$.

[187] T.G. Rossman, M. Molina, L. Meyer, P. Boone, C.B. Klein, Z. Wang, F. Li, W.C. Lin, P.L. Kinney, Performance of 133 compounds in the lambda prophage induction endpoint of the Microscreen assay and a comparison with $S$. typhimurium mutagenicity and rodent carcinogenicity assays, Mutat. Res. 260 (1991) 349-367.

[188] V. Sasek, M. Bhatt, T. Cajthaml, K. Malachova, D. Lednicka, Compost-mediated removal of polycyclic aromatic hydrocarbons from contaminated soil, Arch. Environ. Contam. Toxicol. 44 (2003) 336-342.

[189] F. Haeseler, D. Blanchet, V. Druelle, P. Werner, J.-P. Vandecasteele, Ecotoxicological assessment of soils of former manufactured gas plant sites: bioremediation potential and pollutant mobility, Environ. Sci. Technol. 33 (1999) 4379-4384.

[190] P.H. Lee, S.K. Ong, J. Golchin, G.L. Nelson, Use of solvents to enhance PAH biodegradation of coal tar-contaminated soils, Water Res. 35 (2001) 3941-3949.

[191] S.B. Hawthorne, D.G. Poppendieck, C.B. Grabanski, R.C. Loehr, Comparing PAH availability from manufactured gas plant soils and sediments with chemical and biological tests.
1. PAH release during water desorption and supercritical carbon dioxide extraction, Environ. Sci. Technol. 36 (2002) 4795-4803.

[192] D. Mackay, W.Y. Shiu, K.C. Ma, Illustrated Handbook of Physical-Chemical Properties and Environmental fate for Organic Chemicals: Polynuclear Aromatic Hydrocarbons, Polychlorinated Dioxins and Dibenzofurans, vol. 2, Lewis Publishers, Boca Raton, FL, 1992, pp. 608.

[193] P.Y. Robidoux, P. Gong, M. Sarrazin, G. Bardai, L. Paquet, J. Hawari, C. Dubois, G.I. Sunahara, Toxicity assessment of contaminated soils from an antitank firing range, Ecotoxicol. Environ. Saf. 58 (2004) 300-313.

[194] S.E. George, G. Huggins-Clark, L.R. Brooks, Use of a Salmonella microsuspension bioassay to detect the mutagenicity of munitions compounds at low concentrations, Mutat. Res. 490 (2001) 45-56.

[195] V.S. Houk, D.M. DeMarini, Induction of prophage lambda by chlorinated pesticides, Mutat. Res. 182 (1987) 193-201.

[196] V.S. Houk, D.M. DeMarini, Use of the microscreen phageinduction assay to assess the genotoxicity of 14 hazardous industrial wastes, Environ. Mol. Mutagen. 11 (1988) 13-29.

[197] Azur Environmental, Mutatox Genotoxicity, Azur Environmental, Newark, DE, 1998, pp. 6.

[198] K.K. Kwan, B.J. Dutka, S.S. Rao, D. Liu, Mutatox test: a new test for monitoring environmental genotoxic agents, Environ. Pollut. 65 (1990) 323-332.

[199] R.S. Cook, G.D. Meyer, T.E. Miller, M.A. Curran, C.B. Cmar, G.L. Miller, L. Carmichael, Assessing the feasibility of an in vitro cytotoxicity method to detect harmful ubiquitous chemicals (detection of non-warfare hazardous chemicals in the operational theater), Drug Chem. Toxicol. 23 (2000) 95-111.

[200] A.S. Jarvis, V.A. McFarland, M.E. Honeycutt, Assessment of the effectiveness of composting for the reduction of toxicity and mutagenicity of explosive-contaminated soil, Ecotoxicol. Environ. Saf. 39 (1998) 131-135.

[201] A. Picado, A. Nogueira, L. Baeta-Hall, E. Mendonca, M. de Fatima Rodrigues, M. do Ceu Saagua, A. Martins, A.M. Anselmo, Landfarming in a PAH-contaminated soil, J. Environ. Sci. Health A 36 (2001) 1579-1588.

[202] T. Frische, Screening for soil toxicity and mutagenicity using luminescent bacteria-a case study of the explosive 2,4,6trinitrotoluene (TNT), Ecotoxicol. Environ. Saf. 51 (2002) 133-144.

[203] T.P. Pererva, N.Y. Miryuta, A.Y. Miryuta, N. Aleksandrov Yu, Biological systems aimed at a control over environmental mutagenic load, Dop. Nat. Akad. Nauk Ukr. 3 (1998) 188192.

[204] G. Shaw, D. Connell, W. Barron, The use of in vitro DNA adduct formation to estimate the genotoxicity of residues at contaminated sites, Chemosphere 30 (1995) 1957-1968.

[205] P.A. White, J.B. Rasmussen, SOS Chromotest results in a broader context. Empirical relationships between genotoxic potency, mutagenic potency and carcinogenic potency, Environ. Mol. Mutagen. 27 (1996) 270-305.

[206] T.S. Sun, H.M. Stahr, Evaluation and application of a bioluminescent bacterial genotoxicity test, J. AOAC Int. 76 (1993) 893-898. 
[207] D.P. Arfsten, R. Davenport, D.J. Schaeffer, Reversion of bioluminescent bacteria (Mutatox) to their luminescent state upon exposure to organic compounds, munitions, and metal salts, Biomed. Environ. Sci. 7 (1994) 144-149.

[208] P.A. White, J.B. Rasmussen, C. Blaise, A semi-automated, microplate version of the SOS Chromotest for the analysis of complex environmental extracts, Mutat. Res. 360 (1996) 5174.

[209] P.A. White, K.T. Ho, T. Ohe, D.M. Demarini, C. Blaise, A mass balance of surface water genotoxicity in the Providence River (Rhode Island, USA), Environ. Mol. Mutagen. 33 (1999) 68.

[210] M. Cohn, J. Monod, Purification and properties of the betagalactosidase (lactase) of Escherichia coli, Biochim. Biophys. Acta 7 (1951) 153-174.

[211] J. Reuter, Alkaline phosphatase inhibition by copper: implications for phosphorus nutrition and use as a biochemical marker of toxicity, Limnol. Oceanogr. 28 (1983) 743-748.

[212] K.T.Y. Ho, J.G. Quinn, Bioassay-directed fractionation of organic contaminants in an estuarine sediment using the new mutagenic bioassay, Mutatox Environ. Toxicol. Chem. 12 (1993) 823-830.

[213] A.S. Jarvis, M.E. Honeycutt, V.A. McFarland, A.A. Bulich, H.C. Bounds, A comparison of the Ames assay and Mutatox in assessing the mutagenic potential of contaminated dredged sediment, Ecotoxicol. Environ. Saf. 33 (1996) 193-200.

[214] B. Larsson, B.A. Kihlman, Chromosome aberrations following irradiation with high-energy protons and their secondary radiation: a study of dose distribution and biological efficiency using root-tips of Vicia faba and Allium cepa, Int. J. Radiat. Biol. 2 (1960) 8-19.

[215] A. Gustafson, Mutations in agricultural plants, Hereditas 33 (1947) 1-100.

[216] A. Marshak, The effects of X-rays on chromosomes in mitosis, Proc. Natl. Acad. Sci. U.S.A. 23 (1937) 362-369.

[217] M. Navashin, A preliminary report on some chromosome alterations by X-rays in Crepis, Am. Nat. 65 (1931) 243-252.

[218] H. Riley, The effects of X-rays on the chromosomes of Tradescantia gigantea, Cytologia 7 (1936) 131-142.

[219] K. Wuu, W. Grant, Morphological and somatic chromosomal aberrations induced by pesticides in barley, Can. J. Genet. Cytol. 8 (1966) 481-501.

[220] D. Tomkins, W. Grant, Comparative cytological effects of the pesticides menazon, metrobromuron and tetrachloroisophthalonitrile in Hordeum and Tradescantia, Can. J. Genet. Cytol. 14 (1972) 245-256.

[221] R.A. Nilan, Potential of plant genetic systems for monitoring and screening mutagens, Environ. Health Perspect. 27 (1978) 181-196.

[222] B. Kihlman, Root tips for studying the effects of chemicals on chromosomes, in: A. Hollaender (Ed.), Chemical Mutagens: Principles and Methods for Their Detection, vol. 2, Plenum Press, New York, NY, 1971pp. 489-514.

[223] A. Underbrink, L. Schairer, A. Sparrow, Tradescantia stamen hairs: a radiobiological test system applicable to chemical mutagenesis, in: A. Hollaender (Ed.), Chemical Mutagens:
Principles and Methods for Their Detection, vol. 3, Plenum Press, New York, NY, 1973pp. 171-207.

[224] M.J. Constantin, Utility of specific locus systems in higher plants to monitor for mutagens, Environ. Health Perspect. 27 (1978) 69-75.

[225] A.H. Sparrow, L.A. Schairer, R. Villalobos-Pietrini, Comparison of somatic mutation rates induced in Tradescantia by chemical and physical mutagens, Mutat. Res. 26 (1974) 265276.

[226] B.A. Kihlman, The production of chromosomal aberrations by streptonigrin in Vicia Faba, Mutat. Res. 106 (1964) 54-62.

[227] J. Van't Hof, L.A. Schairer, Tradescantia assay system for gaseous mutagens. A report of the US Environmental Protection Agency Gene-Tox Program, Mutat. Res. 99 (1982) 303315.

[228] T.H. Ma, Tradescantia cytogenetic tests (root-tip mitosis, pollen mitosis, pollen mother-cell meiosis). A report of the US Environmental Protection Agency Gene-Tox Program, Mutat. Res. 99 (1982) 293-302.

[229] T.H. Ma, Vicia cytogenetic tests for environmental mutagens. A report of the US Environmental Protection Agency GeneTox Program, Mutat. Res. 99 (1982) 257-271.

[230] G.P. Redei, Mutagen assay with Arabidopsis. A report of the US Environmental Protection Agency Gene-Tox Program, Mutat. Res. 99 (1982) 243-255.

[231] W.F. Grant, Chromosome aberration assays in Allium. A report of the US Environmental Protection Agency GeneTox Program, Mutat. Res. 99 (1982) 273-291.

[232] M.J. Plewa, Specific-locus mutation assays in Zea mays. A report of the US Environmental Protection Agency Gene-Tox Program, Mutat. Res. 99 (1982) 317-337.

[233] T.H. Ma, G.L. Cabrera, A. Cebulska-Wasilewska, R. Chen, F. Loarca, A.L. Vandenberg, M.F. Salamone, Tradescantia stamen hair mutation bioassay, Mutat. Res. 310 (1994) 211-220.

[234] N. Kanaya, B.S. Gill, I.S. Grover, A. Murin, R. Osiecka, S.S. Sandhu, H.C. Andersson, Vicia faba chromosomal aberration assay, Mutat. Res. 310 (1994) 231-247.

[235] S.S. Sandhu, F.J. de Serres, H.N. Gopalan, W.F. Grant, D. Svendsgaard, J. Veleminsky, G.C. Becking, Environmental monitoring for genotoxicity with plant systems. Results and recommendations, Mutat. Res. 310 (1994) 257-263.

[236] T. Gichner, S.A. Badayev, S.I. Demchenko, J. Relichova, S.S. Sandhu, P.D. Usmanov, O. Usmanova, J. Veleminsky, Arabidopsis assay for mutagenicity, Mutat. Res. 310 (1994) 249256.

[237] W.F. Grant, M.F. Salamone, Comparative mutagenicity of chemicals selected for test in the International Program on Chemical Safety's collaborative study on plant systems for the detection of environmental mutagens, Mutat. Res. 310 (1994) 187-209.

[238] T.H. Ma, G.L. Cabrera, R. Chen, B.S. Gill, S.S. Sandhu, A.L. Vandenberg, M.F. Salamone, Tradescantia micronucleus bioassay, Mutat. Res. 310 (1994) 221-230.

[239] L.A. Schairer, J. Van't Hof, C.G. Hayes, R.M. Burton, F.J. de Serres, Exploratory monitoring of air pollutants for mutagenicity activity with the Tradescantia stamen hair system, Environ. Health Perspect. 27 (1978) 51-60. 
[240] A.H. Sparrow, L.A. Schairer, R. Villalobos-Pietrini, Comparison of somatic mutation rates induced in Tradescantia by chemical and physical mutagens, Mutat. Res. 26 (1974) 265276.

[241] C.Q. Duan, B. Hu, Z.H. Wang, C.H. Wen, S.Q. Yan, X.H. Jiang, D.K. Wang, Q. Li, X.F. Liang, Tradescantia bioassays for the determination of genotoxicity of water in the Panlong River, Kunming, People's Republic of China, Mutat. Res. 426 (1999) 127-131.

[242] E.F. Ruiz, V.M. Rabago, S.U. Lecona, A.B. Perez, T.H. Ma, Tradescantia-micronucleus (Trad-MCN) bioassay on clastogenicity of wastewater and in situ monitoring, Mutat. Res. 270 (1992) 45-51.

[243] J. Rank, M.H. Nielsen, Evaluation of the Allium anaphase-telophase test in relation to genotoxicity screening of industrial wastewater, Mutat. Res. 312 (1994) $17-24$.

[244] M.H. Nielsen, J. Rank, Screening of toxicity and genotoxicity in wastewater by the use of the Allium test, Hereditas 121 (1994) 249-254.

[245] T.H. Ma, Application of quick and simple plant bioassays to assess the genotoxicity of environmental pollutantsdetection of potential health hazards of air, water and soil contaminants, Arch. Toxicol. Suppl. 17 (1995) 420-433.

[246] T.H. Ma, W.F. Grant, F.J. De Serres, The genotoxicity monitoring of air, water and soil: a preliminary report of the International Programme on Plant Bioassays (IPPB), Mutat. Res. 379 (1997) 7-12.

[247] T.H. Ma, M.S. Kong, Genotoxicity of contaminated soil and well water detected by plant bioassays, Environ. Mol. Mutagen. 29 (1997) 19-23.

[248] W.F. Grant, The present status of higher plant bioassays for the detection of environmental mutagens, Mutat. Res. 310 (1994) 175-185.

[249] W. Grant, A. Zinov'eva-Stahevitch, K. Zura, Plant genetic test systems for the detection of chemical mutagens, in: $\mathrm{H}$. Stich, R. San (Eds.), Short-term Tests for Chemical Carcinogenesis, Springer-Verlag, New York, NY, 1981, pp. 200216.

[250] S.S. Sandhu, F.J. de Serres, H.N. Gopalan, W.F. Grant, J. Veleminsky, G.C. Becking, Environmental monitoring for genotoxicity with plant systems. An introduction and study design, Mutat. Res. 310 (1994) 169-173.

[251] M.J. Plewa, Specific-locus mutation assays in Zea mays. A report of the US Environmental Protection Agency Gene-Tox Program, Mutat. Res. 99 (1982) 317-337.

[252] M.S. Kong, T.H. Ma, Genotoxicity of contaminated soil and shallow well water detected by plant bioassays, Mutat. Res. 426 (1999) 221-228.

[253] G.S. Rodrigues, D. Pimentel, L.H. Weinstein, In situ assessment of pesticide genotoxicity in an integrated pest management program I-Tradescantia micronucleus assay, Mutat. Res. 412 (1998) 235-244.

[254] J.R. Meier, L.W. Chang, S. Jacobs, J. Torsella, M.C. Meckes, M.K. Smith, Use of plant and earthworm bioassays to evaluate remediation of soil from a site contaminated with polychlorinated biphenyls, Environ. Toxicol. Chem. 16 (1997) 928-938.

[255] A. Levan, The effect of cholchicine on root mitosis of Allium, Hereditas 24 (1938) 471-486.

[256] W.F. Grant, Higher plant assays for the detection of genotoxicity in air polluted environments, Ecosyst. Health 4 (1998) 210-229.

[257] O. Kovalchuk, I. Kovalchuk, A. Arkhipov, P. Telyuk, B. Hohn, L. Kovalchuk, The Allium cepa chromosome aberration test reliably measures genotoxicity of soils of inhabited areas in the Ukraine contaminated by the Chernobyl accident, Mutat. Res. 415 (1998) 47-57.

[258] V.I. Kriukov, V.A. Shashkin, S.F. Sokolenko, Effects of chronic effects of lead nitrate and ionizing radiation on mutagenesis in Arabidopsis thaliana (L.) Heynh, Radiat. Biol. Radioecol. 36 (1996) 209-218.

[259] G.P. Redei, Arabidopsis as a genetic tool, Annu. Rev. Genet. 9 (1975) 111-127.

[260] A.J. Müller, On the time period of mutation induction after treatment with N-nitroso-N-methylurea of swelling seeds of Arabidopsis, Mutat. Res. 2 (1965) 426-437.

[261] M. Koornneef, L.W. Dellaert, J.H. van der Veen, EMS- and radiation-induced mutation frequencies at individual loci in Arabidopsis thaliana (L.) Heynh, Mutat. Res. 93 (1982) 109_ 123.

[262] V.A. Kal'chenko, D.A. Spirin, Genetic effects revealed in populations of Pinus sylvestris L. growing under exposure to small doses of chronic irradiation, Genetika 25 (1989) 10591064.

[263] V.I. Shershunova, E.R. Vilenskii, A.I. Voronin, I.G. Kochan, Genetic effects of a combination of chronic cobalt-60 gamma-radiation and lead nitrate on barley waxy-locus, Radiobiologiya 30 (1990) 224-227.

[264] I. Bubryak, E. Vilensky, V. Naumenko, D. Grodzisky, Influence of combined alpha, beta and gamma radionuclide contamination on the frequency of waxy-reversions in barley pollen, Sci. Total Environ. 112 (1992) 29-36.

[265] E. Andersen, On the frequency and transmitted chromosome alterations and gene mutations induced by atomic bomb radiations in maize, Proc. Natl. Acad. Sci. U.S.A. 34 (1948) 386-390.

[266] L.J. Stadler, Spontaneous mutation in maize, Cold Spring Harb. Symp. Quant. Biol. 16 (1951) 49-63.

[267] L. Stadler, The genetic effects of X-rays in maize, Proc. Natl. Acad. Sci. U.S.A. 30 (1944) 123-128.

[268] C.J. Lawrence, Q. Dong, M.L. Polacco, T.E. Seigfried, V. Brendel, MaizeGDB, the community database for maize genetics and genomics, Nucleic Acids Res. 32 (2004) D393-D397.

[269] R. Scholl, M.M. Sachs, D. Ware, Maintaining collections of mutants for plant functional genomics, Methods Mol. Biol. 236 (2003) 311-326.

[270] M.J. Plewa, E.D. Wagner, G.J. Gentile, J.M. Gentile, An evaluation of the genotoxic properties of herbicides following plant and animal activation, Mutat. Res. 136 (1984) 233-245. 
[271] J.M. Gentile, G.J. Gentile, J. Bultman, R. Sechriest, E.D. Wagner, M.J. Plewa, An evaluation of the genotoxic properties of insecticides following plant and animal activation, Mutat. Res. 101 (1982) 19-29.

[272] M.J. Plewa, E.D. Wagner, Germinal cell mutagenesis in specially designed maize genotypes, Environ. Health Perspect. 37 (1981) 61-73.

[273] M. de Bertoldi, M. Griselli, M. Giovannetti, R. Barale, Mutagenicity of pesticides evaluated by means of gene-conversion in Saccharomyces cerevisiae and in Aspergillus nidulans, Environ. Mutagen. 2 (1980) 359-370.

[274] I. Rahden-Staron, M. Szumilo, P. Ziemkiewicz, The effects of captan and captafol on different bacterial strains and on cmitosis in V79 Chinese hamster fibroblasts, Acta Biochim. Pol. 41 (1994) 45-55.

[275] S. Saxena, B.T. Ashok, J. Musarrat, Mutagenic and genotoxic activities of four pesticides: captan, foltaf, phosphamidon and furadan, Biochem. Mol. Biol. Int. 41 (1997) 1125-1136.

[276] M.J. Ruiz, D. Marzin, Genotoxicity of six pesticides by Salmonella mutagenicity test and SOS chromotest, Mutat. Res. 390 (1997) 245-255.

[277] A. Kappas, On the mutagenic and recombinogenic activity of certain herbicides in Salmonella typhimurium and in Aspergillus nidulans, Mutat. Res. 204 (1988) 615-621.

[278] M. de Bertoldi, M. Griselli, M. Giovannetti, R. Barale, Mutagenicity of pesticides evaluated by means of gene-conversion in Saccharomyces cerevisiae and in Aspergillus nidulans, Environ. Mutagen. 2 (1980) 359-370.

[279] E.E. Emnova, G.V. Mereniuk, L.G. Tsurkan, Genetic activity of sim-triazine herbicides on Saccharomyces cerevisiae yeast strains, Tsitol Genet. 21 (1987) 127-131.

[280] M. Ahmed, W. Grant, Cytological effects of the pesticides Phosdrin and Bladex on Tradescantia and Vicia faba, Can. J. Genet. Cytol. 14 (1972) 157-165.

[281] T.-H. Ma, Micronuclei induced by X-rays and chemical mutagens in meiotic pollen mother cells of Tradescantia, Mutat. Res. 64 (1979) 307-313.

[282] T.-H. Ma, Tradescantia micronucleus bioassay and pollen tube chromatid aberration test for in situ monitoring and mutagen screening, Environ. Health Perspect. 37 (1981) 8590.

[283] G.L. Cabrera, D.M. Rodriguez, Genotoxicity of leachates from a landfill using three bioassays, Mutat. Res. 426 (1999) 207-210.

[284] G. Cabrera, M. Guadalupe Rodriguez, A. Perez, Genotoxicity of soil irrigated with wastewater using three bioassays, Mutat. Res. 379 (1997) 7-12.

[285] A. Underbrink, T. Ranney, A. Yanders, W.R. Lower, D. Hemphill, Use of Tradescantia to assay the toxicity and mutagenicity of waters, sediments and soils, Environ. Mutagen. 7 (Suppl. 3) (1985) 60.

[286] G. Peng, R. Chen, The mutagenicity of wastewater and its mire of a rubber factory by Tradescantia micronucleus (TradMCN), Environ. Mol. Mutagen. 25 (Suppl. 25) (1995) 41.

[287] H.N. Gopalan, Ecosystem health and human well being: the mission of the international programme on plant bioassays, Mutat. Res. 426 (1999) 99-102.
[288] B.S. Gill, S.S. Sandhu, Application of the Tradescantia micronucleus assay for the genetic evaluation of chemical mixtures in soil and aqueous media, Mutat. Res. 270 (1992) 65-69.

[289] S.S. Sandhu, T.H. Ma, Y. Peng, X.D. Zhou, Clastogenicity evaluation of seven chemicals commonly found at hazardous industrial waste sites, Mutat. Res. 224 (1989) 437-445.

[290] J.C. Codina, C. Perez-Torrente, A. Perez-Garcia, F.M. Cazorla, A. de Vicente, Comparison of microbial tests for the detection of heavy metal genotoxicity, Arch. Environ. Contam. Toxicol. 29 (1995) 260-265.

[291] S.P. Bhunya, G.B. Jena, Clastogenic effects of copper sulphate in chick in vivo test system, Mutat. Res. 367 (1996) 5763.

[292] K. Kuroda, G. Endo, A. Okamoto, Y.S. Yoo, S. Horiguchi, Genotoxicity of beryllium, gallium and antimony in shortterm assays, Mutat. Res. 264 (1991) 163-170.

[293] N. Gurnani, A. Sharma, G. Talukder, Comparison of the clastogenic effects of antimony trioxide on mice in vivo following acute and chronic exposure, Biometals 5 (1992) 47-50.

[294] B.M. Elliott, J.M. Mackay, P. Clay, J. Ashby, An assessment of the genetic toxicology of antimony trioxide, Mutat. Res. 415 (1998) 109-117.

[295] S. De Flora, M. Bagnasco, D. Serra, P. Zanacchi, Genotoxicity of chromium compounds. A review, Mutat. Res. 238 (1990) 99-172.

[296] S. Itoh, H. Shimada, Clastogenicity and mutagenicity of hexavalent chromium in lacZ transgenic mice, Toxicol. Lett. 91 (1997) 229-233.

[297] A.A. Abdullaev, A.S. Sultanov, R.M. Kamilova, M. Azimova, Mutagenic consequence of long-term soil application of the herbicides cotoran and toluin, Cytol. Genet. 19 (1985) 61-63.

[298] S.H. Rogstad, B. Keane, M.H. Collier, Minisatellite DNA mutation rate in dandelions increases with leaf-tissue concentrations of $\mathrm{Cr}, \mathrm{Fe}, \mathrm{Mn}$, and Ni, Environ. Toxicol. Chem. 22 (2003) 2093-2099.

[299] L.M. McMurphy, A.L. Rayburn, Nuclear alterations of maize plants growth in soil contaminated with coal fly ash, Arch. Environ. Contam. Toxicol. 25 (1993) 520-524.

[300] S. Citterio, R. Aina, M. Labra, A. Ghiani, P. Fumagalli, S. Sgorbati, A. Santagostino, Soil genotoxicity assessment: a new strategy based on biomolecular tools and plant bioindicators, Environ. Sci. Technol. 36 (2002) 2748-2753.

[301] H. Dulieu, Somatic variations on a yellow mutant in Nicotiana tabacum L. $\left(a_{1}^{+} / a_{1} \quad a_{2}^{+} / a_{2}\right)$. II. Reciprocal genetic events occurring in leaf cells, Mutat. Res. 28 (1975) 69-77.

[302] X. Verge, A. Chapuis, M. Delpoux, H. Dulieu, A. Fabre, M.P. Meybeck, Tobacco plants detect a decrease of environmental genotoxicity in Toulouse (France), Environ. Monit. Assess. 91 (2004) 199-209.

[303] International Agency for Research on Cancer (IARC), Miscellaneous Pesticides, International Agency for Research on Cancer, Lyons, France, 1983, pp. 424.

[304] International Agency for Research on Cancer (IARC), Occupational Exposures in Insecticide Application and Some 
Pesticides, International Agency for Research on Cancer, Lyons, France, 1991, pp. 612.

[305] A.L. Rayburn, J.A. Auger, L.M. McMurphy, Estimating percentage constitutive heterochromatin by flow cytometry, Exp. Cell Res. 198 (1992) 175-178.

[306] P. Vos, R. Hogers, M. Bleeker, M. Reijans, T. van de Lee, M. Hornes, A. Frijters, J. Pot, J. Peleman, M. Kuiper, et al. AFLP: a new technique for DNA fingerprinting, Nucleic Acids Res. 23 (1995) 4407-4414.

[307] A. Arencibia, E. Gentinetta, E. Cuzzoni, S. Castiglione, A. Kohli, P. Vain, M. Leech, P. Christou, F. Sala, Molecular analysis of the genome of transgenic rice plants produced via particle bombardment or intact cell electroporation, Mol. Breed. 4 (1998) 99-109.

[308] A. Terziyska, L. Waltschewa, P. Venkov, A new sensitive test based on yeast cells for studying environmental pollution, Environ. Pollut. 109 (2000) 43-52.

[309] A. Zia'ee, F. Sabouni, Studies on the genotoxicity of untreated and unused soil prepared for agriculture purposes, Environ. Mol. Mutagen. 19 (1992) 75.

[310] J. Parry, Use of tests in yeasts and fungi in the detection and evaluation of carcinogens, in: D. McGregor, J. Rice, S. Venitt (Eds.), The Use of Short-term and Medium-term Tests for Carcinogens and Data on Genetic Effects in Carcinogenic Hazard Evaluation, International Agency for Research on Cancer, Lyon, France, 1999, pp. 471-485.

[311] R. von Borstel, The yeast Saccharomyces cerivisiae: an assay organism for environmental mutagens, in: H. Stich, R. San (Eds.), Short-term Tests for Chemical Carcinogens, Springer Verlag, New York, NY, 1981, pp. 161-174.

[312] E. Parry, J. Parry, The assay of genotoxicity of chemicals using the budding yeast Saccharomyces cerivisiae, in: S. Venitt, P. JM (Eds.), Mutagenicity Testing. A Practical Approach, IRL Press, Oxford, UK, 1984 , pp. 119-147.

[313] E. Kafer, P. Marshall, G. Cohen, Well-marked strains of Aspergillus for tests of environmental mutagens: identification of induced mitotic recombination and mutation, Mutat. Res. 38 (1976) 141-146.

[314] E. Kafer, Meiotic and mitotic recombination in Aspergillus and its chromosomal aberrations, Adv. Genet. 19 (1977) 33131.

[315] B.R. Scott, G.L. Dorn, E. Kafer, R. Stafford, Aspergillus nidulans: systems and results of tests for induction of mitotic segregation and mutation. II. Haploid assay systems and overall response of all systems. A report of the US EPA Gene-Tox Program, Mutat. Res. 98 (1982) 4994.

[316] E. Kafer, B.R. Scott, G.L. Dorn, R. Stafford, Aspergillus nidulans: systems and results of tests for chemical induction of mitotic segregation and mutation. I. Diploid and duplication assay systems. A report of the US EPA Gene-Tox Program, Mutat. Res. 98 (1982) 1-48.

[317] K.C. Donnelly, K.W. Brown, B.R. Scott, Chemical and biological characterization of hazardous industrial waste. II. Eukaryotic bioassay of a wood-preserving bottom sediment, Mutat. Res. 180 (1987) 43-53.
[318] K. Krishnamurthi, F. Devi, T. Chakrabarti, Genotoxic effects of PAH containing sludge extracts in Chinese hamster ovary cell cultures, Biomed. Environ. Sci. 16 (2003) 68-82.

[319] T. McFall, G.M. Booth, M.L. Lee, Y. Tominaga, R. Pratap, M. Tedjamulia, R.N. Castle, Mutagenic activity of methyl-substituted tri- and tetracyclic aromatic sulfur heterocycles, Mutat. Res. 135 (1984) 97-103.

[320] L. Staleva, L. Waltscheva, E. Golovinsky, P. Venkov, Enhanced cell permeability increases the sensitivity of a yeast test for mutagens, Mutat. Res. 370 (1996) 81-89.

[321] N.M. Gevirkian, I.E. Drobinskaia, T.P. Glotova, F.I. Ingel, N.A. Iliushina, V.A. Bratslavskii, E.K. Krivtsova, L.A. Korostyleva, N.A. Afanaseva, A. Revazova Iu, Comprehensive evaluation of environmental pollution and incidence of genetic disorders in the population of Atbasar city (Kazakhstan), Gig Sanit. (1994) 37-40.

[322] U. Graf, F.E. Wurgler, A.J. Katz, H. Frei, H. Juon, C.B. Hall, P.G. Kale, Somatic mutation and recombination test in Drosophila melanogaster, Environ. Mutagen. 6 (1984) 153-188.

[323] R. Valencia, S. Abrahamson, W.R. Lee, E.S. Von Halle, R.C. Woodruff, F.E. Wurgler, S. Zimmering, Chromosome mutation tests for mutagenesis in Drosophila melanogaster. A report of the US Environmental Protection Agency Gene-Tox Program, Mutat. Res. 134 (1984) 61-88.

[324] M.M. Aslanian, A.I. Kim, M.A. Magomedova, N.L. Fatkulbaianova, Analysis of dominant and recessive sex-linked lethal mutations induced by low radiation doses in genetically different strains of Drosophila melanogaster w and MS, Genetika 30 (1994) 1220-1223.

[325] W.R. Lee, S. Abrahamson, R. Valencia, E.S. von Halle, F.E. Wurgler, S. Zimmering, The sex-linked recessive lethal test for mutagenesis in Drosophila melanogaster. A report of the US Environmental Protection Agency Gene-Tox Program, Mutat. Res. 123 (1983) 183-279.

[326] N.R. Bordelon, K.C. Donnelly, L.C. King, D.C. Wolf, W.R. Reeves, S.E. George, Bioavailability of the genotoxic components in coal tar contaminated soils in Fischer 344 rats, Toxicol. Sci. 56 (2000) 37-48.

[327] M. Matsushita, T. Tamura, Y. Kato, T. Nishimura, Mutagenic activities of organic components in soil collected in Tokyo, Bangkok, Chaing Mai and Manila, Mutat. Res. 130 (1984) 370.

[328] K. Malachova, Estimating the mutagenicity of soils after their biological decontamination, Mutat. Res. 379 (1997) S118.

[329] S. Monarca, A. Zanardini, D. Feretti, S. Resola, R. Marchetti, S. Manfredi, G. Nardi, Evaluation of mutagens in contaminated soils using bacterial and plant assays, Mutat. Res. 379 (1997) S101.

[330] J. Meier, S. Jacobs, T. Ma, L. Chang, J. Torsella, M. Meckes, M. Smith, Use of plant toxicity assays to evaluate a mobile solvent extraction system for remediation of soil from a hazardous waste site, Environ. Mol. Mutagen. 25 (Suppl. 25) (1995) 35.

[331] L. Chang, J. Meier, M. Smith, Evaluation of remediation of lead contaminated soil using plant toxicity and genotoxicity assays, Environ. Mol. Mutagen. 27 (Suppl. 27) (1996) 13. 
[332] B. Gill, J. Rice, S. Sandhu, In situ evaluation of potential genetic hazards from chemical waste sites, Environ. Mol. Mutagen. 14 (Suppl. 15) (1989) 69.

[333] B. Tadesse, J.D. Donaldson, S.M. Grimes, Contaminated and polluted land: a general review of decontamination management and control, J. Chem. Technol. Biotech. 60 (1994) 227240.

[334] K.S. Udell, D.G. Grubb, N. Sitar, Technologies for in situ cleanup of contaminated sites, Cent. Eur. J. Public Health 3 (1995) 67-76.

[335] J. Werther, M. Wilchowski, Investigation of the physical mechanisms involved in the purification of contaminated soils by washing process, in: J. Ardent (Ed.), Contaminated Soil'90, Kluwer Academic Publishers, Dordrecht, The Netherlands, 1990, pp. 907-920.

[336] M. Ziggler, R. Reintless, Decontamination of a former gasworks site with an in situ high pressure soil washing technique, in: T. Cairney (Ed.), Reclaiming Contaminated Land, Blackie Press, London, UK, 1987, pp. 921-927.

[337] R. Sims, Soil remediation techniques at uncontrolled hazardous waste sites: a critical review, J. Air Waste Manage. Assoc. 40 (1990) 704-732.

[338] R. Sims, D. Sorensen, I. Sims, J. McLean, R. Mahmood, R. Dupont, Contaminated Surface Soils In-place Treatment Techniques, Noyes Data Corporation, Park Ridge, NJ, 1986, pp. 536.

[339] W.F. Ritter, R.W. Scarborough, A review of bioremediation of contaminated soils and groundwater, J. Environ. Sci. Health A 30 (1995) 333-357.

[340] O.V. Singh, R.K. Jain, Phytoremediation of toxic aromatic pollutants from soil, Appl. Microbiol. Biotechnol. 63 (2003) $128-135$.

[341] S.C. Wilson, K.C. Jones, Bioremediation of soil contaminated with polynuclear aromatic hydrocarbons PAHs a review, Environ. Pollut. 81 (1993) 229-249.

[342] C.R. Soccol, L.P. Vandenberghe, A.L. Woiciechowski, V. Thomaz-Soccol, C.T. Correia, A. Pandey, Bioremediation: an important alternative for soil and industrial wastes cleanup, Indian J. Exp. Biol. 41 (2003) 1030-1045.

[343] D.T. Tsao, Overview of phytotechnologies, Adv. Biochem. Eng. Biotechnol. 78 (2003) 1-50.

[344] C.M. Peres, S.N. Agathos, Biodegradation of nitroaromatic pollutants: from pathways to remediation, Biotechnol. Annu. Rev. 6 (2000) 197-220.

[345] K. Brown, G. Evens, D. Anderson, S.C.K. Donnelly, J. Thomas, D. Kissock, J. Adams, S. Jones, Hazardous Land Treatment, US EPA, Municipal Environmental Research Laboratory, Cincinnati, OH, 1983, pp. 703.

[346] Z. Snellinx, A. Nepovim, S. Taghavi, J. Vangronsveld, T. Vanek, D. van der Lelie, Biological remediation of explosives and related nitroaromatic compounds, Environ. Sci. Pollut. Res. Int. 9 (2002) 48-61.

[347] T.A. Lewis, D.A. Newcombe, R.L. Crawford, Bioremediation of soils contaminated with explosives, J. Environ. Manage. 70 (2004) 291-307.

[348] W.W. Mohn, C.Z. Radziminski, M.C. Fortin, K.J. Reimer, On site bioremediation of hydrocarbon-contaminated Arctic tun- dra soils in inoculated biopiles, Appl. Microbiol. Biotechnol. 57 (2001) 242-247.

[349] L.R. Brooks, T.J. Hughes, L.D. Claxton, B. Austern, R. Brenner, F. Kremer, Bioassay-directed fractionation and chemical identification of mutagens in bioremediated soils, Environ. Health Perspect. 106 (Suppl. 6) (1998) 14351440.

[350] T.J. Hughes, L.D. Claxton, L. Brooks, S. Warren, R. Brenner, F. Kremer, Genotoxicity of bioremediated soils from the Reilly Tar site, St. Louis Park, Minnesota, Environ. Health Perspect. 106 (Suppl. 6) (1998) 1427-1433.

[351] T. Cajthaml, M. Bhatt, V. Sasek, V. Mateju, Bioremediation of PAH-contaminated soil by composting: a case study, Folia Microbiol. (Praha) 47 (2002) 696-700.

[352] W.H. Griest, R.L. Tyndall, A.J. Stewart, C.H. Ho, K.S. Ironside, J.E. Caton, W.M. Caldwell, E. Tan, Characterization of Explosives Processing Waste Decomposition Due to Composting: Phase 2, Final Report, DOE Interagency Agreement No. 1016-B123-A1, Oak Ridge National Laboratory, Oak Ridge, TN, 1991, pp. 142.

[353] S. Lundstedt, P. Haglund, L. Oberg, Degradation and formation of polycyclic aromatic compounds during bioslurry treatment of an aged gasworks soil, Environ. Toxicol. Chem. 22 (2003) 1413-1420.

[354] C.F. Shen, S.R. Guiot, S. Thiboutot, G. Ampleman, J. Hawari, Fate of explosives and their metabolites in bioslurry treatment processes, Biodegradation 8 (1997) 339-347.

[355] C.D. Miller, K. Hall, Y.N. Liang, K. Nieman, D. Sorensen, B. Issa, A.J. Anderson, R.C. Sims, Isolation and characterization of polycyclic aromatic hydrocarbon-degrading Mycobacterium isolates from soil, Microb. Ecol., 2004, in press.

[356] K.W. Brown, K.C. Donnelly, Mutagenic activity of runoff and leachate water from hazardous waste land treatment, Environ. Pollut. 35 (1984) 229-246.

[357] S. Gibson, G. Sewell, Stimulation of reductive dechlorination of tetrachloroethene in anaerobic aquifer microcosms by addition of short-chain organic acids or alcohols, Appl. Environ. Microbiol. 58 (1992) 1392-1393.

[358] J. Davis, C. Carpenter, Aerobic biodegradation of vinyl chloride in groundwater samples, Appl. Environ. Microbiol. 56 (1990) 3878-3880.

[359] D.T. Adamson, J.M. McDade, J.B. Hughes, Inoculation of a DNAPL source zone to initiate reductive dechlorination of PCE, Environ. Sci. Technol. 37 (2003) 2525-2533.

[360] J. He, K.M. Ritalahti, K.L. Yang, S.S. Koenigsberg, F.E. Loffler, Detoxification of vinyl chloride to ethene coupled to growth of an anaerobic bacterium, Nature 424 (2003) $62-65$.

[361] J. He, K. Ritalahti, M. Aiello, F. Löffler, Complete detoxification of vinyl chloride (VC) by an anaerobic enrichment culture and identification of the reductively dechlorinating population as a Dehalococcoides population, Appl. Environ. Microbiol. 69 (2003) 996-1003.

[362] O.V. Singh, S. Labana, G. Pandey, R. Budhiraja, R.K. Jain, Phytoremediation: an overview of metallic ion decontamination from soil, Appl. Microbiol. Biotechnol. 61 (2003) 405412. 
[363] A. Vassilev, J.P. Schwitzguebel, T. Thewys, D. Van Der Lelie, J. Vangronsveld, The use of plants for remediation of metalcontaminated soils, Sci. World J. 4 (2004) 9-34.

[364] T. Macek, M. Mackova, J. Kas, Exploitation of plants for the removal of organics in environmental remediation, Biotechnol. Adv. 18 (2000) 23-34.

[365] A. Ramaswami, E. Rubin, S. Bonola, Non-significance of rhizosphere degradation during phytoremediation of MTBE, Int. J. Phytoremediation 5 (2003) 315-331.

[366] A. Schwab, M. Banks, Biologically mediated dissipation of polyaromatic hydrocarbons in the root zone, in: T. Anderson, J. Coats (Eds.), Bioremediation Through Rhizosphere Technology, American, Chemical Society, Washington, DC, 1994, pp. 132-141.

[367] N. Terry, G. Banuelos, Phytoremediation of Contaminated Soil and Water, CRC Press LLC, Boca Raton, FL, 1999, pp. 408.

[368] S. Suthersan, Natural and Enhanced Remediation Systems, CRC Press LLC, Boca Raton, FL, 2001, pp. 440.

[369] M. Sara, Site Assessment and Remediation Handbook, CRC Press LLC, Boca Raton, FL, 2003, pp. 1160.

[370] G.C. Barbee, K.W. Brown, J.C. Thomas, K.C. Donnelly, H.E. Murray, Mutagenic activity (Ames test) of wood-preserving waste sludge applied to soil, Bull. Environ. Contam. Toxicol. 57 (1996) 54-62.

[371] R.R. Alexander, M. Alexander, Genotoxicity of two polycyclic aromatic hydrocarbons declines as they age in soil, Environ. Toxicol. Chem. 18 (1999) 1140-1143.

[372] J.S. Angle, D.M. Baudler, Persistence and degradation of mutagens in sludge-amended soil, J. Environ. Qual. 13 (1984) 143-146.

[373] H. Yu, Environmental carcinogenic polycyclic aromatic hydrocarbons: photochemistry and phototoxicity, J. Environ. Sci. Health C 20 (2002) 149-183.

[374] M.D. Ferrari, Biodegradation of polycyclic aromatic hydrocarbons and its application to the bioremediation of contaminated soils and sludges, Rev. Argent Microbiol. 28 (1996) 83-98.

[375] C. Kazunga, M.D. Aitken, A. Gold, R. Sangaiah, Fluoranthene-2,3- and -1,5-diones are novel products from the bacterial transformation of fluoranthene, Environ. Sci. Technol. 35 (2001) 917-922.

[376] L. Flowers-Geary, W. Bleczinki, R.G. Harvey, T.M. Penning, Cytotoxicity and mutagenicity of polycyclic aromatic hydrocarbon ortho-quinones produced by dihydrodiol dehydrogenase, Chem. Biol. Interact. 99 (1996) 55-72.

[377] L. Flowers, S.T. Ohnishi, T.M. Penning, DNA strand scission by polycyclic aromatic hydrocarbon o-quinones: role of reactive oxygen species, $\mathrm{Cu}(\mathrm{II}) / \mathrm{Cu}(\mathrm{I})$ redox cycling, and $o$ semiquinone anion radicals, Biochemistry 36 (1997) 86408648.

[378] J.N. Pitts Jr., D.M. Lokensgard, W. Harger, T.S. Fisher, V. Mejia, J.J. Schuler, G.M. Scorziell, Y.A. Katzenstein, Mutagens in diesel exhaust particulate. Identification and direct activities of 6-nitrobenzo[a]pyrene, 9-nitroanthracene, 1nitropyrene and 5h-phenanthro[4,5-bcd]pyran-5-one, Mutat. Res. 103 (1982) 241-249.
[379] J.L. Durant, W.F. Busby Jr., A.L. Lafleur, B.W. Penman, C.L. Crespi, Human cell mutagenicity of oxygenated, nitrated and unsubstituted polycyclic aromatic hydrocarbons associated with urban aerosols, Mutat. Res. 371 (1996) 123-157.

[380] C.P. Weisel, W.K. Jo, Ingestion, inhalation, and dermal exposures to chloroform and trichloroethene from tap water, Environ. Health Perspect. 104 (1996) 48-51.

[381] B.S. Cohen, W. Popendorf, A method for monitoring dermal exposure to volatile chemicals, Am. Ind. Hyg. Assoc. J. 50 (1989) 216-223.

[382] M.L. Gargas, M.A. Medinsky, M.E. Andersen, Pharmacokinetic modeling approaches for describing the uptake, systemic distribution, and disposition of inhaled chemicals, Crit. Rev. Toxicol. 25 (1995) 237-254.

[383] K.D. Thrall, T.S. Poet, R.A. Corley, H. Tanojo, J.A. Edwards, K.K. Weitz, X. Hui, H.I. Maibach, R.C. Wester, A real-time in-vivo method for studying the percutaneous absorption of volatile chemicals, Int. J. Occup. Environ. Health 6 (2000) 96-103.

[384] L.J. Lee, C.C. Chan, C.W. Chung, Y.C. Ma, G.S. Wang, J.D. Wang, Health risk assessment on residents exposed to chlorinated hydrocarbons contaminated in groundwater of a hazardous waste site, J. Toxicol. Environ. Health A 65 (2002) 219235.

[385] L. Ritter, K. Solomon, P. Sibley, K. Hall, P. Keen, G. Mattu, B. Linton, Sources, pathways, and relative risks of contaminants in surface water and groundwater: a perspective prepared for the Walkerton inquiry, J. Toxicol. Environ. Health A 65 (2002) 1-142.

[386] M. Salkinoja-Salonen, J. Uotila, J. Jokela, M. Laine, E. Saski, Organic halogens in the environment: studies of environmental biodegradability and human exposure, Environ. Health Perspect. 103 (Suppl. 5) (1995) 63-69.

[387] C.M. Aelion, B.C. Conte, Susceptibility of residential wells to VOC and nitrate contamination, Environ. Sci. Technol. 38 (2004) 1648-1653.

[388] D.J. Lisk, Environmental implications of incineration of municipal solid waste and ash disposal, Sci. Total Environ. 74 (1988) 39-66.

[389] P.J. Sheehan, D.M. Meyer, M.M. Sauer, D.J. Paustenbach, Assessment of the human health risks posed by exposure to chromium-contaminated soils, J. Toxicol. Environ. Health 32 (1991) 161-201.

[390] E. Stanek, E.J. Calabrese, Daily soil ingestion estimates for children at a Superfund site, Risk Anal. 20 (2000) 627635.

[391] E.J. Stanek, E.J. Calabrese, Daily estimates of soil ingestion in children, Environ. Health Perspect. 103 (1995) 276-285.

[392] R.M. Sedman, The development of applied action levels for soil contact: a scenario for the exposure of humans to soil in a residential setting, Environ. Health Perspect. 79 (1989) 291313.

[393] K. Fent, Ecotoxicological problems associated with contaminated sites, Toxicol. Lett. 140-141 (2003) 353-365.

[394] United States Environmental Protection Agency (USEPA), Risk Assessment Guidance for Superfund: Human Health Evaluation manual Supplemental Guidance. Standard Default 
Exposure Factors, vol. I, Office of Emergency and Remedial Response, US EPA, Washington, DC, 1991, pp. 30.

[395] H. Gruttke, W. Kratz, G. Weigmann, A. Haque, Terrestrial model food chain and environmental chemicals. I. Transfer of sodium $\left[{ }^{14} \mathrm{C}\right]$ pentachlorophenate between springtails and carabids, Ecotoxicol. Environ. Saf. 15 (1988) 253-259.

[396] B.T. Elkin, R.W. Bethke, Environmental contaminants in caribou in the Northwest Territories, Canada, Sci. Total Environ. 160-161 (1995) 307-321.

[397] D.J. Lisk, R.D. Boyd, J.N. Telford, J.G. Babish, G.S. Stoewsand, C.A. Bache, W.H. Gutenmann, Toxicologic studies with swine fed corn grown on municipal sewage sludge-amended soil, J. Anim. Sci. 55 (1982) 613-619.

[398] J.N. Telford, M.L. Thonney, D.E. Hogue, J.R. Stouffer, C.A. Bache, W.H. Gutenmann, D.J. Lisk, J.G. Babish, G.S. Stoewsand, Toxicologic studies in growing sheep fed silage corn cultured on municipal sludge-amended acid subsoil, J. Toxicol. Environ. Health 10 (1982) 73-85.

[399] G.S. Stoewsand, J.G. Babish, J.N. Telford, C. Bahm, C.A. Bache, W.H. Gutenmann, D.J. Lisk, Response of Japanese quail fed seed meal from sunflowers grown on a municipal sludge-amended soil: elevation of cadmium in tissues, J. Toxicol. Environ. Health 17 (1986) 91-100.

[400] J.N. Telford, J.G. Babish, P.B. Dunham, D.E. Hogue, K.W. Miller, G.S. Stoewsand, B.H. Magee, J.R. Stouffer, C.A. Bache, D.J. Lisk, Toxicologic studies with lambs fed sugar beets grown on municipal sludge-amended soil: lowered relative hemoglobin in red blood cells and mutagens in blood and excreta, Am. J. Vet. Res. 45 (1984) 2490-2494.

[401] B.S. Shane, C.B. Littman, L.A. Essick, W.H. Gutenmann, G.J. Doss, D.J. Lisk, Uptake of selenium and mutagens by vegetables grown in fly ash containing greenhouse media, $\mathrm{J}$. Agric. Food Chem. 36 (1988) 328-333.

[402] R.W. Field, D.J. Steck, B.J. Smith, C.P. Brus, E.F. Fisher, J.S. Neuberger, C.F. Lynch, The Iowa radon lung cancer study. Phase I. Residential radon gas exposure and lung cancer, Sci. Total Environ. 272 (2001) 67-72.

[403] R.F. Jostes, Genetic, cytogenetic, and carcinogenic effects of radon: a review, Mutat. Res. 340 (1996) 125-139.

[404] C.S. Clark, C.R. Meyer, W.F. Balistreri, P.S. Gartside, V.J. Elia, V.A. Majeti, B. Specker, An environmental health survey of drinking water contamination by leachate from a pesticide waste dump in Hardeman County, Tennessee, Arch. Environ. Health 37 (1982) 9-18.

[405] D. Ozonoff, M.E. Colten, A. Cupples, T. Heeren, A. Schatzkin, T. Mangione, M. Dresner, T. Colton, Health problems reported by residents of a neighborhood contaminated by a hazardous waste facility, Am. J. Ind. Med. 11 (1987) 581597.

[406] C.W. Heath Jr., M.R. Nadel, M.M. Zack Jr., A.T. Chen, M.A. Bender, R.J. Preston, Cytogenetic findings in persons living near the Love Canal, JAMA 251 (1984) 1437-1440.

[407] L.D. Budnick, J.N. Logue, D.C. Sokal, J.M. Fox, H. Falk, Cancer and birth defects near the Drake Superfund site, Pennsylvania, Arch. Environ. Health 39 (1984) 409413.
[408] D. Campos-Outcalt, Trichloroethylene: environmental and occupational exposure, Am. Fam. Physician 46 (1992) 495-500.

[409] A.M. Phillips, E.K. Silbergeld, Health effects studies of exposure from hazardous waste sites-where are we today? Am. J. Ind. Med. 8 (1985) 1-7.

[410] L.J. Lee, C.W. Chung, Y.C. Ma, G.S. Wang, P.C. Chen, Y.H. Hwang, J.D. Wang, Increased mortality odds ratio of male liver cancer in a community contaminated by chlorinated hydrocarbons in groundwater, Occup. Environ. Med. 60 (2003) 364-369.

[411] J.D. Zhang, S. Li, Cancer mortality in a Chinese population exposed to hexavalent chromium in water, J. Occup. Environ. Med. 39 (1997) 315-319.

[412] D.D. Weisenburger, Environmental epidemiology of nonHodgkin's lymphoma in eastern Nebraska, Am. J. Ind. Med. 18 (1990) 303-305.

[413] K.H. Kilburn, Is neurotoxicity associated with environmental trichloroethylene (TCE)? Arch. Environ. Health 57 (2002) 113-120.

[414] P.B. Tchounwou, J.A. Centeno, A.K. Patlolla, Arsenic toxicity, mutagenesis, and carcinogenesis-a health risk assessment and management approach, Mol. Cell Biochem. 255 (2004) 47-55.

[415] E.J. Stanek, E.J. Calabrese, Soil ingestion in children: outdoor soil or indoor dust? J. Soil Contam. 1 (1992) 1-28.

[416] G.R. Najem, I.S. Thind, M.A. Lavenhar, D.B. Louria, Gastrointestinal cancer mortality in New Jersey counties, and the relationship with environmental variables, Int. J. Epidemiol. 12 (1983) 276-289.

[417] G.R. Najem, D.B. Louria, M.A. Lavenhar, M. Feuerman, Clusters of cancer mortality in New Jersey municipalities; with special reference to chemical toxic waste disposal sites and per capita income, Int. J. Epidemiol. 14 (1985) 528-537.

[418] G.R. Najem, T.W. Greer, Female reproductive organs and breast cancer mortality in New Jersey counties and the relationship with certain environmental variables, Prev. Med. 14 (1985) 620-635.

[419] M.F. Vine, L. Stein, K. Weigle, J. Schroeder, D. Degnan, C.K. Tse, C. Hanchette, L. Backer, Effects on the immune system associated with living near a pesticide dump site, Environ. Health Perspect. 108 (2000) 1113-1124.

[420] United States Environmental Protection Agency (USEPA), Risk Assessment Guidance for Superfund: Human Health Evaluation Manual (Part A), vol. I, Office of Emergency and Remedial Response, US EPA, Washington, DC, 1989, pp. 222.

[421] Comprehensive Environmental Response, Compensation, and Liability Act, US Code, Chapter 42, Title 103, 2002.

[422] G. Chen, P. White, The mutagenic hazards of aquatic sediments, Mutat. Res. 567 (2004) 151-226.

[423] Y.Y. Wang, P.J. Marsden, C.P. Flessel, L.R. Williams, Evaluation and validation of protocols for measurement of the mutagenicity of environmental samples, in: D. Friedman (Ed.), Waste Testing and Quality Assurance, vol. 2, American Society for Testing and Materials, Philadelphia, PA, 1990pp. 176-196. 
[424] J.M. Kiel, K.V. Markiewicz, T.A. Chase, K.C. Donelly, K.W. Brown, Mutagenic activity of sediment samples from a coal gasification site: effect of extraction solvents on mutagenic response, Environ. Mol. Mutagen. 19 (1992) 29.

[425] H. Lee, S.M. Law, S.T. Lin, The effect of extraction solvent on the mutagenicity of airborne particles, Toxicol. Lett. 58 (1991) 59-68.

[426] S. Lundstedt, B. van Bavel, P. Haglund, M. Tysklind, L. Oberg, Pressurised liquid extraction of polycyclic aromatic hydrocarbons from contaminated soils, J. Chromatogr. A 883 (2000) 151-162.

[427] International Agency for Research on Cancer (IARC), Polynuclear Aromatic Compounds. Part 4. Bitumens, Coal-tars and Derived Products, Shale-oils and Soots, IARC Press, Lyon, France, 1984, pp. 219.

[428] F.A. Beland, The metabolic activation and DNA adducts of dinitropyrenes, Res. Rep. Health Eff. Inst. 4 (1986) 3-30.

[429] V.M. Arlt, A. Hewer, B.L. Sorg, H.H. Schmeiser, D.H. Phillips, M. Stiborova, 3-Aminobenzanthrone, a human metabolite of the environmental pollutant 3-nitrobenzanthrone, forms DNA adducts after metabolic activation by human and rat liver microsomes: evidence for activation by cytochrome P4501A1 and P4501A2, Chem. Res. Toxicol. 17 (2004) 1092-1101.

[430] V.M. Arlt, K.J. Cole, D.H. Phillips, Activation of 3-nitrobenzanthrone and its metabolites to DNA-damaging species in human B lymphoblastoid MCL-5 cells, Mutagenesis 19 (2004) 149-156.

[431] K. Tamakawa, Y. Takahashi, Y. Mishima, T. Seki, A. Tsunoda, Mutagenicity and benzo(a)pyrene contents in soils in Sendai City Japan. Influences of particulate substances produced by studded tires of automobiles, Eisei Kagaku 31 (1985) 329-333.

[432] D. Schoen, J. Brownstein, P.A. White, Mutation load in natural populations of the sensitive fern Onoclea sensibilis exposed to soil mutagens, Ecol. Appl. 12 (2002) 124-137.

[433] J.M. Gentile, M. Lippert, P. Johnson, T. Shafer, Activation of chemical promutagens by Selenastrum capricornutum in the plant cell-microbe coincubation assay, Bull. Environ. Contam. Toxicol. 44 (1990) 729-736.

[434] M.J. Plewa, E.D. Wagner, Activation of promutagens by green plants, Annu. Rev. Genet. 27 (1993) 93-113.

[435] R. Schoeny, T. Cody, D. Warshawsky, M. Radike, Metabolism of mutagenic polycyclic aromatic hydrocarbons by photosynthetic algal species, Mutat. Res. 197 (1988) 289-302.

[436] Y.H. Ju, M.J. Plewa, Mutant spectra analysis at hisG46 in Salmonella typhimurium strain YG1029 induced by mammalian S9- and plant-activated aromatic amines, Teratog. Carcinog. Mutagen. Suppl. 1 (2003) 47-60.

[437] C.H. Marvin, M. Tessaro, B.E. McCarry, D.W. Bryant, A bioassay-directed investigation of Sydney Harbour sediment, Sci. Total Environ. 156 (1994) 119-131.

[438] S. Estes, P.C. Phillips, D.R. Denver, W.K. Thomas, M. Lynch, Mutation accumulation in populations of varying size: the distribution of mutational effects for fitness correlates in Caenorhabditis elegans, Genetics 166 (2004) 1269-1279.
[439] M. Lynch, Mutation accumulation in nuclear, organelle, and prokaryotic transfer RNA genes, Mol. Biol. E 14 (1997) 914925.

[440] L.L. Vassilieva, A.M. Hook, M. Lynch, The fitness effects of spontaneous mutations in Caenorhabditis elegans, Evol. Int. J. Org. Evol. 54 (2000) 1234-1246.

[441] K. McBee, J.W. Bickham, K.W. Brown, K.C. Donnelly, Chromosomal aberrations in native small mammals (Peromyscus leucopus and Sigmodon hispidus) at a petrochemical waste disposal site. I. Standard karyology, Arch. Environ. Contam. Toxicol. 16 (1987) 681-688.

[442] S.A. Reinecke, A.J. Reinecke, The comet assay as biomarker of heavy metal genotoxicity in earthworms, Arch. Environ. Contam. Toxicol. 46 (2004) 208-215.

[443] C.W. Kaplan, C.L. Kitts, Bacterial succession in a petroleum land treatment unit, Appl. Environ. Microbiol. 70 (2004) 1777-1786.

[444] I. Kovalchuk, V. Abramov, I. Pogribny, O. Kovalchuk, Molecular aspects of plant adaptation to life in the Chernobyl zone, Plant Physiol. 135 (2004) 357-363.

[445] D.E. Nacci, D. Champlin, L. Coiro, R. McKinney, S. Jayaraman, Predicting the occurrence of genetic adaptation to dioxinlike compounds in populations of the estuarine fish Fundulus heteroclitus, Environ. Toxicol. Chem. 21 (2002) $1525-1532$.

[446] W. Göggelmann, P. Spitzauer, Mutagenicity studies on agricultural soil using the Salmonella/microsome assay, Mutat. Res. 85 (1981) 442-443.

[447] P. Clausing, B. Brunekreef, J.H. van Wijnen, A method for estimating soil ingestion by children, Int. Arch. Occup. Environ. Health 59 (1987) 73-82.

[448] R. Maertens, J. Bailey, P. White, The mutagenic Hazards of settled house dust, Mutat. Res. 567 (2004) 401425.

[449] R. Williams, D. Rathbone, P. Moody, N. Scrutton, N. Bruce, Degradation of explosives by nitrate ester reductases, in: A. Berry, S. Radford (Eds.), From Protein Folding to New Enzymes: Biochemical Society Symposium, vol. 68, Portland Press, London, UK, 2000, pp. 143-153.

[450] C.E. French, S.J. Rosser, G.J. Davies, S. Nicklin, N.C. Bruce, Biodegradation of explosives by transgenic plants expressing pentaerythritol tetranitrate reductase, Nat. Biotechnol. 17 (1999) 491-494.

[451] J. He, K.M. Ritalahti, M.R. Aiello, F.E. Loffler, Complete detoxification of vinyl chloride by an anaerobic enrichment culture and identification of the reductively dechlorinating population as a Dehalococcoides species, Appl. Environ. Microbiol. 69 (2003) 996-1003.

[452] G. Prokop, M. Schamann, I. Edelgaard, Management of Contaminated Sites in Western Europe, European Environment Agency, Copenhagen, Denmark, 2000, pp. 171.

[453] Ad Hoc International Working Group on Contaminated Land, Management of Contaminated Sites and Land in Central and Eastern Europe, Danish Cooperation for Environment in Eastern Europe, Ministry of Environment and Energy, Copenhagen, Denmark, 2000, pp. 151. 
[454] M.D. Waters, H.F. Stack, M.A. Jackson, Genetic toxicology data in the evaluation of potential human environmental carcinogens, Mutat. Res. 437 (1999) 21-49.

[455] M.D. Waters, H.F. Stack, N.E. Garrett, M.A. Jackson, The genetic activity profile database, Environ. Health Perspect. 96 (1991) 41-45.

[456] M. Watanabe, M.J. Ishidate, T. Nohmi, A sensitive method for the detection of mutagenic nitroarenes: construction of nitroreductase-overproducing derivatives of Salmonella typhimurium strains TA98 and TA100, Mutat. Res. 216 (1989) 211220.

[457] M. Watanabe, M.J. Ishidate, T. Nohmi, Sensitive method for the detection of mutagenic nitroarenes and aromatic amines: new derivatives of Salmonella typhimurium tester strains possessing elevated $O$-acetyltransferase levels, Mutat. Res. 234 (1990) 337-348.

[458] H.S. Rosenkranz, R. Mermelstein, Mutagenicity and genotoxicity of nitroarenes. All nitro-containing chemicals were not created equal, Mutat. Res. 114 (1983) 217-267.

[459] E.C. McCoy, M. Anders, H.S. Rosenkranz, The basis of the insensitivity of Salmonella typhimurium strain TA98/1,8$\mathrm{DNP}_{6}$ to the mutagenic action of nitroarenes, Mutat. Res. 121 (1983) 17-23.

[460] Y. Hagiwara, M. Watanabe, Y. Oda, T. Sofuni, T. Nohmi, Specificity and sensitivity of Salmonella typhimurium YG1041 and YG1042 strains possessing elevated levels of both nitroreductase and acetyltransferase activity, Mutat. Res. 291 (1993) 171-180.

[461] H. Yamazaki, Y. Oda, T. Shimada, Use of a newly developed tester strain Salmonella typhimurium NM2009 for the study of metabolic activation of carcinogenic aromatic amines by rat liver microsomal cytochrome P-450 enzymes, Mutat. Res. 272 (1992) 183-192.

[462] M. Yamada, K. Matsui, T. Sofuni, T. Nohmi, New tester strains of Salmonella typhimurium lacking O6methylguanine DNA methyltransferases and highly sensitive to mutagenic alkylating agents, Mutat. Res. 381 (1997) $15-24$.

[463] N. Sera, H. Tokiwa, N. Miyata, Mutagenicity of the fullerene C60-generated singlet oxygen dependent formation of lipid peroxides, Carcinogenesis 17 (1996) 2163-2169.
[464] R. Blevins, L. Brennan, O. Pancorbo, Fate of mutagenic chemicals in soil columns treated with municipal wastewater sludge, Environ. Mutagen. 8 (Suppl. 6) (1986) 12.

[465] R. Rojièkovà, B. Marsàlek, B. Dutka, R. McInnis, Bioassays used for detection of ecotoxicity at contaminated areas, NATO Sci. Ser. 2 (1998) 227-232.

[466] A. Putrament, J. Guzewska, D. Pienliazek, Further genetic characteristics of methionine mutants and their suppressors in Aspergillus nidulans, Mol. Gen. Genet. 109 (1970) 209-218.

[467] U. Graf, F.E. Wurgler, The present status of validation of the wing spot test in Drosophila, Prog. Clin. Biol. Res. 209B (1986) 391-398.

[468] J. Smith, Mutagenicity of extracts from agricultural soil in the Salmonella/microsome test, Environ. Mutagen. 4 (1982) 369.

[469] Z. Wong, J. MacGregor, The effects of biodegradation and leaching on the mutagenic potential of heavy cycle oils on landfarm sites, Environ. Mutagen. 3 (1981) 348.

[470] P. Stapleton, M. Plewa, P. Hopke, P. Dowd, The effect of soil application on the mutagenic activity of wastewater, Environ. Mutagen. 6 (1984) 433-434.

[471] C. Lim-Sylianco, V. Inofinada, M. Botuyan, Genotoxicity of organic extracts of street soils in eight districts in metro Manila, Philippines, Environ. Mol. Mutagen. 14 (Suppl. 15) (1989) 114-115.

[472] W. Göggelmann, P. Spitzauer, Mutagenic activity, content of polycyclic aromatic hydrocarbon $(\mathrm{PAH})$ and humus in agricultural soils, Mutat. Res. 97 (1982) 189-190.

[473] K. Ohyama, R. Endo, H. Kawahara, Mutagenicity of surface soil, Mutat. Res. 216 (1989) 372.

[474] T.H. Ma, K.H. Lee, M.S. Kong, C.D. Won, Tradescantia micronucleus (Trad-MCN) assay on the clastogenicity of pesticide contaminated soil, Environ. Mol. Mutagen. 25 (1995) 32.

[475] A. Fomin, C. Hafner, Evaluation of genotoxicity of emissions from municipal waste incinerators with Tradescantia-micronucleus bioassay (Trad-MCN), Mutat. Res. 414 (1998) 139-148.

[476] T. Nishimura, S. Goto, Y. Kato, M. Okunuki, H. Matsushita, Mutagenicity and benzo(a)pyrene contents of soils in Tokyo, J. Jpn. Soc. Air Pollut. 19 (1984) 228-238.

[477] D. Tripathi, S. Roy, Comparison of MIC polluted soils of Bhopal, Cytology 53 (1988) 465-468. 